\title{
A BRIEF REVIEW OF BOREHOLE GEOPHYSICAL LOGGING ACTIVITIES IN ARMENIA:
}

Part I. Geophysical Logs from Coal Exploration boreholes of the Antaramut-Kurtan-Dzoragukh Coal Field, North-Central Armenia

Part II. Geophysical Logs from Non-Coal Exploration Boreholes

Part III. Archival Geophysical Logs from Various Exploration Boreholes throughout the Republic of Armenia

\section{U.S. Geological Survey Open-File Report 99-561}

1999

\begin{abstract}
Brenda S. Pierce ${ }^{1}$ and Grigor Grigorian ${ }^{2}$
${ }^{1}$ U.S. Geological Survey, 956 National Center, Reston, VA 20192; bpierce@usgs.gov

${ }^{2}$ Ministry of Environment, Geocomplex Government Closed Joint Stock Co., 47 Tblisian Road, Yerevan, Armenia; gast@freenet.am
\end{abstract}

This report is preliminary and has not been reviewed for conformity with U.S. Geological Survey editorial standards and stratigraphic nomenclature. Any use of trade, product, or firm names is for descriptive purposes only and does not imply endorsement by the U.S. Government. 


\section{INTRODUCTION}

The U.S. Geological Survey (USGS), with funding from the U.S. Agency for International Development (USAID), provided technical assistance to the Republic of Armenia (RA) to assess the country's potential coal resources. Exploration drilling and borehole geophysical logging were integral parts of this technical assistance known as the Coal Exploration and Resource Assessment Program of Armenia.

Specific activities in this regard included:

1. Geophysical logging of boreholes drilled in Armenia in the past four years, for coal and other mineral deposits (salt, water, non-ferrous metals). Twenty-six boreholes were geophysically logged in the Antaramut-Kurtan-Dzoragukh coal deposit, one hole was logged in the Ijevan coal deposit, and eight non-coal exploration boreholes were logged in other areas of Armenia.

2. Creation of a new database including digitizing archival geophysical logs for Armenia, with borehole coordinates and elevations, and geology of the holes. The work is still in progress, as the number of boreholes is large. There are approximately 3,500 logs in the archives and the work contained here represents about 3 percent of those geophysical logs.

\section{PART I \\ ANTARAMUT-KURTAN-DZORAGUKH COAL FIELD}

\section{Study Area}

As part of the Coal Exploration and Resource Assessment Program, the USGS conducted exploration drilling in the Antaramut-Kurtan-Dzoragukh coal field in north-central Armenia 
between May 1997 and June 1999. This coal deposit lies approximately $15 \mathrm{~km}$ north of the town of Vanadzor (fig. 1).

\section{Methods}

As part of the Coal Exploration Program, prior to exploration drilling, the USGS installed computerized (Century Geophysical) geophysical logging equipment in the Republic of Armenia. The purpose of the borehole logging activities was to help determine core loss, define stratigraphic horizons, especially for non-cored holes, and aid in geologic correlation. All of these factors are important in the exploration and assessment of the coal resources of Armenia. The following set of borehole geophysical logs were routinely run on most of the boreholes drilled:

\section{- Gamma Gamma Density \\ - Natural Gamma \\ - Spontaneous Potential \\ - Resistivity \\ - Caliper}

There were three geophysical probes used. The caliper tool is a three arm probe used to measure the diameter of the borehole. The multifunction tool measures, in a single run, the natural gamma, spontaneous potential, single point resistance, 16-inch and 64-inch normal resistivity, 48-inch lateral resistivity, fluid resistivity, temperature, and differential temperature. The compensated density tool records apparent bulk density of the formation, natural gamma, caliper, and short guard resistivity. The sampling interval is $2 \mathrm{~cm}$.

A NaJ crystal was used as a detector of natural gamma activity. The tool was standardized 
(the microroentgen/hour to counts-per-second conversion factor was determined), allowing one to compare the data obtained using the American equipment with those obtained earlier using Soviet equipment. $\mathrm{A} \mathrm{Ra}^{226}$ source was used for standardization.

The spontaneous potential tool measures electrical potential between an electrode at some depth in the borehole and a surface electrode grounded in the mud pit. Resistivity was measured using long- and short-normal tools, with AM electrode spacing of about $40 \mathrm{~cm}$ (16 inches) and $162 \mathrm{~cm}$ (64 inches), respectively. Density was measured using a 125 millicurie $\mathrm{Cs}^{137}$ source. The response was detected by a $\mathrm{NaJ}$ crystal located adjacent to $(14.9 \mathrm{~cm})$ and distant from $(30.9 \mathrm{~cm})$ the gamma ray source (this is necessary to reject, by software means, rays directly emanating from the gamma source). Temperature $\left({ }^{\circ} \mathrm{C}\right)$ was measured using a thermocouple.

All coal boreholes drilled as part of the USGS exploration drilling were geophysically logged immediately upon completion of drilling. Locations of the boreholes are found in figure 2 .

\section{Results}

Although 32 sites were drilled as part of the exploration of the Antaramut-KurtanDzoragukh Coal Field, some of the sites were twin holed, using a combination of rotary and core drilling methods. A few of the holes were abandoned due to technical difficulties, and if the hole was too shallow to be useful, we did not geophysically log the hole. A total of 26 boreholes were logged and these geophysical logs are found in Appendix 1 of this report. A complete list of borehole descriptions can be found in Pierce and others (1999).

There are some holes with textbook examples of coal bed geophysical log response. Examples of these textbook responses include boreholes $4 \mathrm{C}(73 \mathrm{~m}), 18 \mathrm{~A}(122 \mathrm{~m}$ and $138 \mathrm{~m})$, 
24A (98 m), 26A (41 m and $44 \mathrm{~m}$ ), and 28A (117 m and $136 \mathrm{~m})$ (Appendix 1).

In addition, a table showing the physical parameters of the Antaramut-Kurtan-Dzoragukh rocks was made based on the results of geophysical logging. The table represents the average physical characteristics of the majority of the rocks in the region.

\section{Average Physical Characteristics of Rocks in the Antaramut-Kurtan-Dzoragukh Coal Field}

\begin{tabular}{|l|c|c|c|}
\hline \multicolumn{1}{|c|}{ Rock type } & $\begin{array}{c}\text { Resistivity } \\
\mathbf{o h m}-\mathbf{m}\end{array}$ & $\begin{array}{c}\text { Radioactivity } \\
\mathbf{C P S}(\boldsymbol{\mu R} \mathbf{h})\end{array}$ & $\begin{array}{c}\text { Density } \\
\mathbf{g} / \mathbf{c m}^{\mathbf{3}}\end{array}$ \\
\hline Sandstone & 10 & $170(20)$ & 2 \\
\hline Tuffaceous sandstone & 12 & $130(15)$ & 2.2 \\
\hline Clay shale & ned $^{*}$ & $65(10)$ & 1.8 \\
\hline Claystone (mudstone) & 10 & ned $^{*}$ & 2.2 \\
\hline Tuff breccia & 20 & $100(13)$ & 2.3 \\
\hline Coal & ned* $^{*}$ & $75(9)$ & 1.3 \\
\hline
\end{tabular}

${ }^{*}$ ned $=$ not enough data to give an average response

\section{PART II}

\section{NON-COAL BOREHOLES}

Also during the past four years, the RA Ministry of Environment has drilled some boreholes for salt, water, copper and other non-ferrous metals. These boreholes were also geophysically logged, using the same equipment as described above. The methods described above pertain to these geophysical logs as well. Eight non-coal boreholes were logged and the results of this work can be found in Appendix 2 of this report. 


\section{PART III \\ ARCHIVAL GEOPHYSICAL DATABASE}

\section{Introduction and Brief Background of Soviet \\ Geopysical Logging Techniques}

Boreholes have been geophysically logged regularly in Armenia since 1950. In Soviet years, all boreholes were geophysically logged, regardless of the type of the deposit. The following standard suite of borehole geophysical logs were recorded:

\section{- Resistivity \\ - Spontaneous Potential \\ - Natural Gamma}

Because of sporadic high noise level on the SP, resistivity, and Induced Polarization logs in Armenia, such measurements were historically carried out using mainly gradient tools (that is, when both $\mathrm{M}$ and $\mathrm{N}$ electrodes are down in the hole). The A2M0.25N probe (A-M is $2 \mathrm{~m}$ and $\mathrm{M}-$ $\mathrm{N}$ is $0.25 \mathrm{~m}$ ) was a standard probe used in Armenia to measure resistivity. Spontaneous potential was also measured using gradient probes (specifically M0.25N (where M-N is $0.25 \mathrm{~m}$ )). For a detailed discussion on Soviet logging methods, see Fedynski $(1978 ; 1983)$.

$\mathrm{NaJ}(\mathrm{Tl})$ crystals were used as detectors for the measurement of Natural Gamma radiation. The probes were standardized and calibrated, and the performance of the photomultipliers was checked. In addition, the probes' sensitivity threshold was checked once a year. A Ra ${ }^{226}$ source was used for the standardization of probes. In order to determine proper probe performance, the differences between the natural/background and control sources $\left(\mathrm{Co}^{60}\right)$ were measured before and after each use to ensure they were the same. 
Depending on the geological tasks or type of the deposit, additional methods were also used: Induced Polarization, Roentgen-Radiometry, Gamma-Gamma Density, Inclinometry, Temperature, Magnetometery, Fluid Resistivity, and Flowmetry (using thermoinductive flowmeters). Starting from mid 1980's, the Partial Metal Extraction Method (ЧИМ or ChIM) was also tested. This is a method to determine the percentage content of a specific metal in a specific area. This is a direct method for searching for gold and other elements. $\mathrm{Cd}^{109}$ and $\mathrm{Cs}^{137}$ sources were used for Roentgen-Radiometry and Gamma-Gamma Density measurements, respectively. Temperature-sensitive resistors were used for Temperature measurements. The inclinometer's accuracy for azimuth and angular measurements was $\pm 5^{\circ}$ and \pm 30 minutes, respectively. Magnetometry was used to measure $\Delta \mathrm{Z}$ and anomalous $\Delta \mathrm{T}$.

Induced Polarization was measured by gradient probes $(\mathrm{MN}=10 \mathrm{~m}$ or $\mathrm{MN}=20 \mathrm{~m})$. One of the electrodes (the current-return electrode, labeled B) was implanted at an "infinite" distance from the hole (at least three times the hole's depth), and the other (the current-emitting electrode, labeled A) was placed either by the hole's mouth or down in the bottom of the hole, while two other electrodes ( $\mathrm{M}$ and $\mathrm{N})$ were located on the probe. This method is used for finding ore bodies located near a borehole.

By "Azimuthal Surveying" (a modification of the Induced Polarization method) the location of the ore body near a borehole, but not cut by the borehole, was determined. In this method, the current-emitting electrode (A) is placed at various positions in a radius around the borehole on the surface in order to locate the position of the ore body.

When an ore body of unknown orientation is encountered while drilling, the Charge- 
Induced Polarization method is used to help determine the lateral extent and direction of the ore body. The $\mathrm{A}$ electrode is placed into the hole and the $\mathrm{M}$ and $\mathrm{N}$ electrodes are placed at various distances away from the borehole in order to build profiles to help determine the extent of the ore body.

Starting in the mid-1980's, the borehole version of the method of Irreversible Processes of Artificially Induced Polarization was used in the USSR for the first time. This is a variation of the Induced Polarization method, but rather than run measurements every 0.5 seconds as done in the normal IP method, measurements are taken incrementally, increasing every 0.02 seconds to 1.0 second, resulting in at least 10 measurements per point. This method is particularly useful for some metals, such as molybdenum, which is undetectable by regular IP methods. But, more importantly, if the body of interest is pyritized, this method discards 90 percent of pyritization interference, which the standard IP method does not.

\section{Methods}

All the geophysical logging data are currently stored in the Geophysical Expedition of the RA Ministry of Environment and their maintenance has become a problem in the last few years. Digitizing the data helped solve the problem of the imminent decay of these data and allowed for categorization of the holes by regions. The following steps were taken in computerizing the data and building the database:

- The archival geophysical log curves were computerized using a digitizer, whereas the text part of the logs was computerized using a scanner.

- The coordinates, elevations, and geology of holes were found, where possible, checked 
and corrected.

The geophysical logs were plotted in a standard format using the new computer programs.

The archival geophysical logs did not have locality coordinates or elevations attached to them as part of the raw data. For these, we needed to cross reference each report in which the geophysical log appeared. However, many of the geophysical logs never appeared in any report and exact locality coordinates are still considered government proprietary in Armenia. Thus, the best we can do is report the general region of the borehole, report which RA Ministry Expedition's Party logged the hole, for what purpose the borehole was drilled, and the date logged. Each Ministry Expedition Party is responsible for logging in a specific geographic territory and therefore, a borehole logged by a certain Expedition Party will be found only in a specific area. A map showing the general regions that each Party is responsible for is found in figure 3. In addition, all of the attached archival logs in Appendix 3, have the names of the closest village to the borehole. Most of the boreholes, and therefore the geophysical logs, are within approximately a $5 \mathrm{~km}$ radius of the village named on each log. The date on each $\log$ is in the format of month/day/year.

Even though we can not provide specific coordinates for these geophysical logs, publication of these logs provides a means of preserving these data. In addition, many of these raw data do not appear in any other text or format. For those that might be interested in using these geophysical logs for exploration or other purposes, exact localities are available from the Republic of Armenia Ministry of Environment or Geophysical Expedition after filing appropriate applications. 


\section{Acknowledgments}

We would like to thank Gaggik Papian for translating the draft copies of this manuscript between Armenian and English for the two authors and for facilitating discussions between them. We also express our appreciation to Ruben Grigorian of the RA Ministry of Environment, Chief of the Geophysical Expedition, for unflagging support throughout our project. We also thank Rafael Mirijanian, of the RA Ministry of Energy, for his interest and helpful comments.

\section{Selected Bibliography}

Fedynski, V.V., 1978 [Borehole nuclear geophysics]: Nedra Press, Moscow, 247p. (In Russian.)

Fedynski, V.V., 1983 [Geophysical borehole logging methods]: Nedra Press, Moscow, 590 p. (In Russian.)

Grichukhin, V.V., 1980 [Investigations of coal-bearing formations by geophysical methods]: Nedra Press, Moscow, 360 p. (In Russian.)

Keys, W. Scott, 1990, Borehole Geophysics Applied to Ground-Water Investigations, in, Techniques of Water-Resources Investigations of the U.S. Geological Survey, Book 2, Chapter E2, $150 \mathrm{p}$.

Pierce, Brenda S., Harutunian, Samvel, Martirosyan, Artur, and Harutunian, Grigory, 1999, Borehole and thin section descriptions from exploration drilling and field work in the Antaramut-Kurtan-Dzoragukh coal field, north-central Armenia, U.S. Geological Survey Open-File Report 99-582, 268 p. 
Figure 1. Location of coal, carbonaceous shale, and oil shale deposits in Armenia.

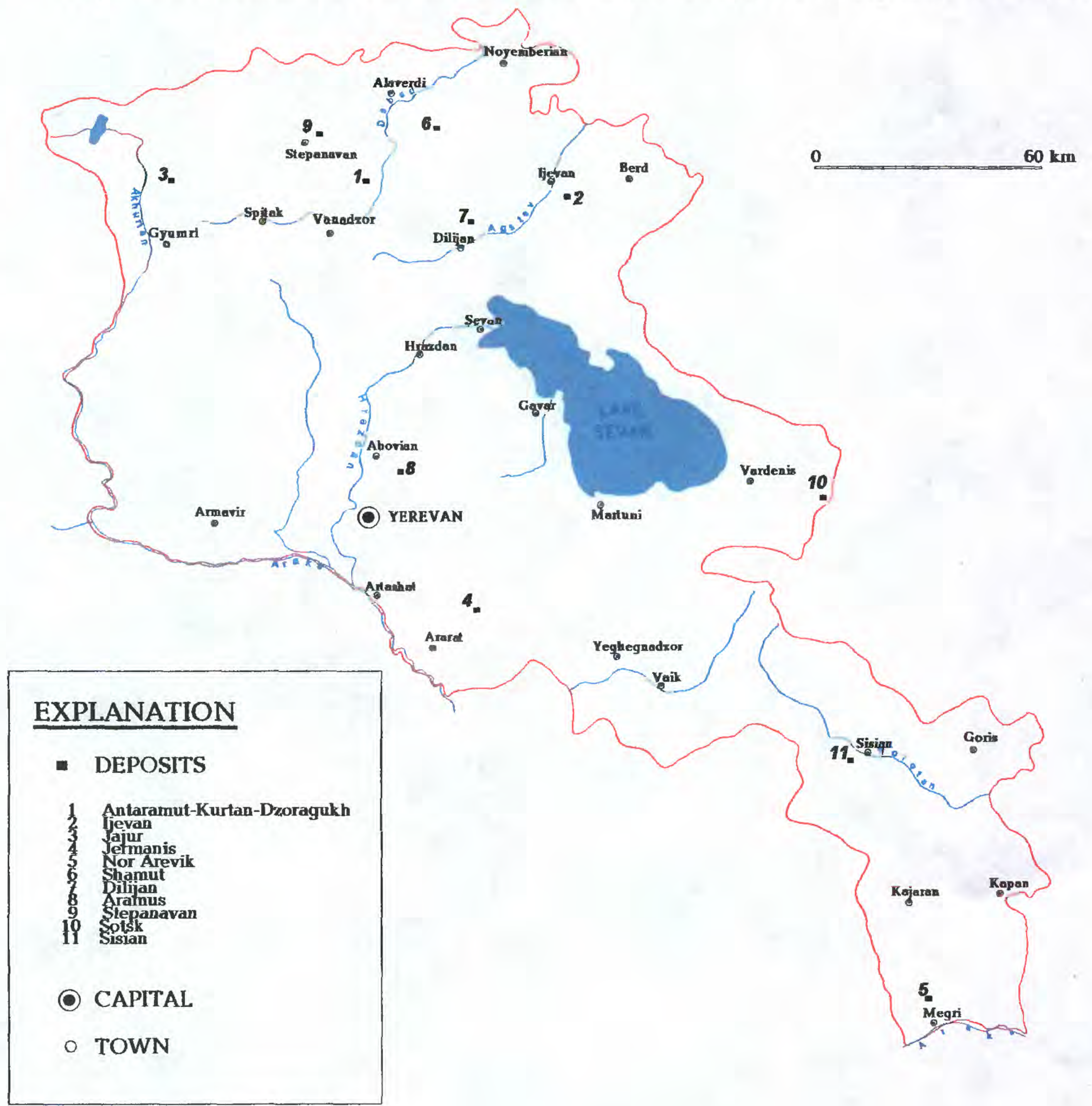


Figure 2. Topographic and locality map of the Antaramut-KurtanDzoragukh coal field, in north-central Armenia. Each grid square is $1 \mathrm{sq} \mathrm{km}$ and the contour interval is $5 \mathrm{~m}$.

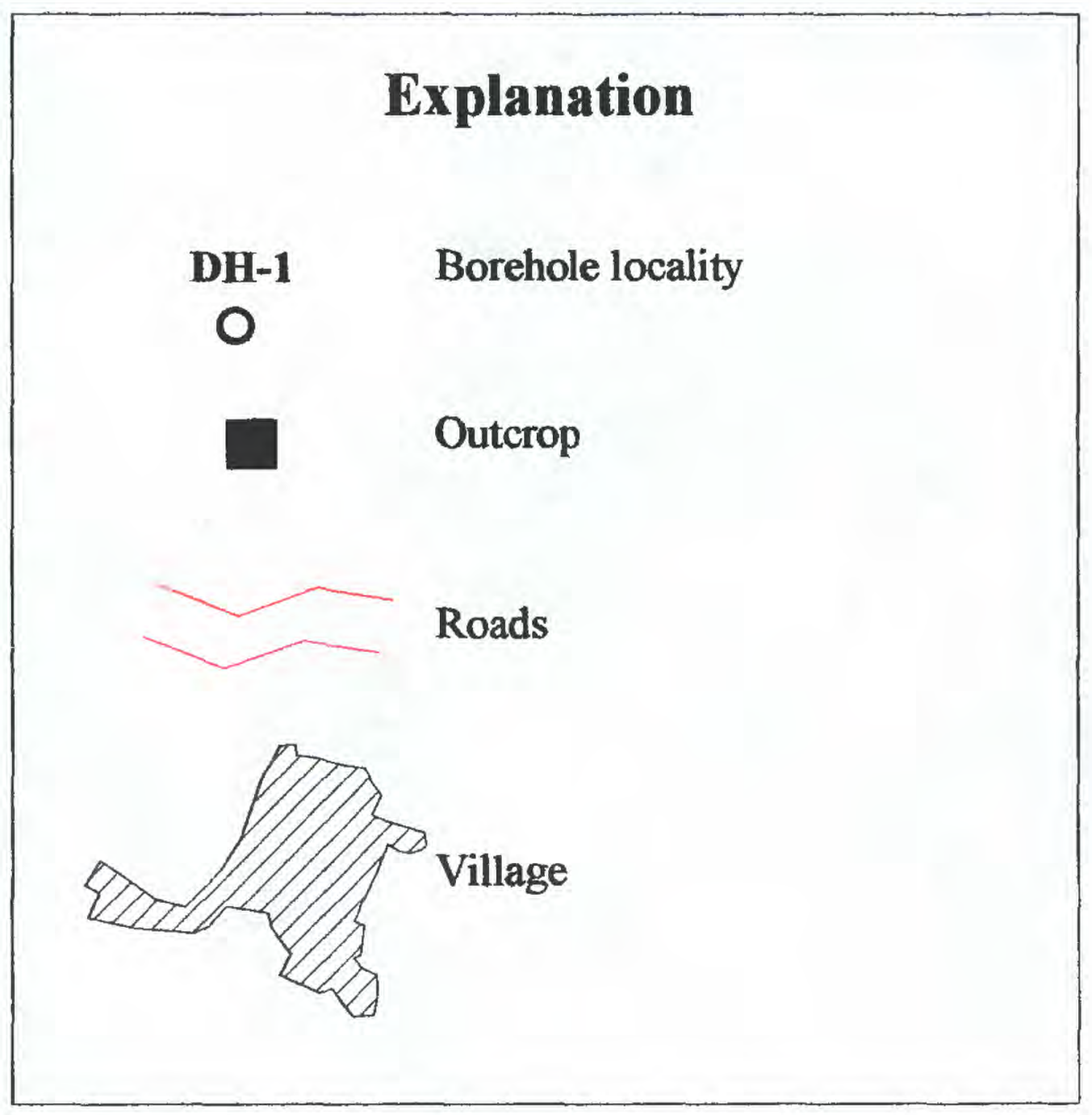




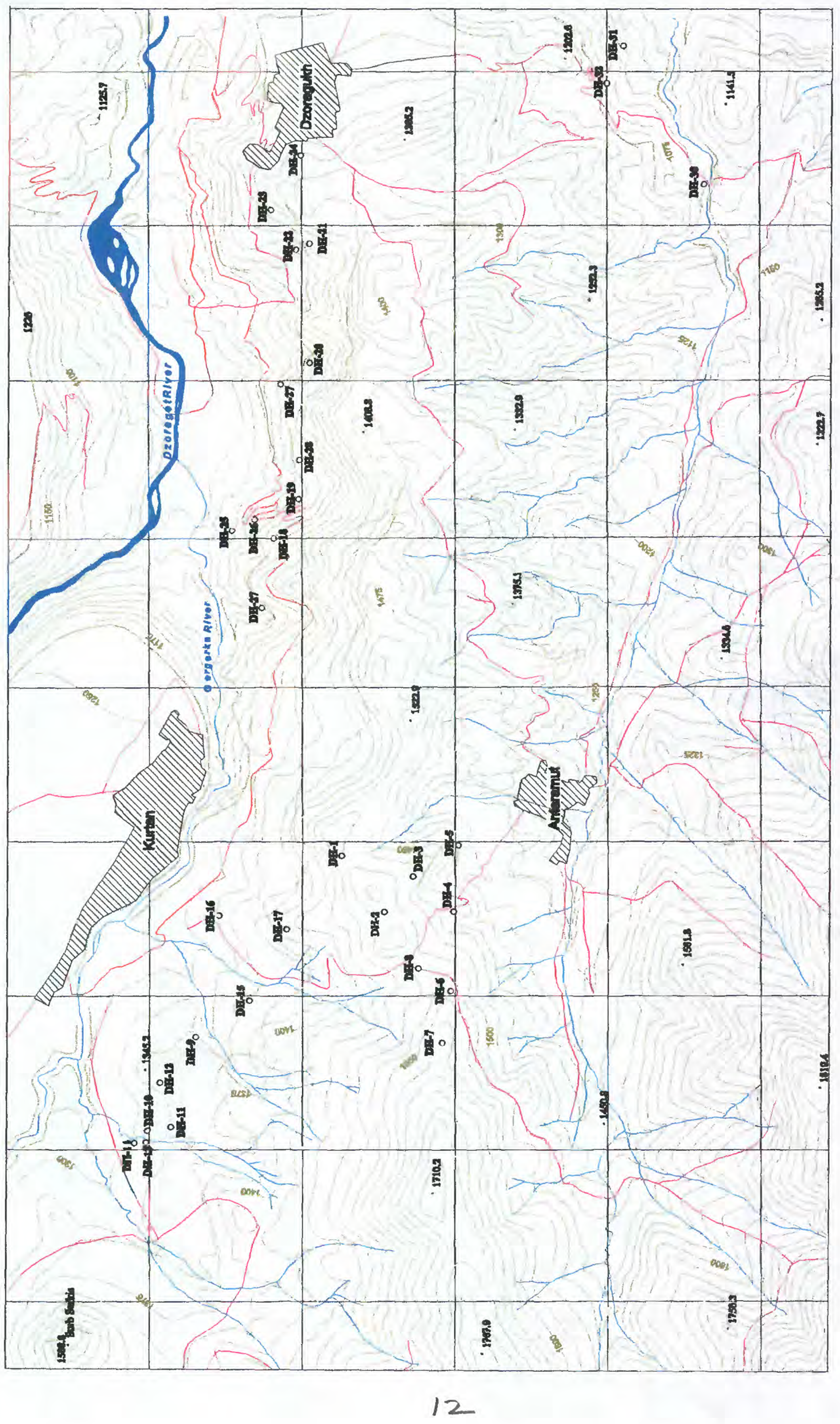


Figure 3. Territorial outlines for locations of geophysical logs found in Appendix 3.

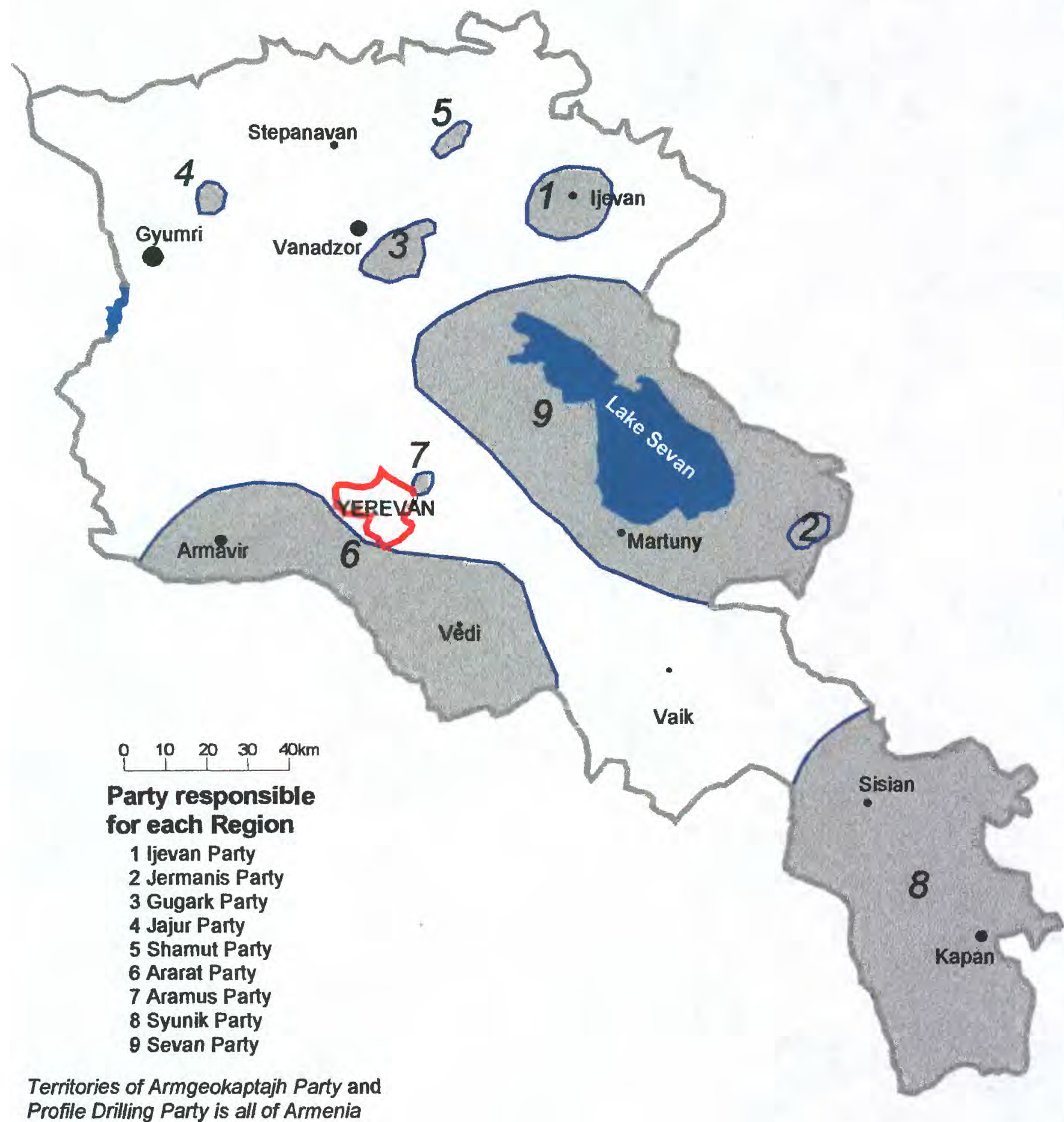

Profile Drilling Party is all of Armenia 


\section{APPENDIX 1}

Geophysical Logs from Exploratory Boreholes of the Antaramut-Kurtan-Dzoragukh Coal Field 


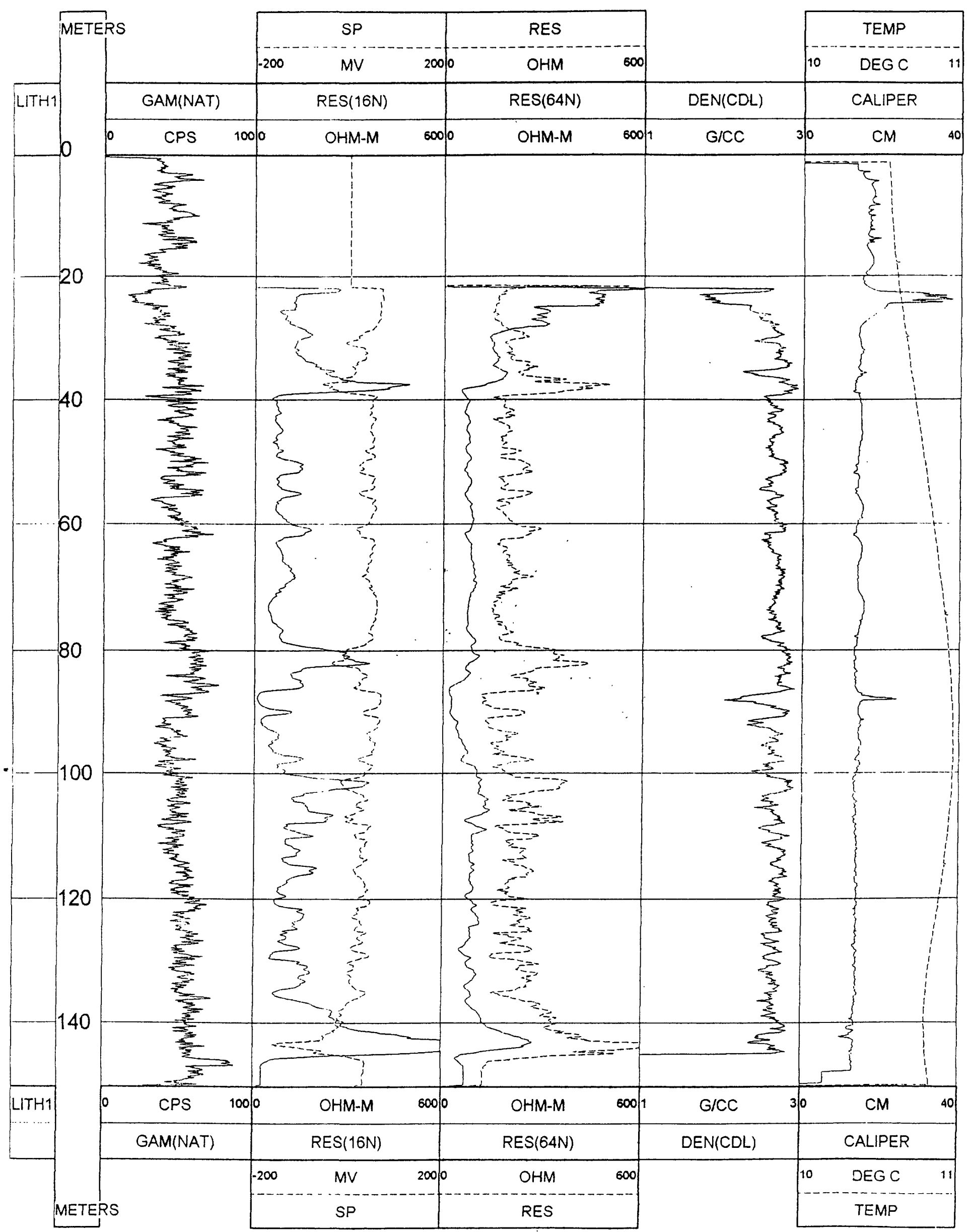

DRILL HOLE \#1A 


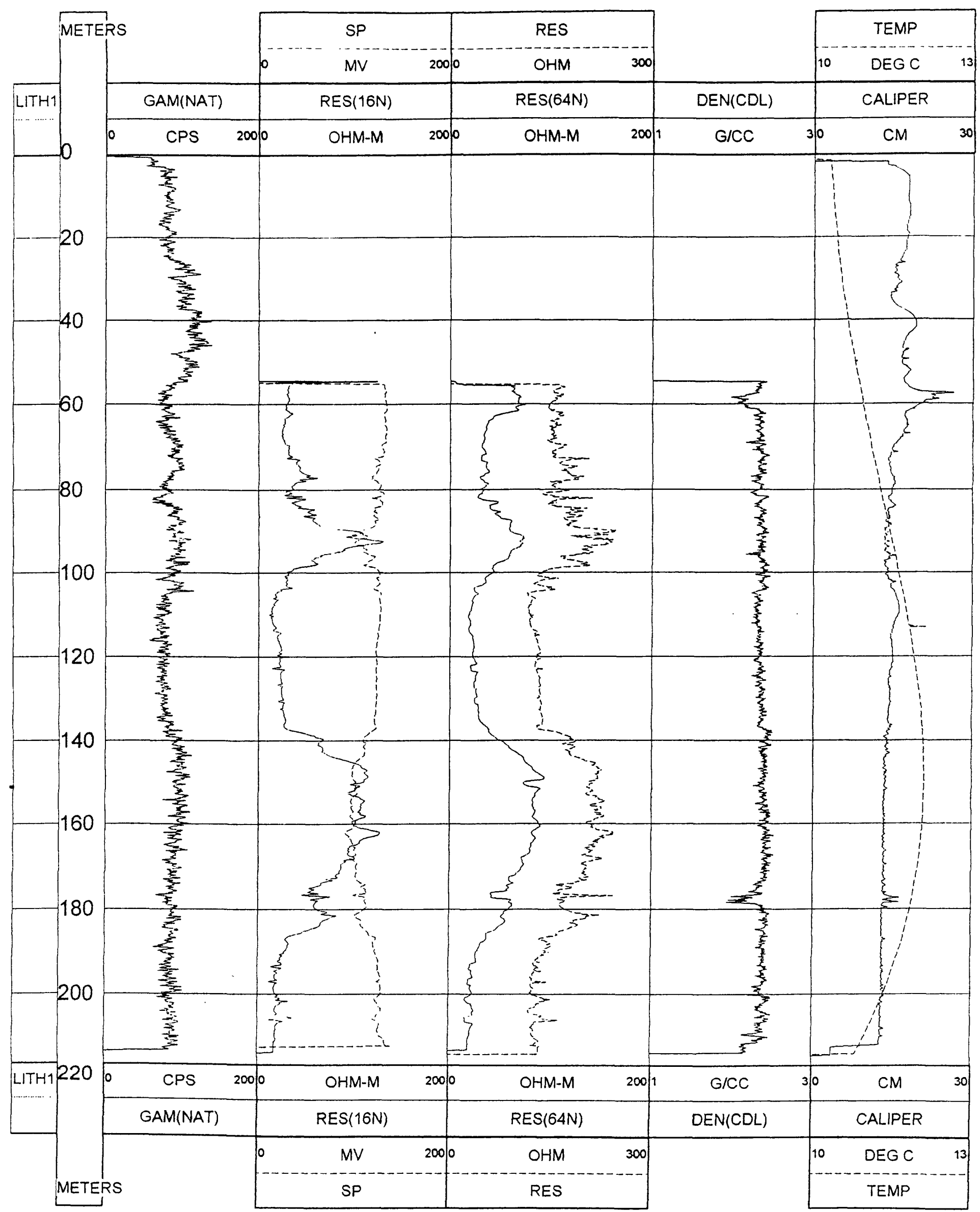

DRILL HOLE \#2A 


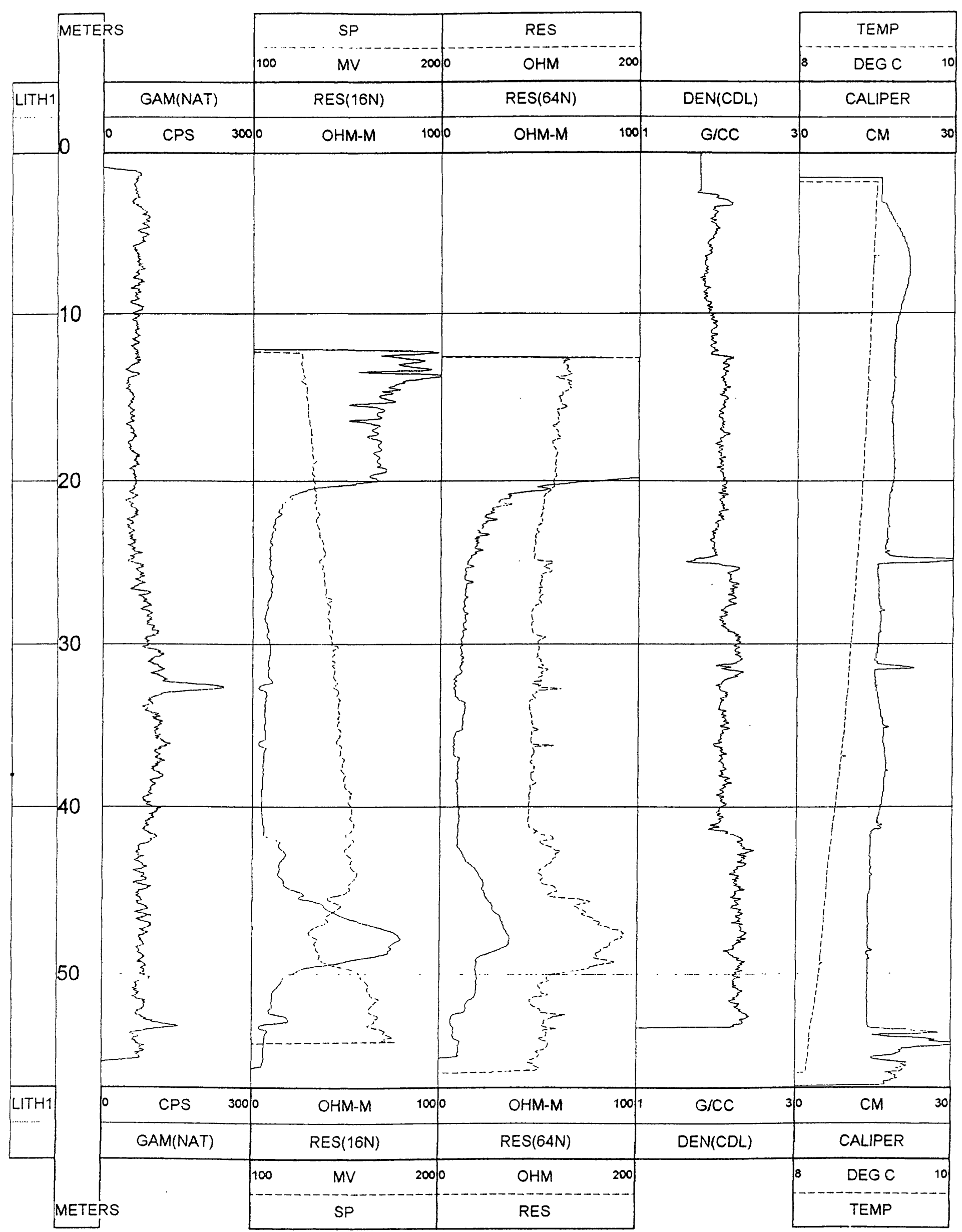

DRILL HOLE \#4A 


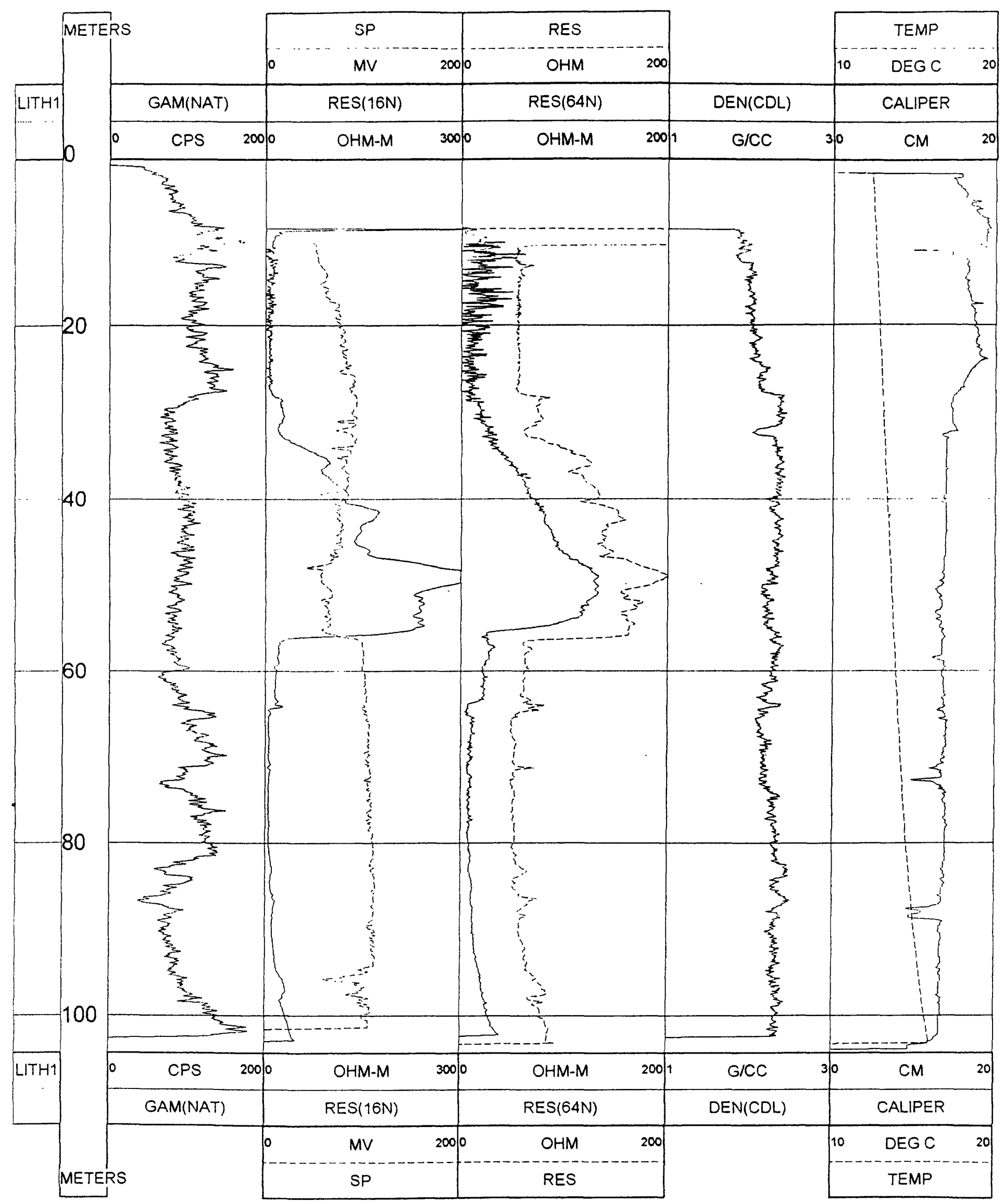

DRILL HOLE \#4B 


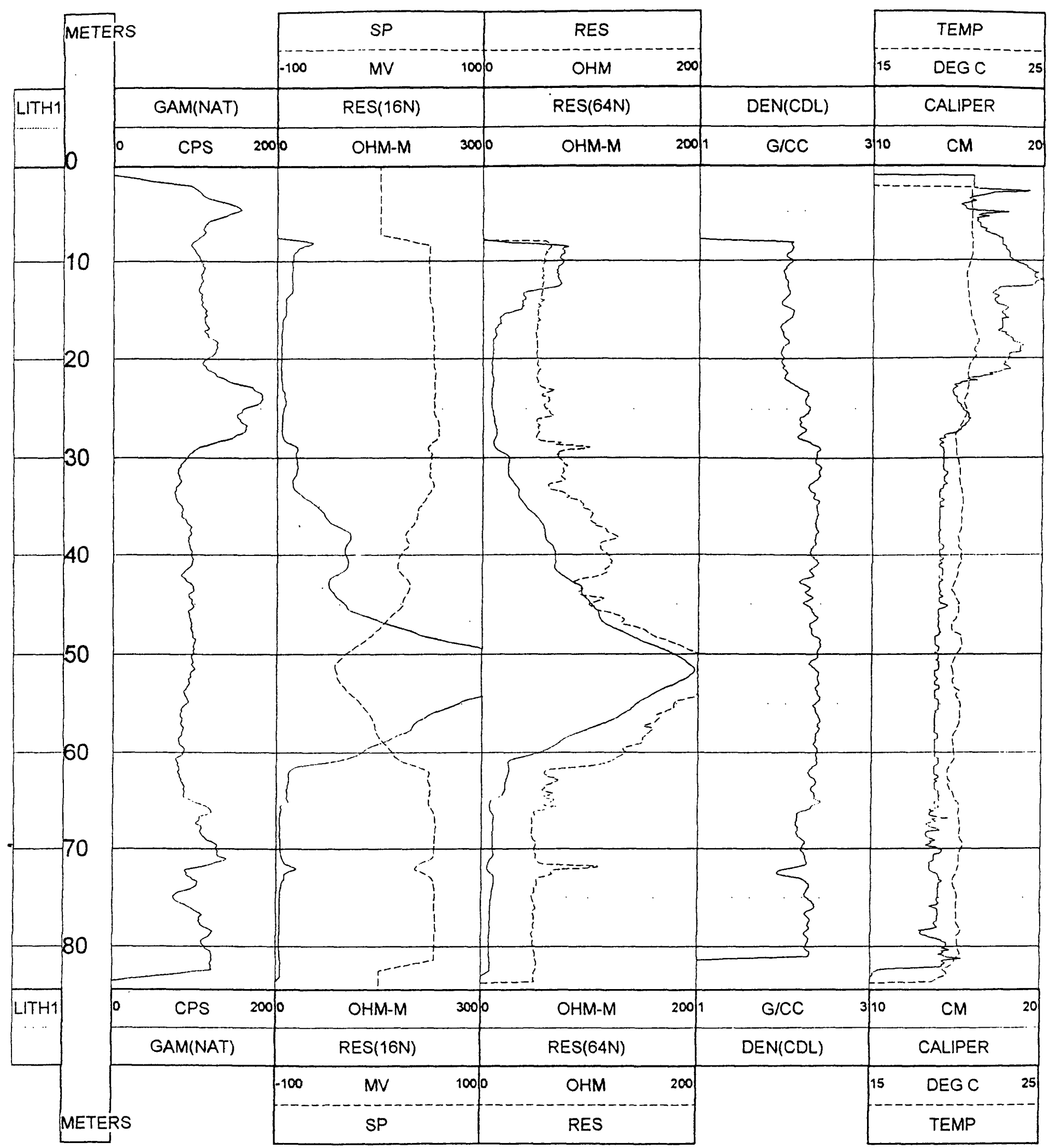

DRILL HOLE \#4C 


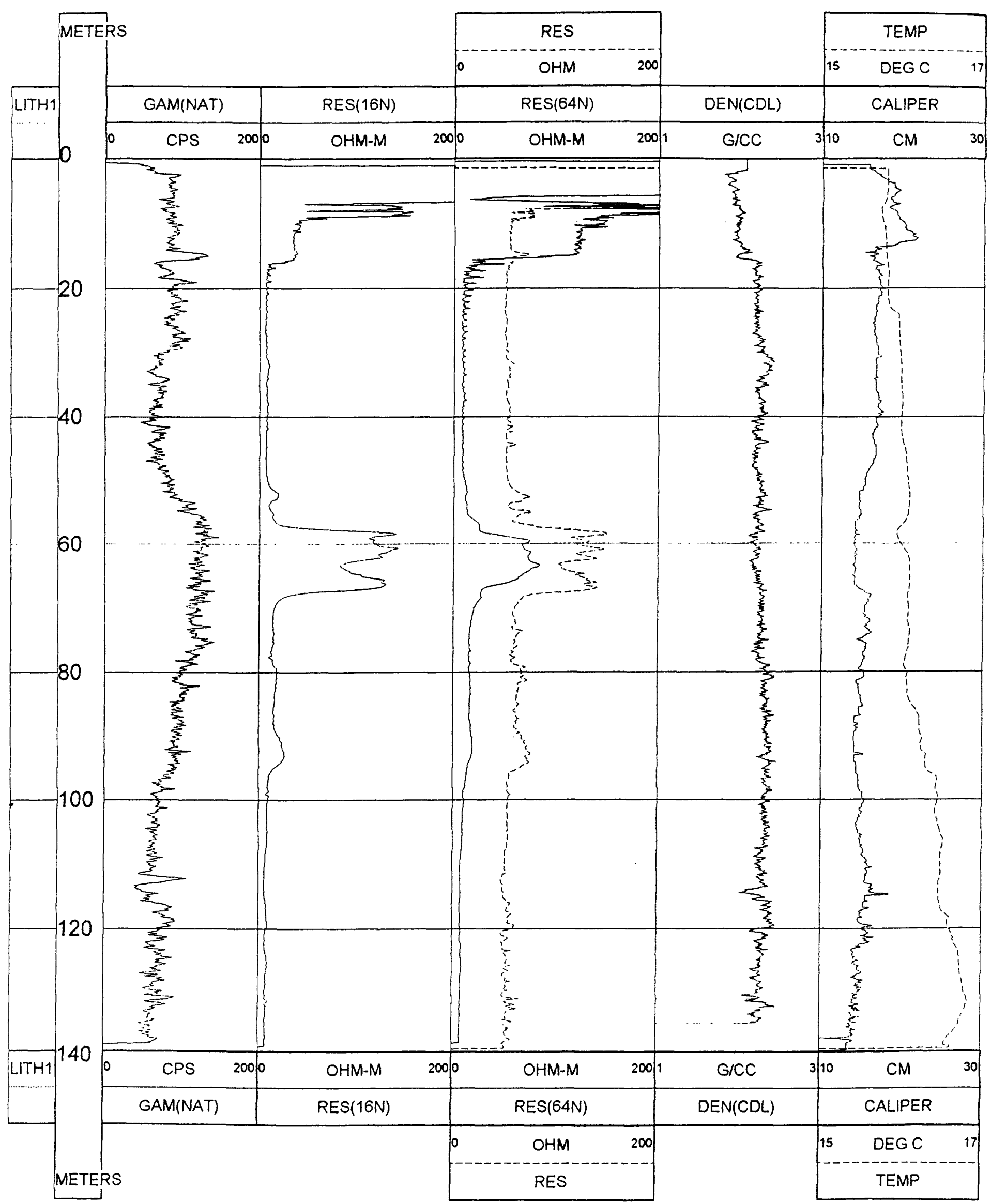

DRILL HOLE \#5A 


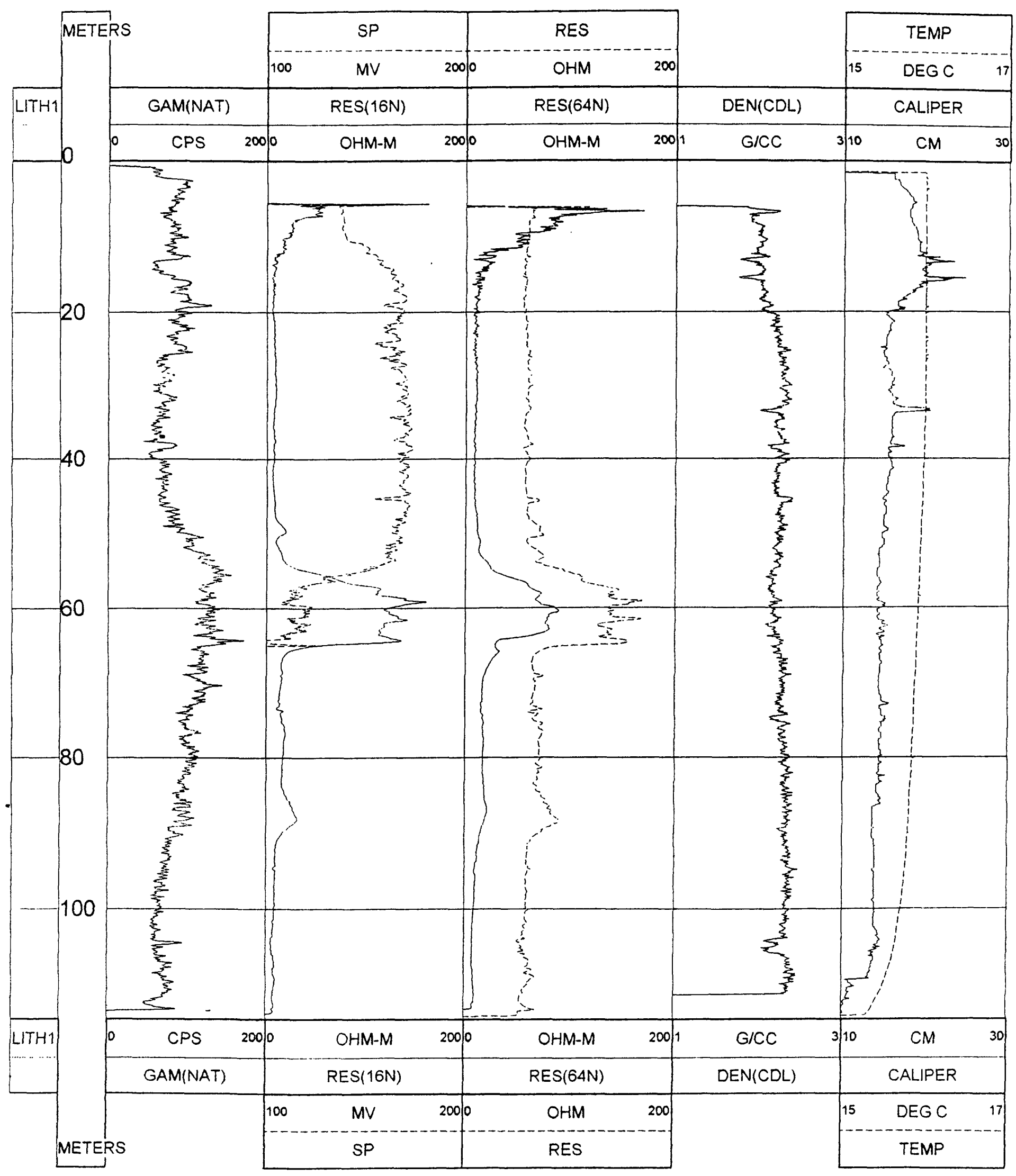

DRILL HOLE \#5B 


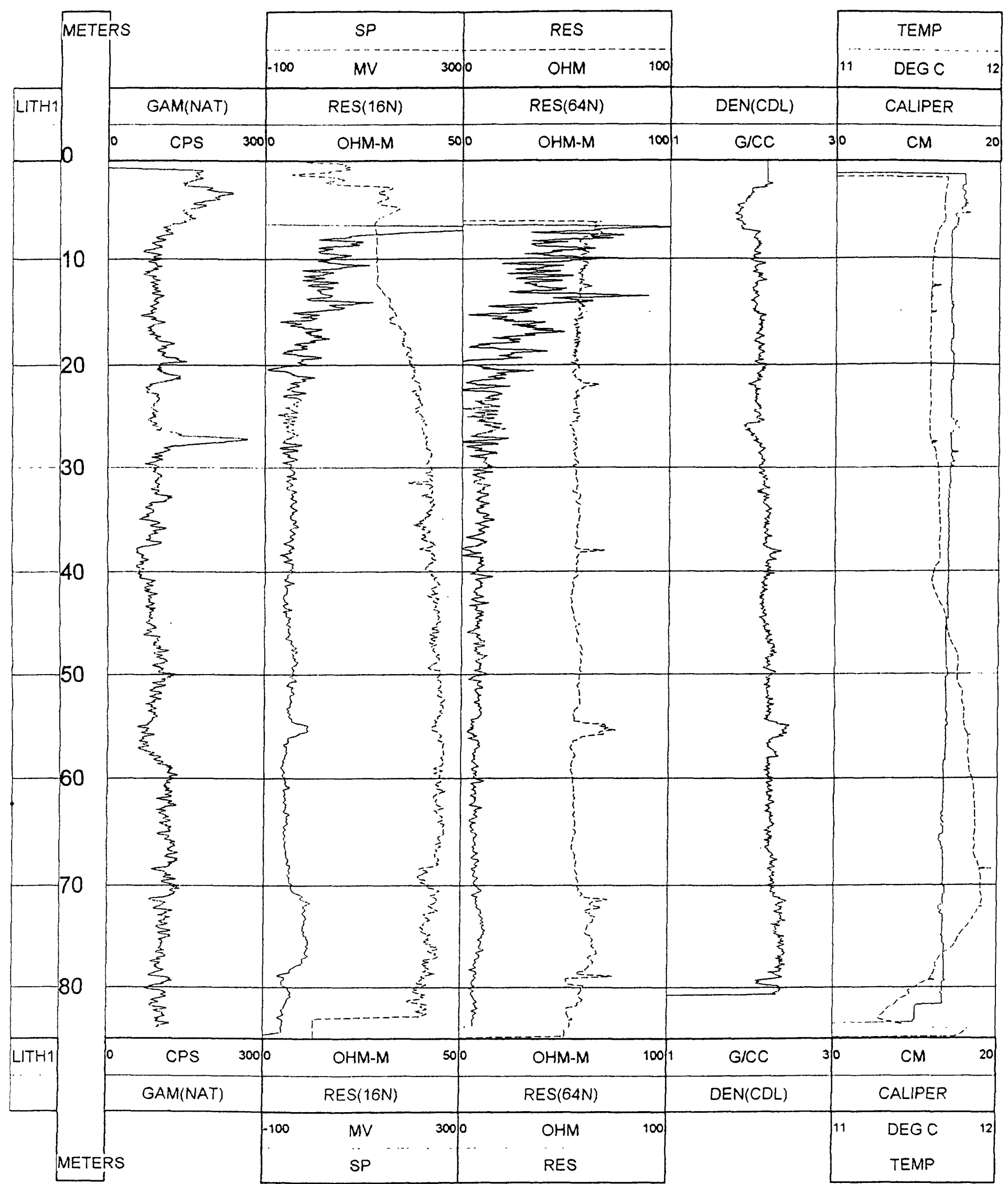

DRILL HOLE \#8B 


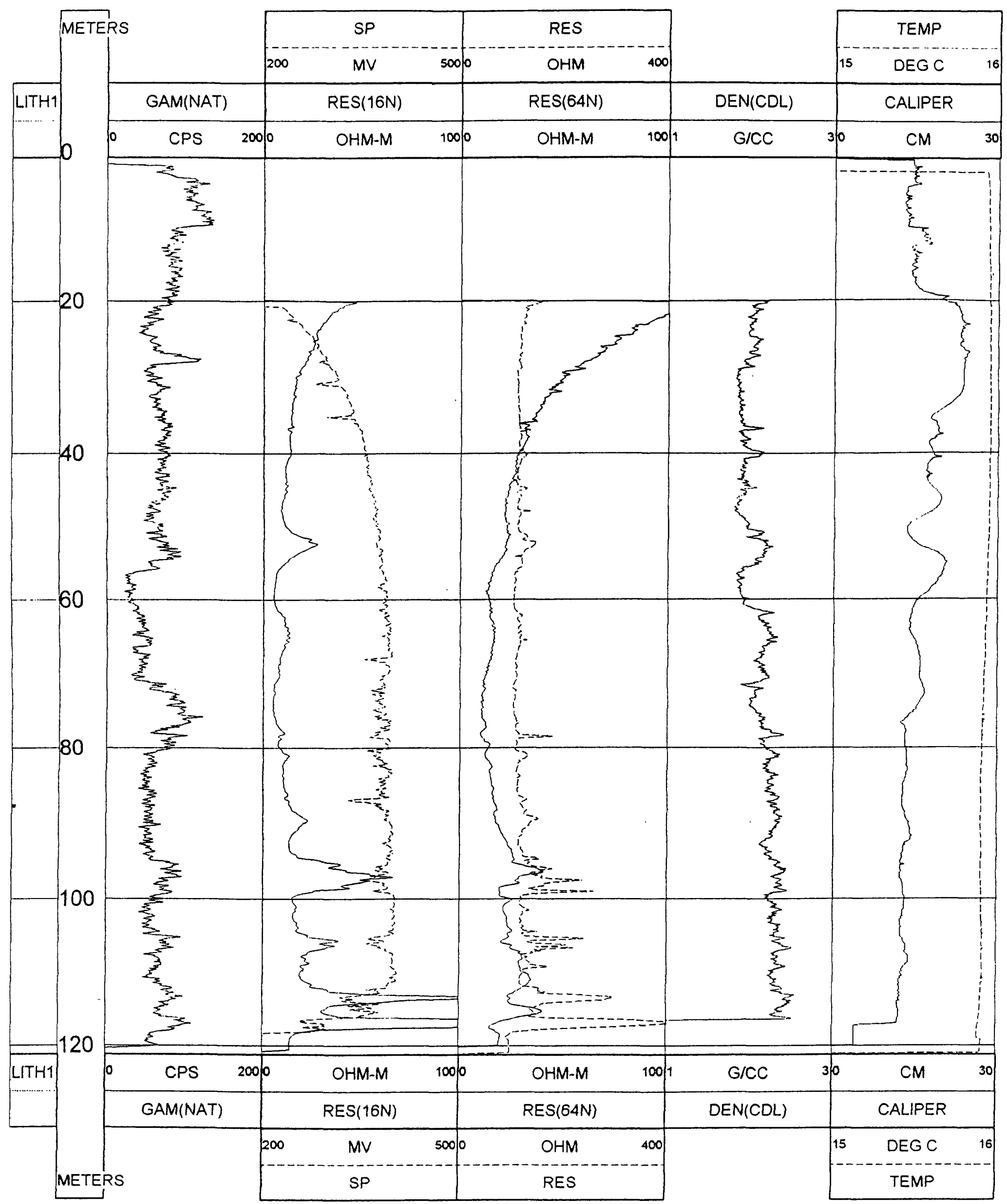

DRILL HOLE \#9A 


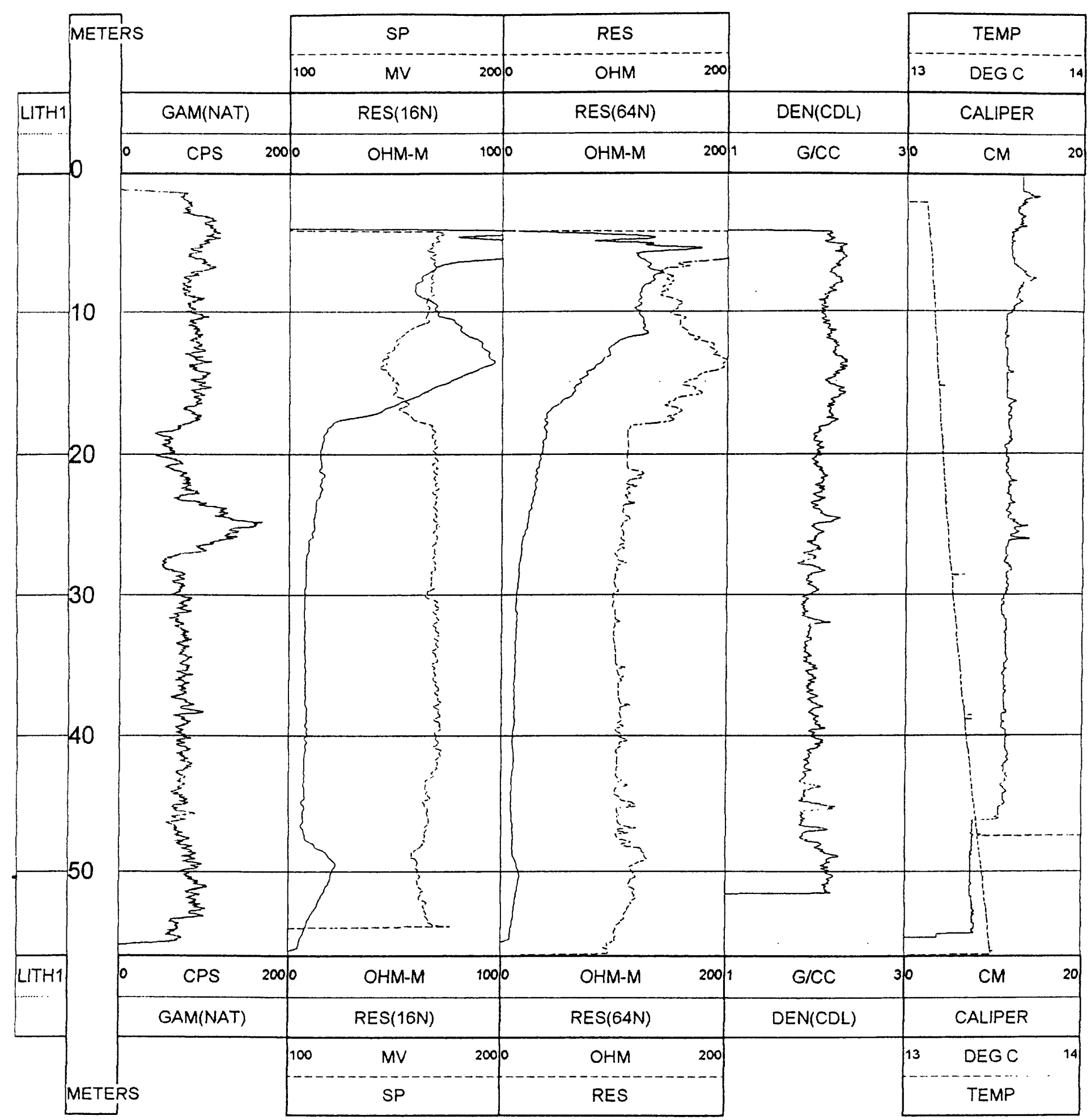




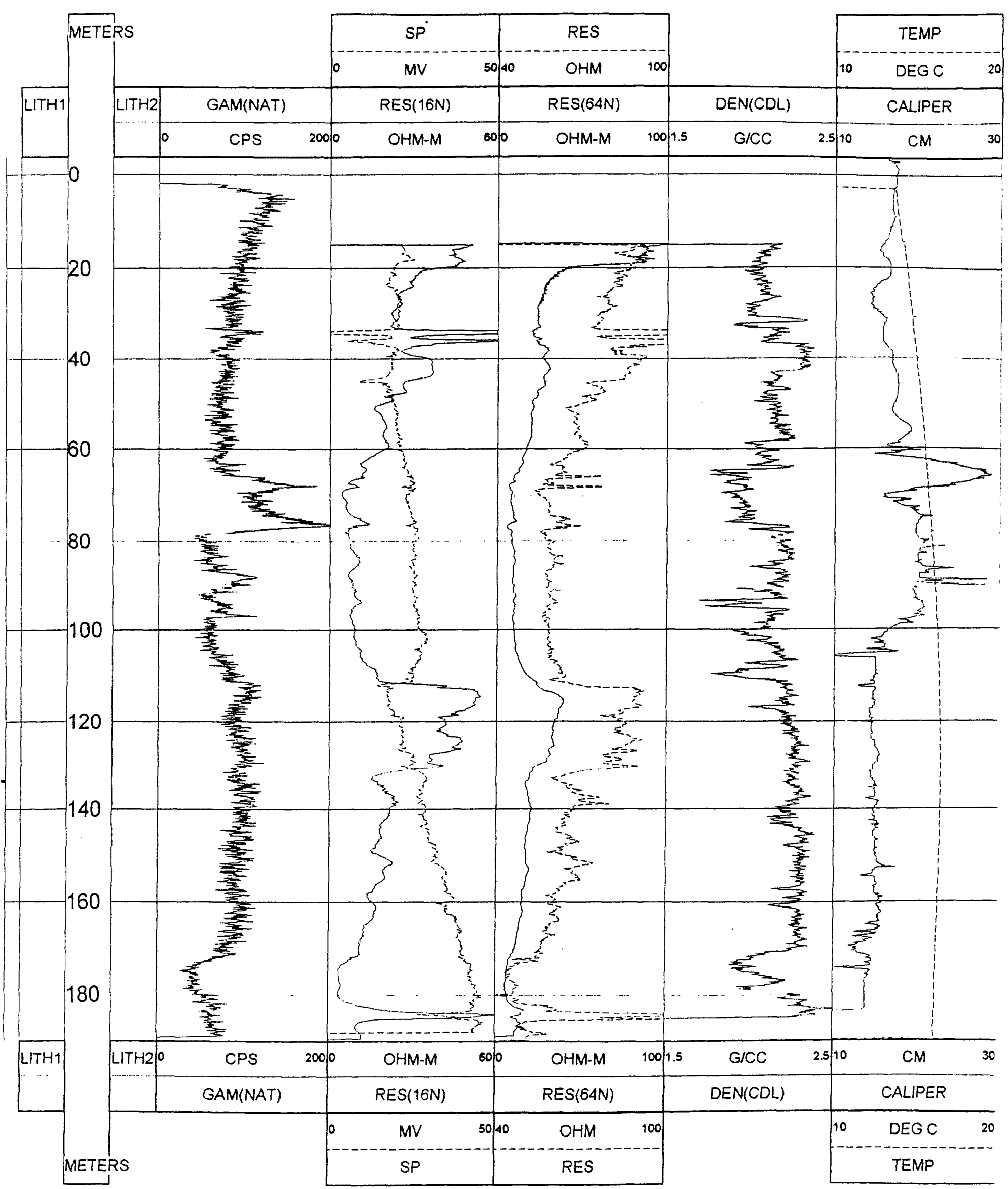

DRILL HOLE \#15A 


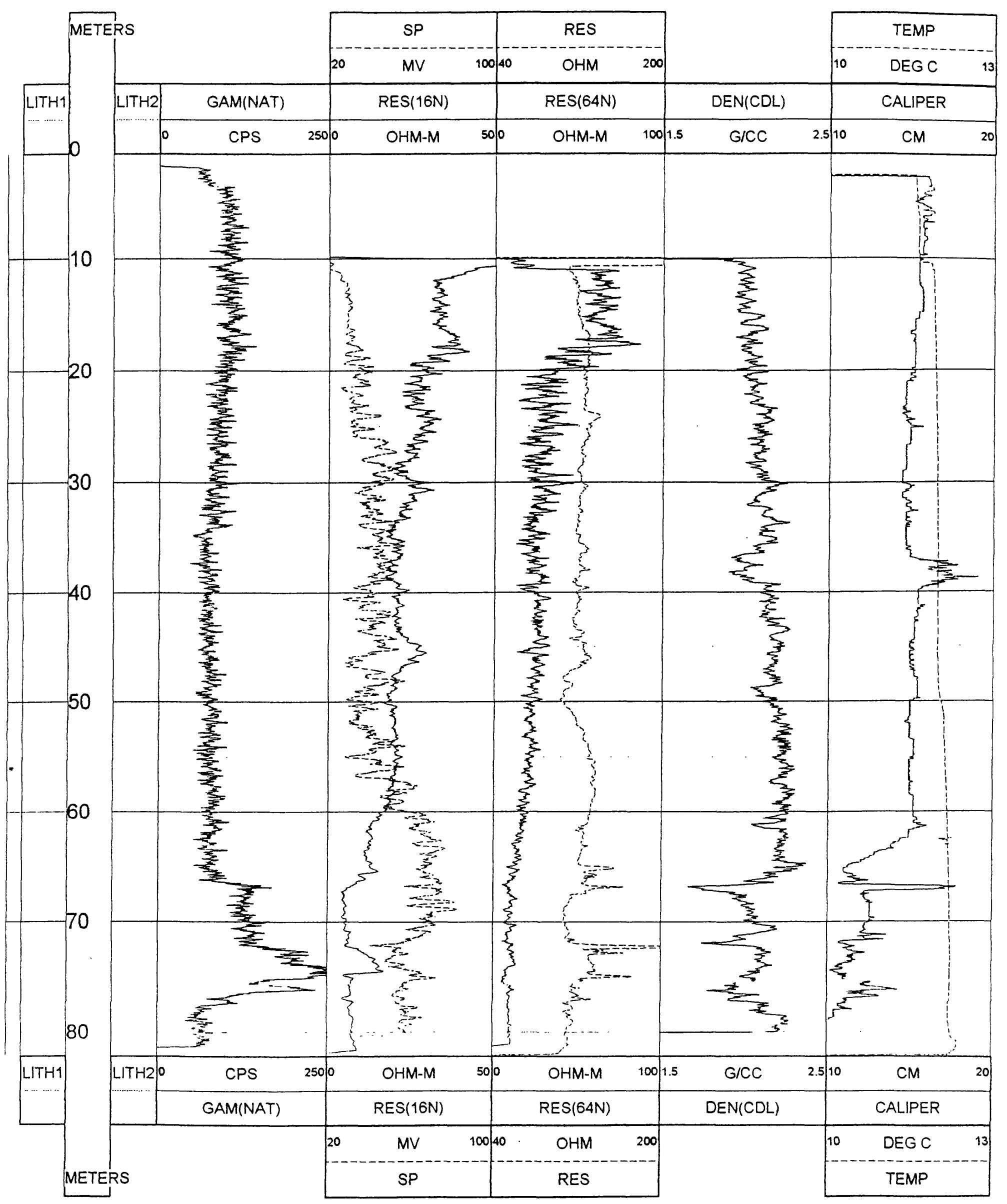




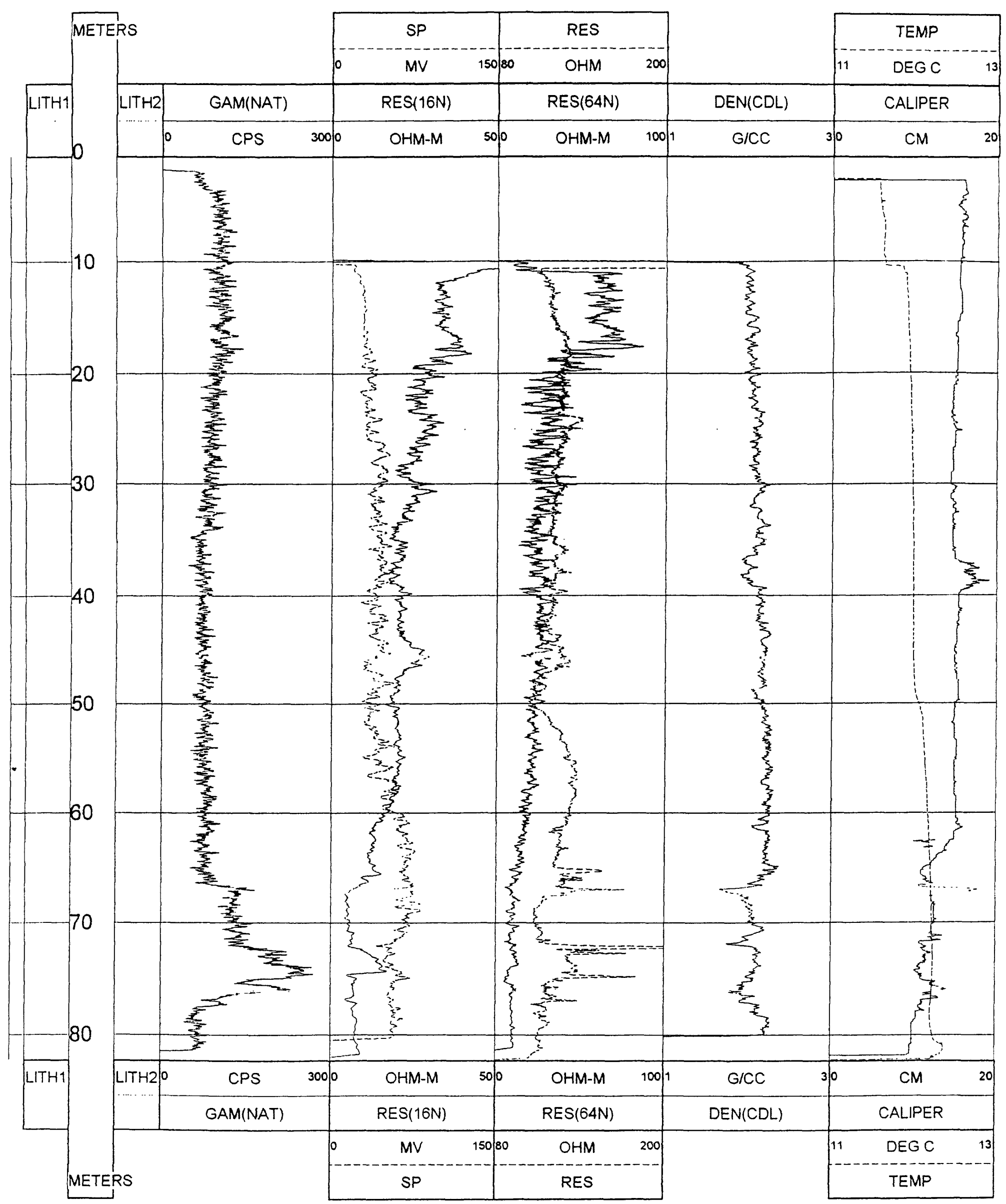

DRILL HOLE \#16A 


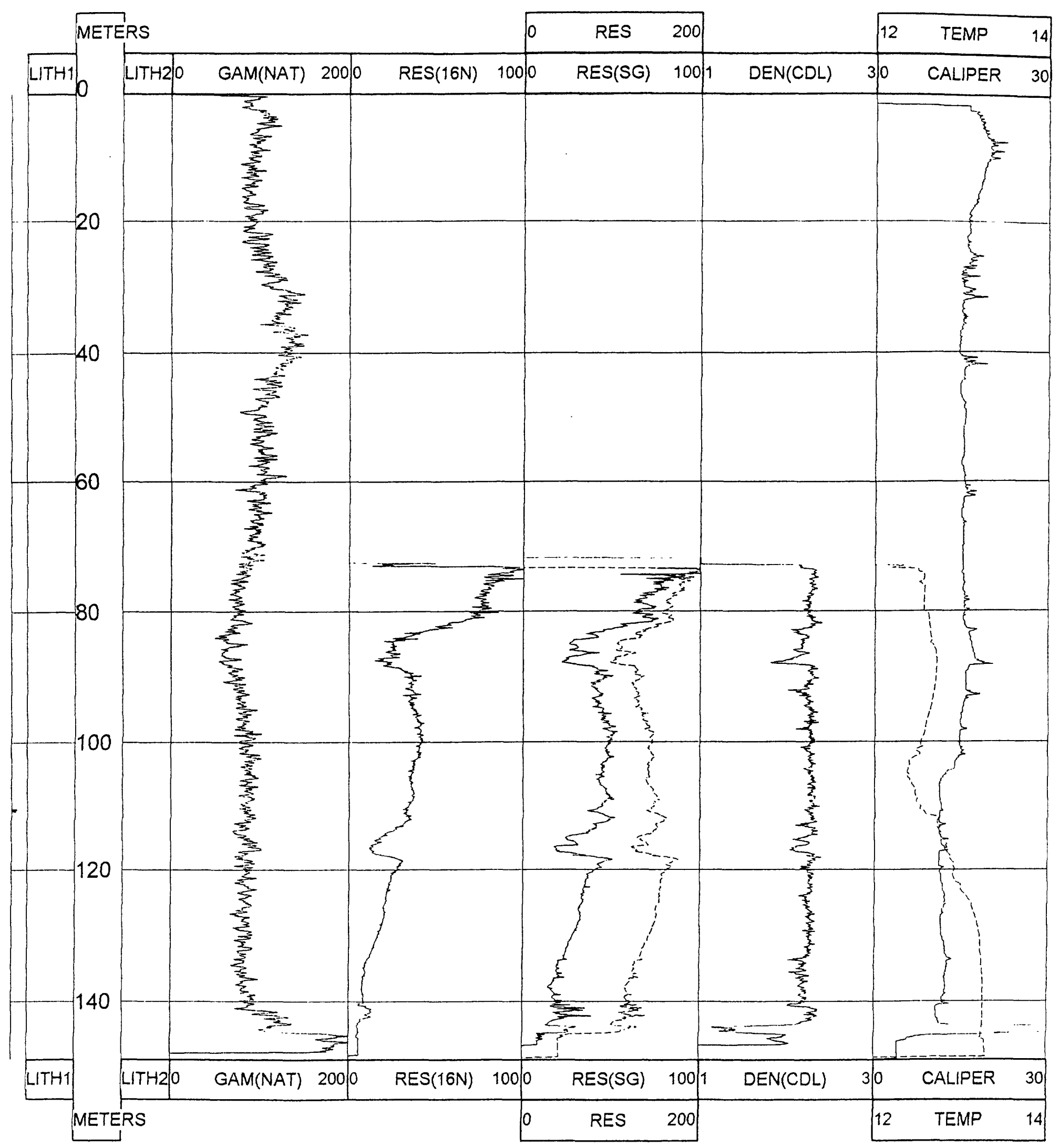

DRILL HOLE \#17A 


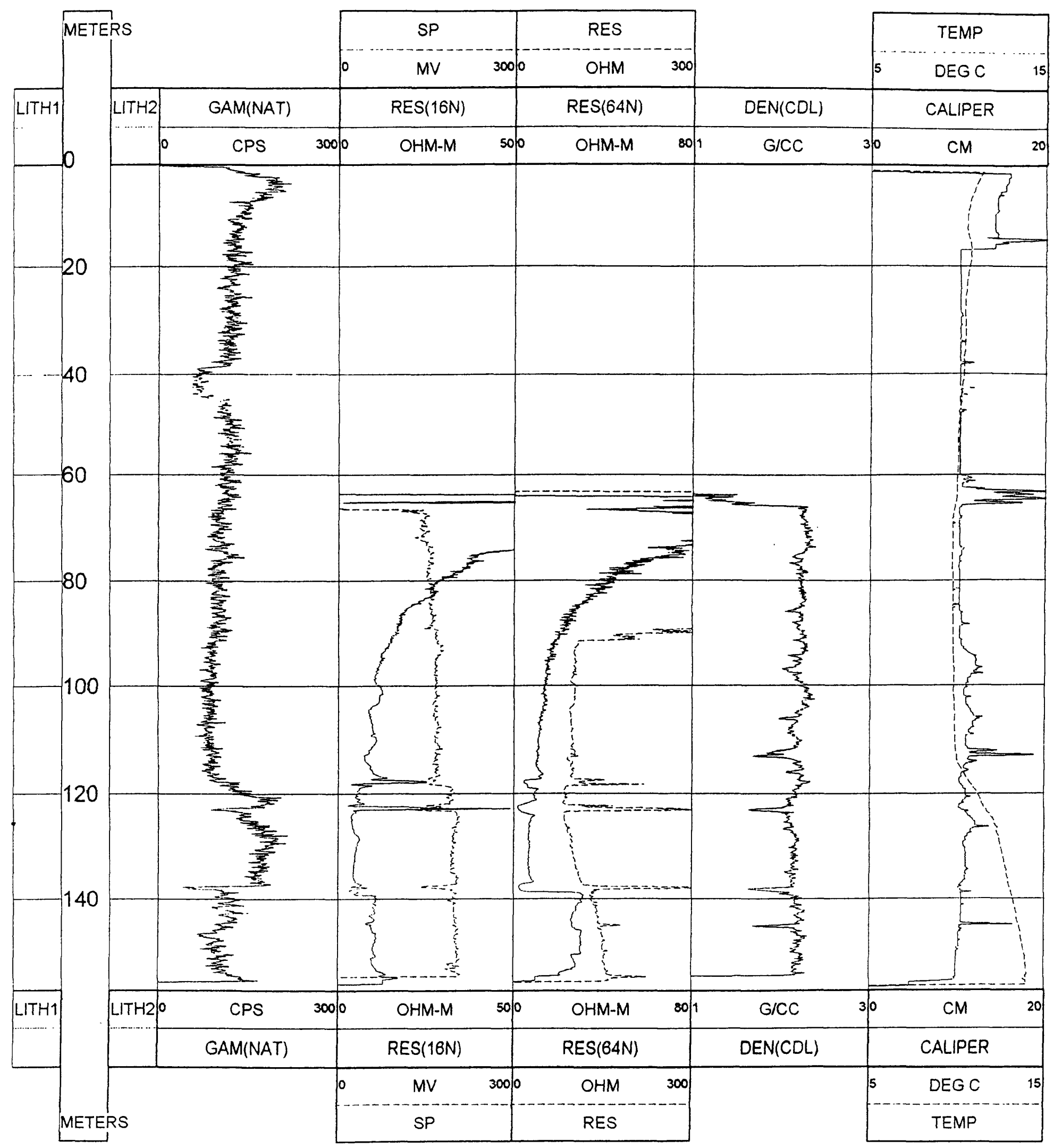

DRILL HOLE \#18A 


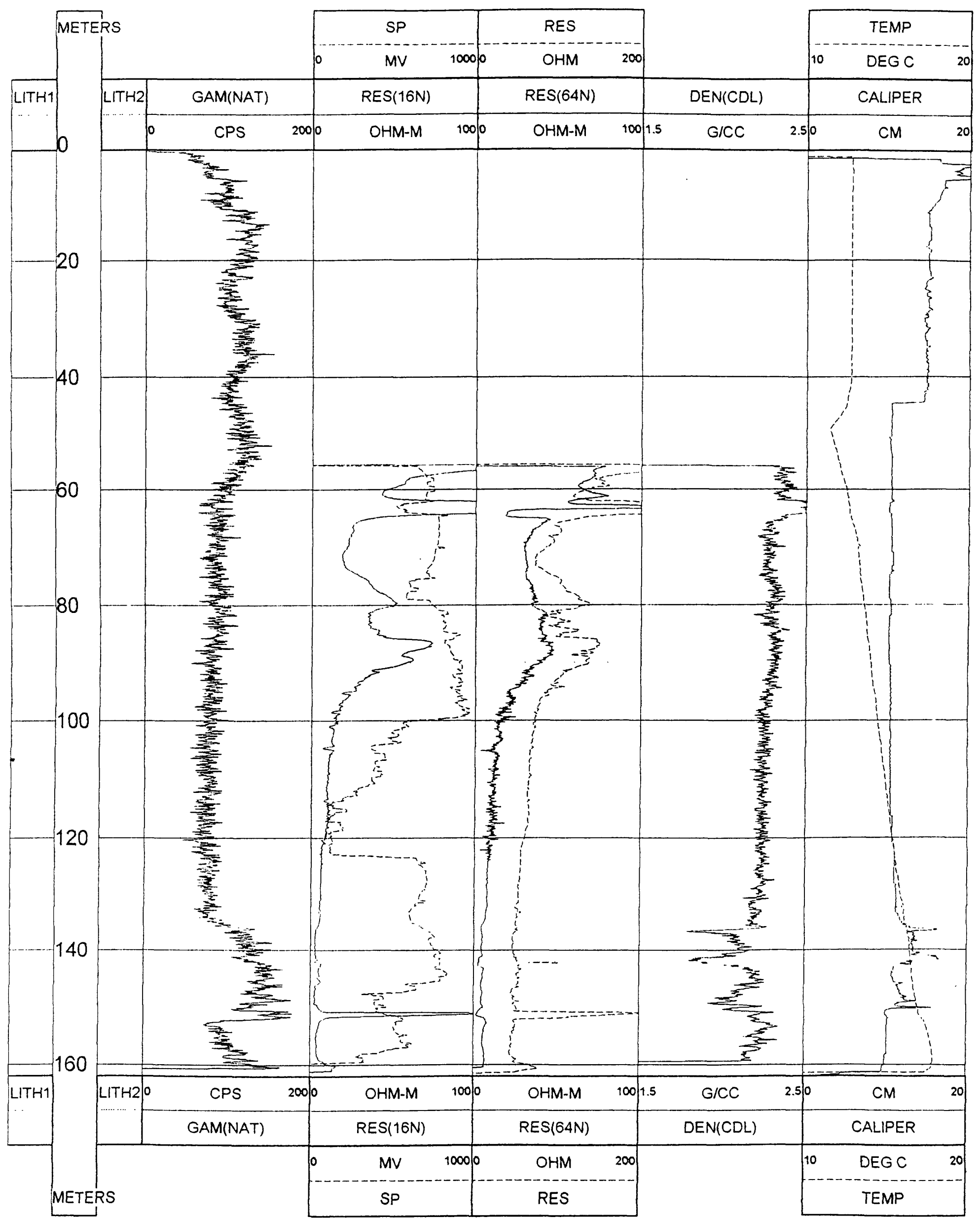

DRILL HOLE \#19A 


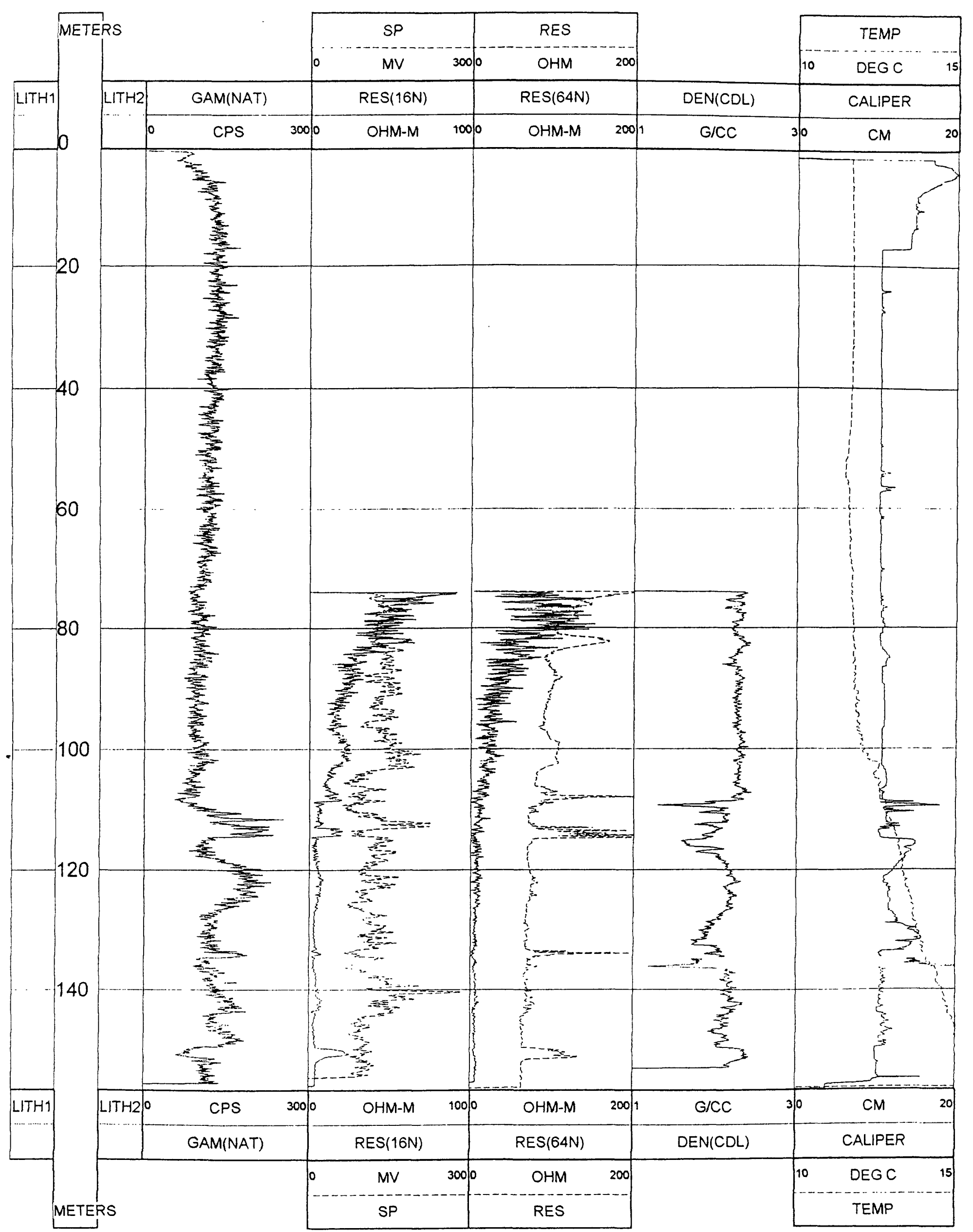

DRILL HOLE \#20A 


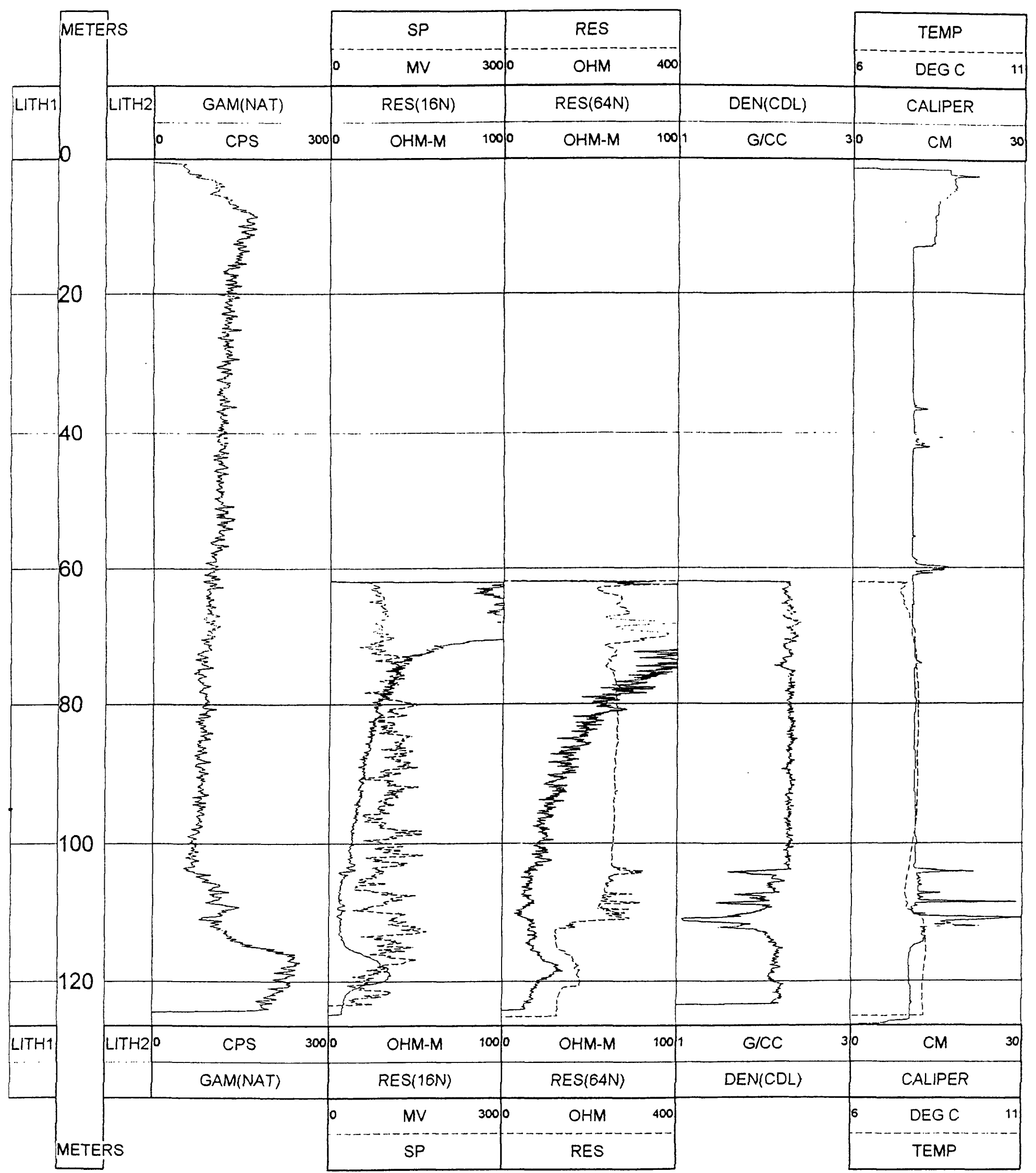

DRILL HOLE \#21A 


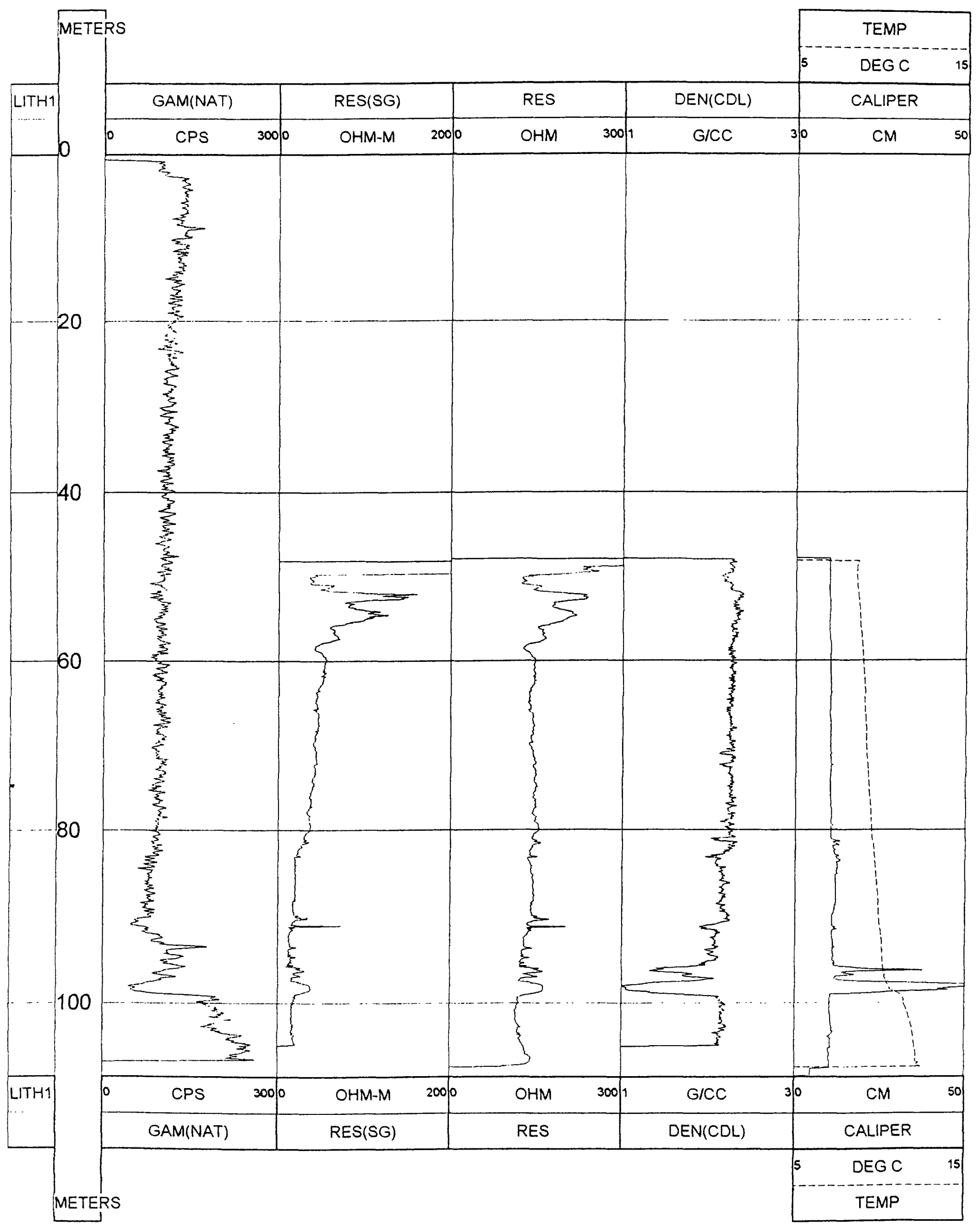

DRILL HOLE \#24A 


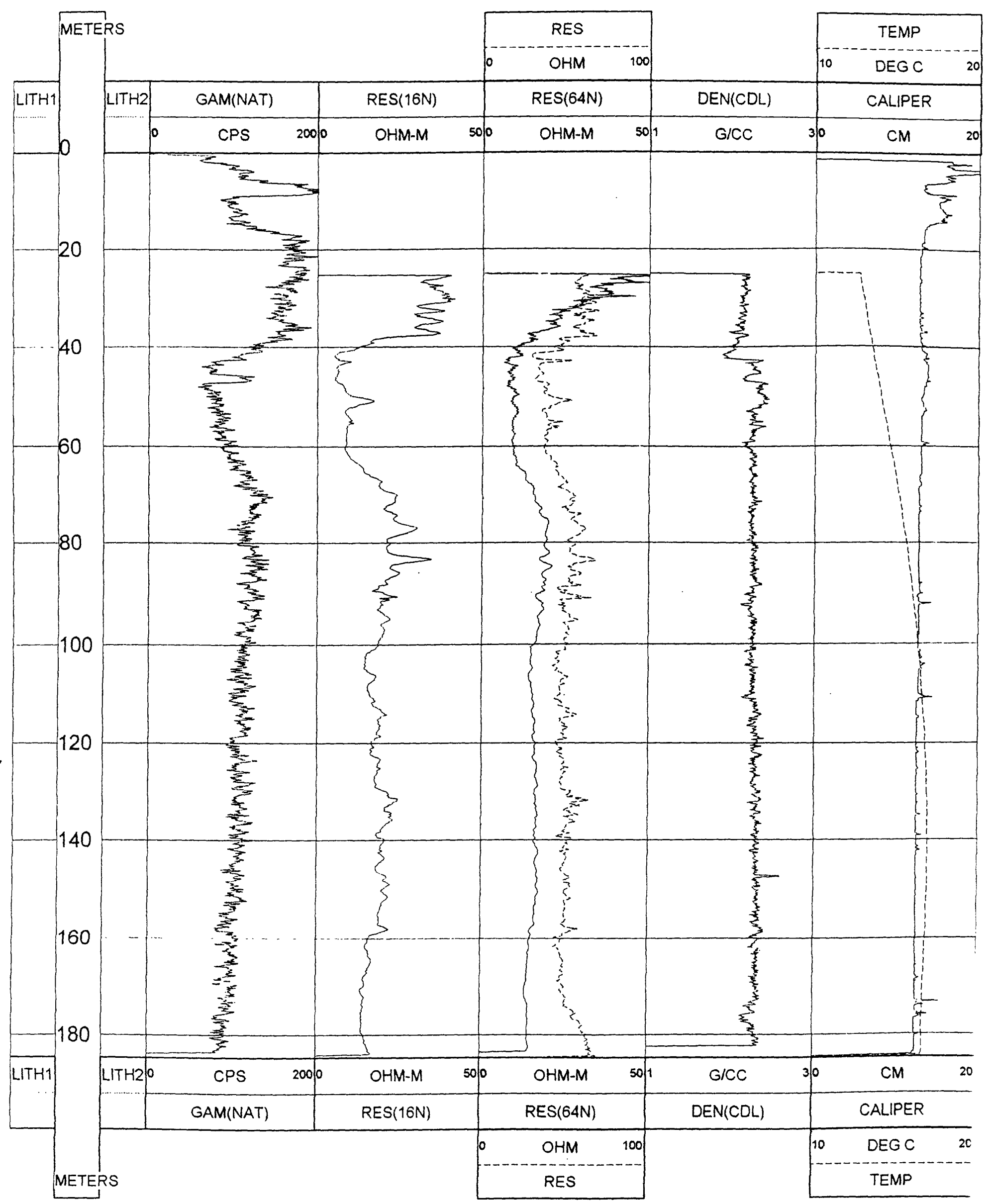




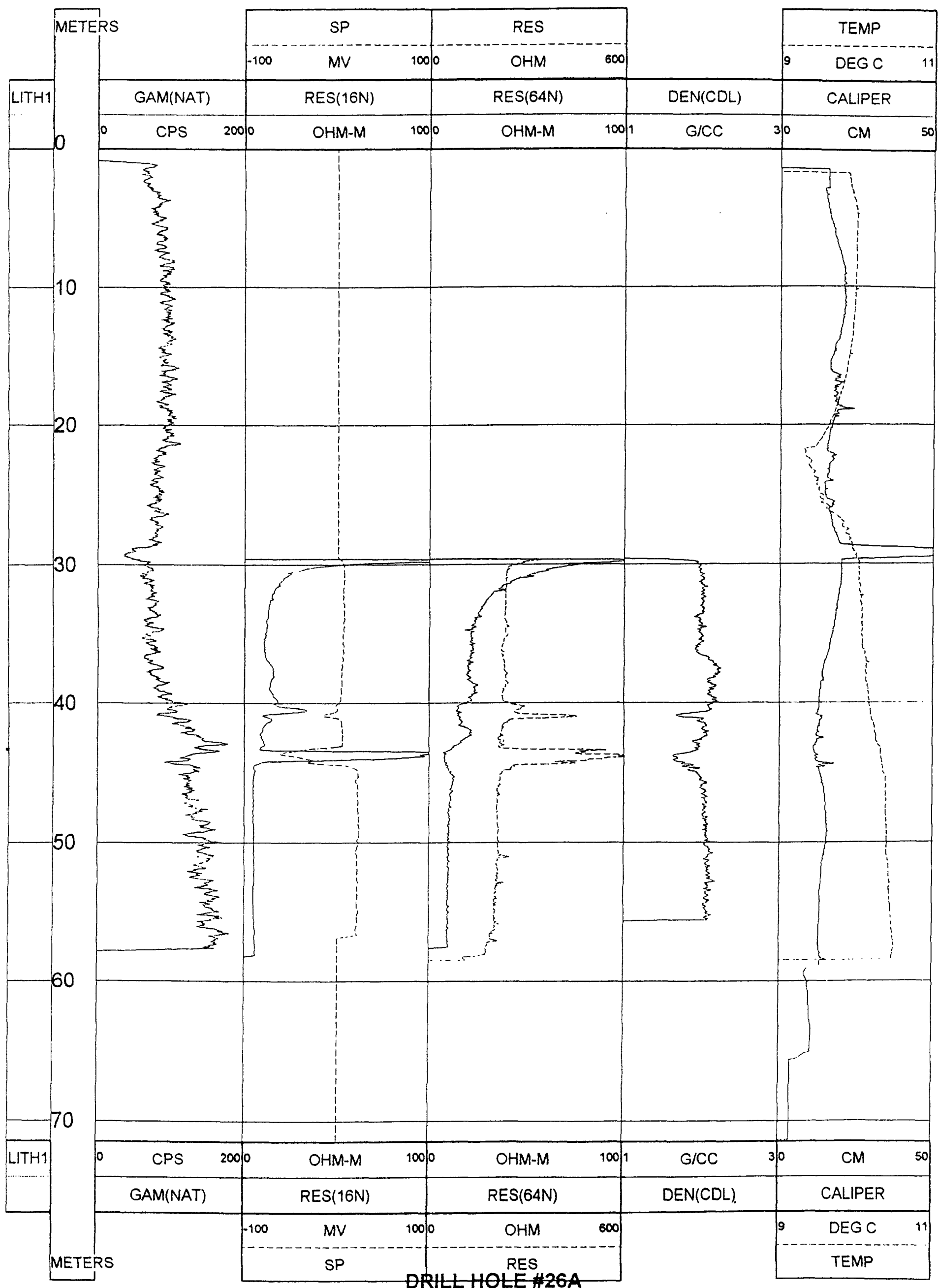




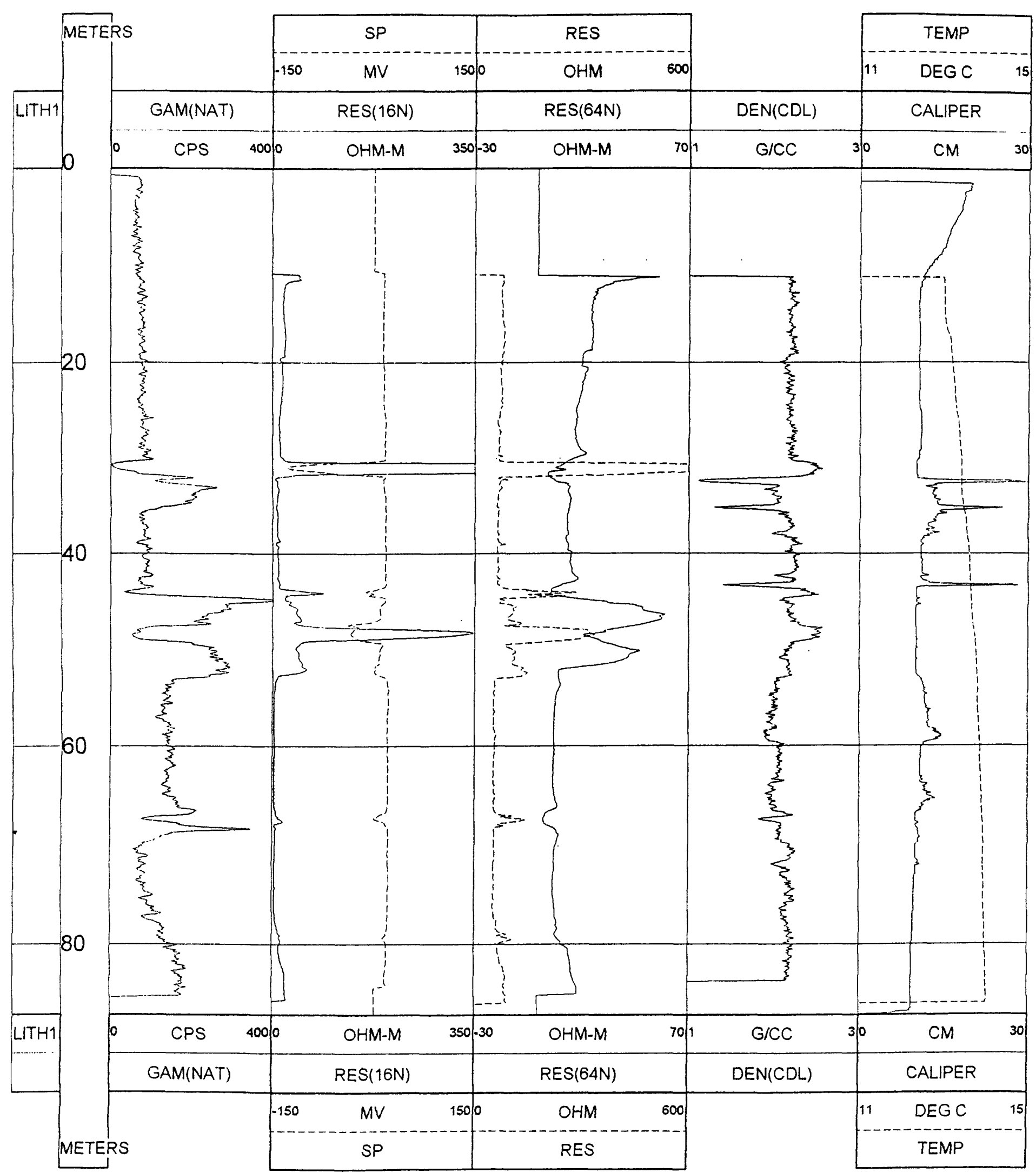




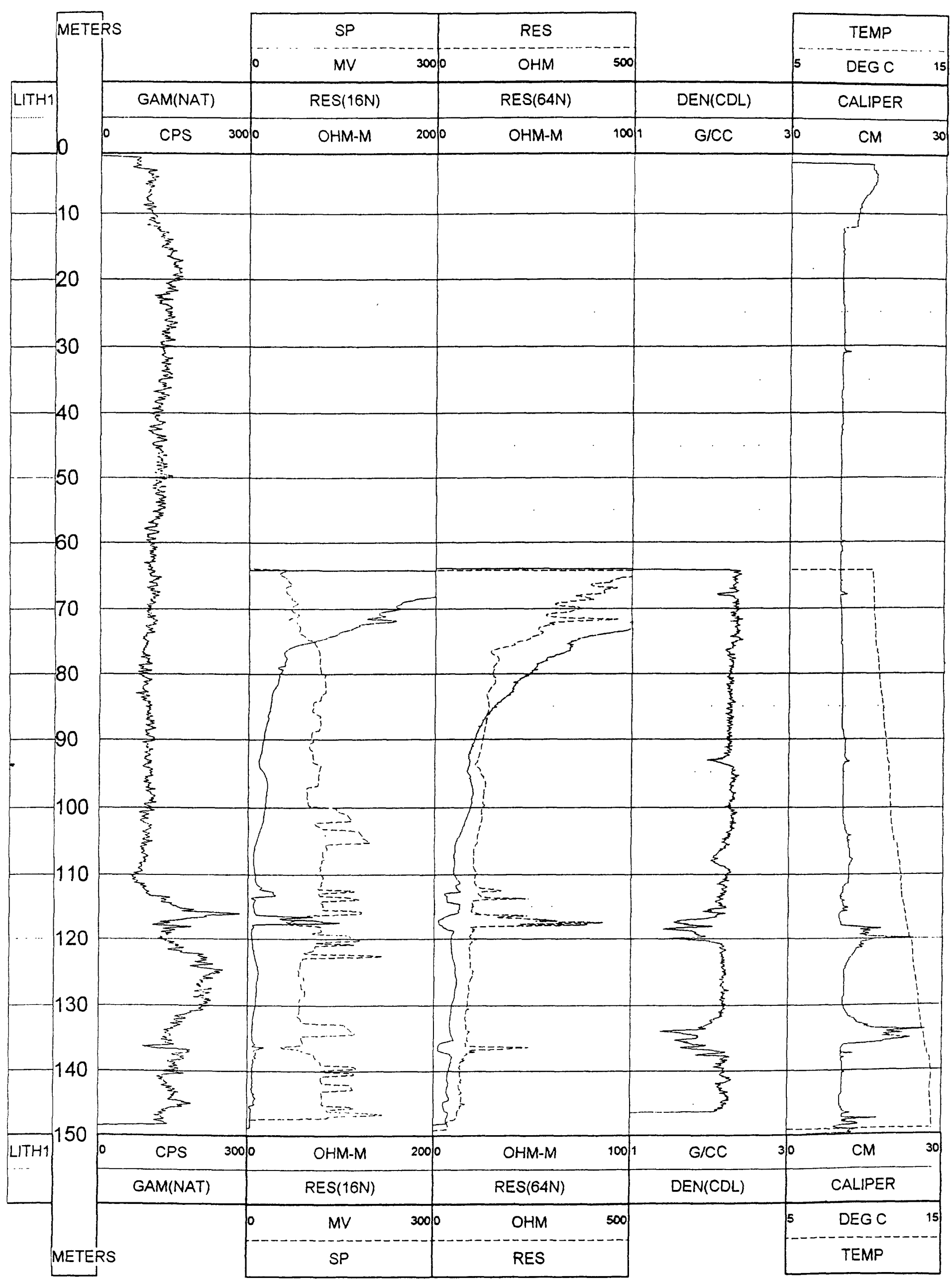

DRILL HOLE \#28A 


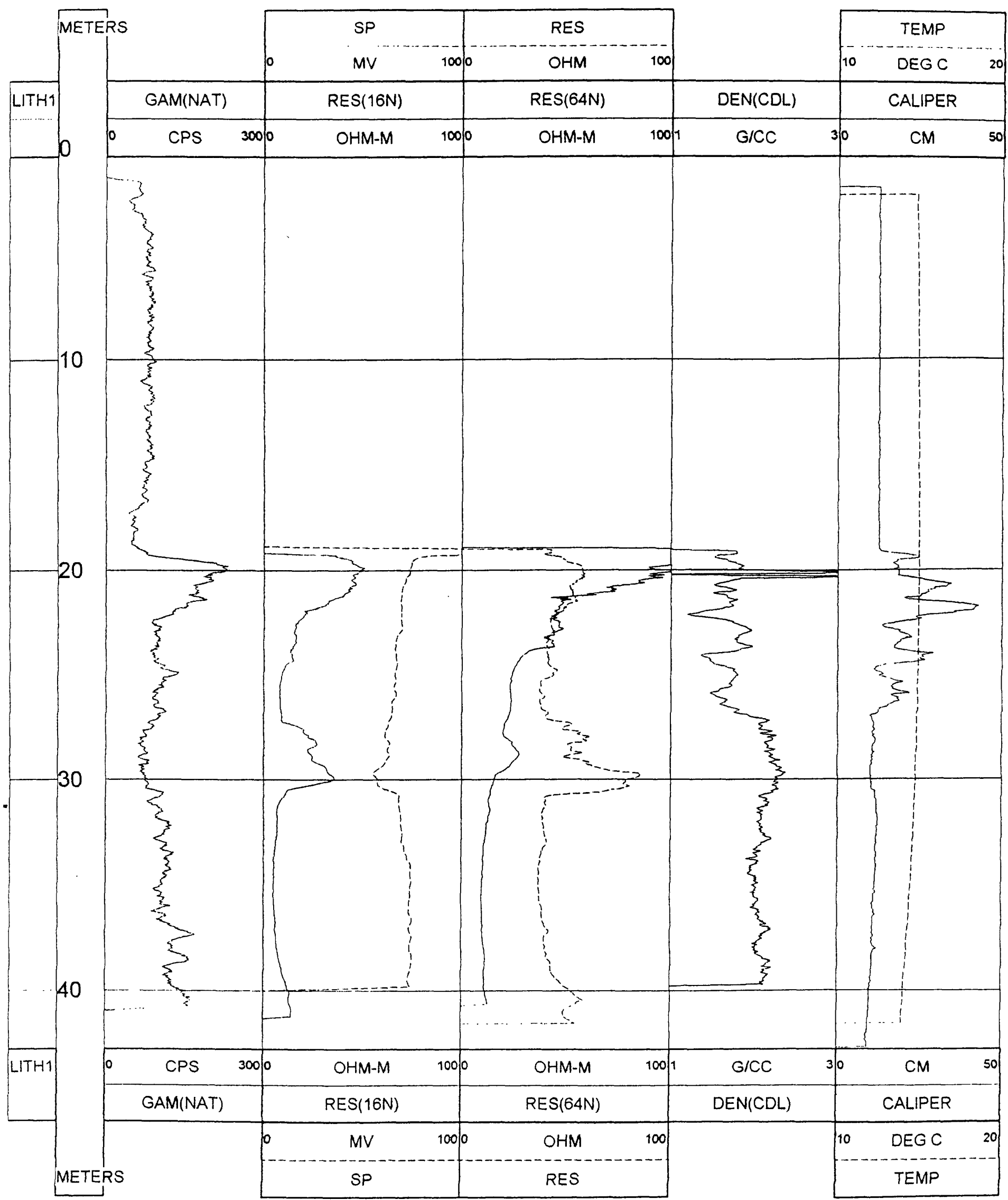

DRILL HOLE \#29A 


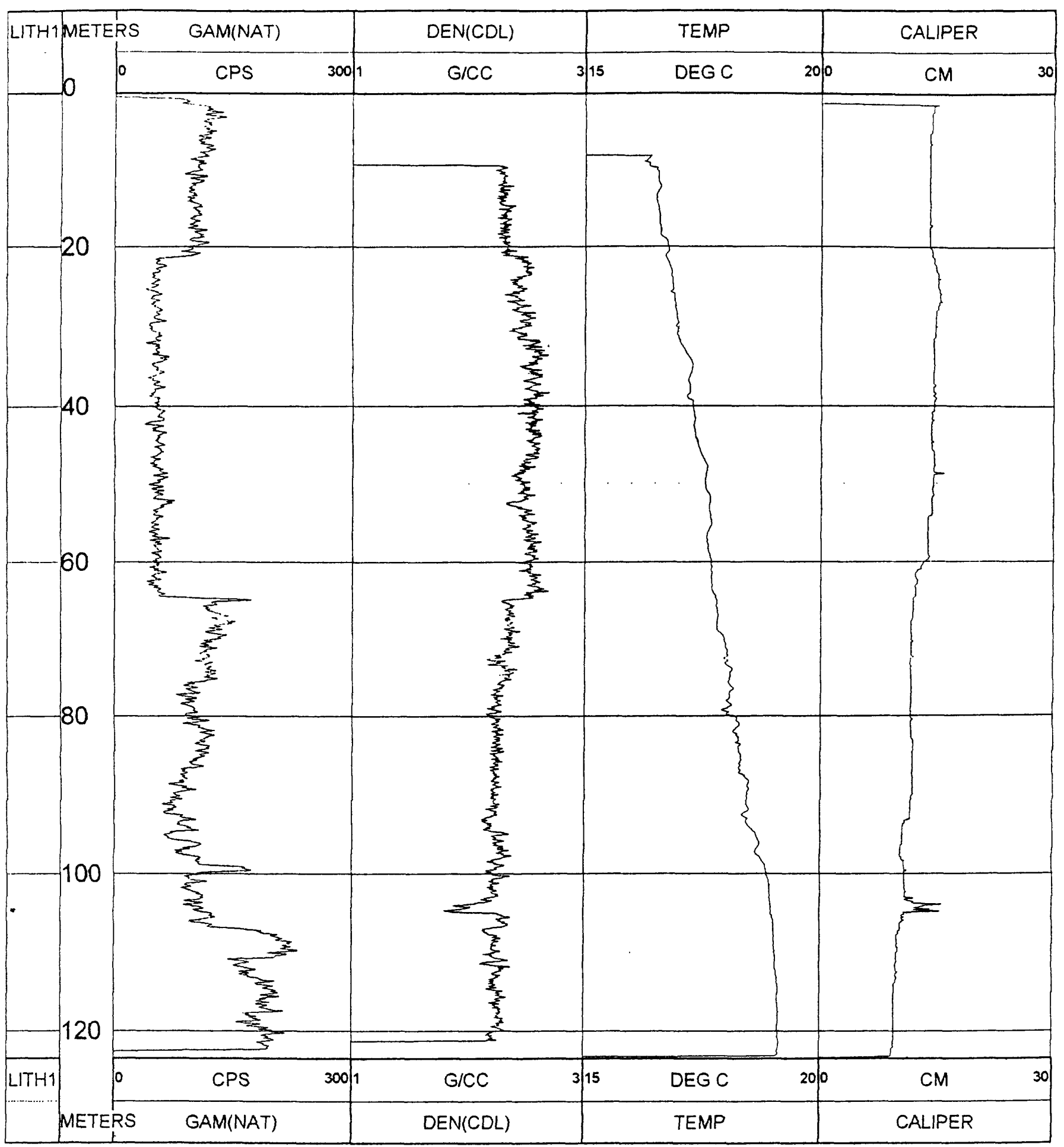

DRILL HOLE \#30A 


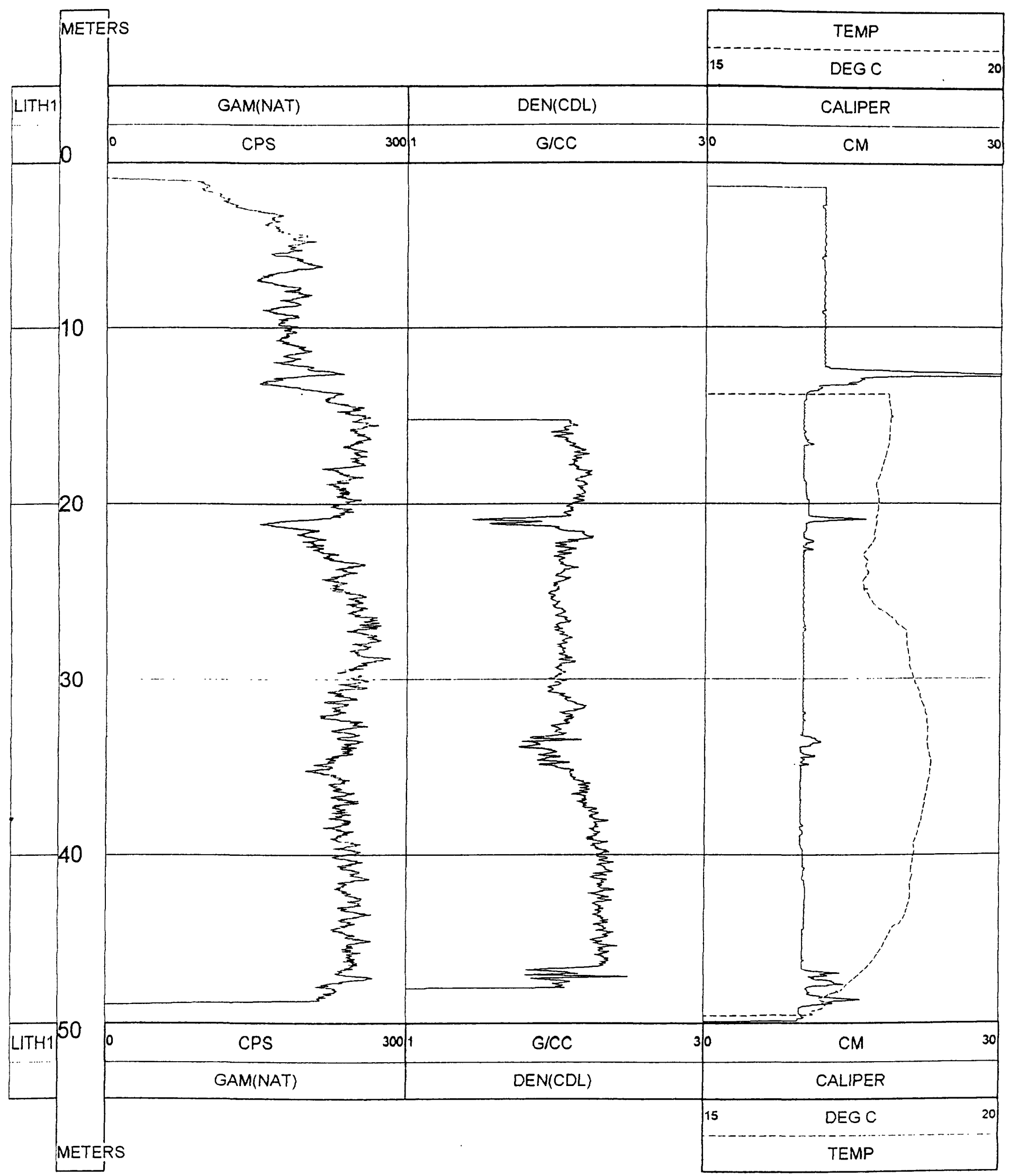

DRILL HOLE \#31A 


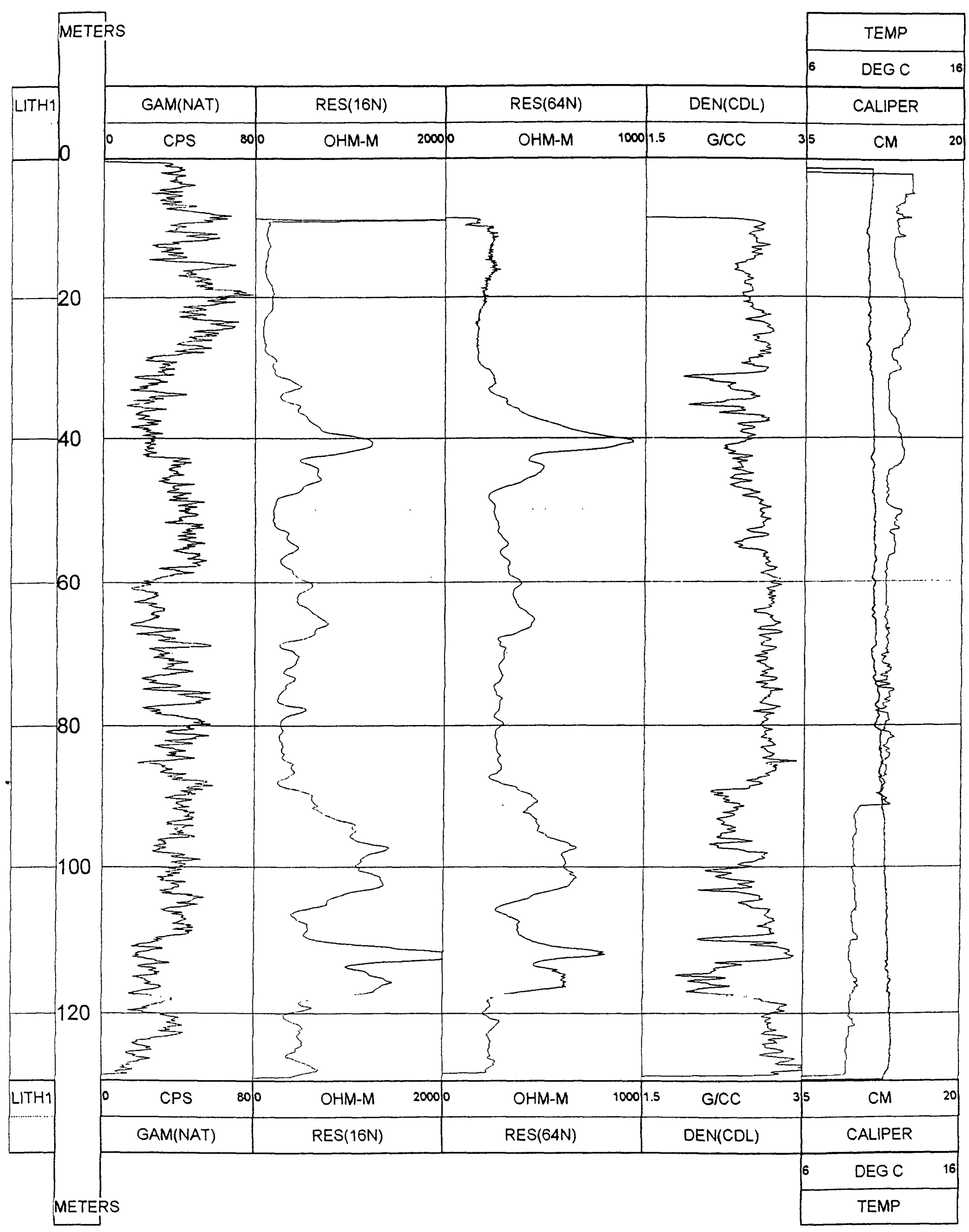

Hole 10 (for coal)

ljevan party, ljevan area 
APPENDIX 2

Geophysical Logs from Recent Exploratory Boreholes Drilled

by the RA Ministry of Environment 


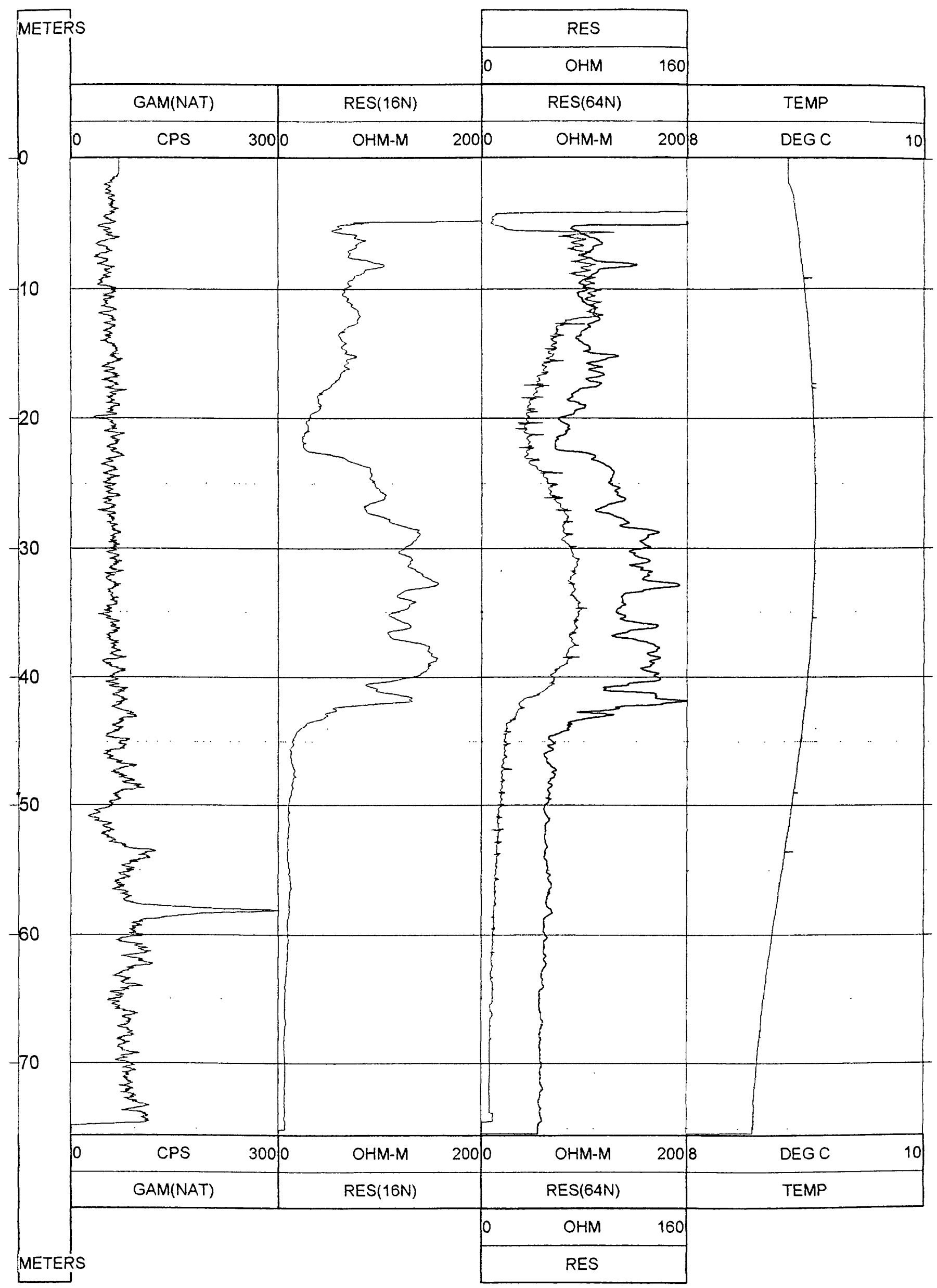

Hole 42 (for coal)

Jajur party, Jajur area 


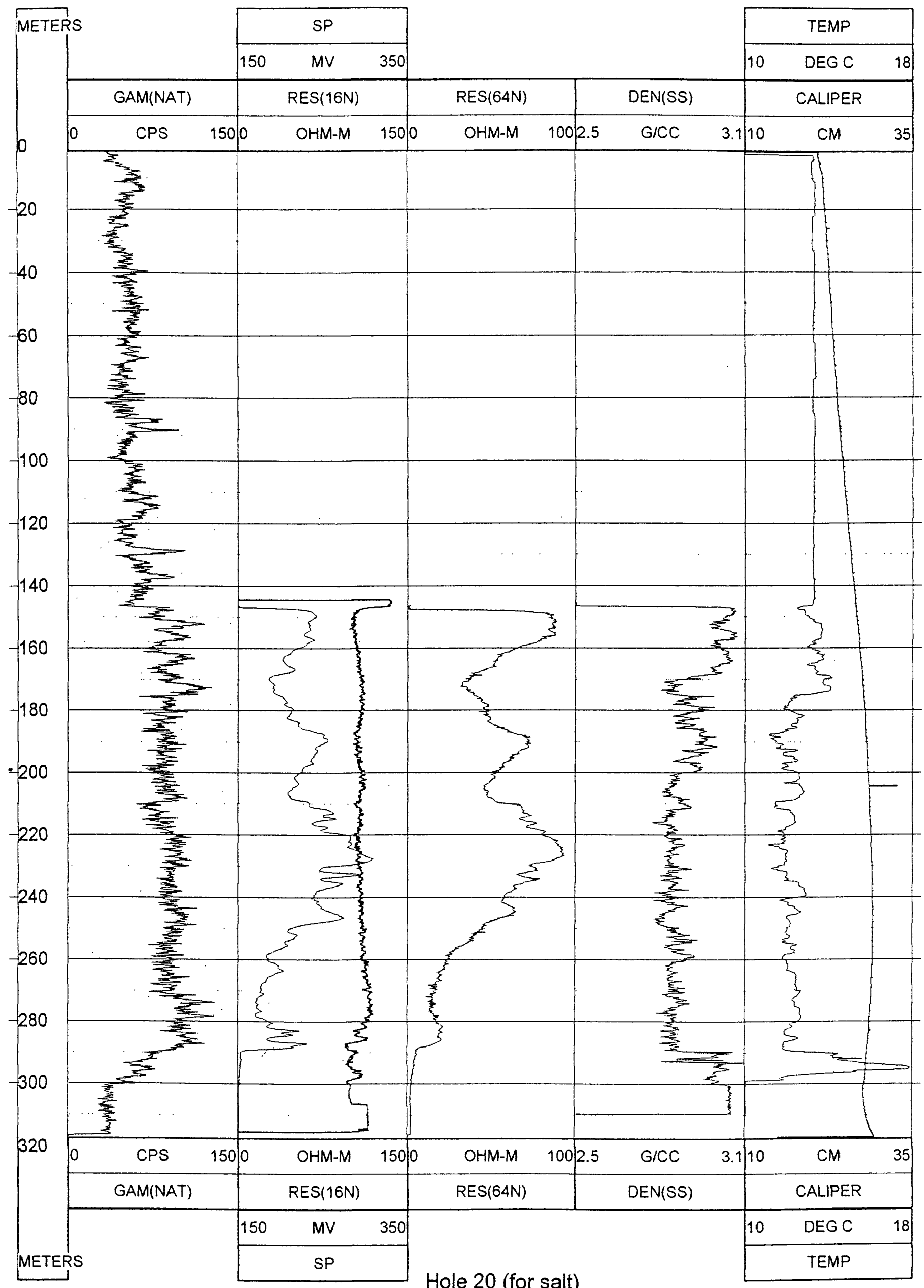

Aramus party, Aramus area 


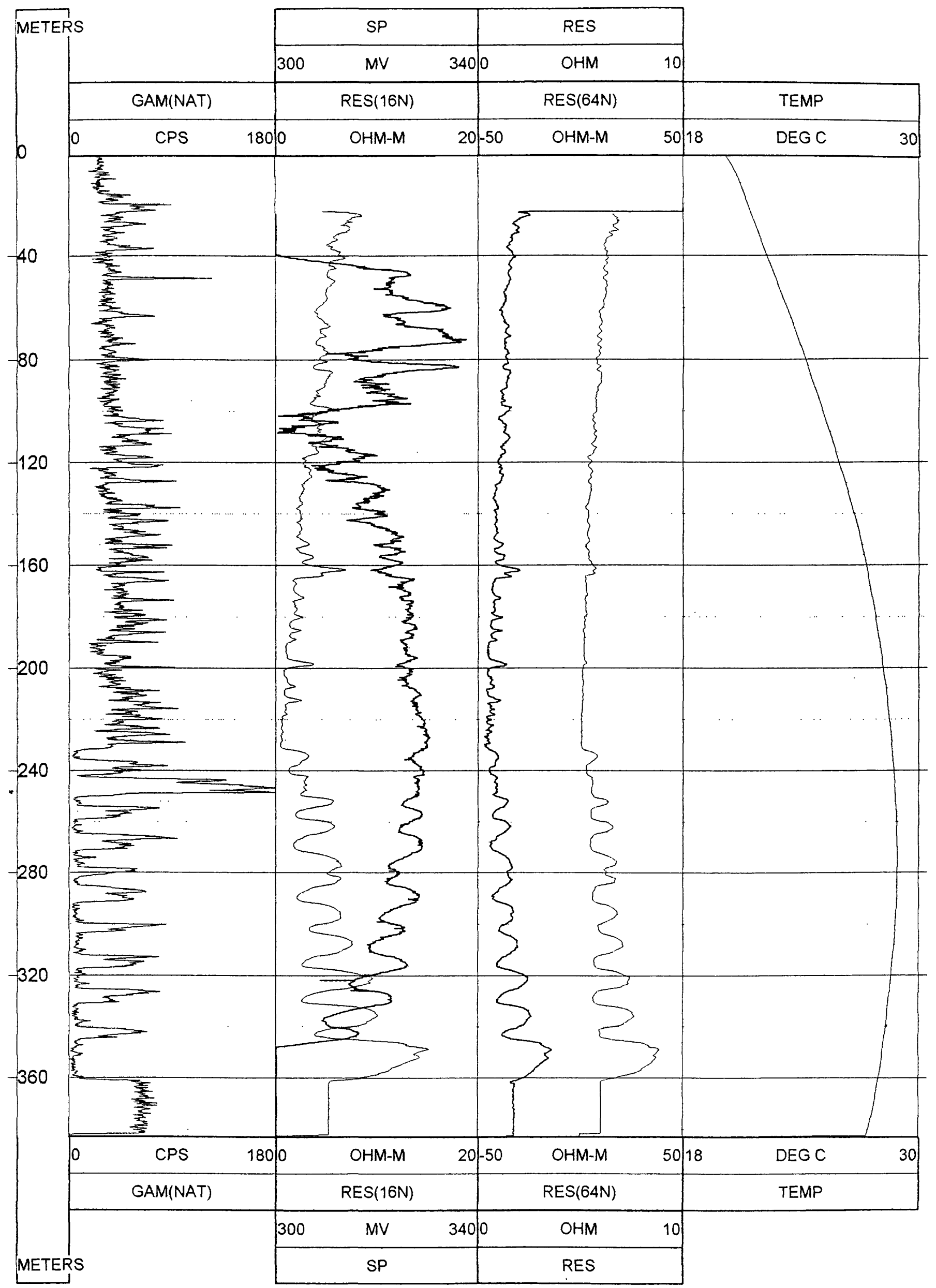

Hole 19 (for salt) 


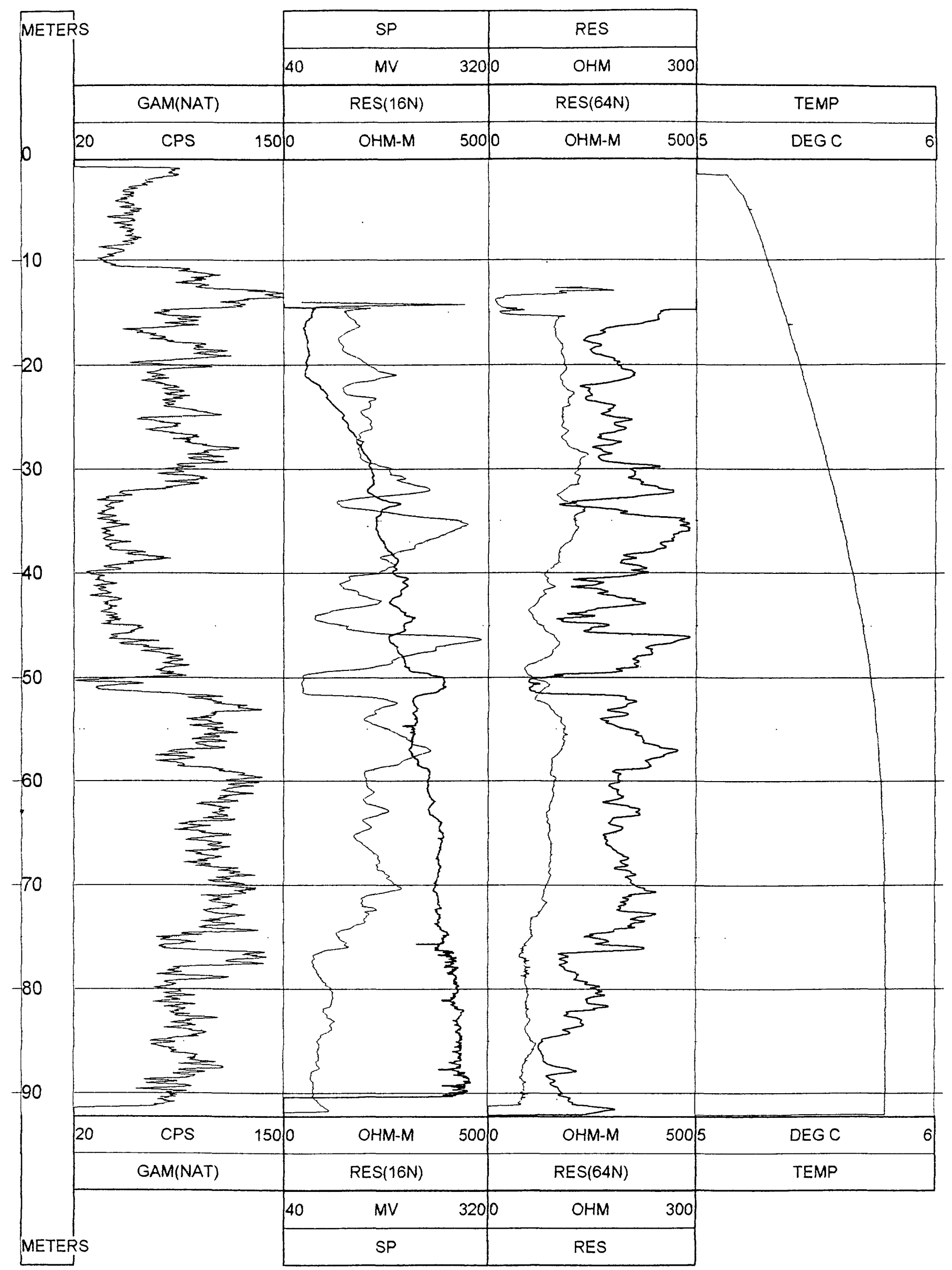

Hole 169 (for copper and other metals)

Margahovit party, Tandzut area 


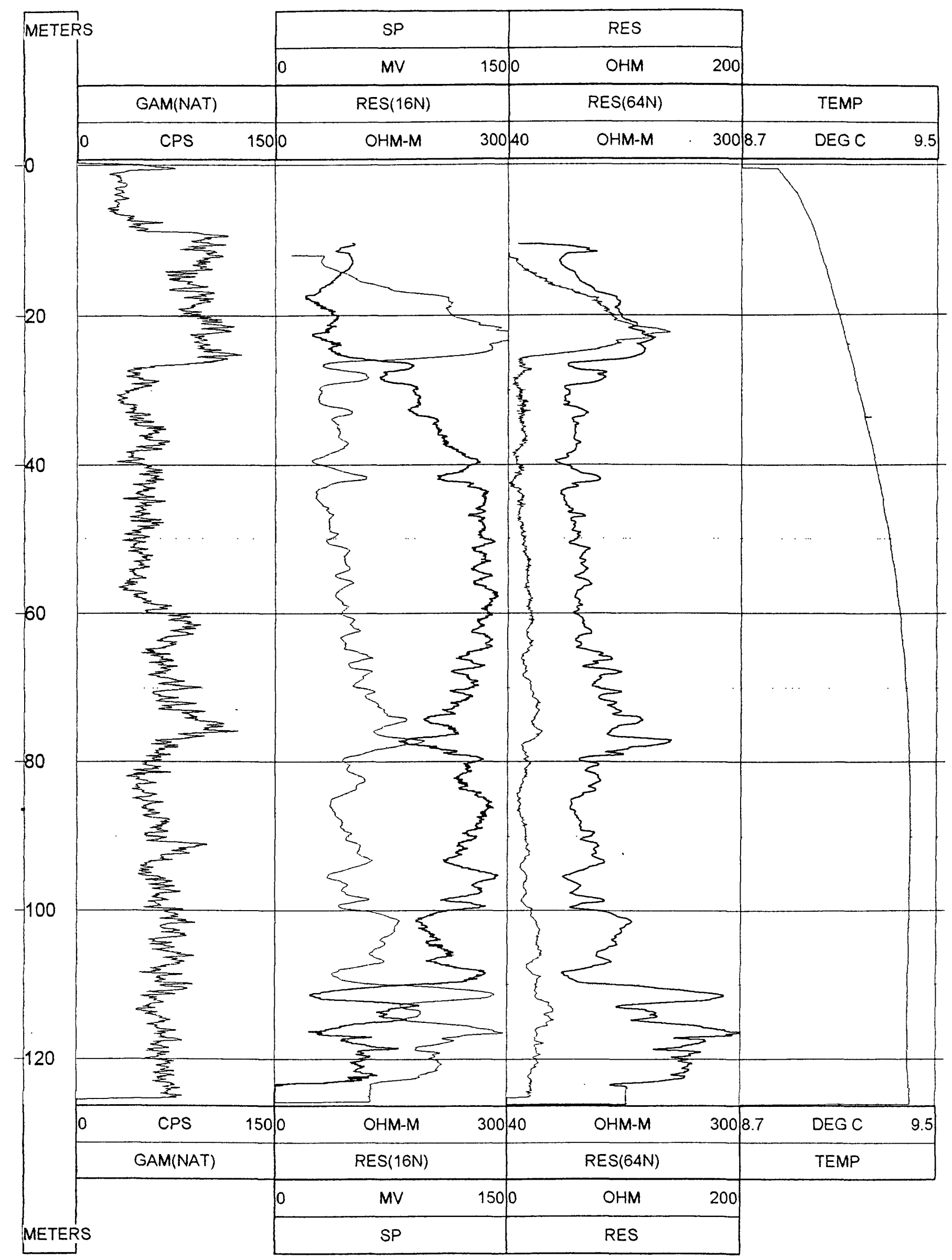

Hole 156 (for copper and other metals)

Margahovit party, Tandzut area 


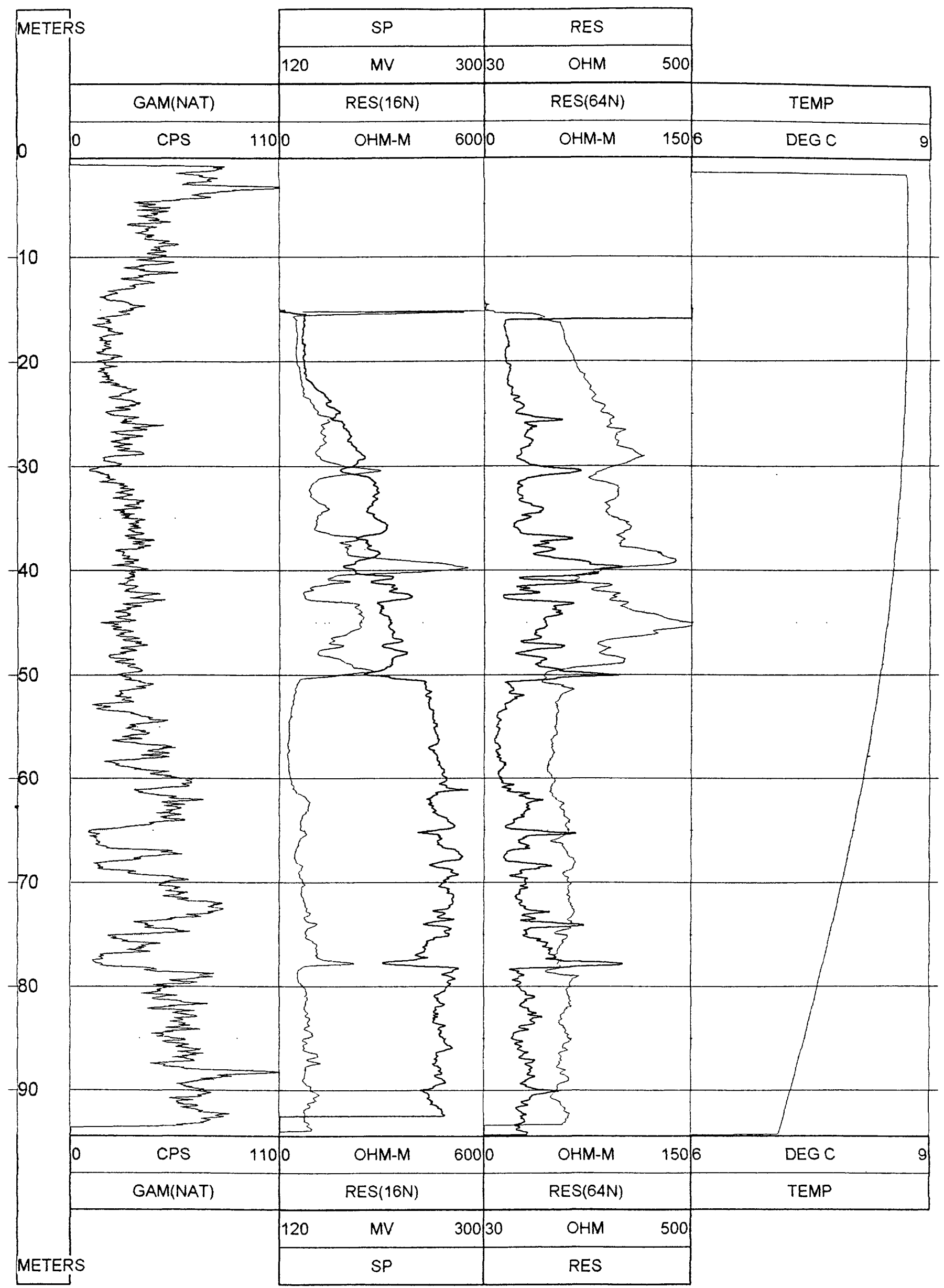

Hole 10 (for copper and other metals) 


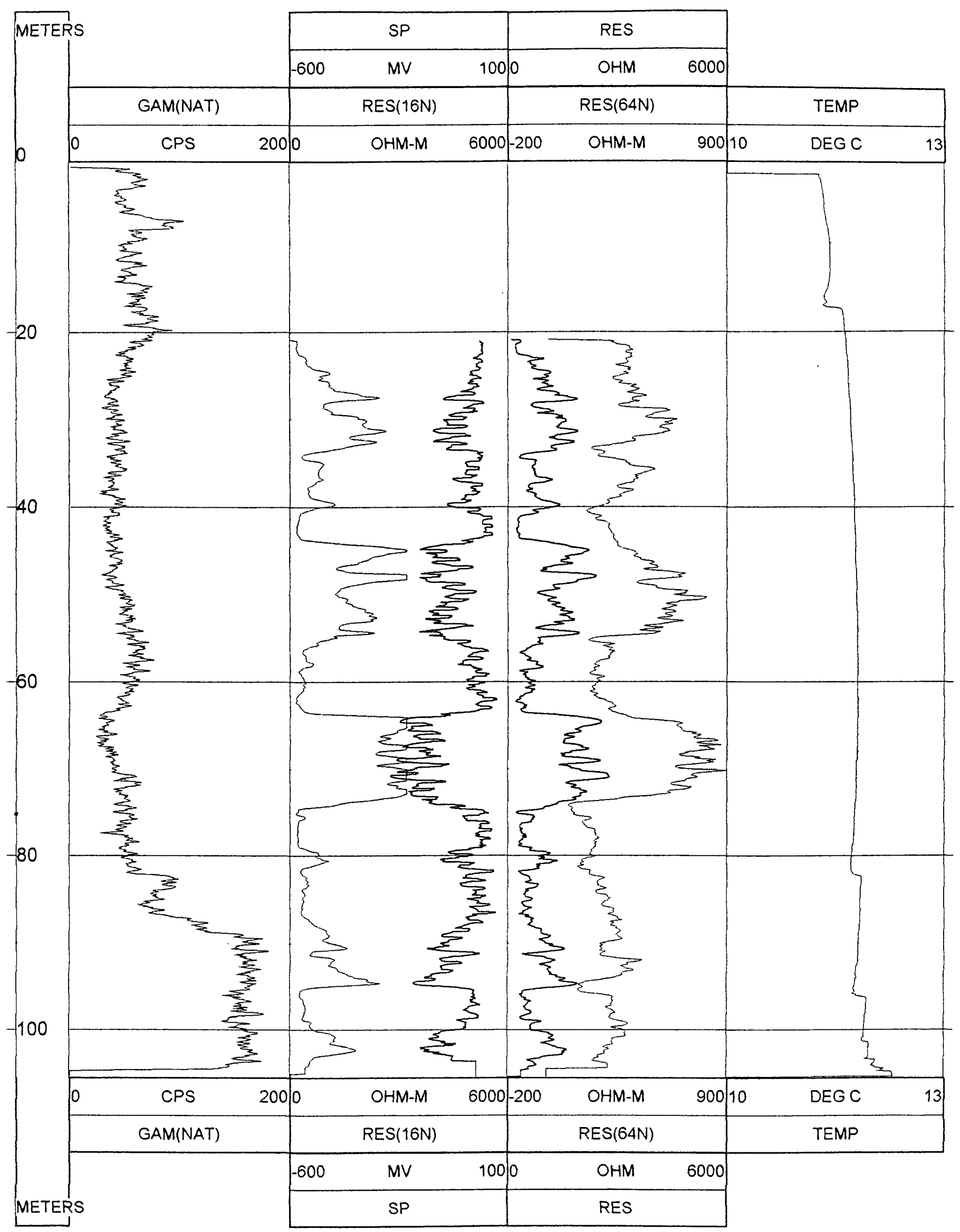

Hole 113 (for copper and other metals) 


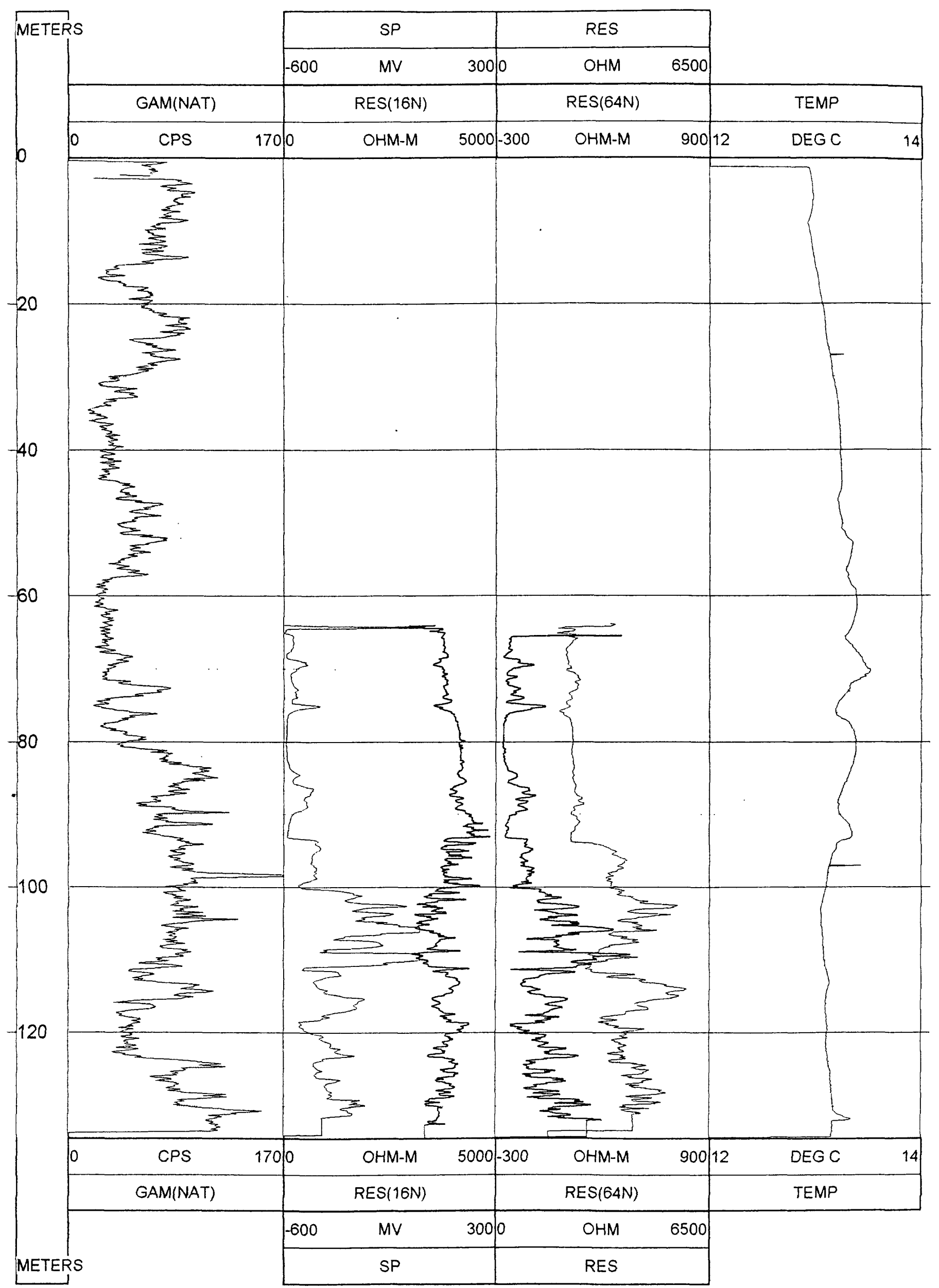

Hole 2 (for copper and other metals)

Jermuk party, Zivlikh area 


\section{APPENDIX 3}

Archival Geophysical Logs from Exploratory Boreholes

throughout the Republic of Armenia 


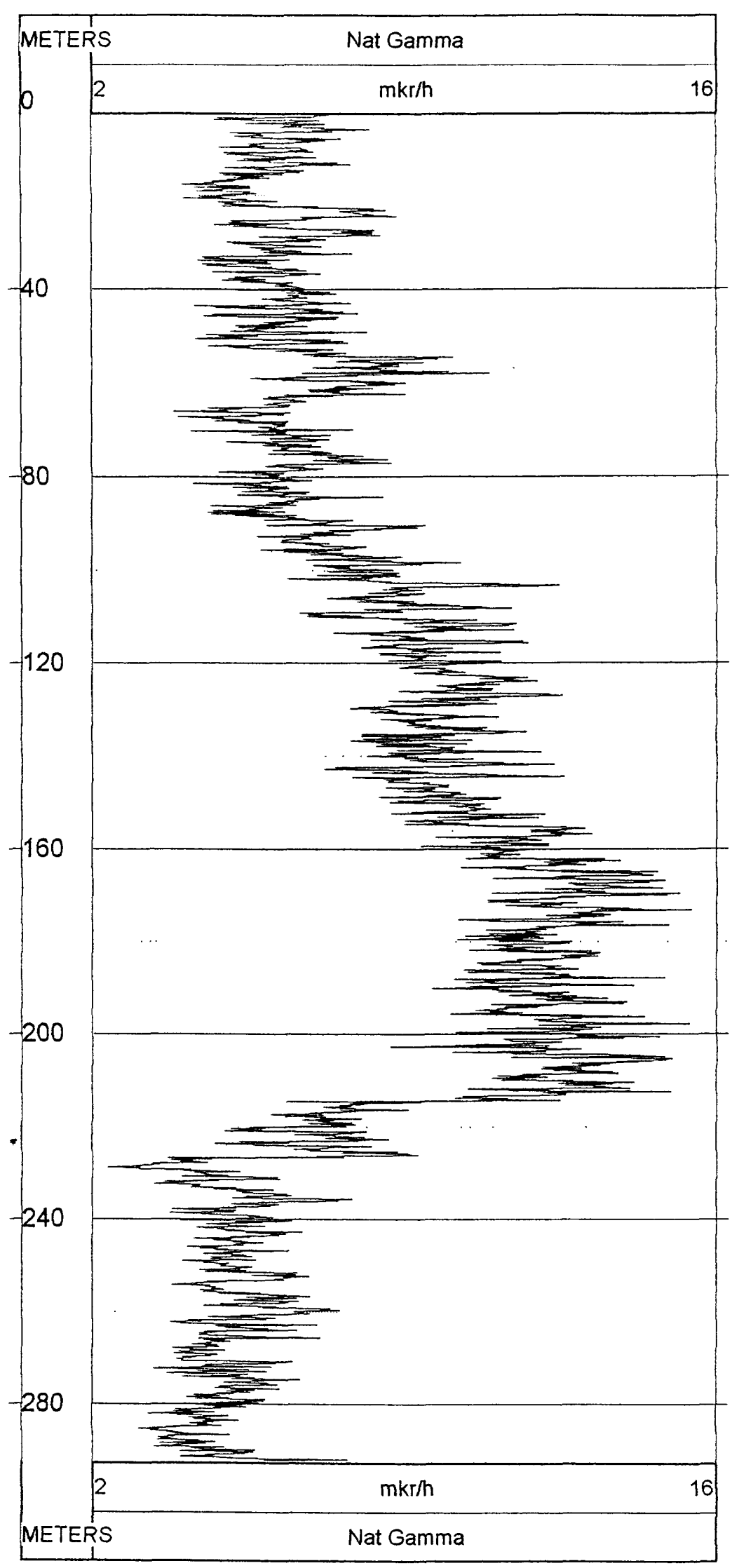

Hole 91-II (for water) Ararat party, Artashen area 


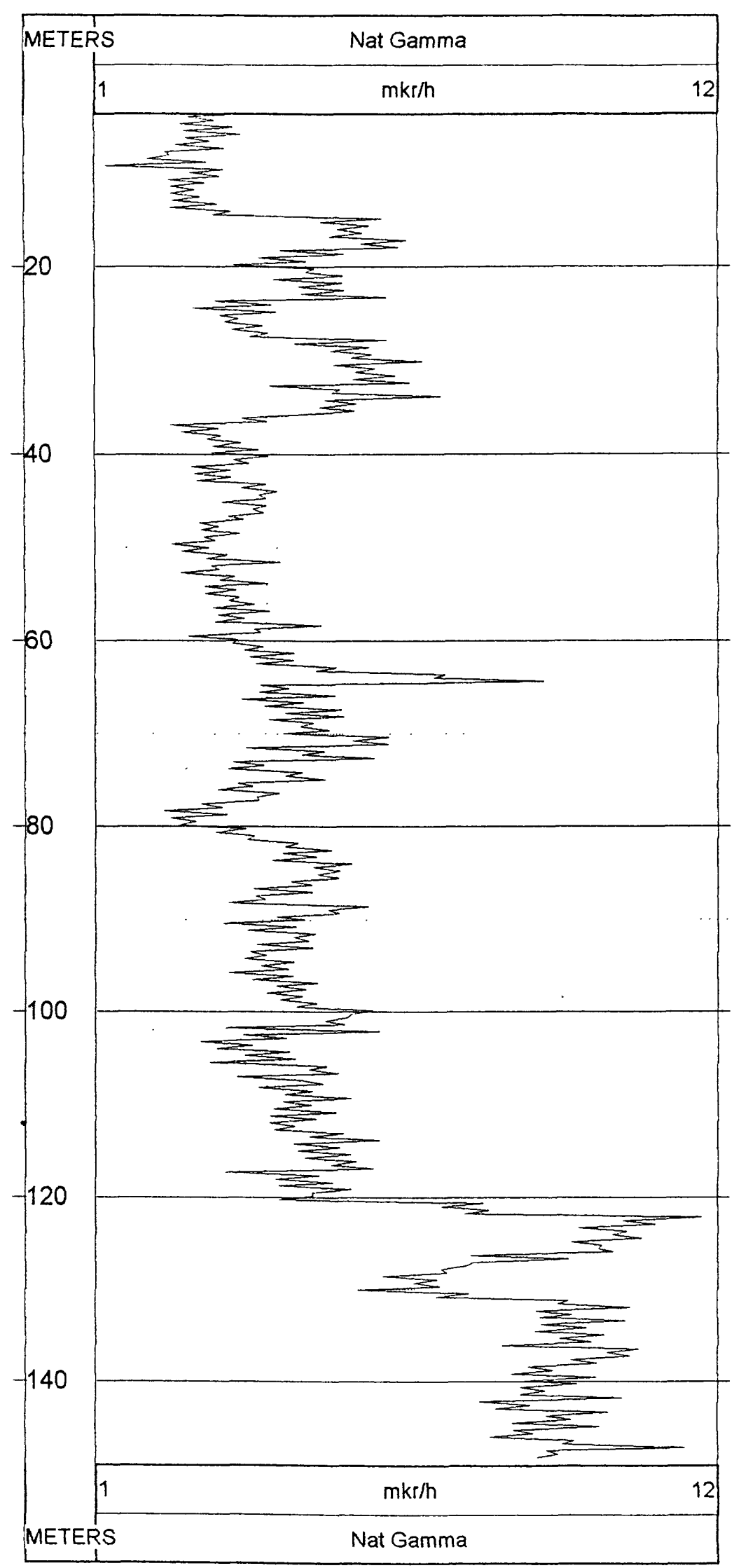

Hole 75 (for water)

Ararat party, Ararat area 


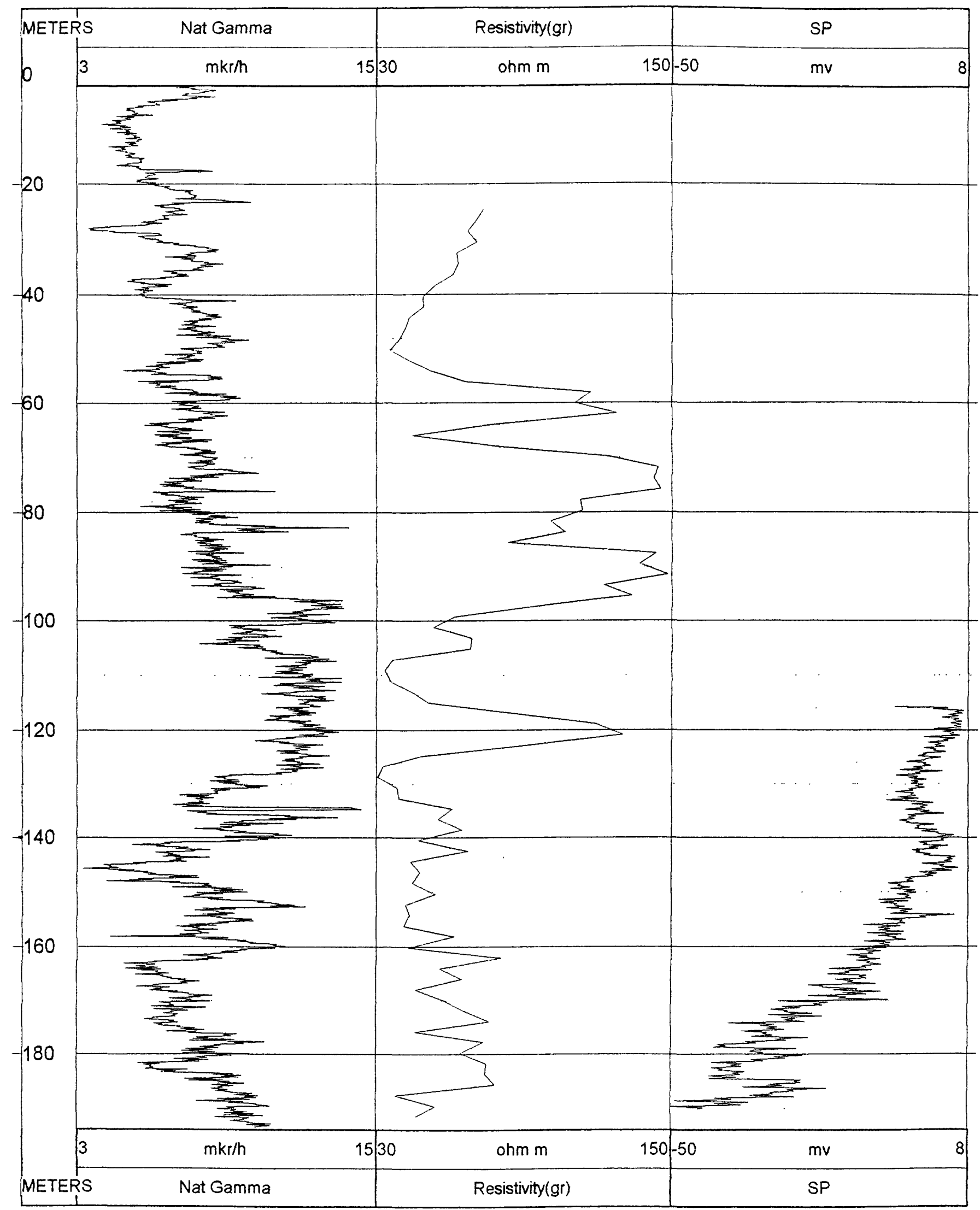

Hole $21 \mathrm{~K}$ (for water) 


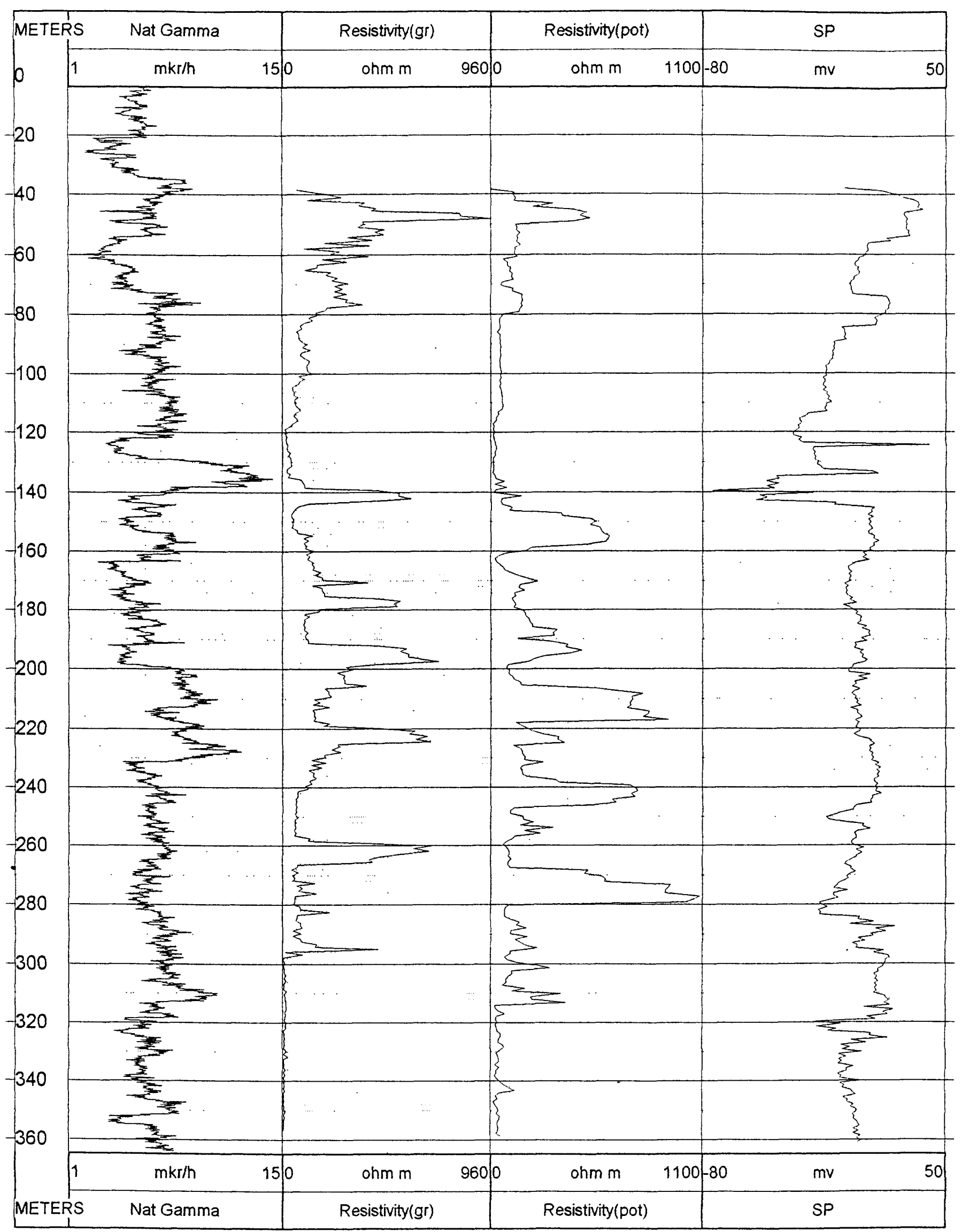

Hole $2 / 17$ (for copper \& other metals)

North party, Chkalovka area

02.05.79 


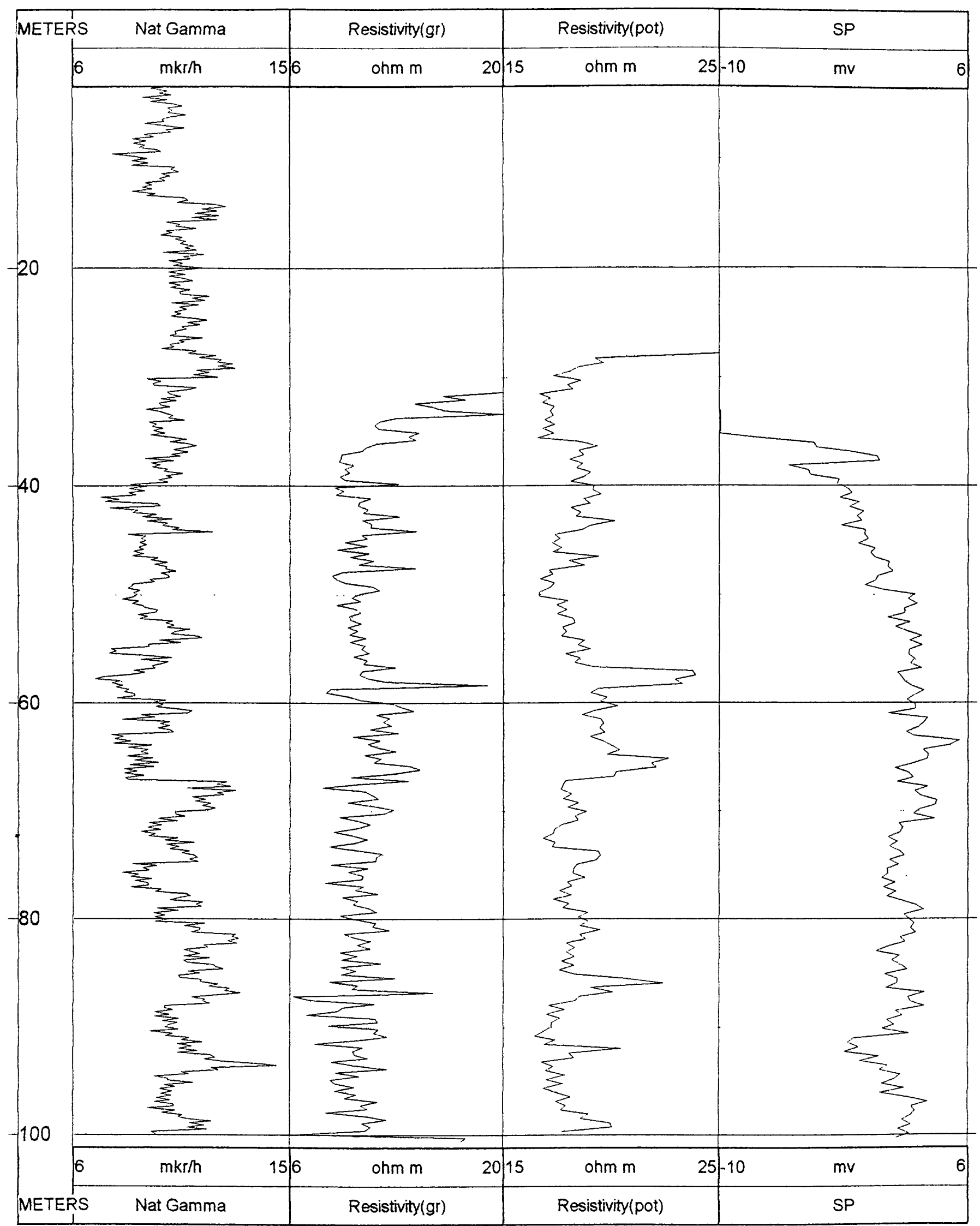

Hole b/n (for structure) 


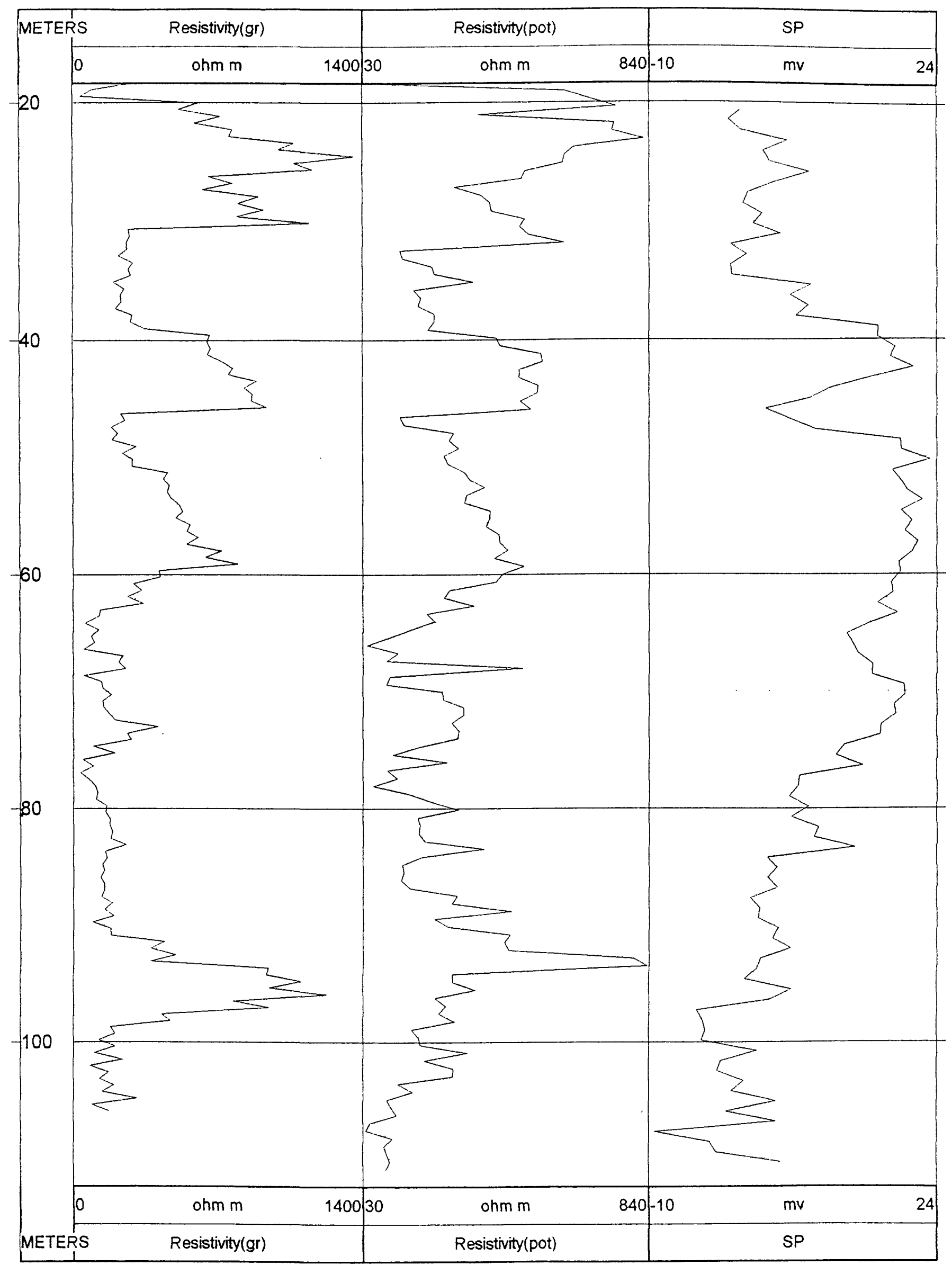

Hole b/n (for water)

Complex party, Solak area 


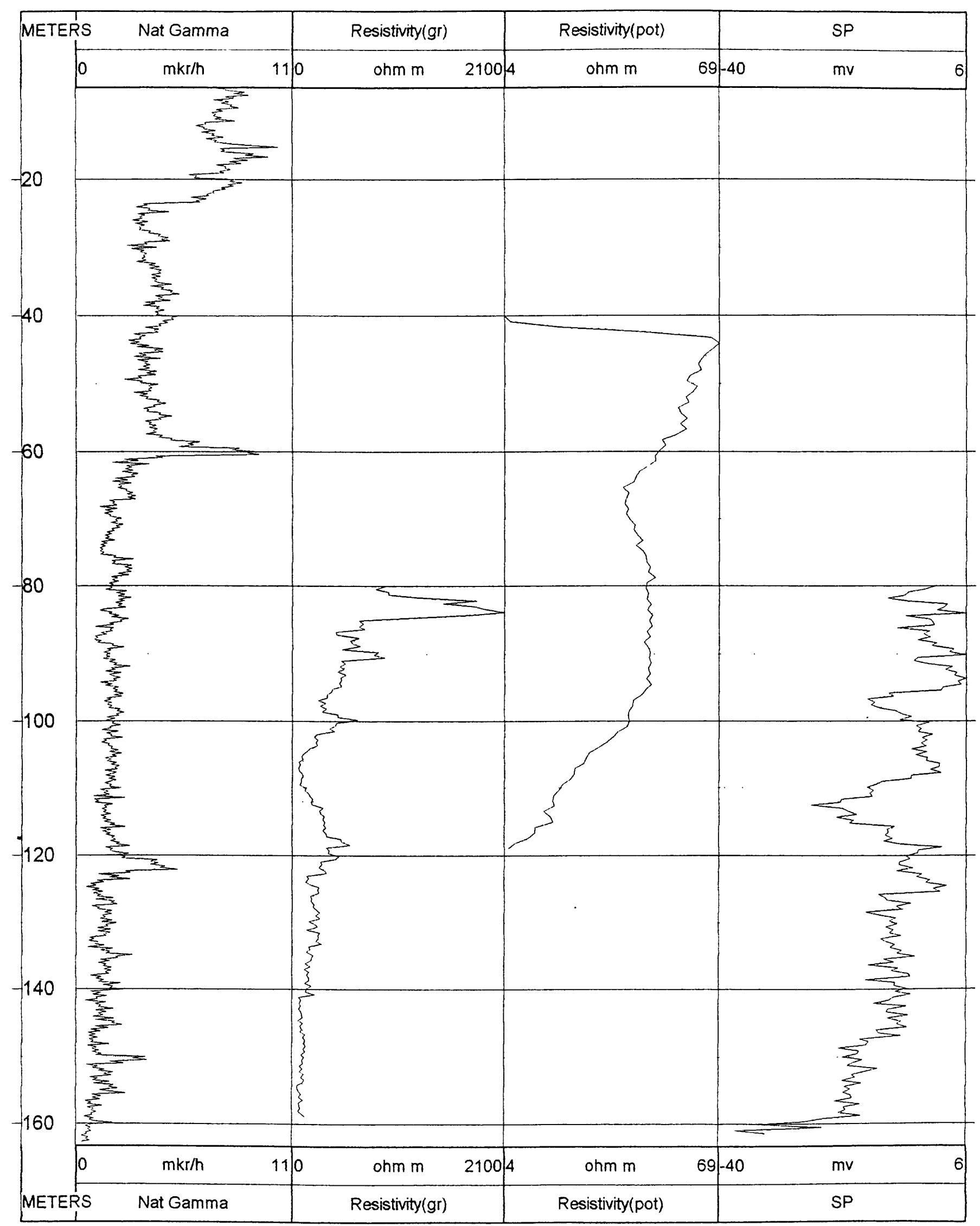

Hole 7 (for water) 


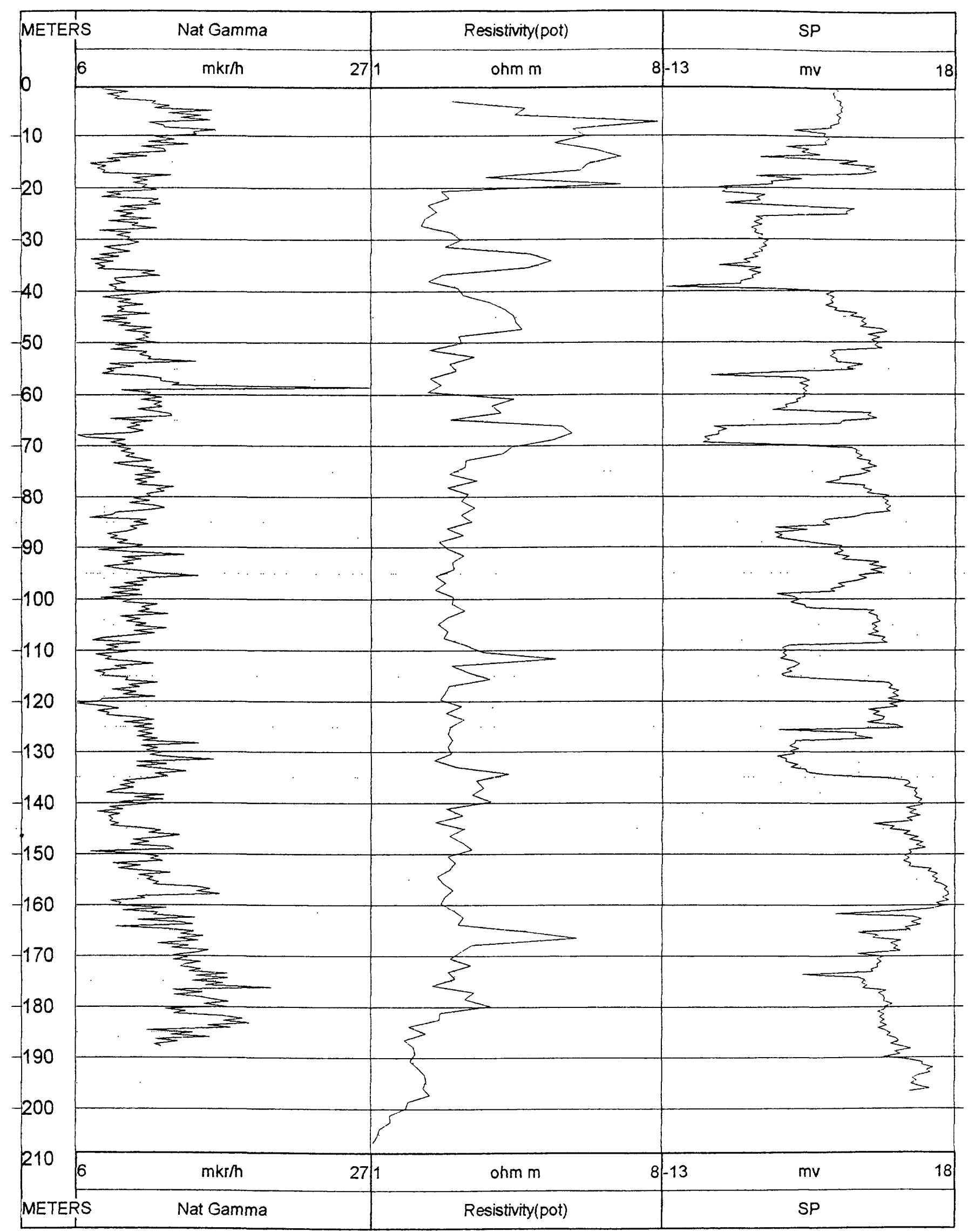

Hole 2 (for structure)

Profile Drilling party, Sovetashen area 


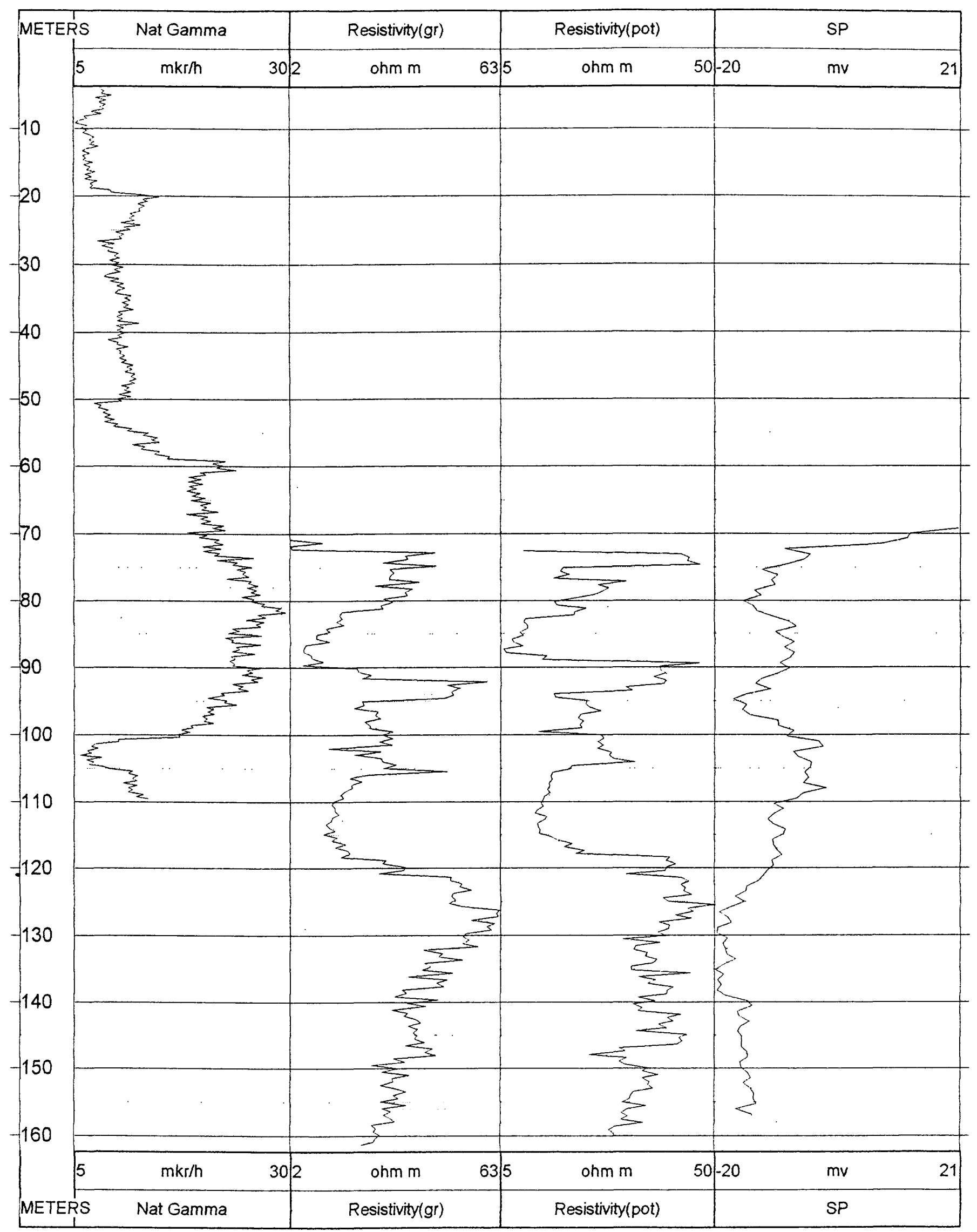

Hole 19 (for water)

Ararat party, Vedy area 


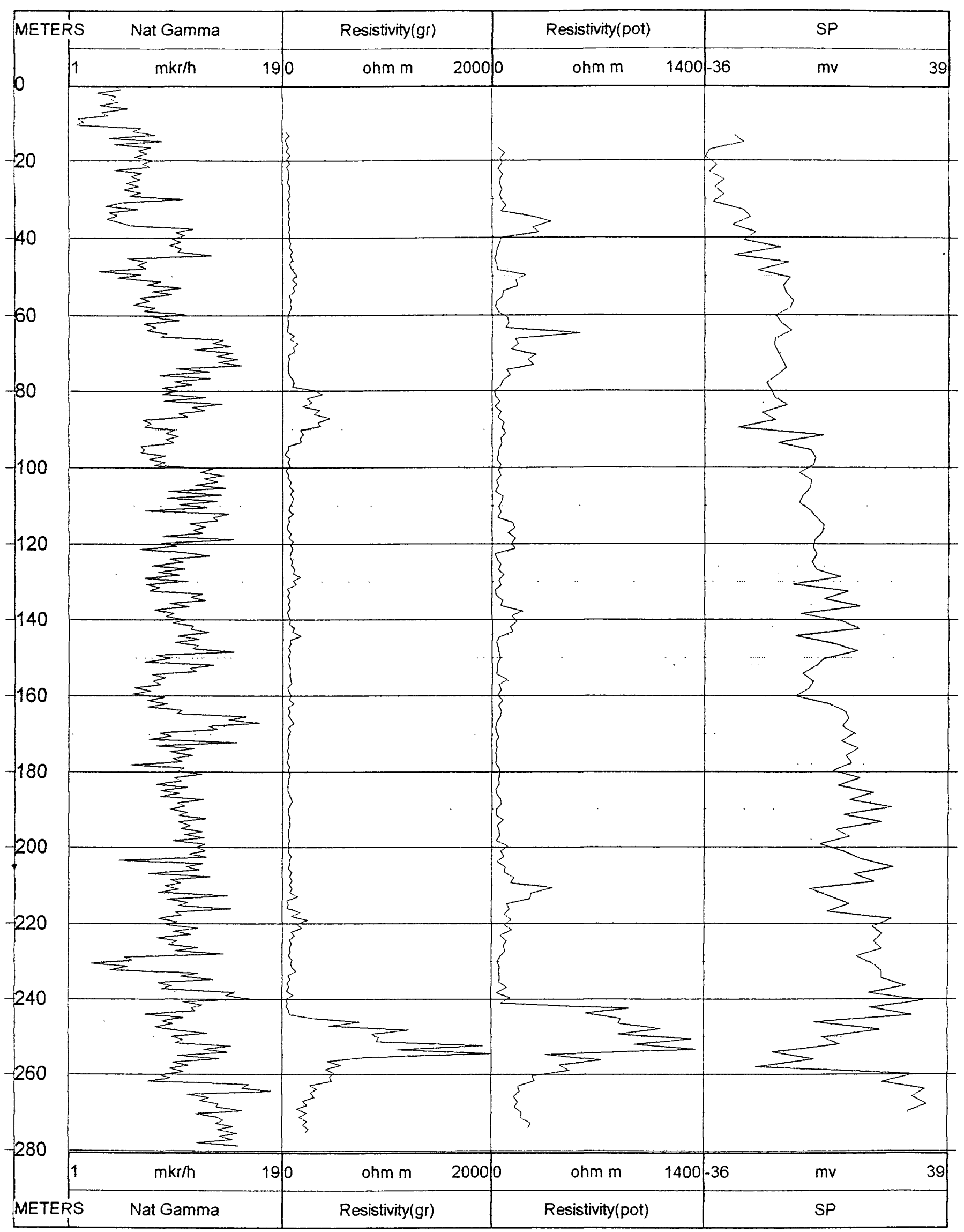

Hole 3 (for structure)

Profile Drilling party, Jajur area 


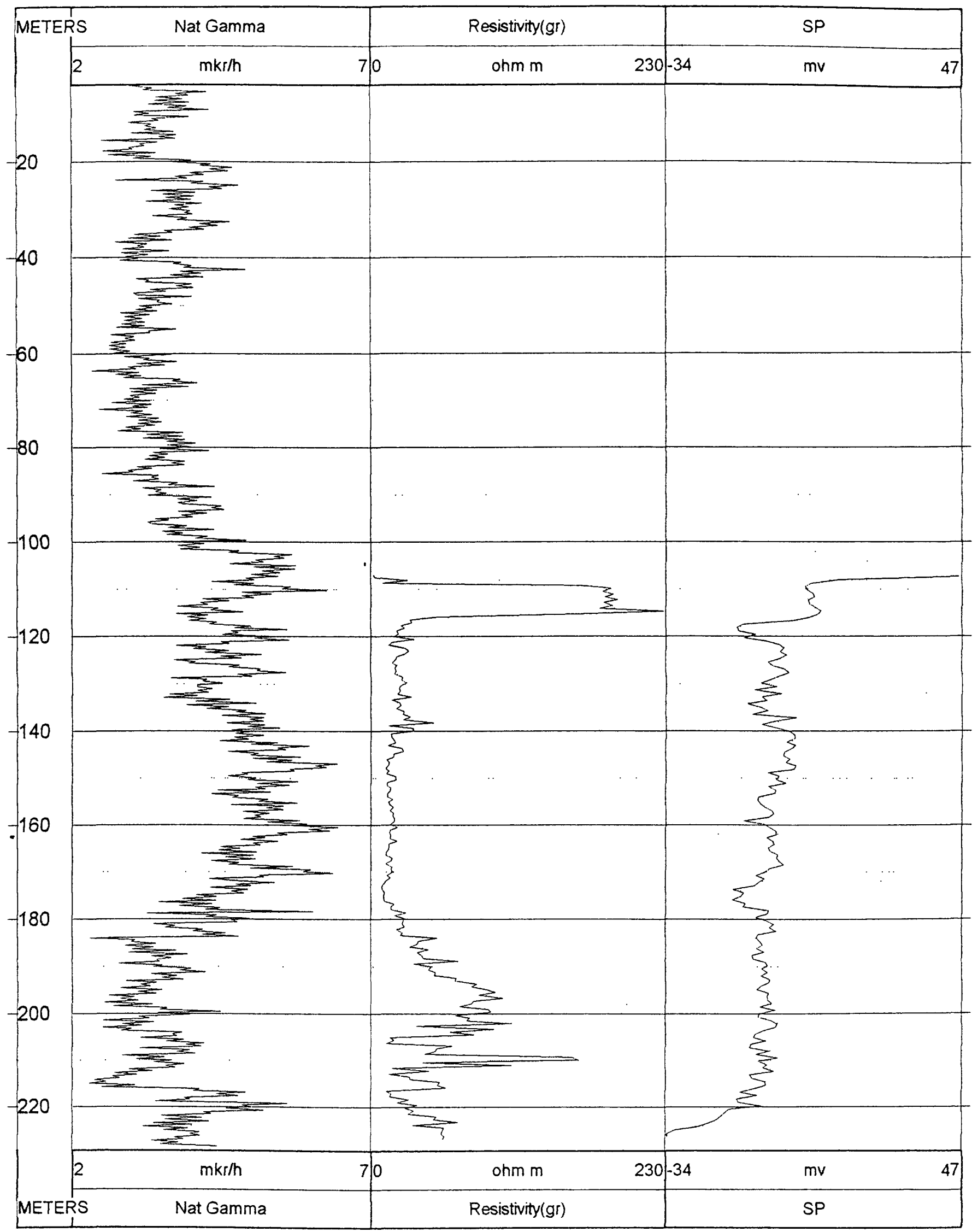

Hole 28 (for water) 


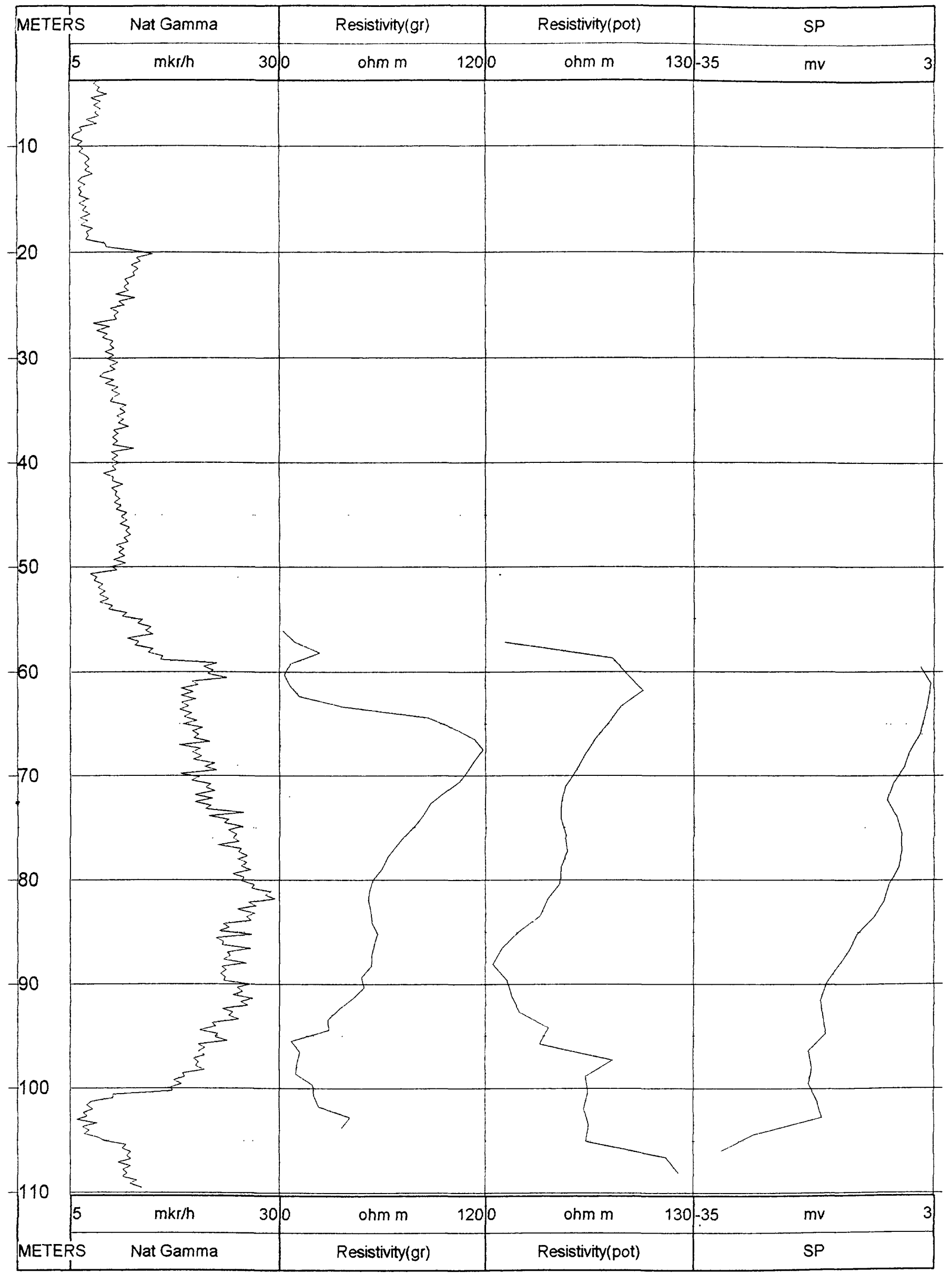

Hole 17 (for water)

Siuniq party, Horadis area 


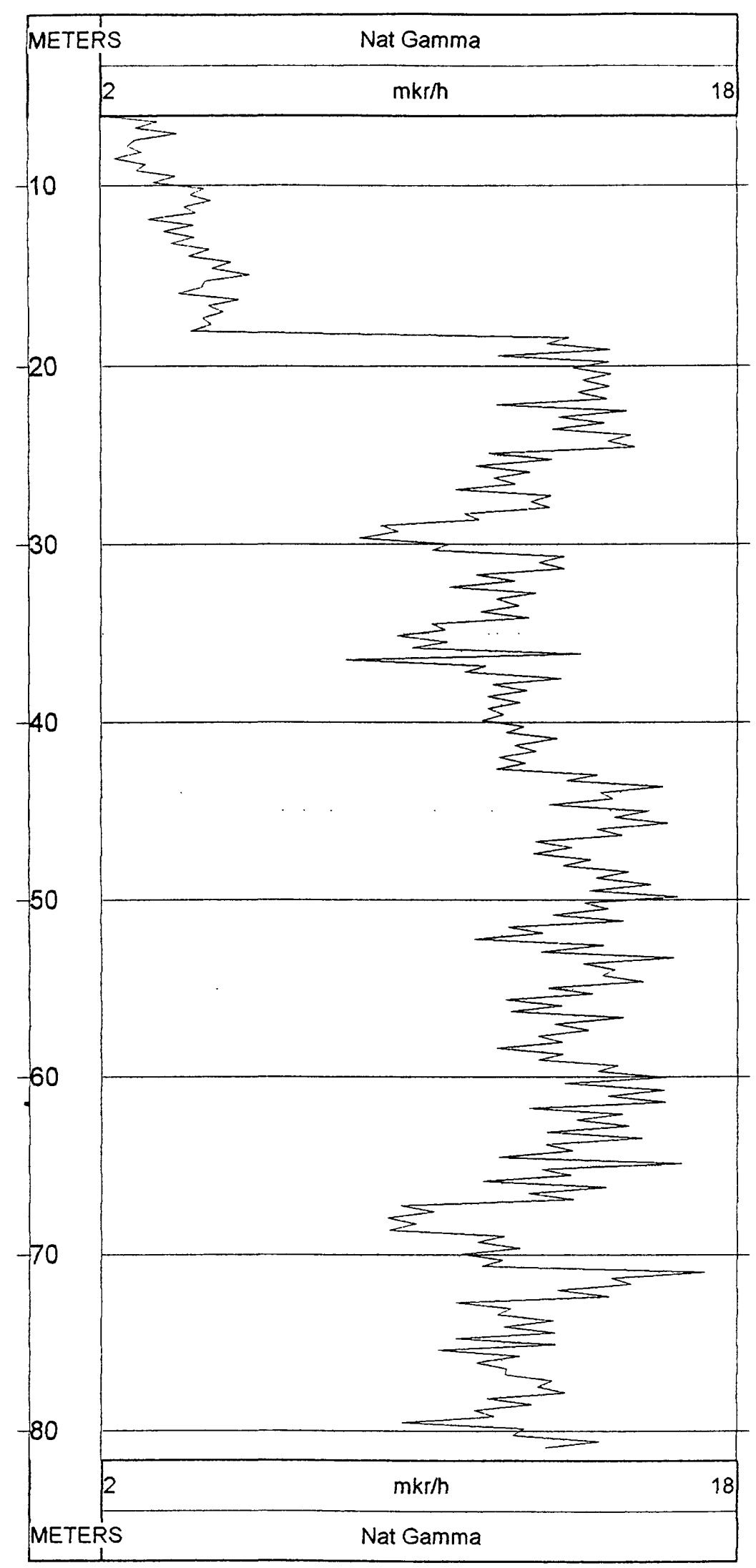

Hole 82 (for water) Siuniq party, Azatek area 


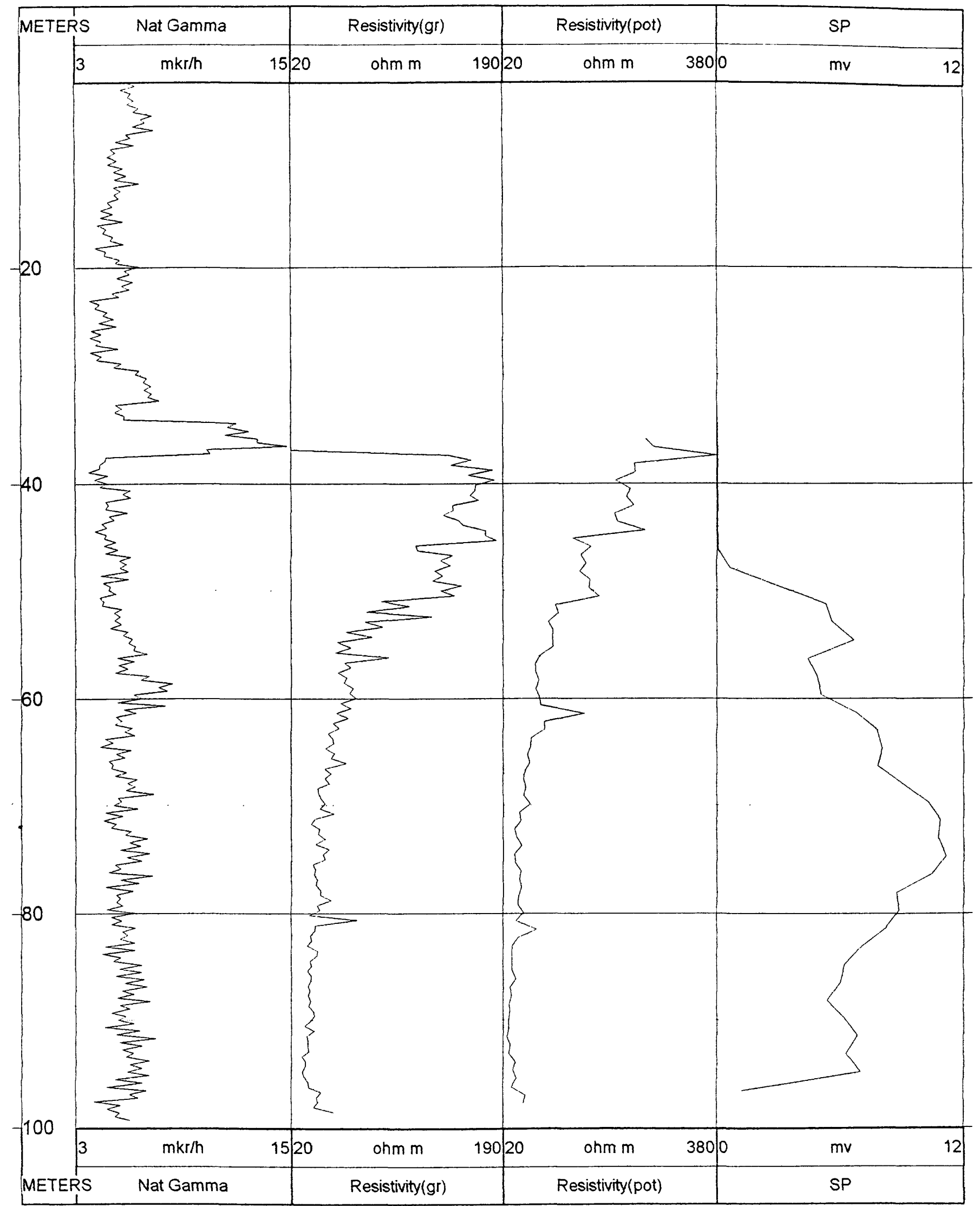

Hole 63 (for water) 


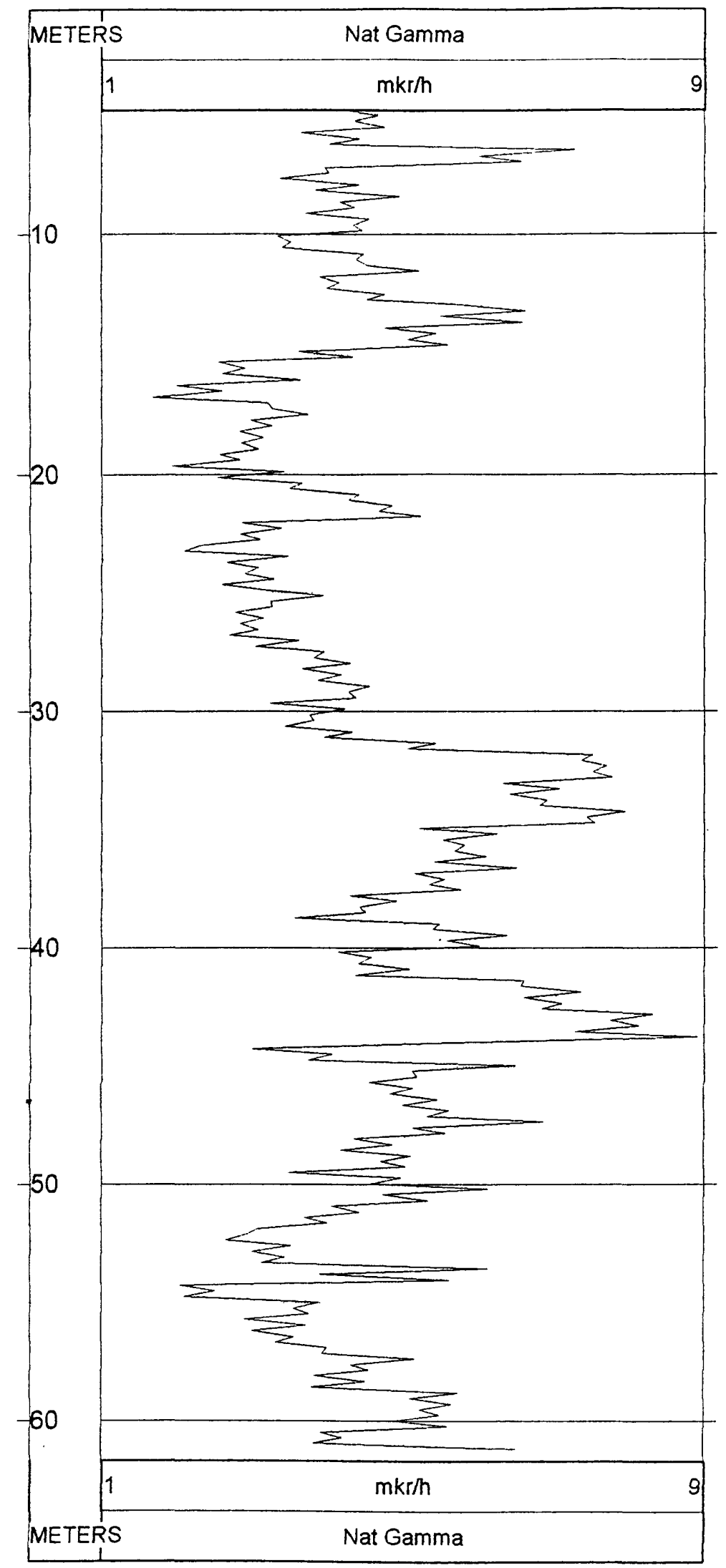

Hole 62 (for water)

Siuniq party, Azatek area

11.28 .79

16 


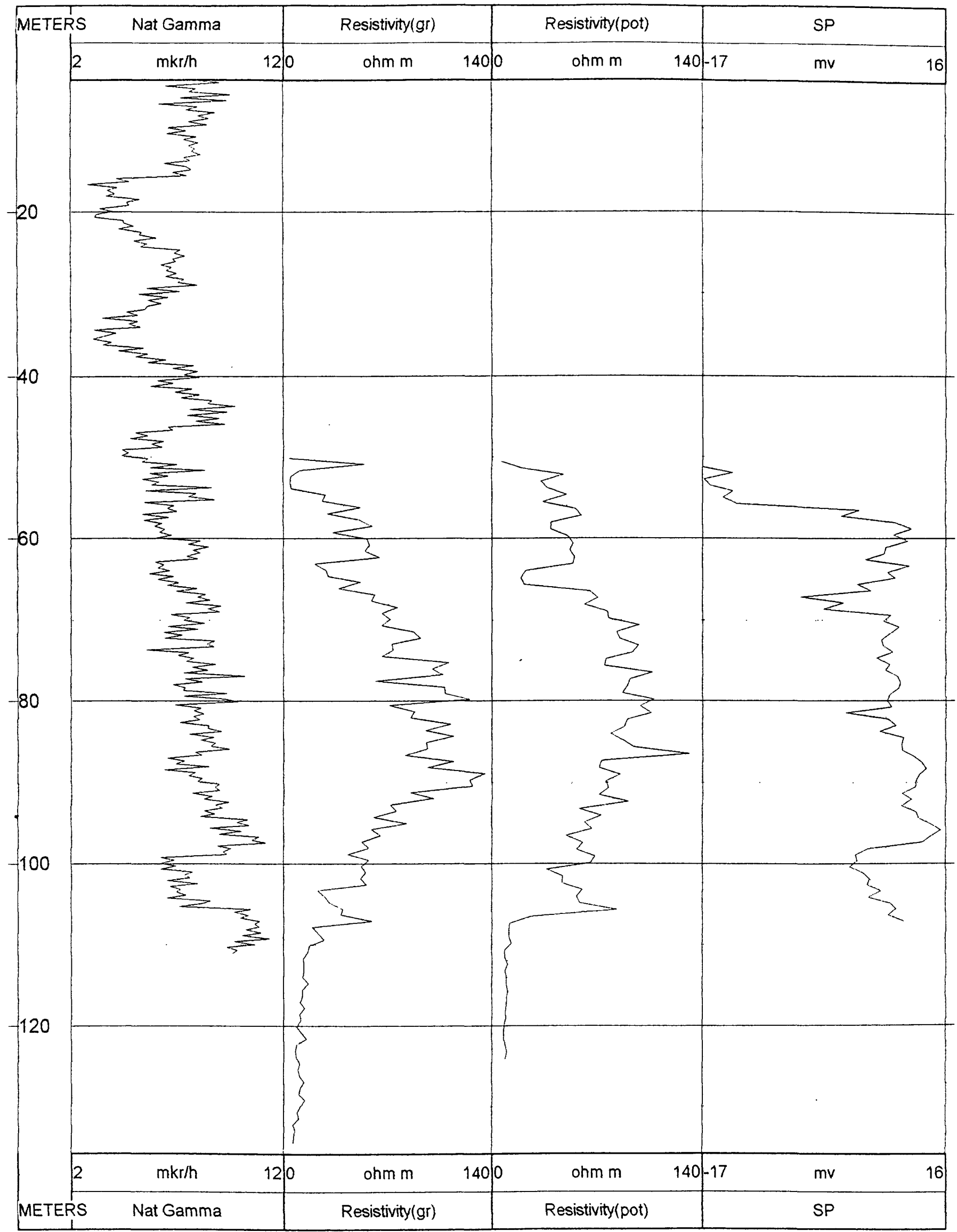

Hole 5 (for water) 


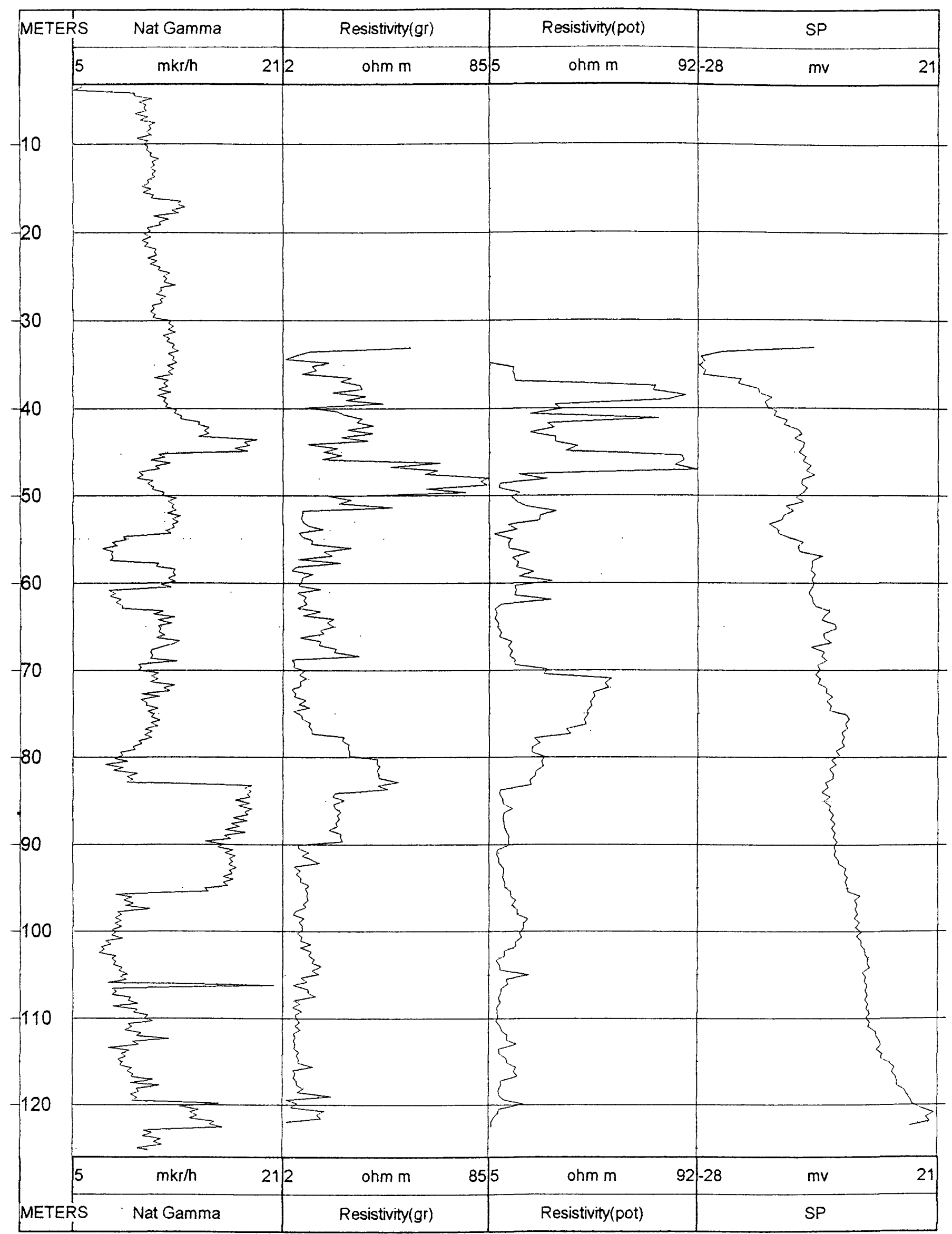

Hole 15 (for water)

Sevan party, Karchaghbiur area 


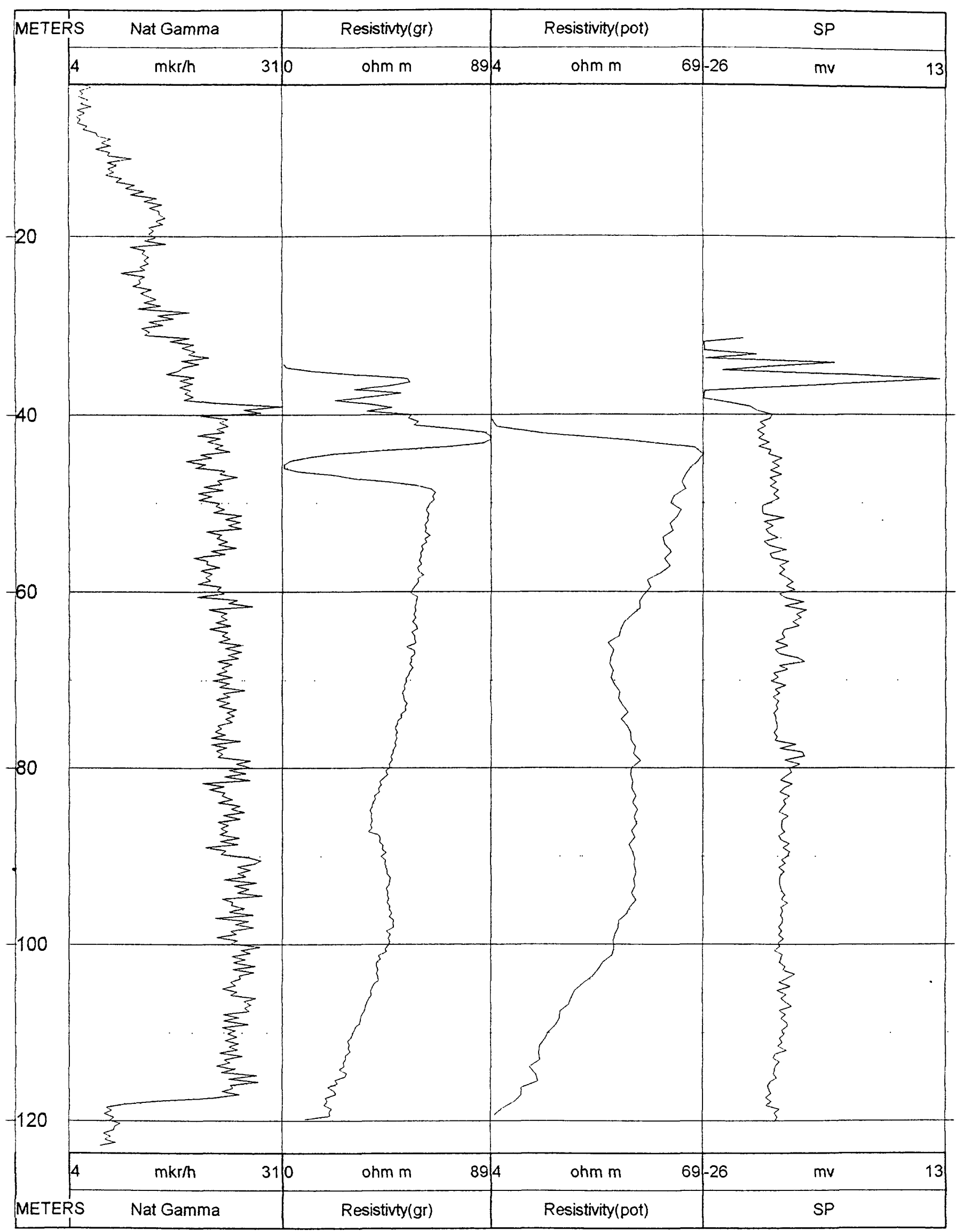

Hole 7(1) (for water)

Sevan party, Subatan area 


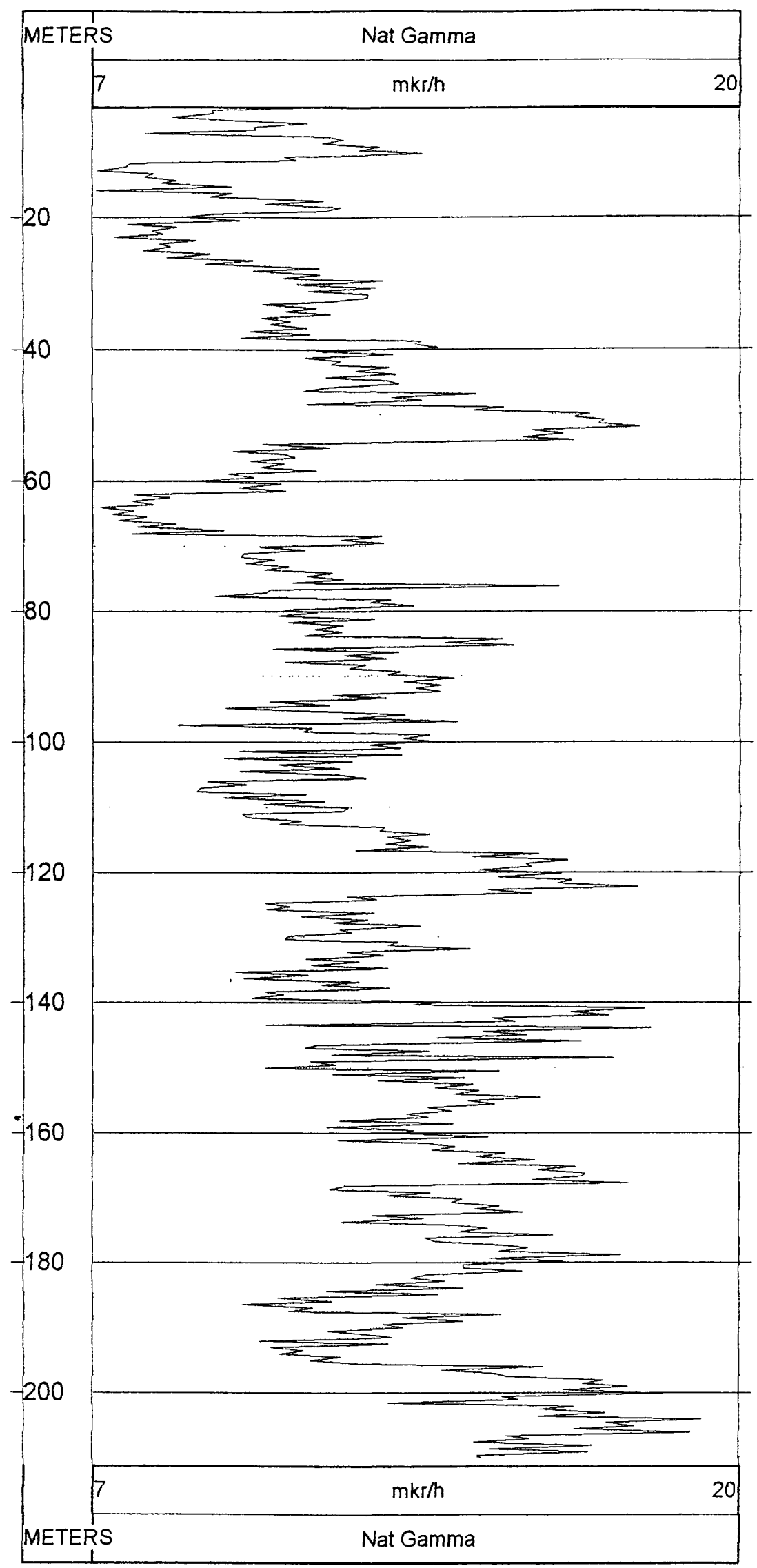

Hole 21n (for water)

Sevan party, Martuny area 


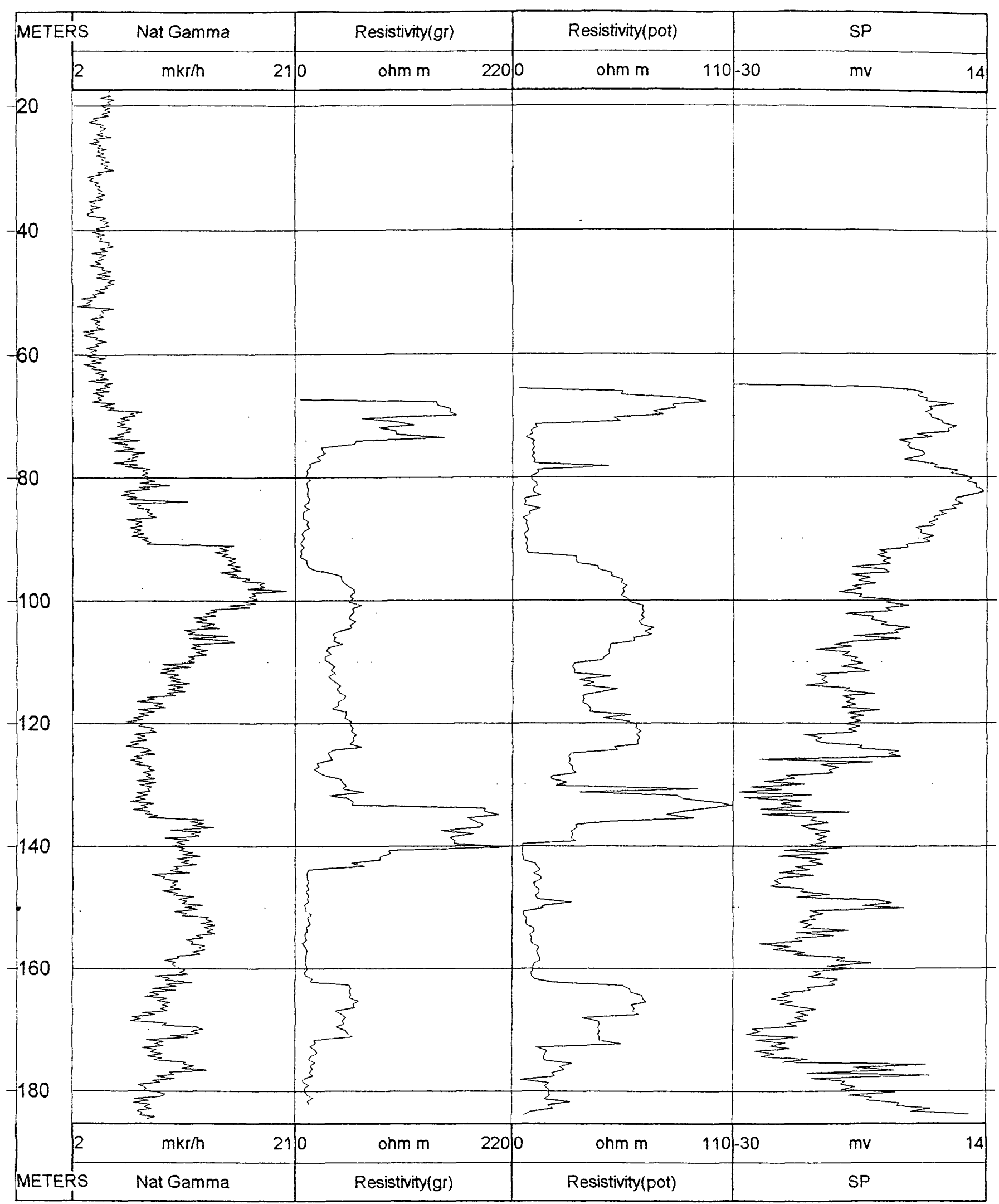

Hole 23K (for water)

Sevan party, Tsovagiugh area

06.16 .82 


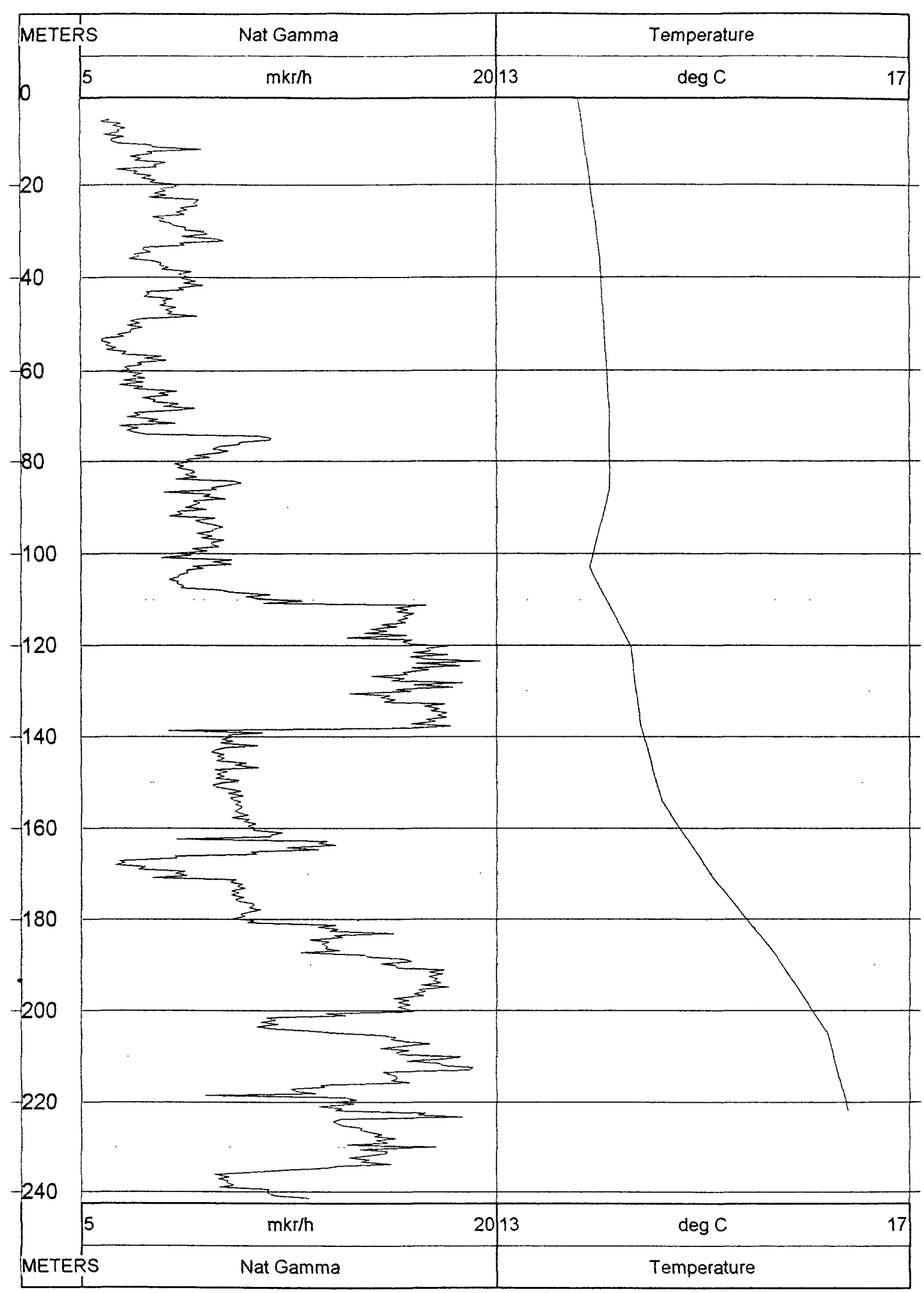

Hole 4C (for water)

Sevan party, Martuny area 


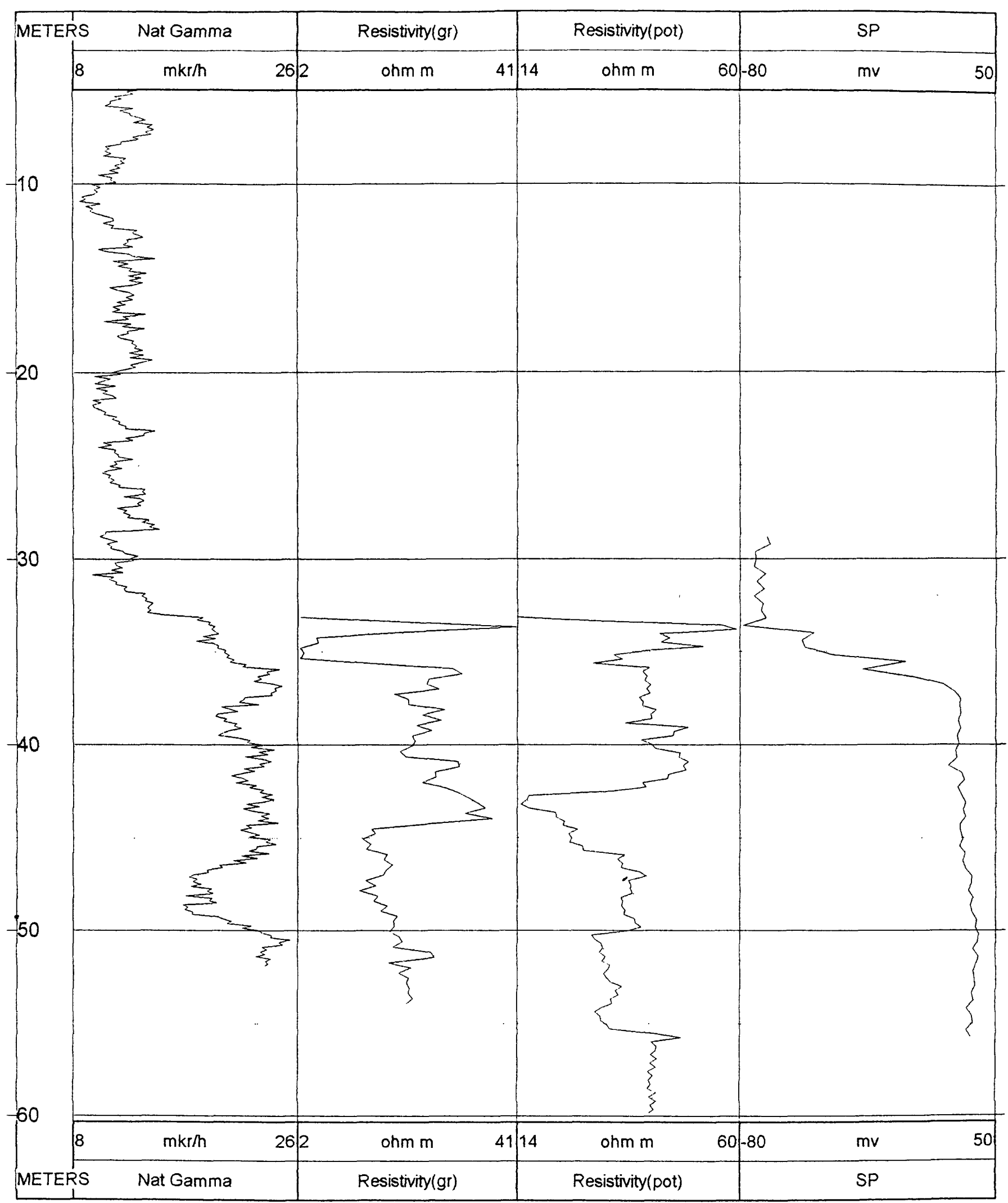

Hole 41 (for water) 


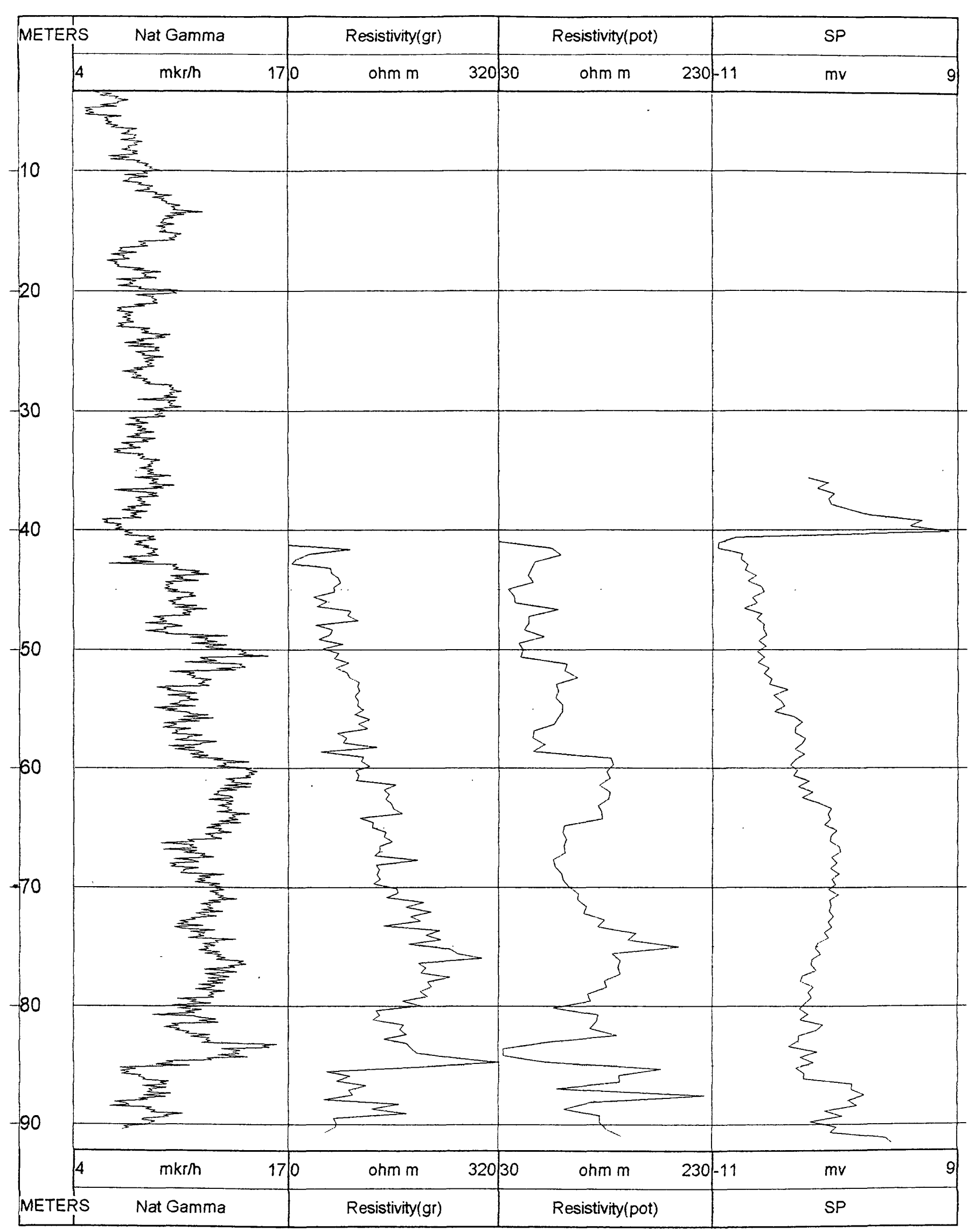

Hole 19 (for water) 


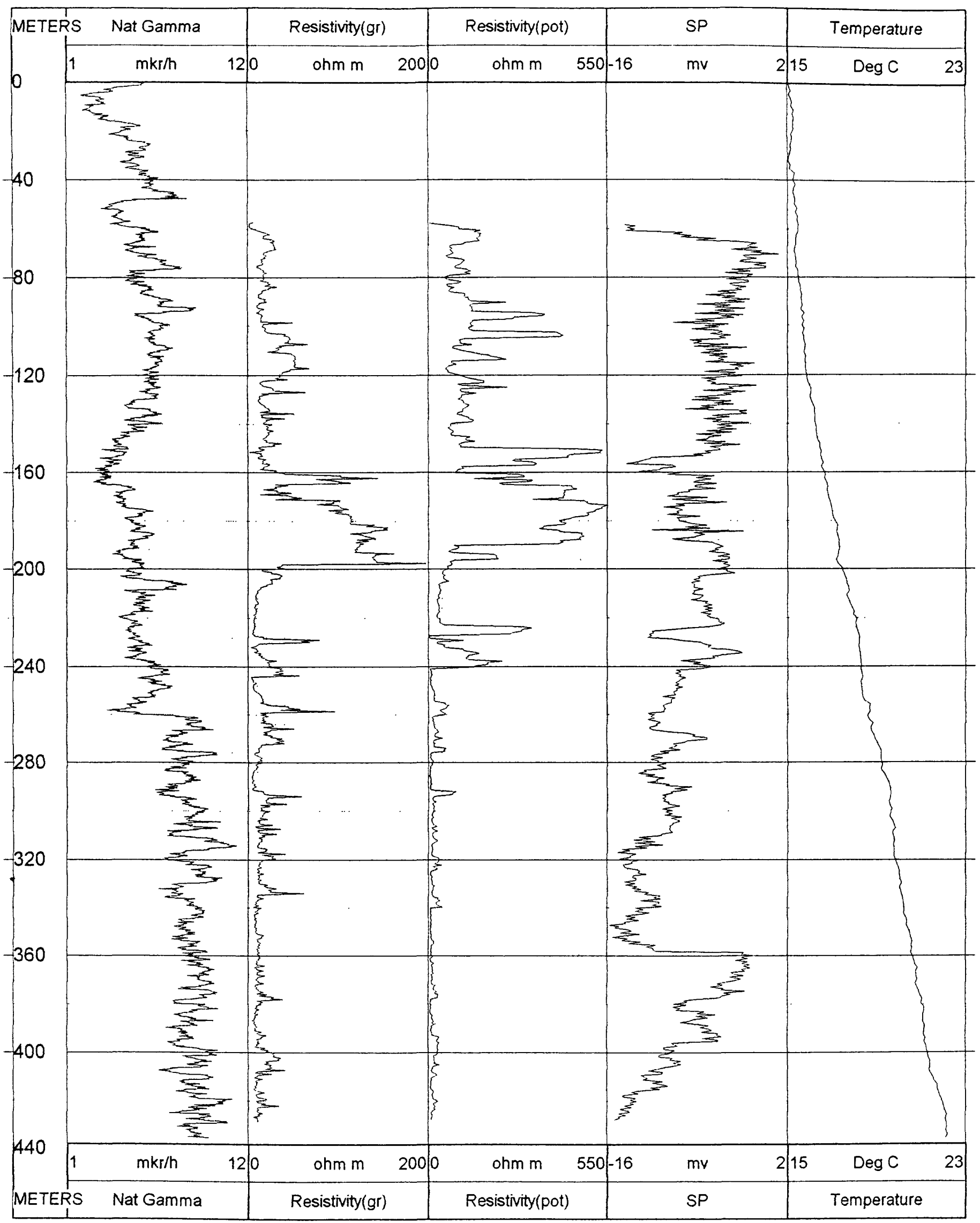

Hole 3 (for water) 


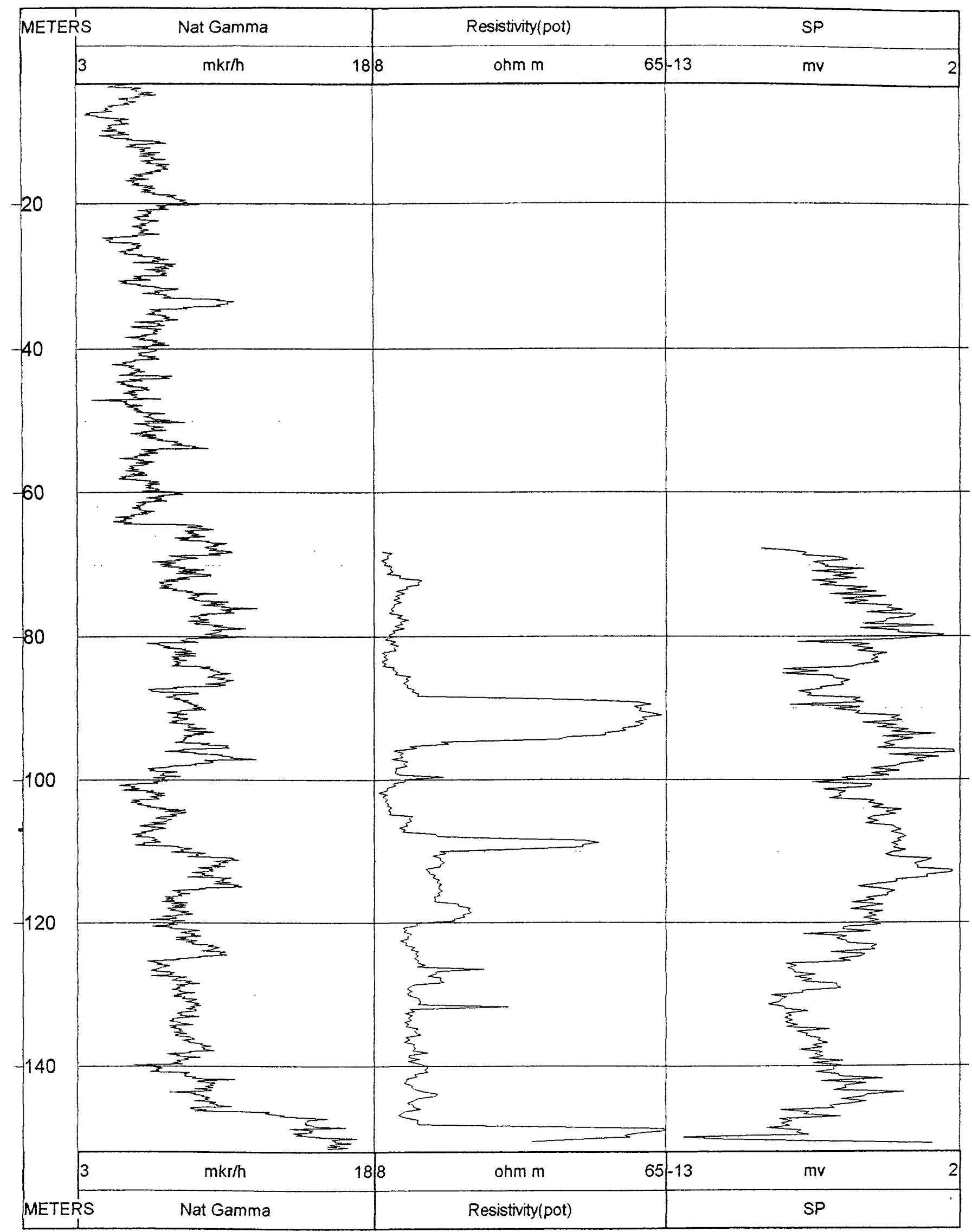

Hole 165 (for water) 


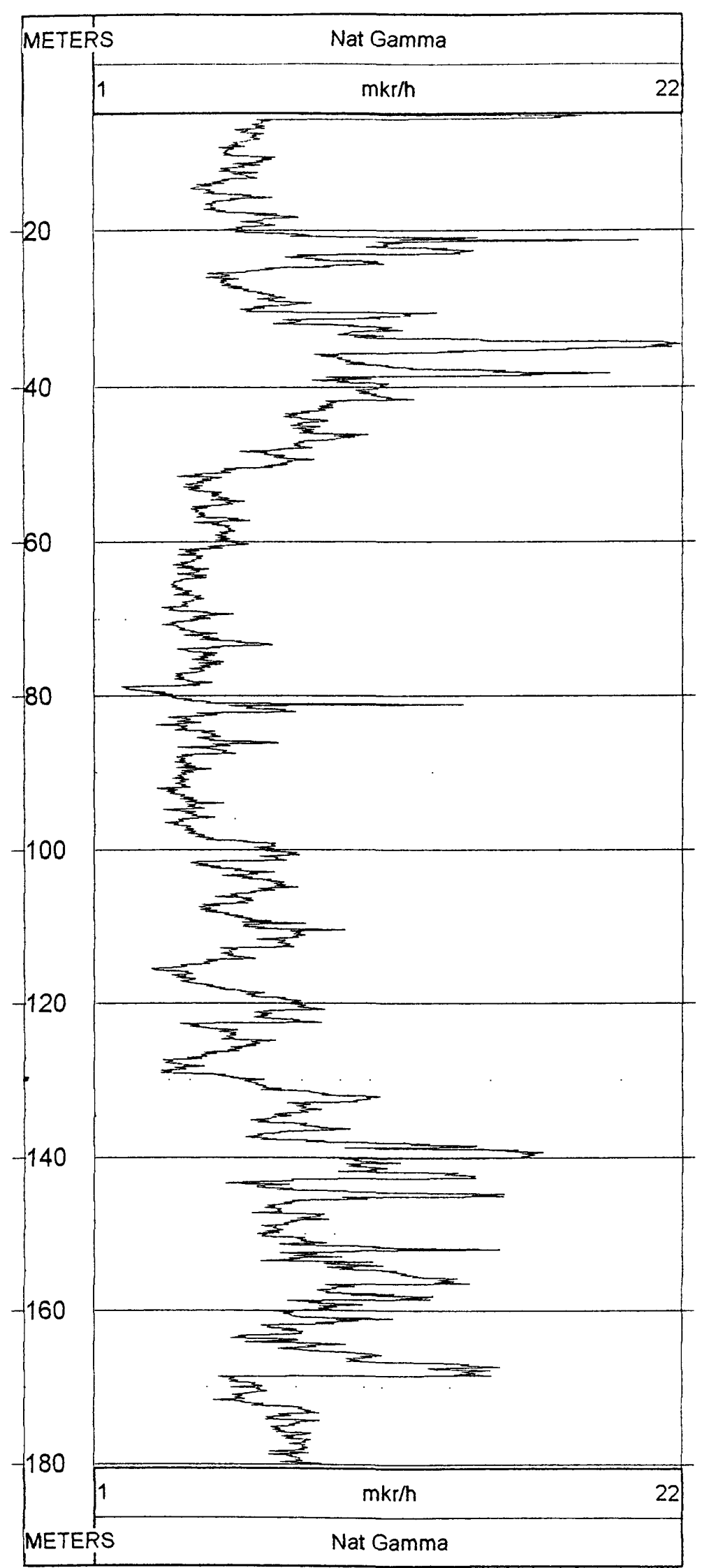

Hole 1A (for water)

Ararat party, Ararat area 


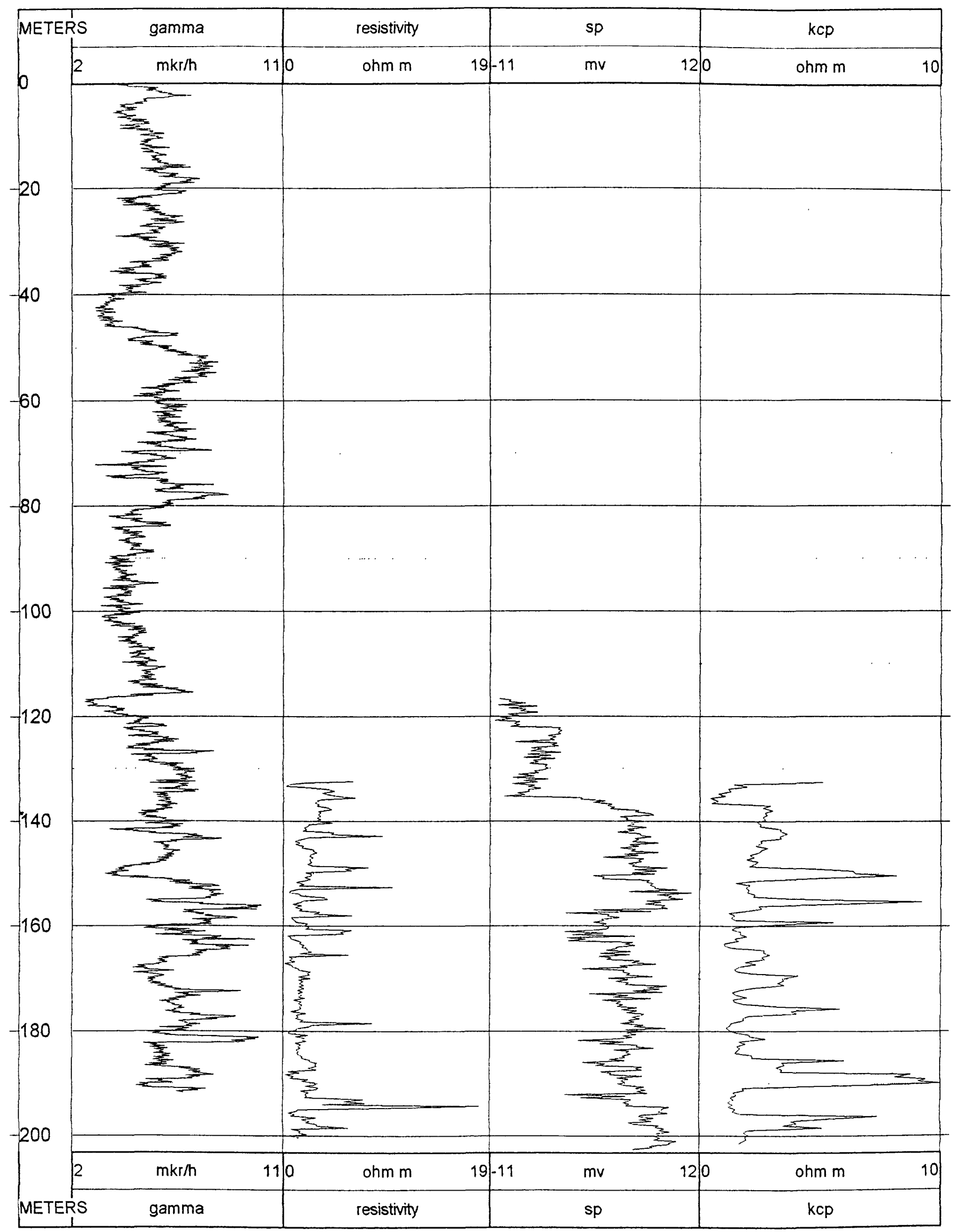

Hole 121-II (for water) 


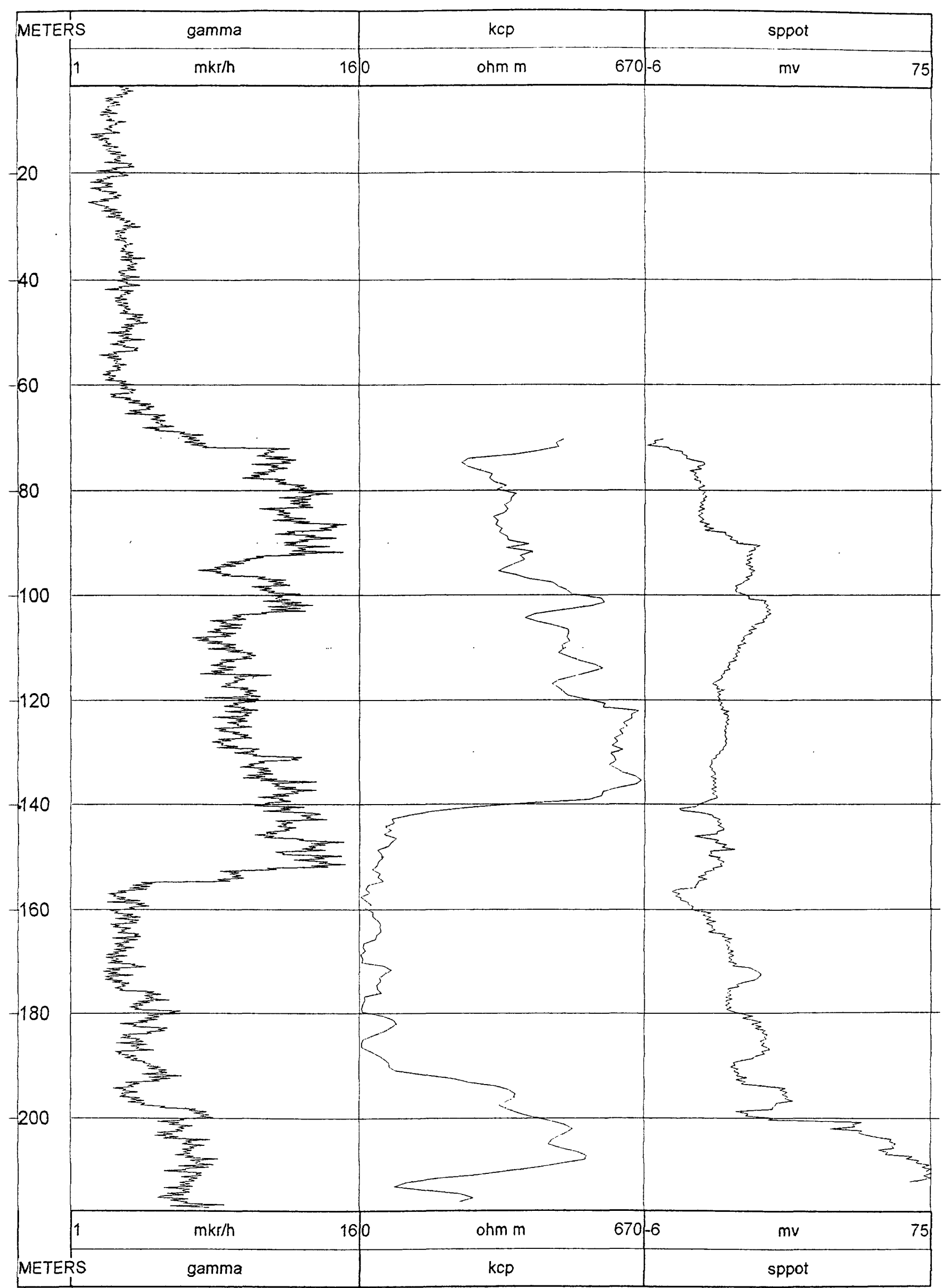

Hole 14A (for water)

Ararat party, Ararat area 


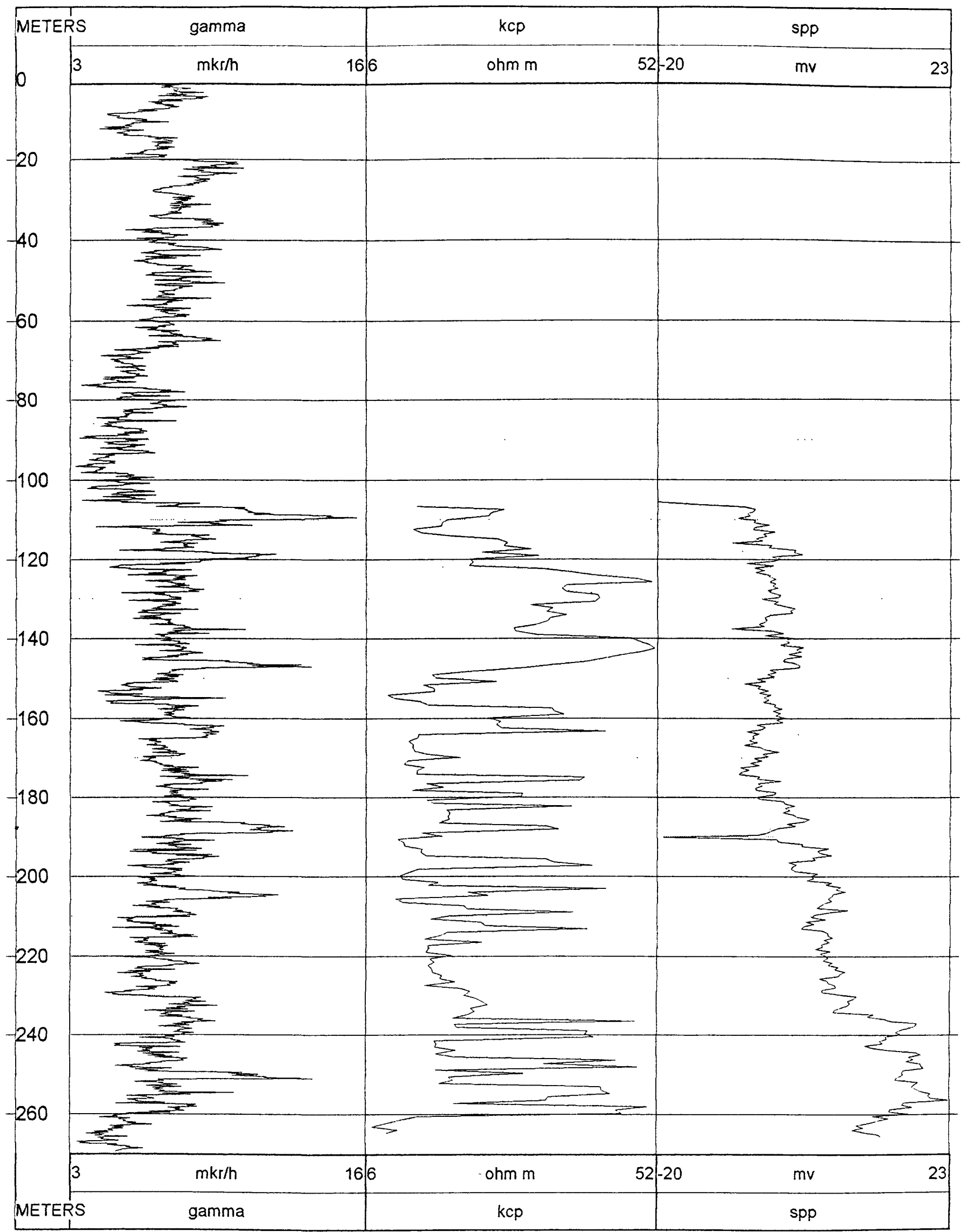

Hole 7 (for water) 


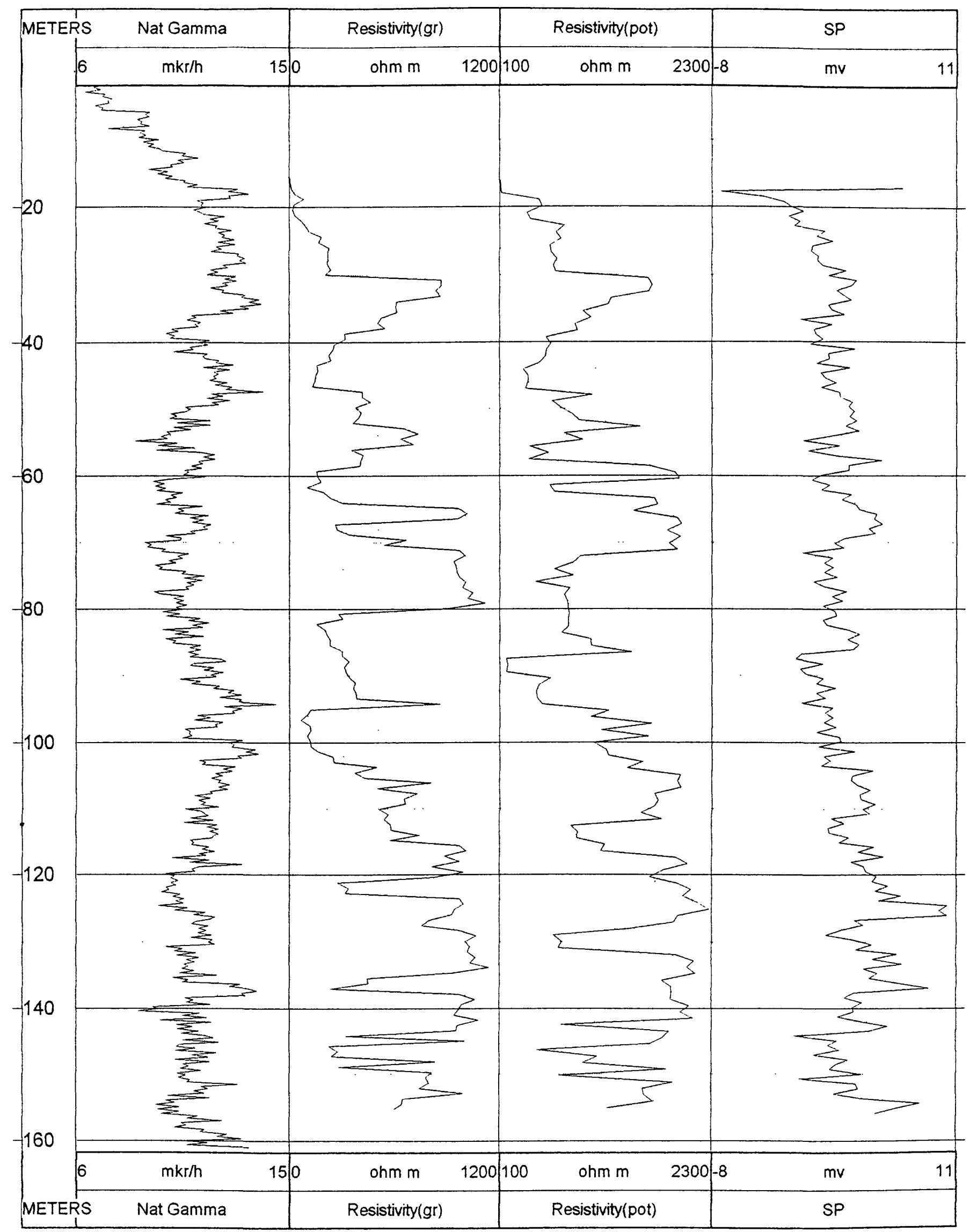

Hole 134 (for water) 


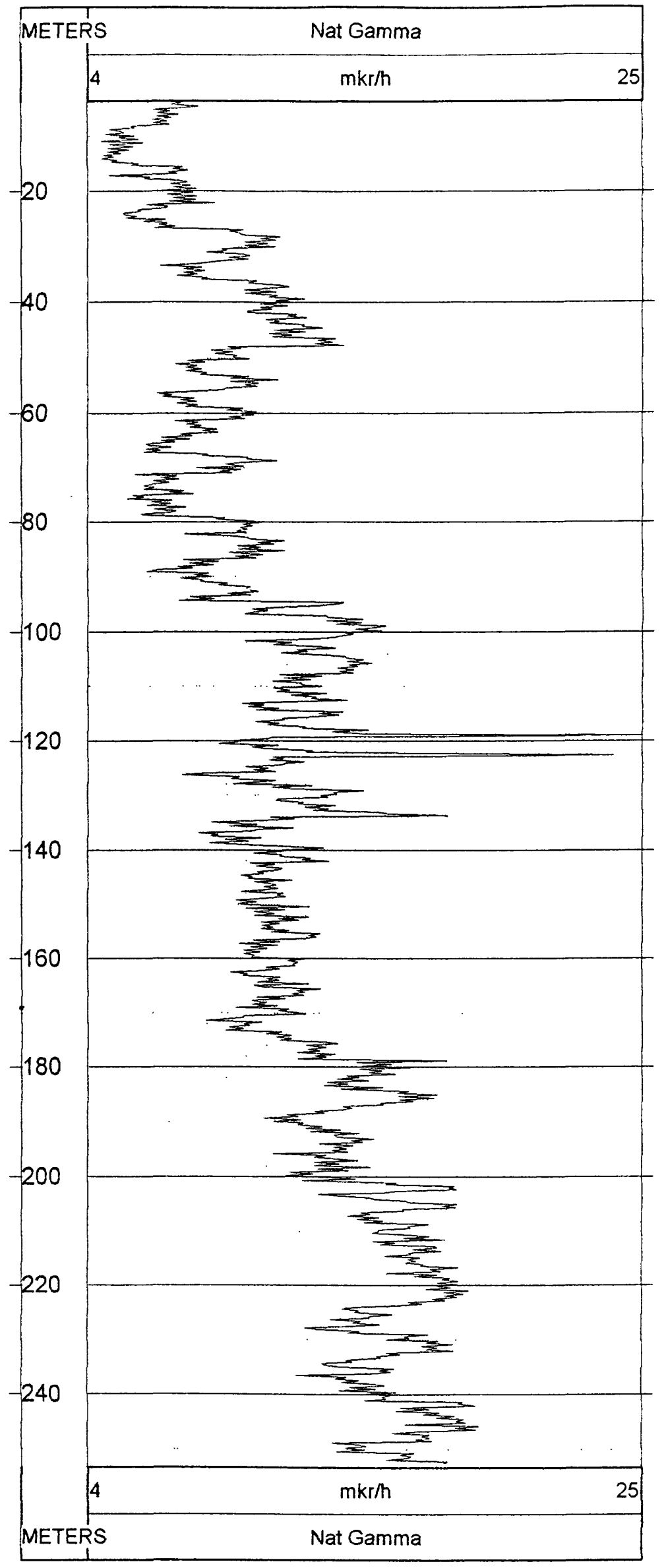

Hole 23 (for water) 


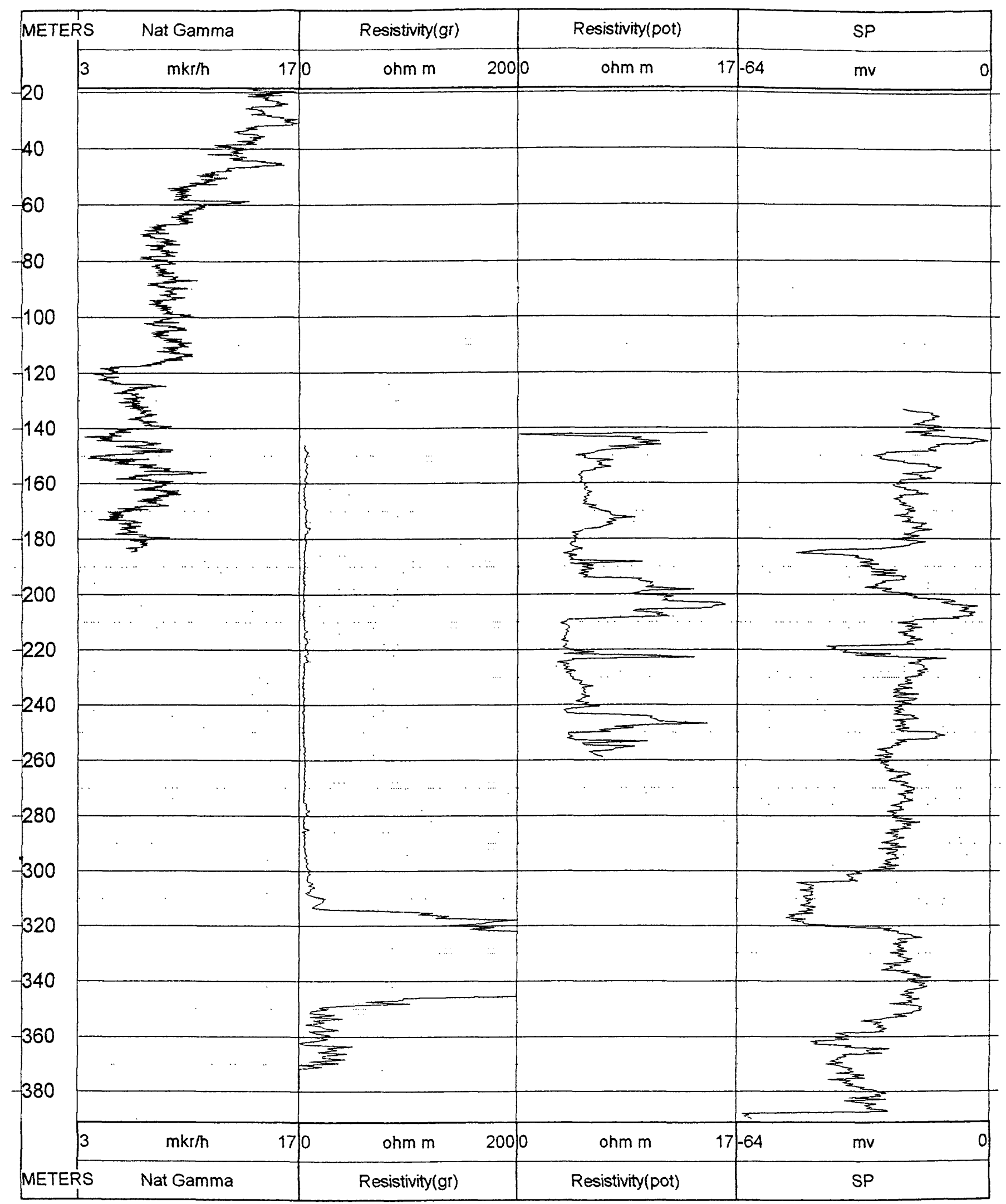

Hole 3(16) (for water)

Sevan party, Norashen area 


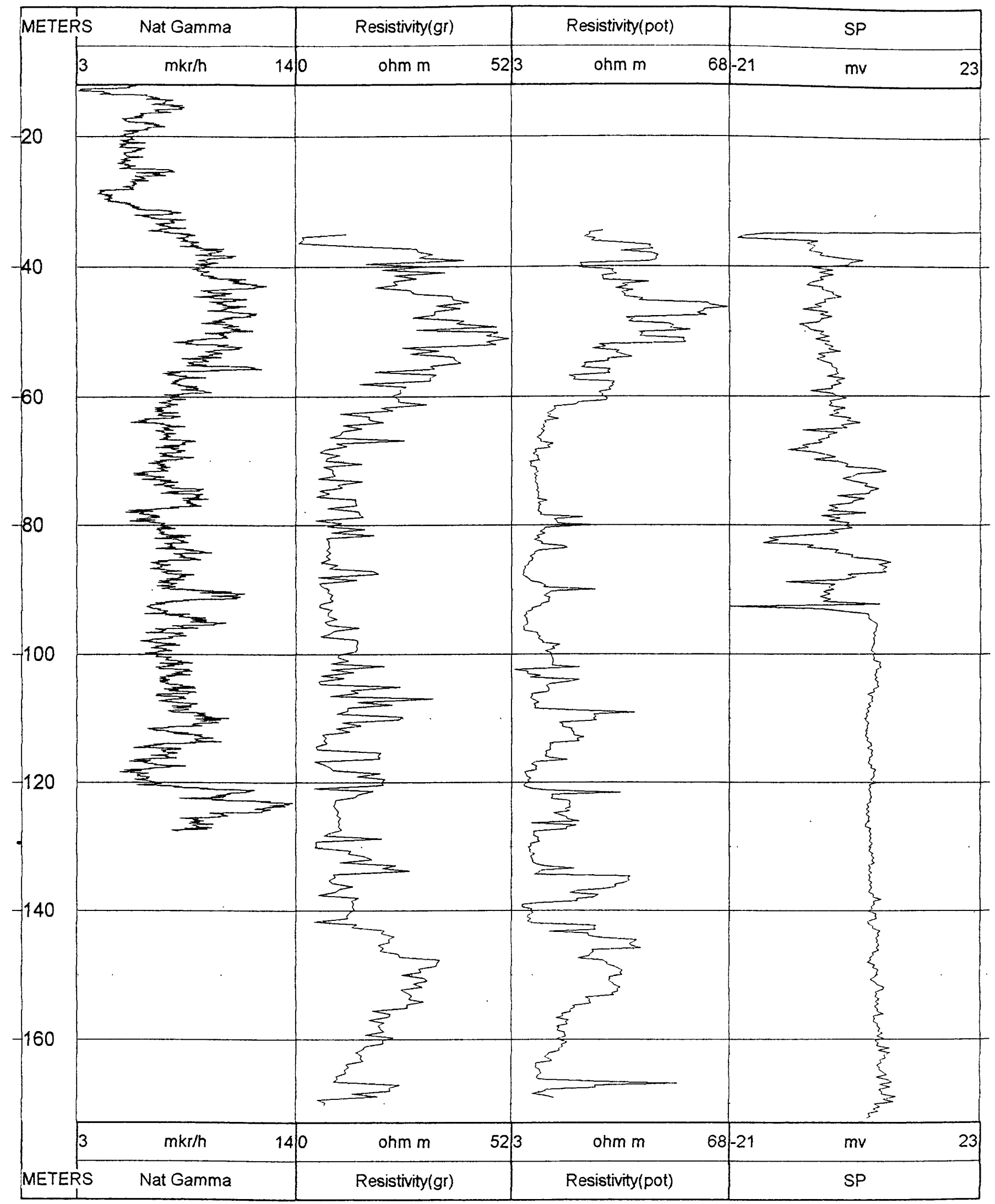

Hole 20 (for water) 


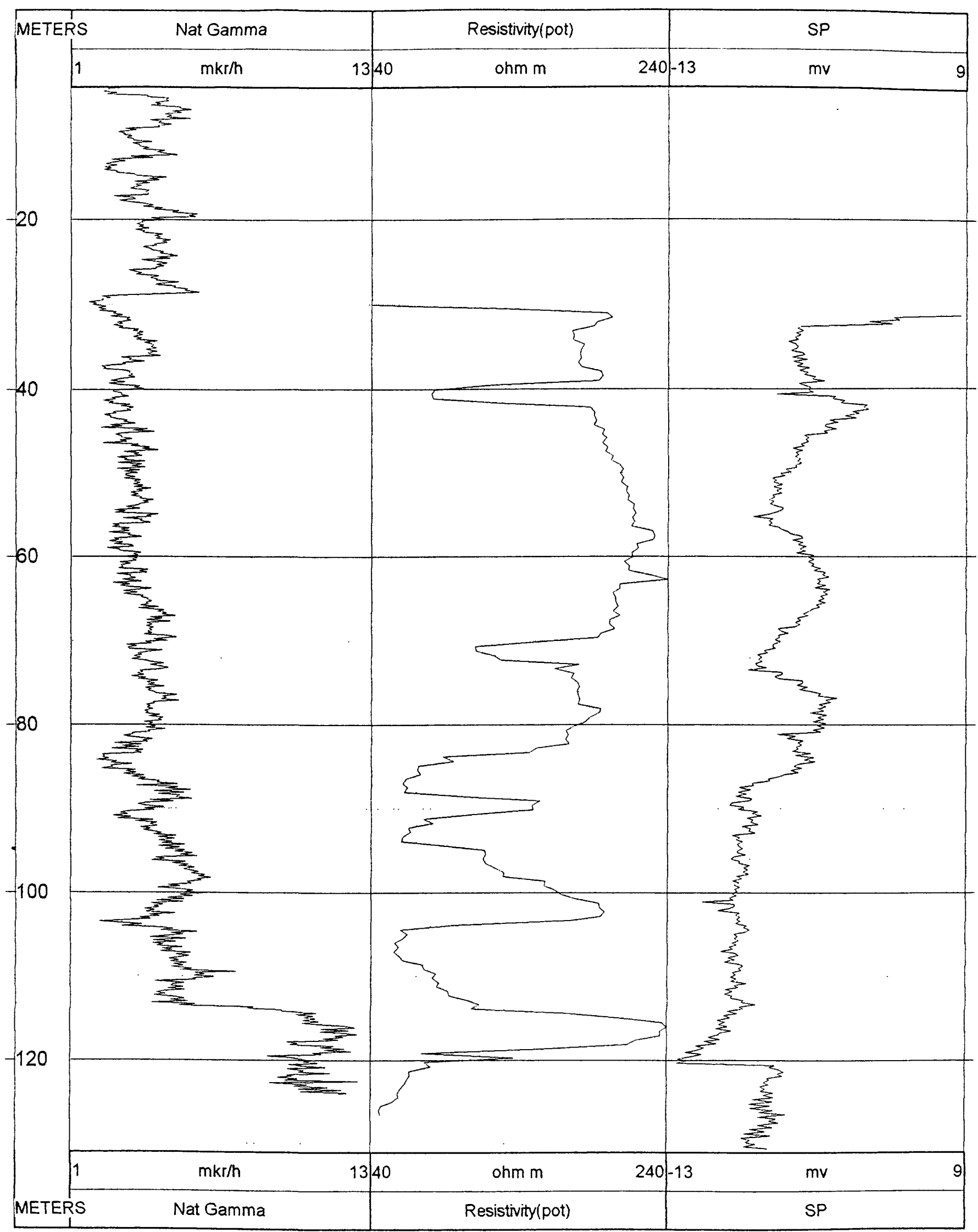

Hole 11-II (for water)

Ararat party, Masis area 


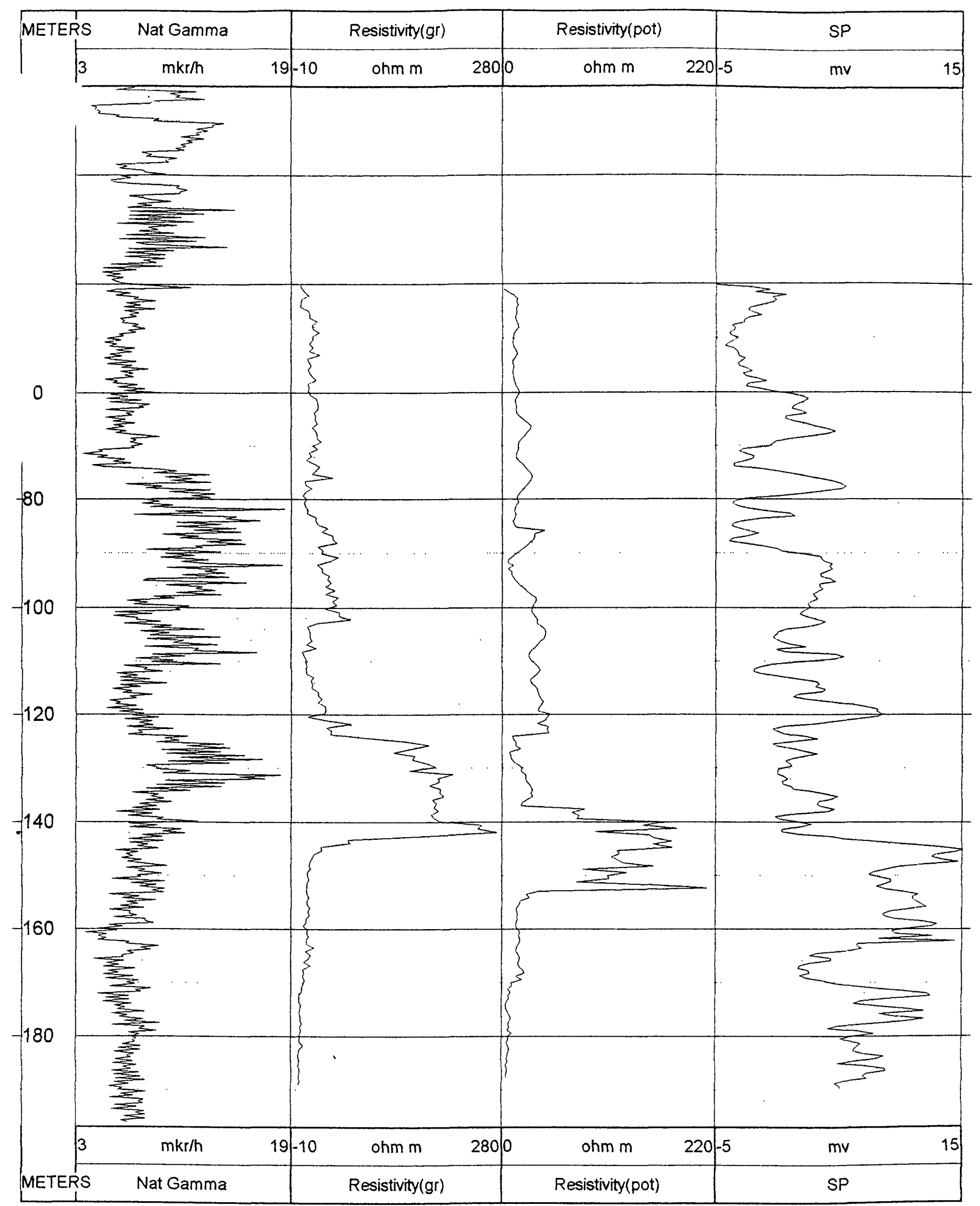

Hole 29 (for water)

Ararat party, Khalisa area

08.28 .79 


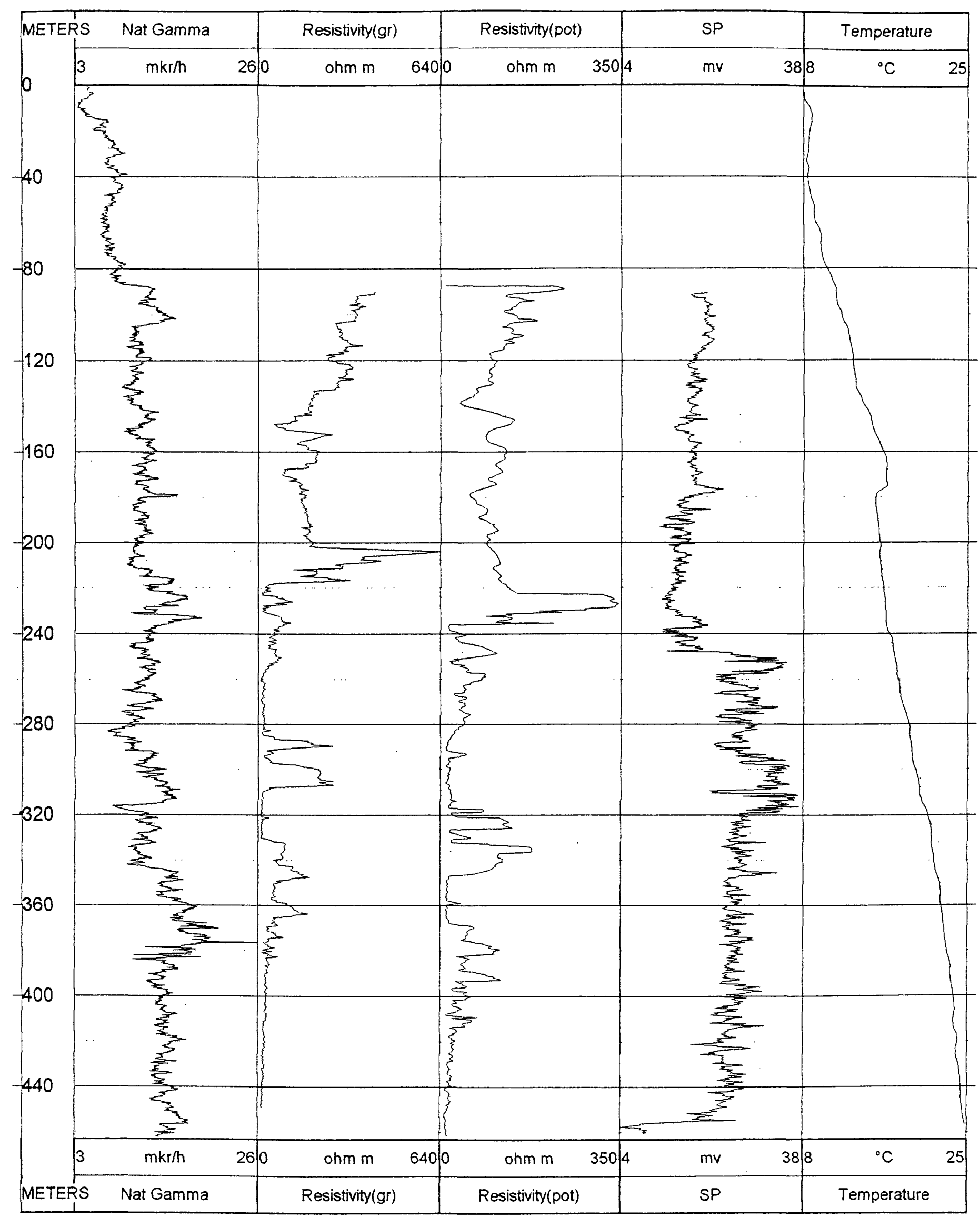

Hole 39 (for water) 


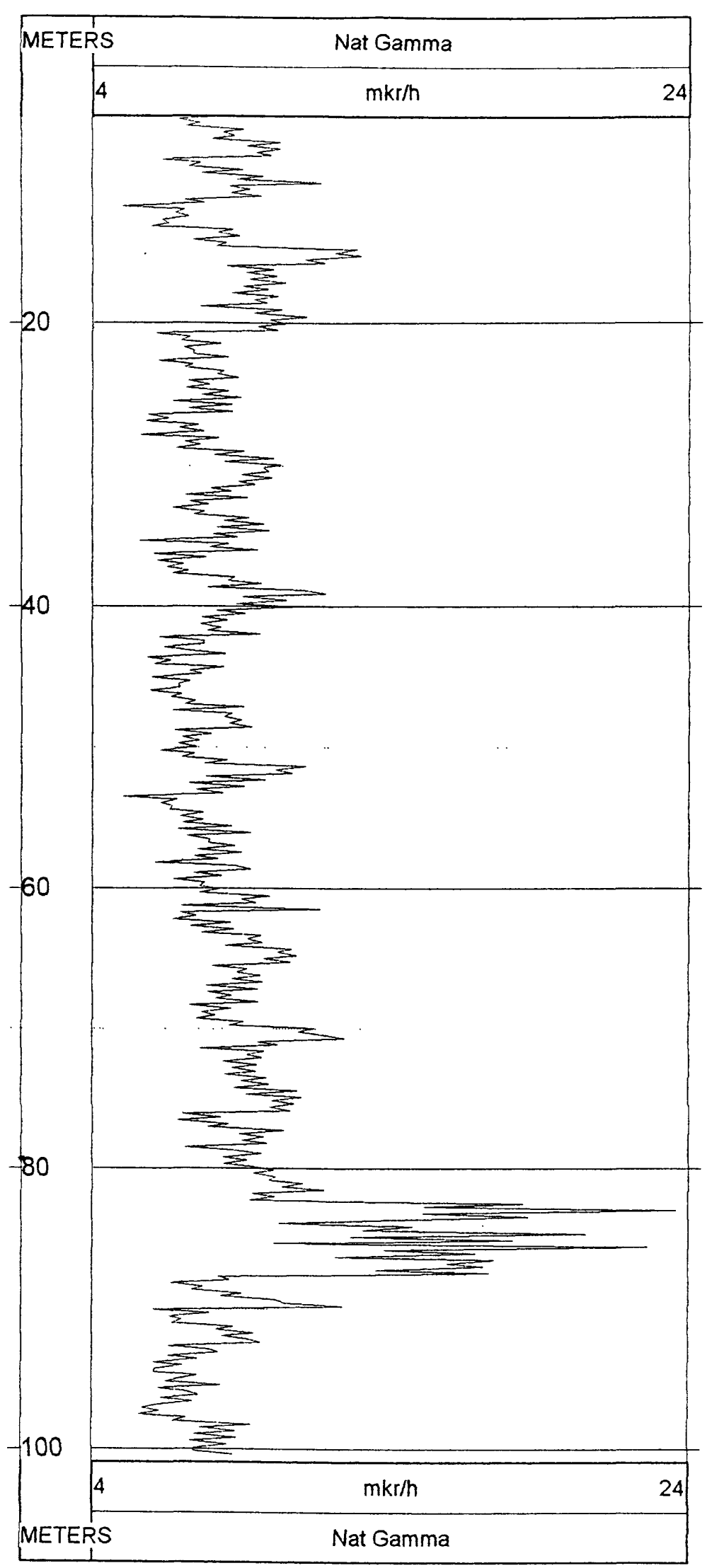

Hole 71 (for water)

Siuniq party, Azatek area 


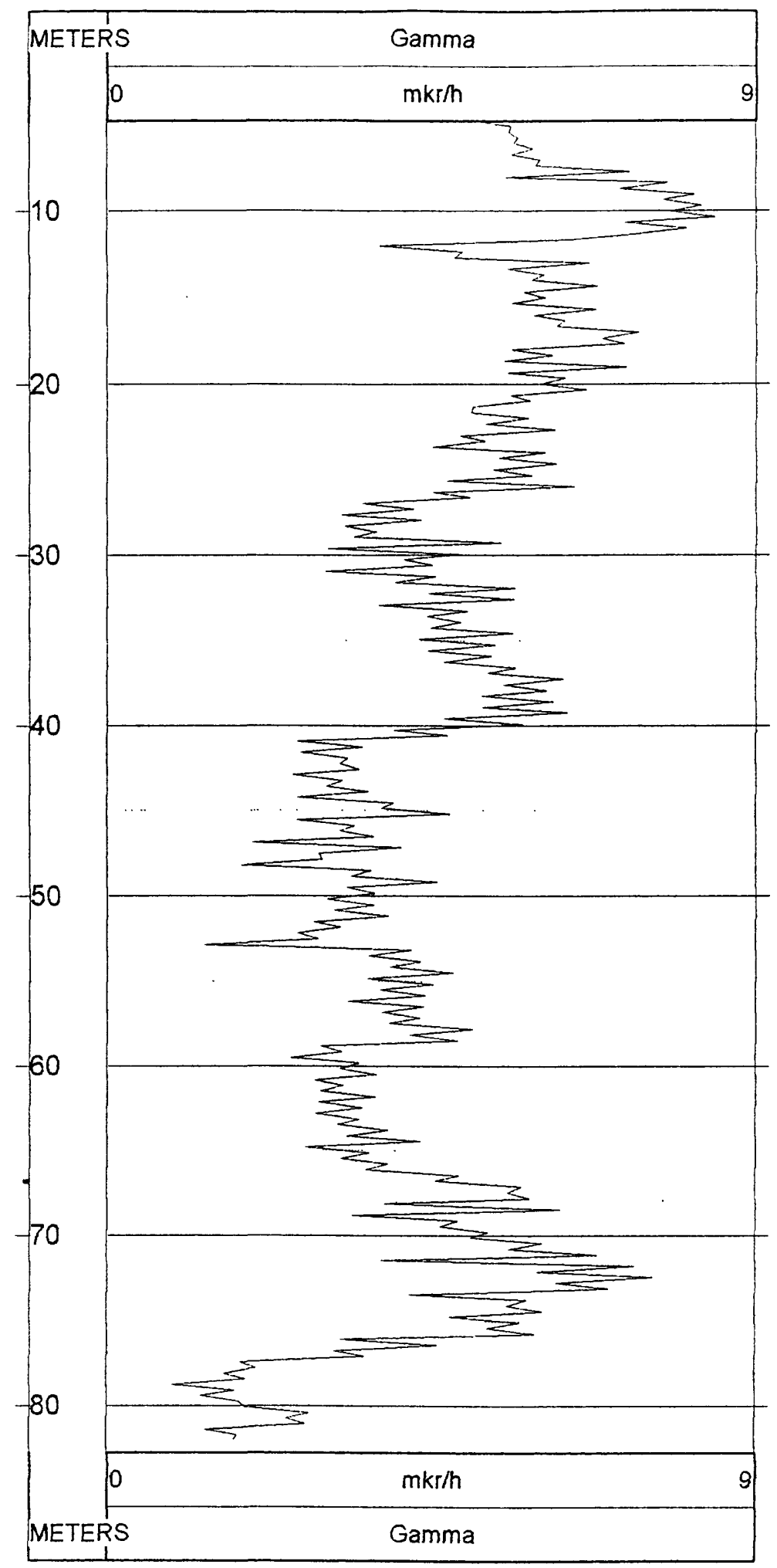

Hole 100 (for water) 


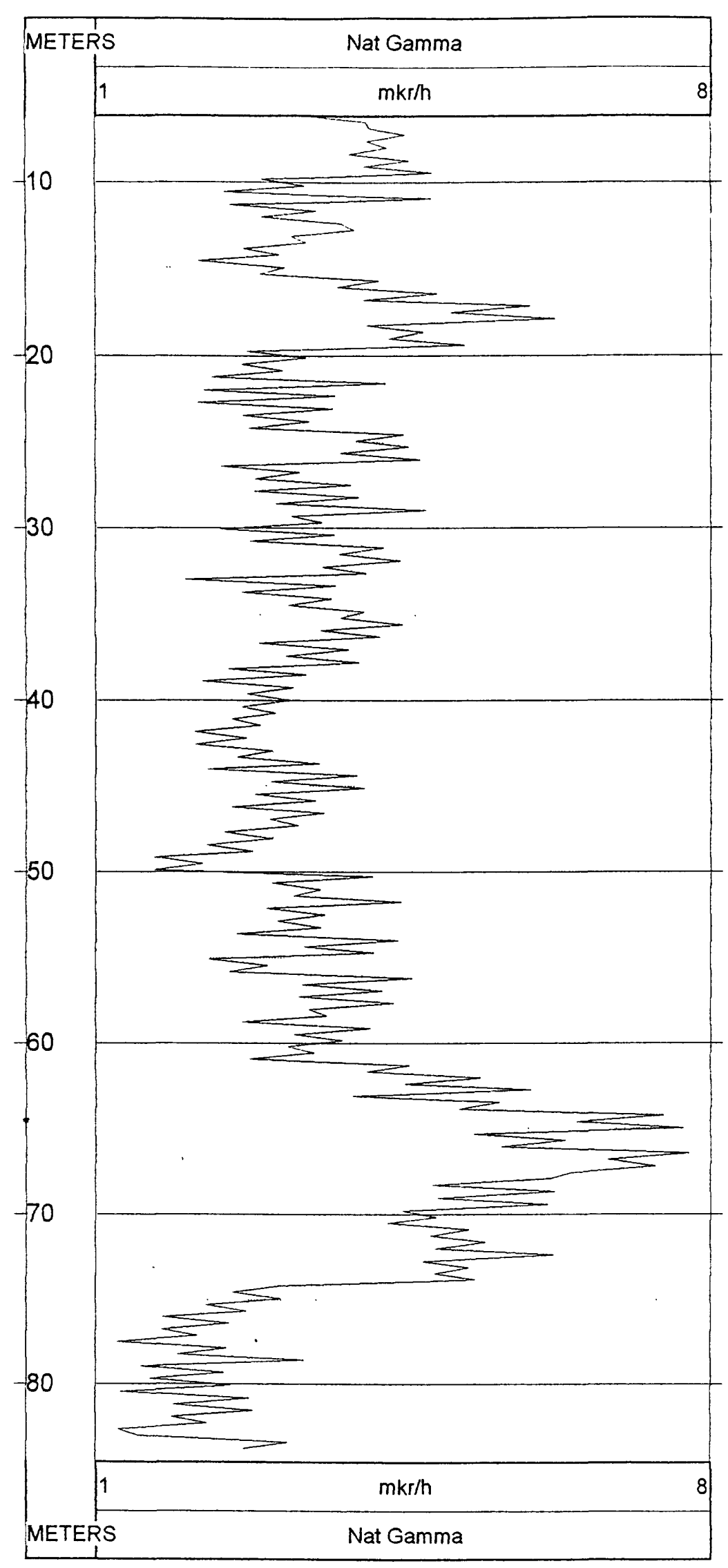

Hole 83 (for water)

Siuniq party, Horadis area 


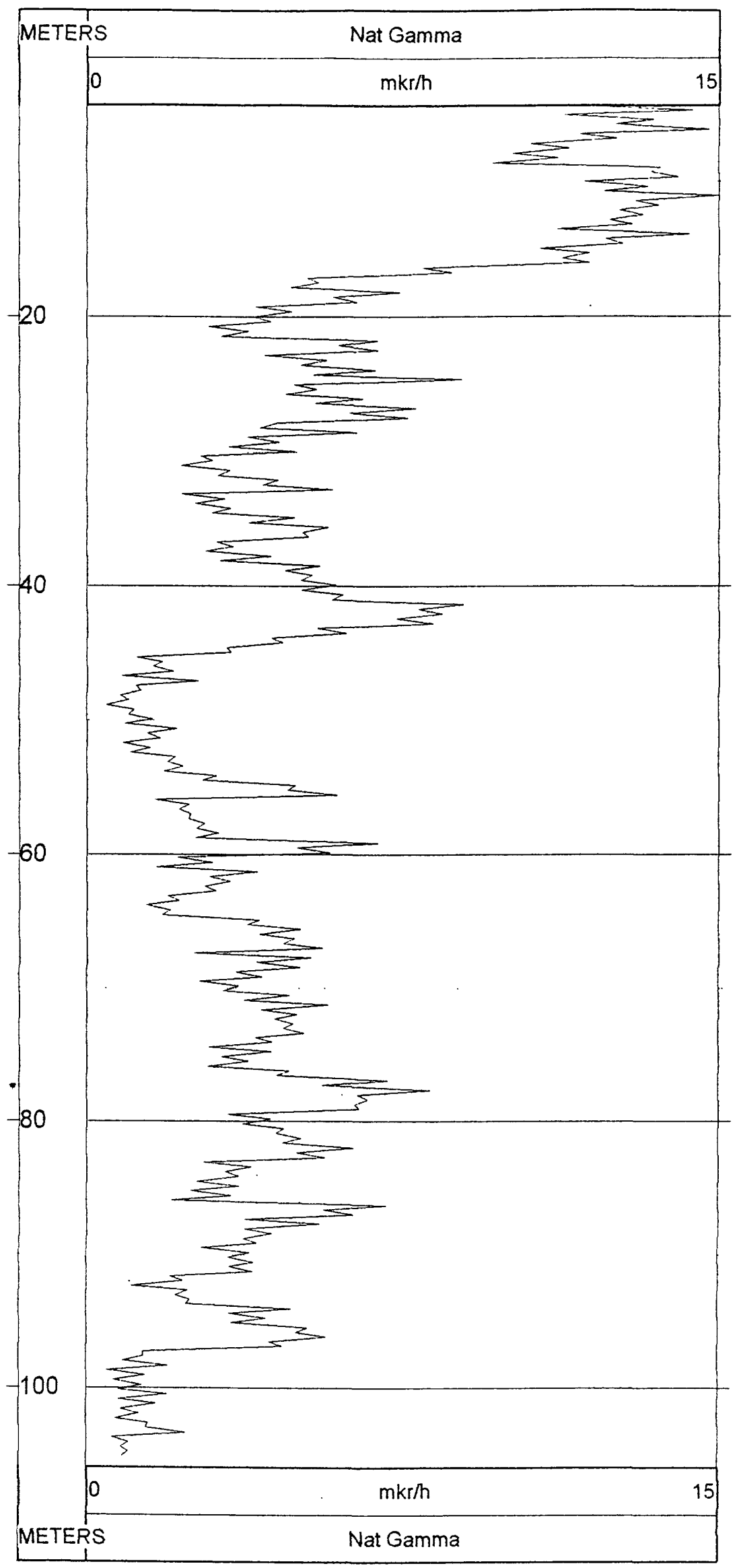

Hole 61 (for water)

Siuniq party, Horadis area 


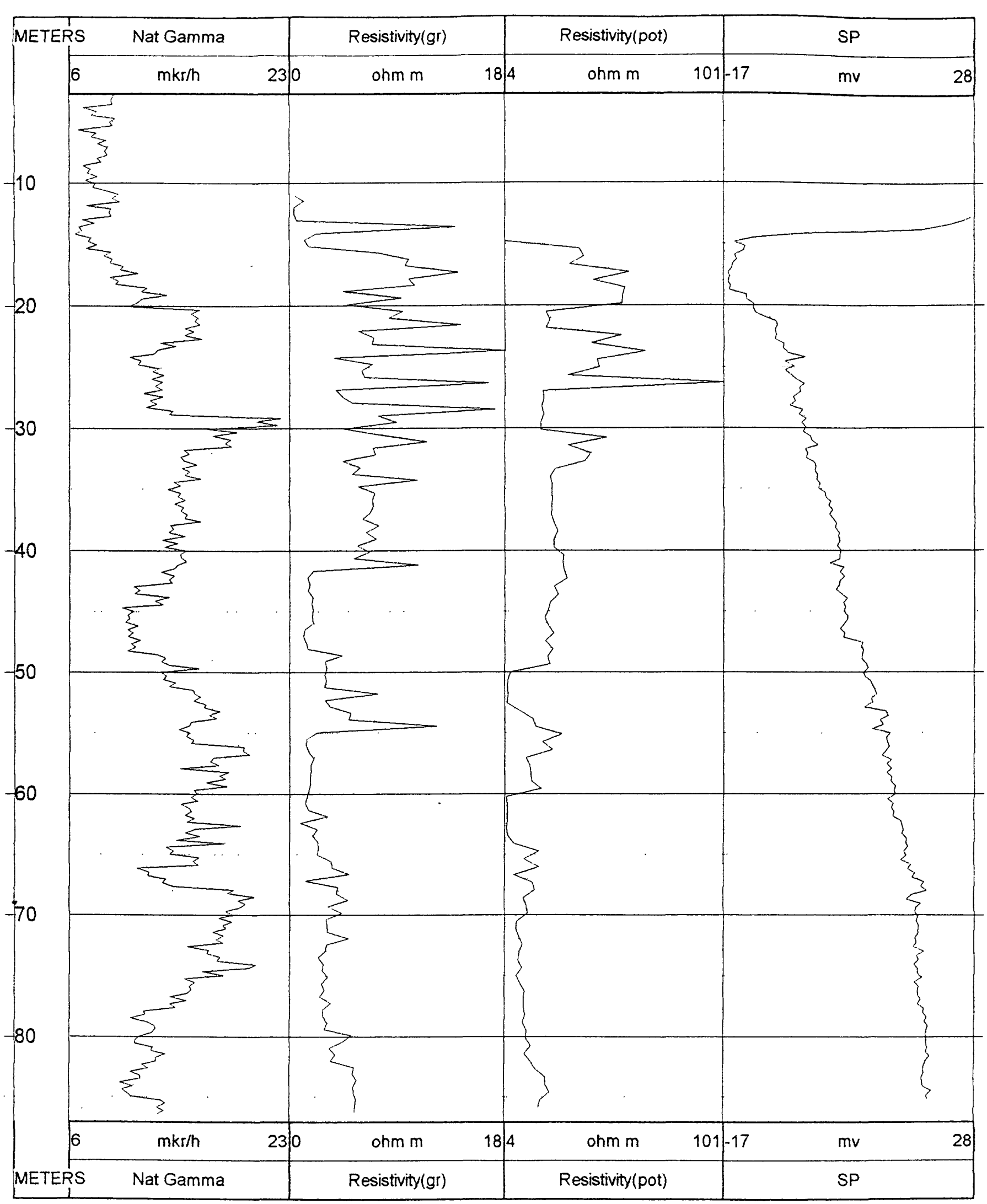

Hole 181 (for water) 


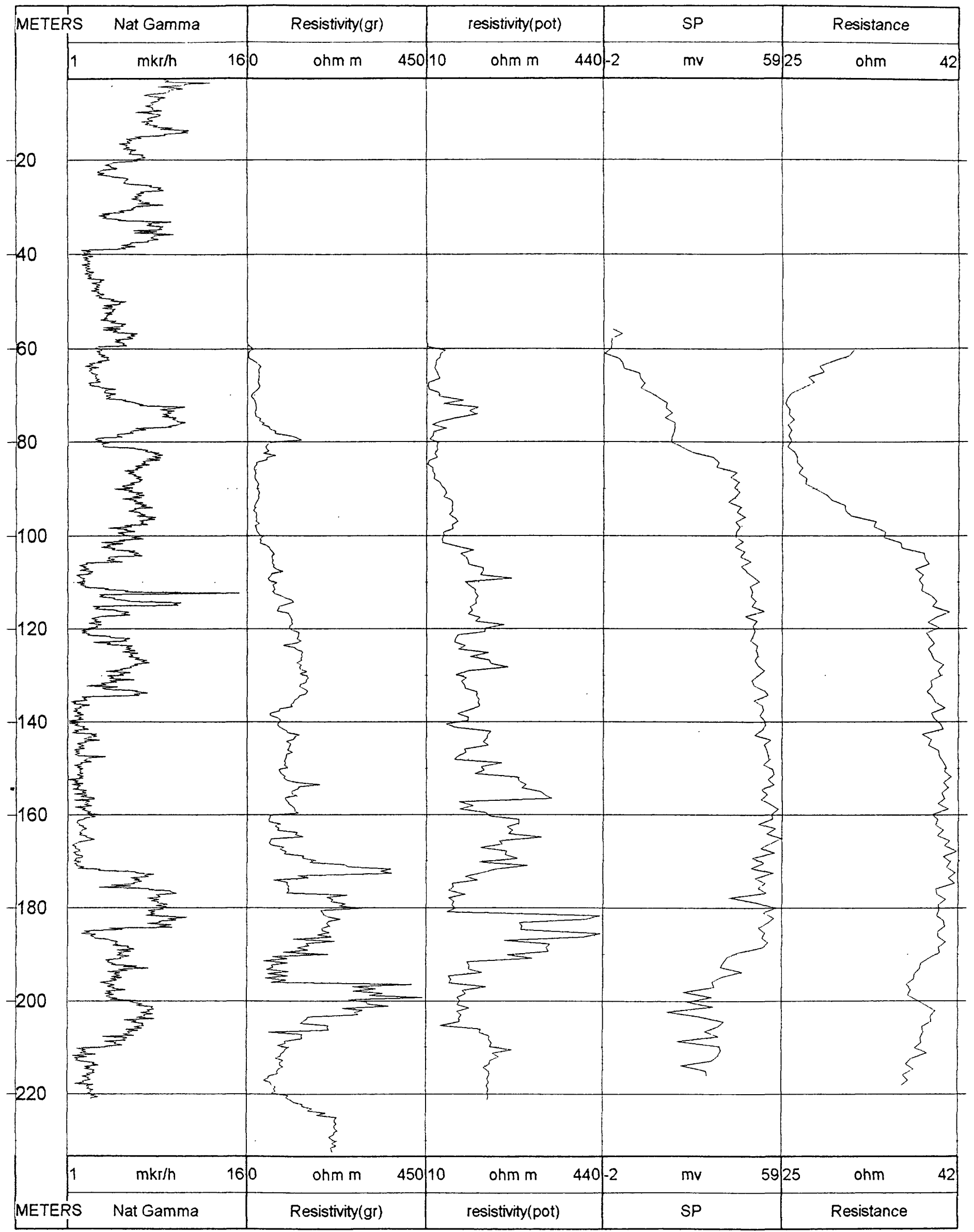

Hole 17/81 (for water) 


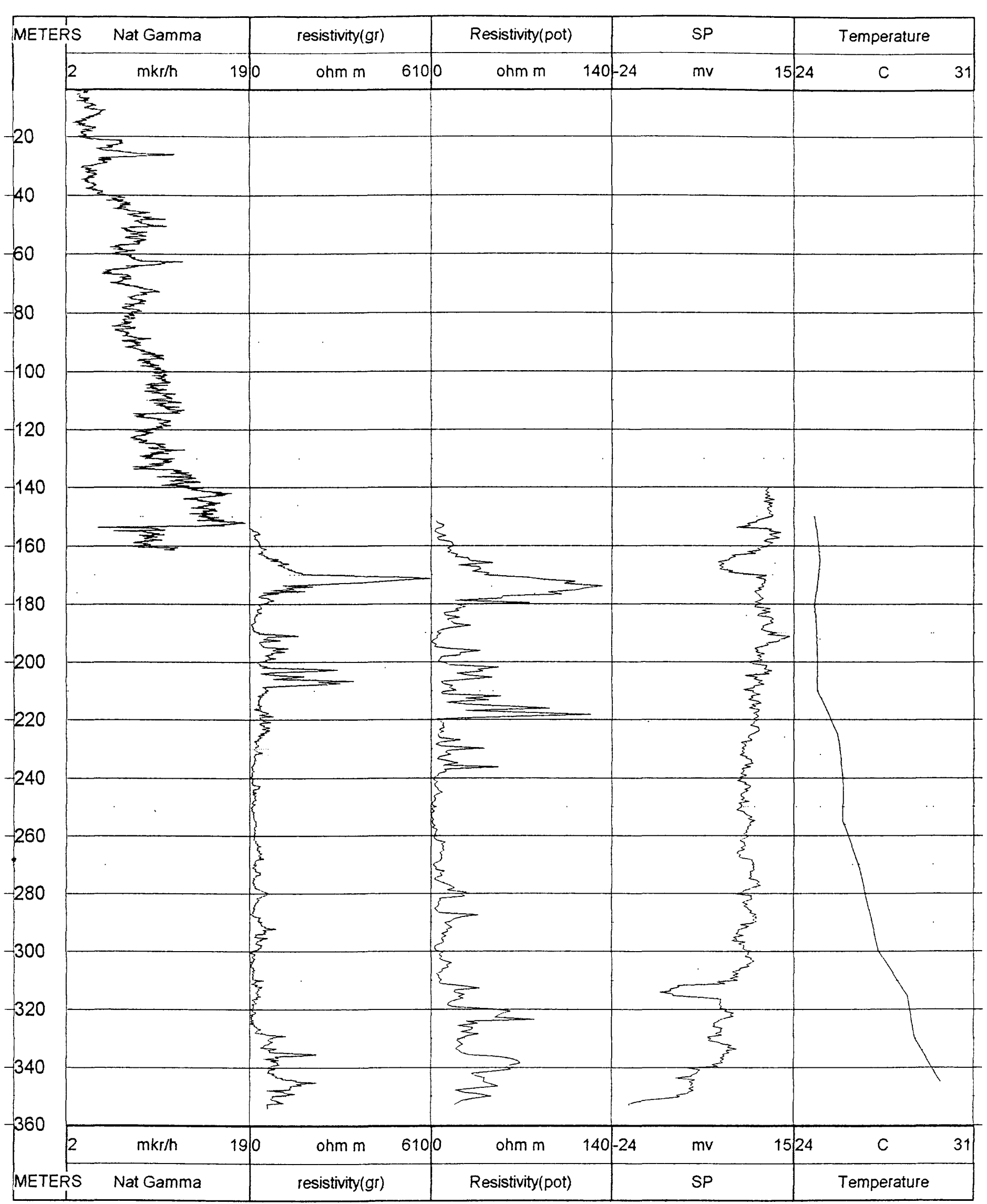

Hole 6 (for water)

Siuniq party, Sisian area 


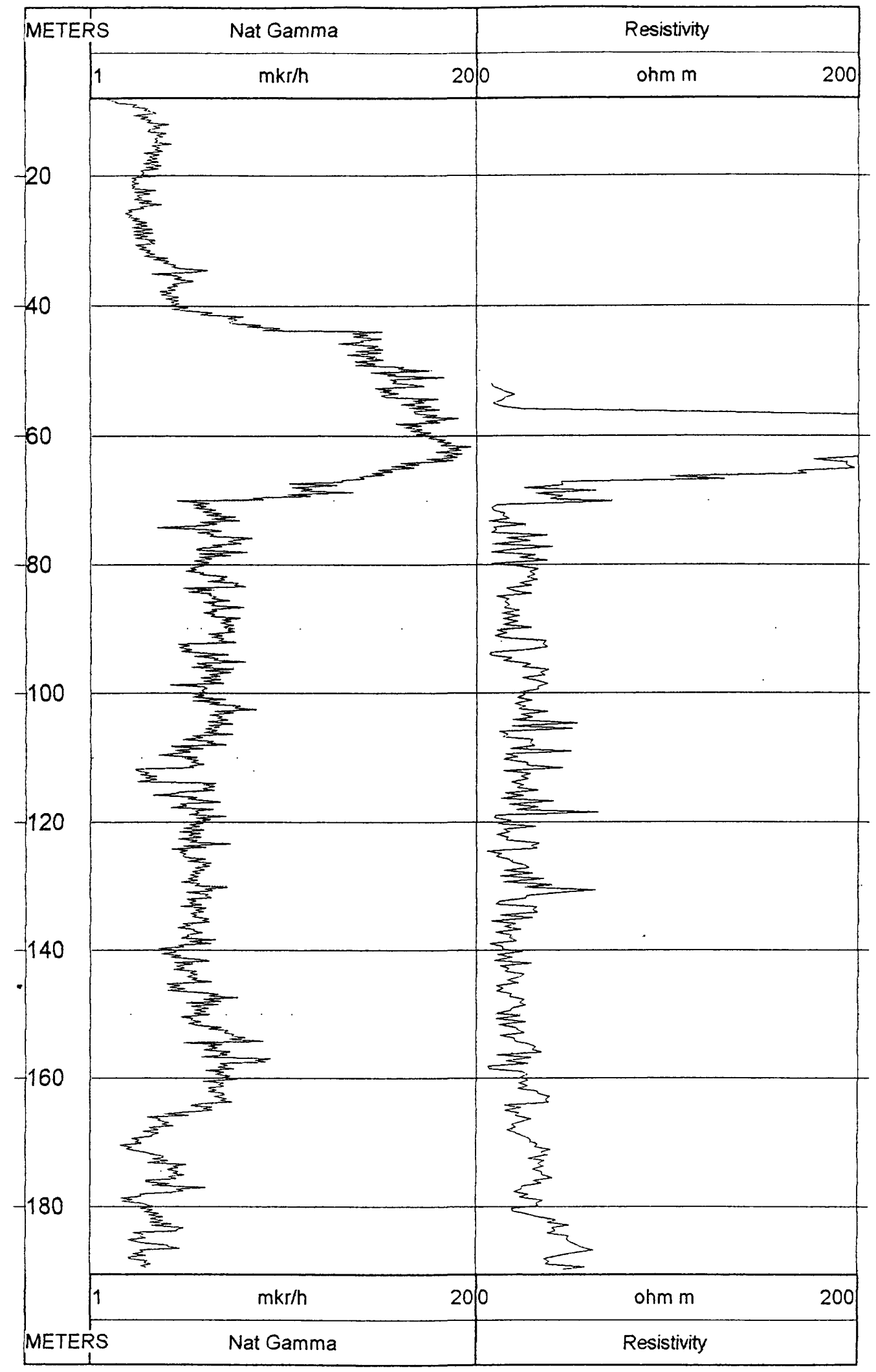

Hole 11 (for water) 


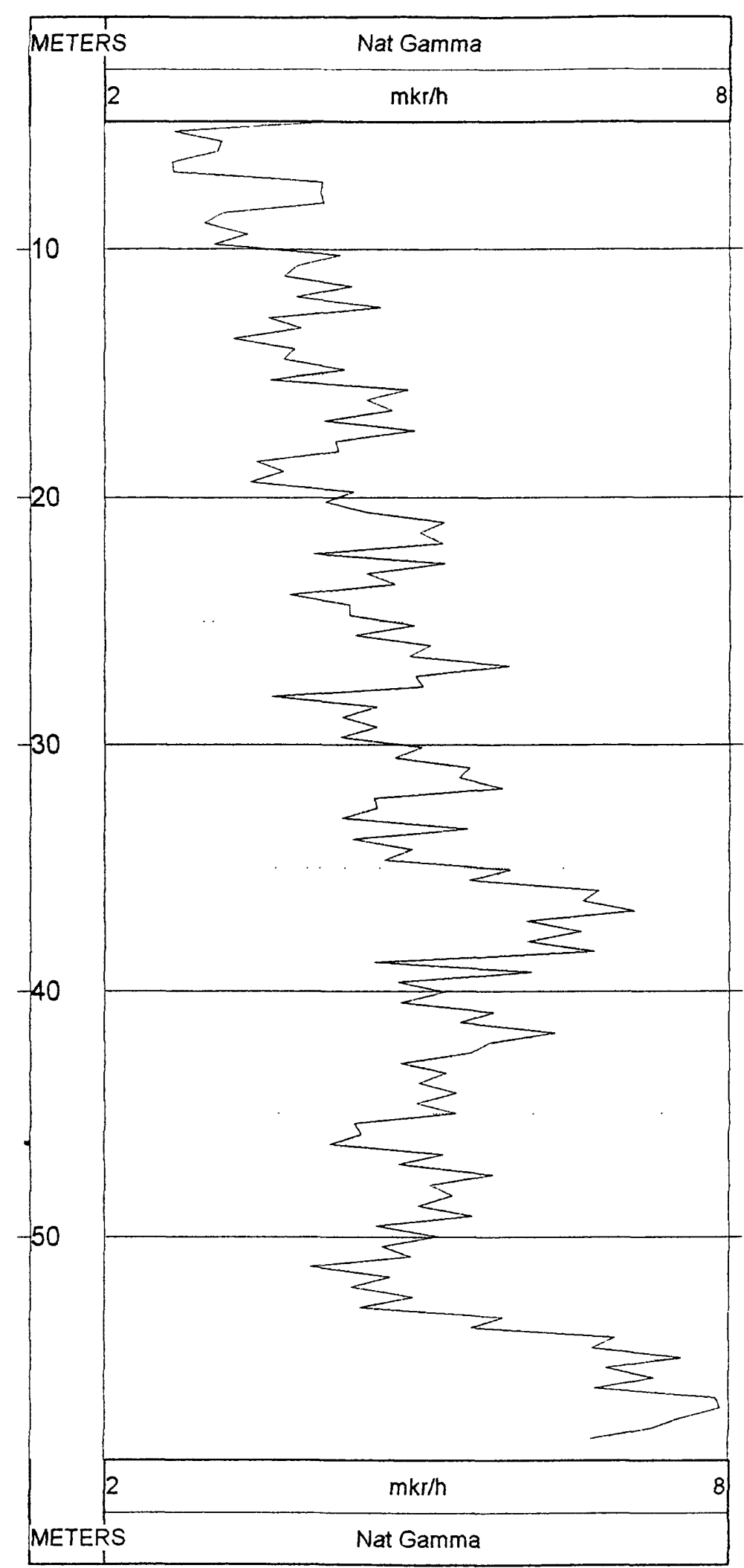

Hole 69 (for water) 


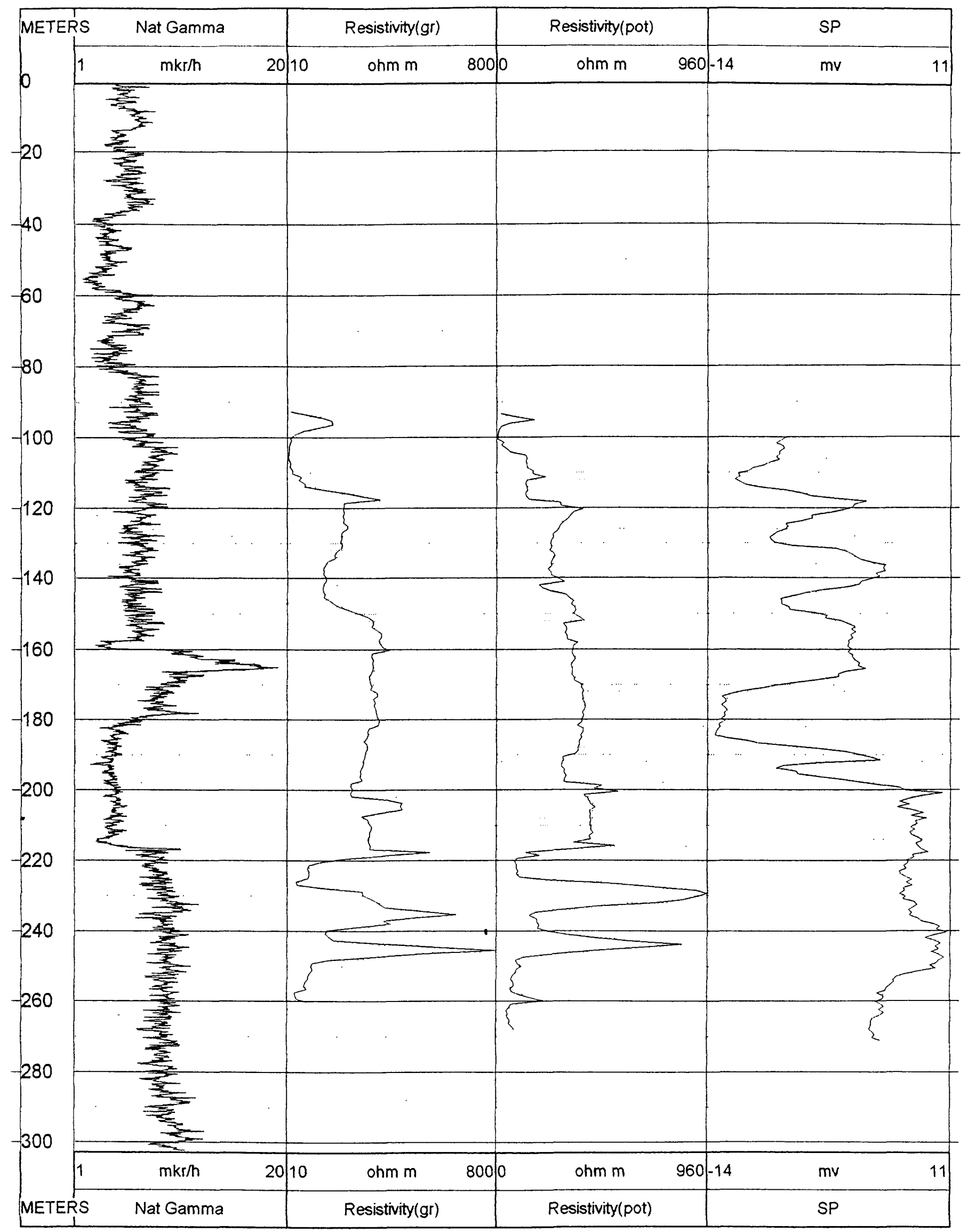

Hole 68-1 (for water)

Ararat party, Mrgashat area 


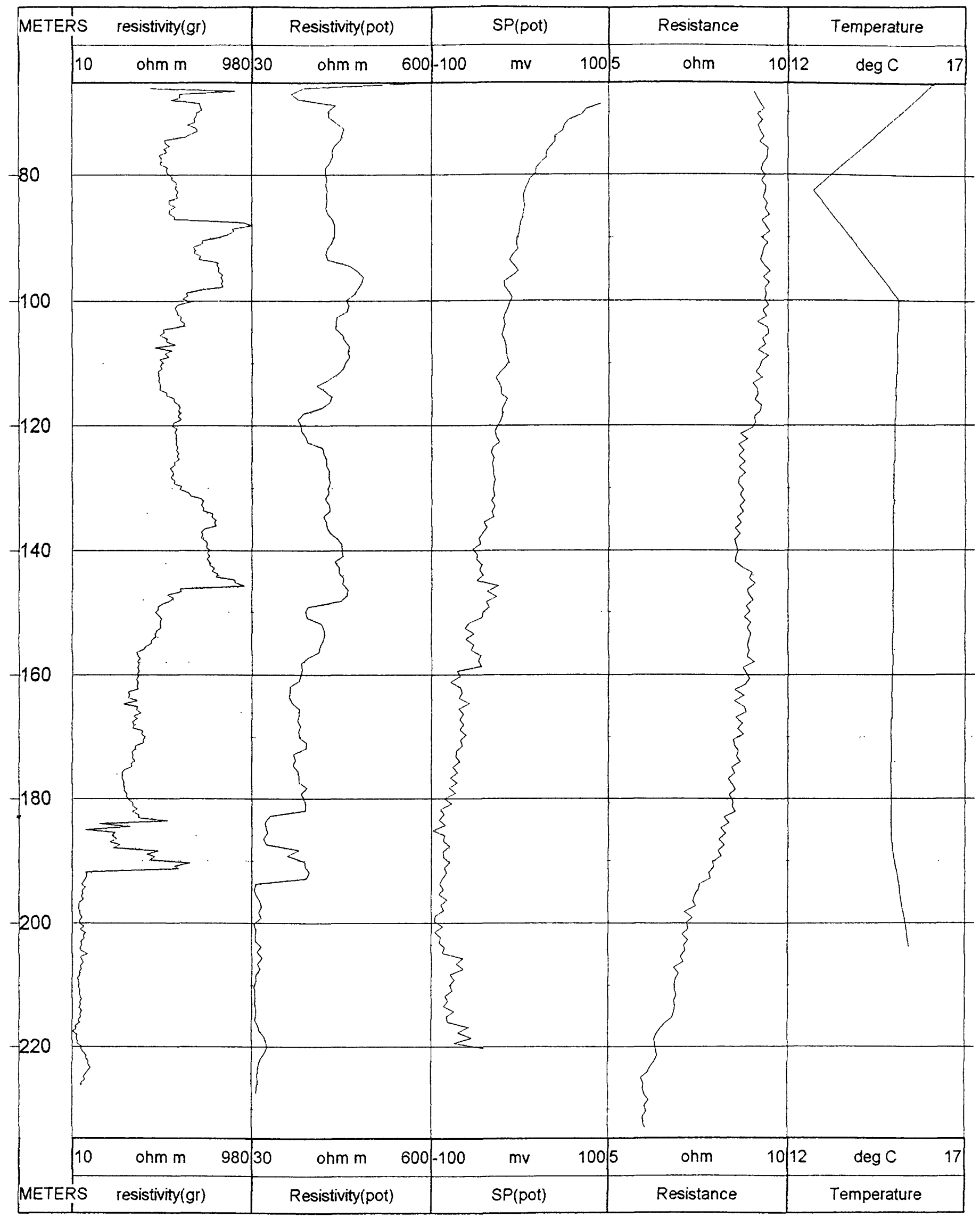

Hole $5 b$ (for water)

Ararat party, Arteny area

50

10.15 .82 


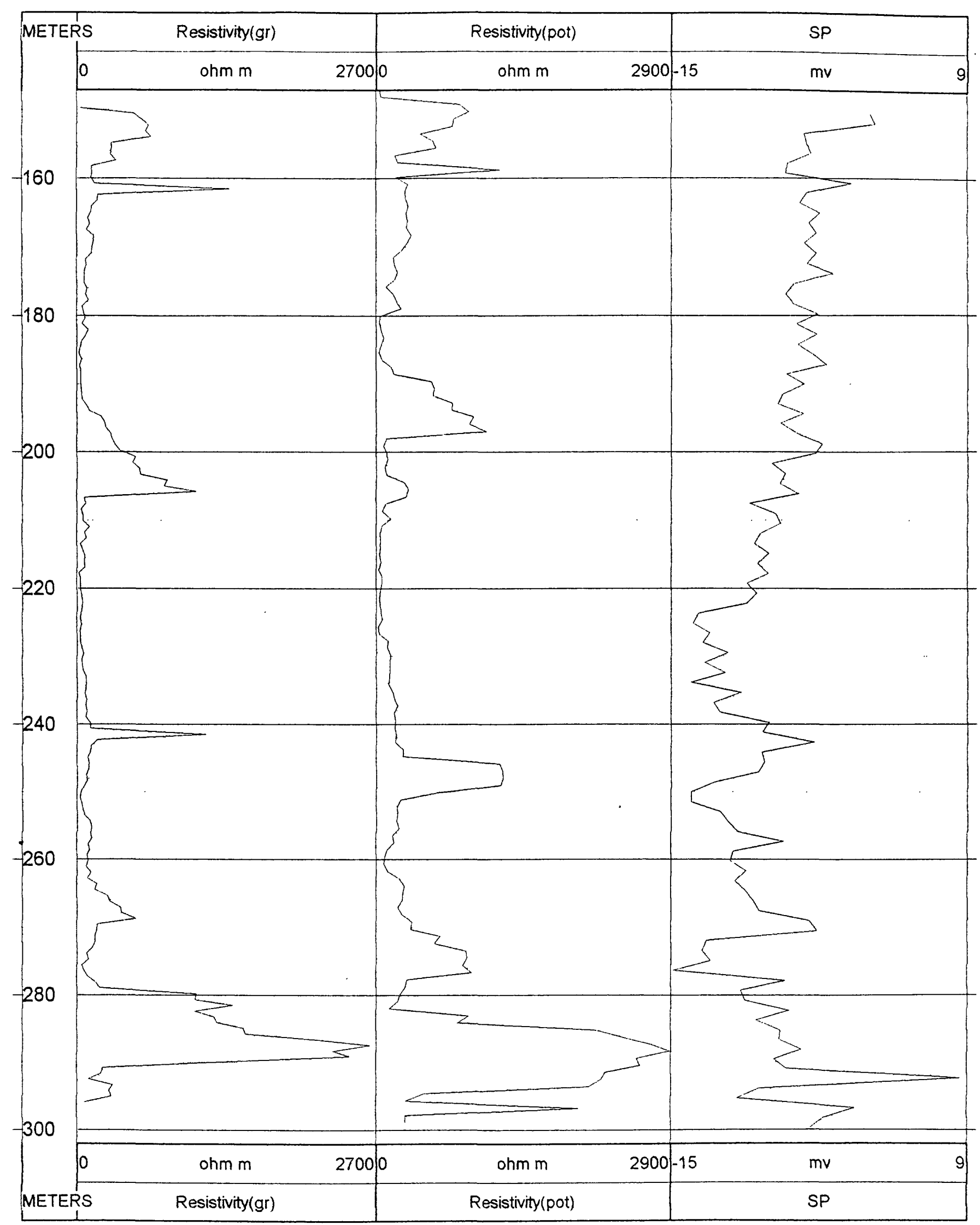

Hole 74/1 (for water)

Ararat party, Armavir area 


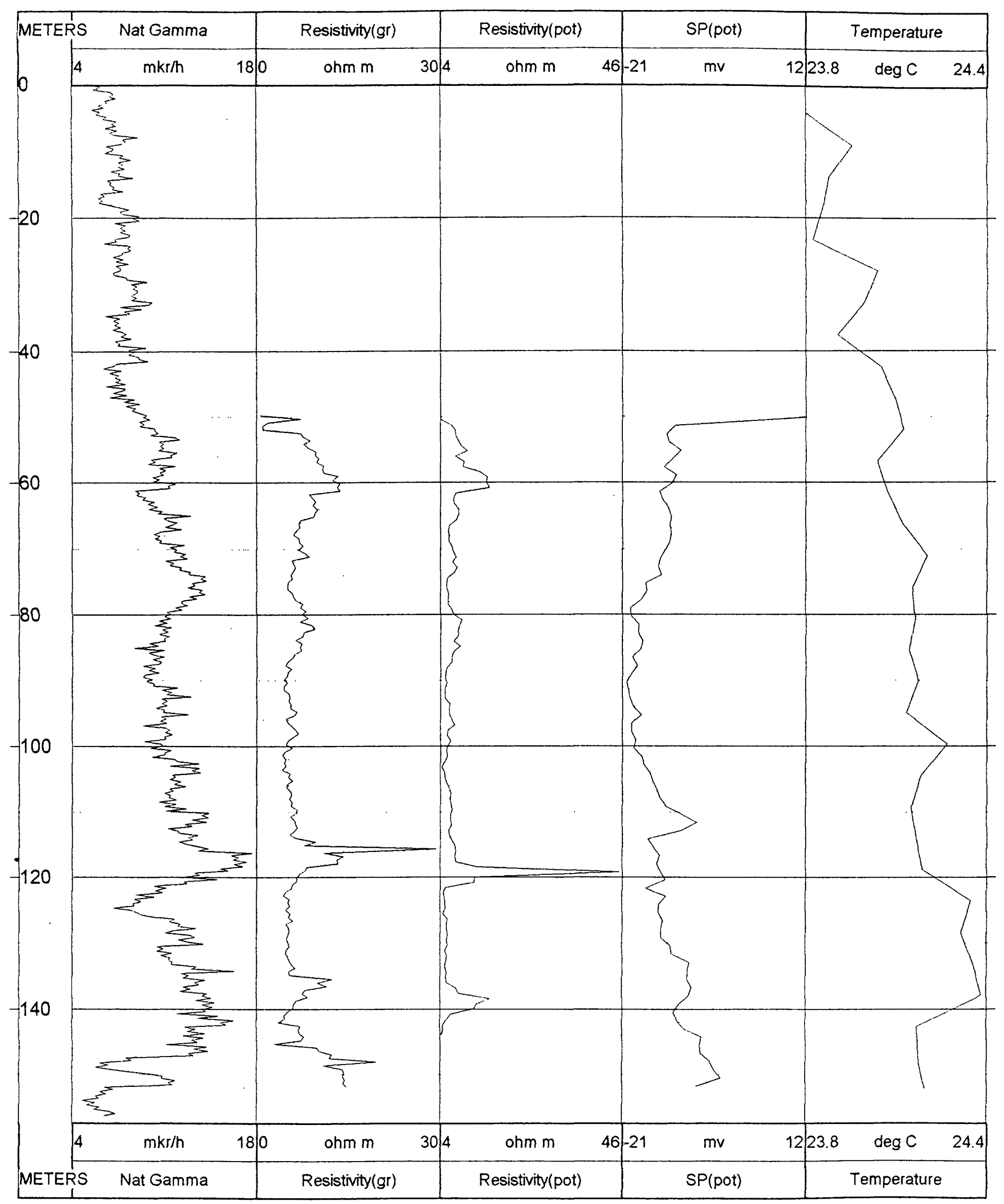

Hole 48 (for water)

Ararat party, Ararat area 


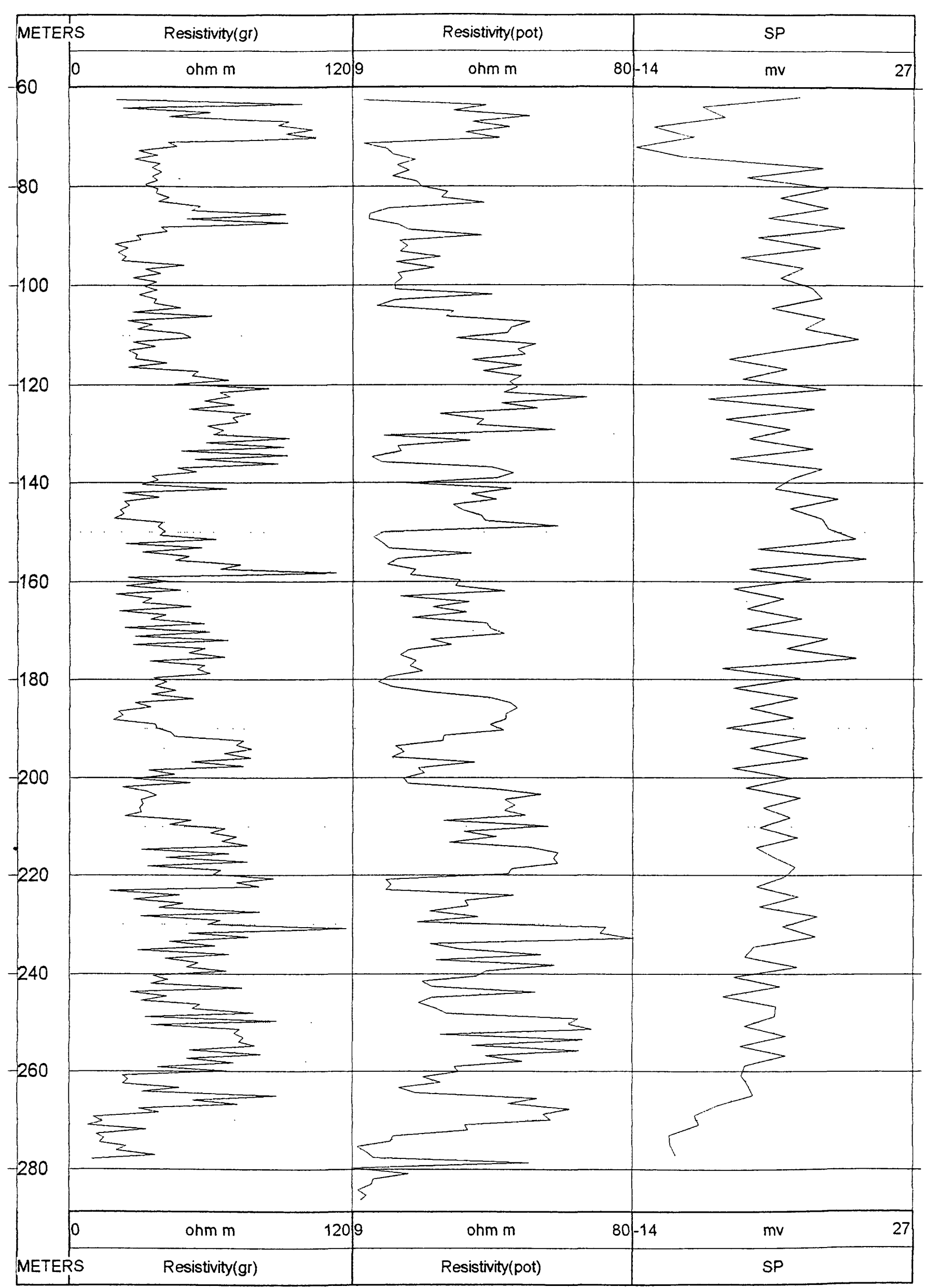

Hole 8 (for water)

Ararat party, Artashat area 


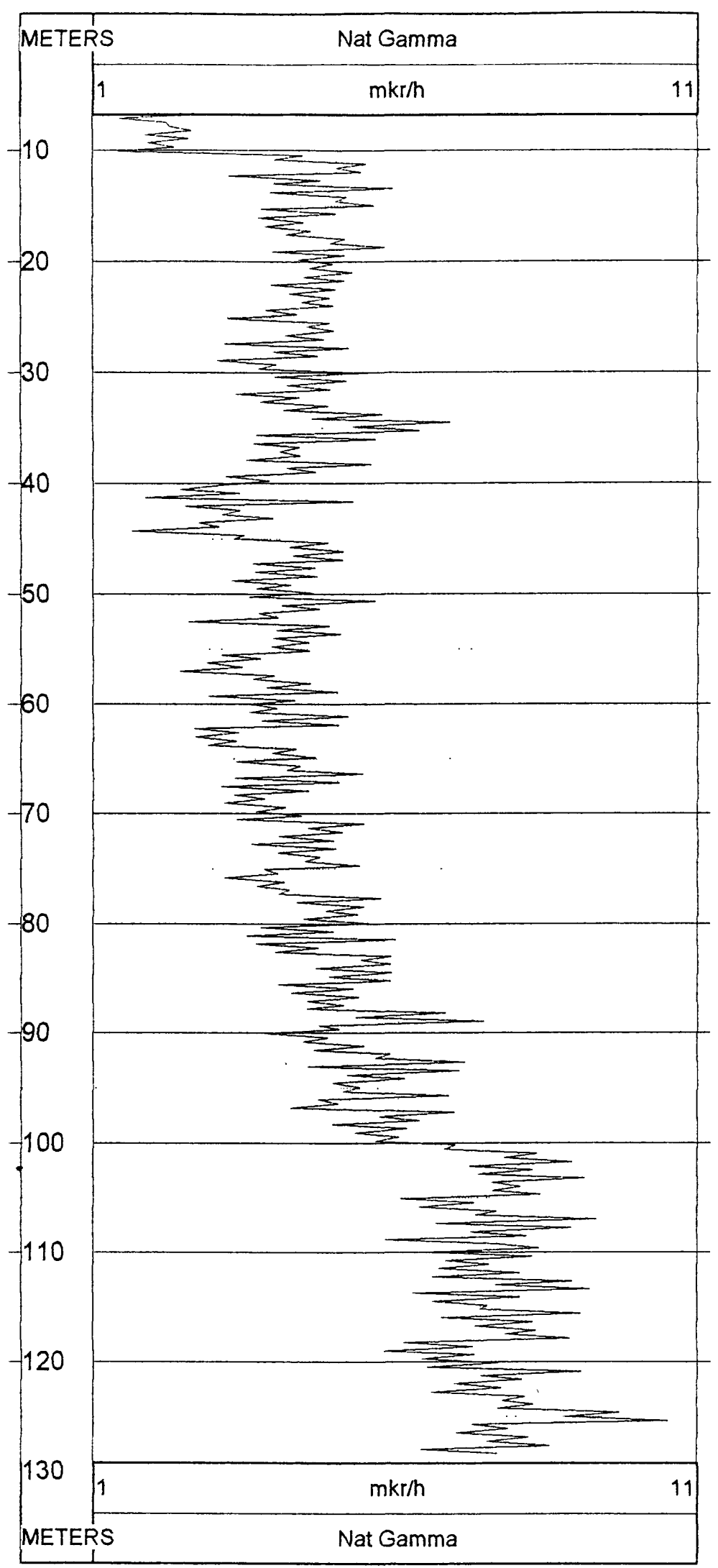

Hole 25 (for water) Ararat party, Arazdajan area 


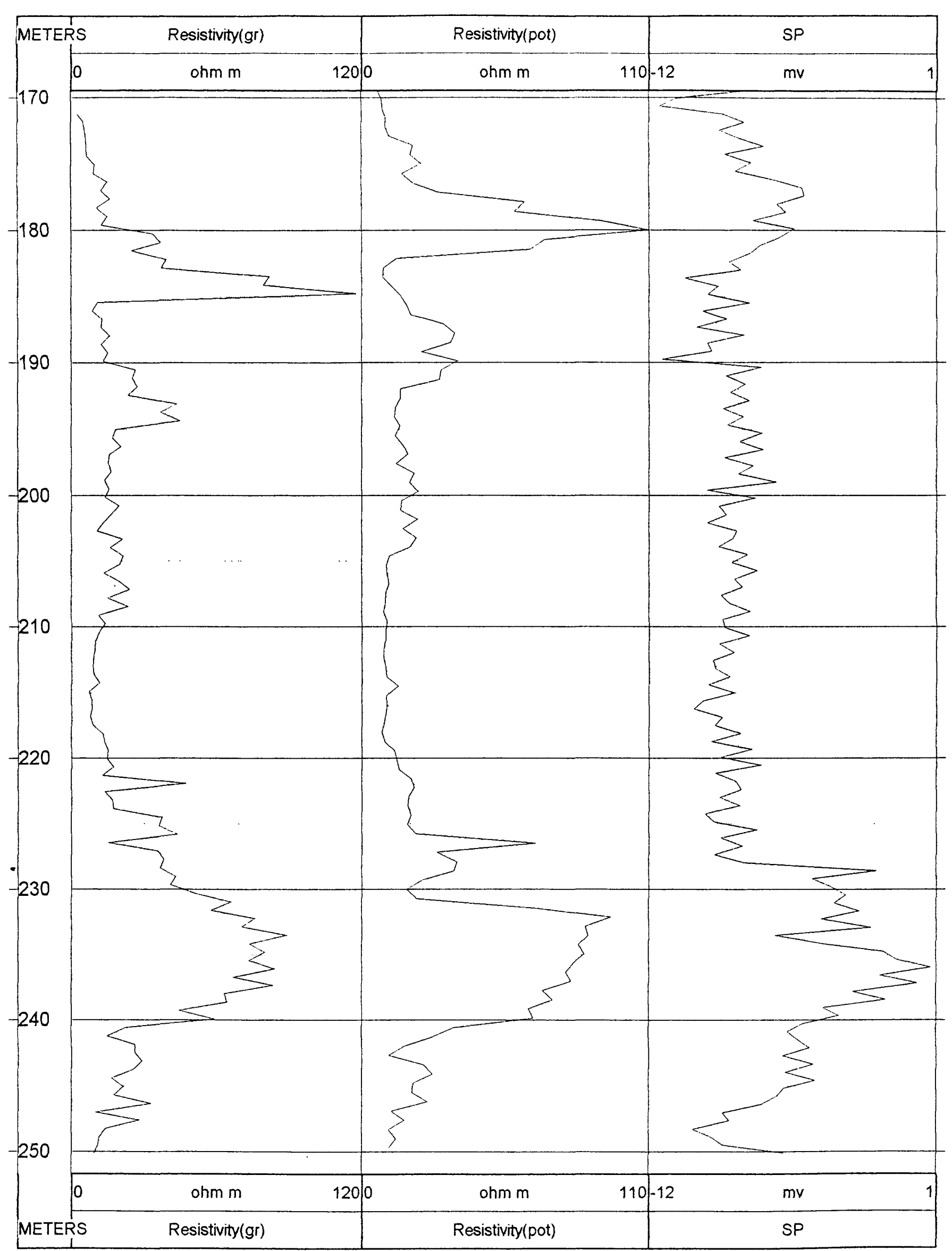

Hole 2 (for water) Ararat party, Dalar area 


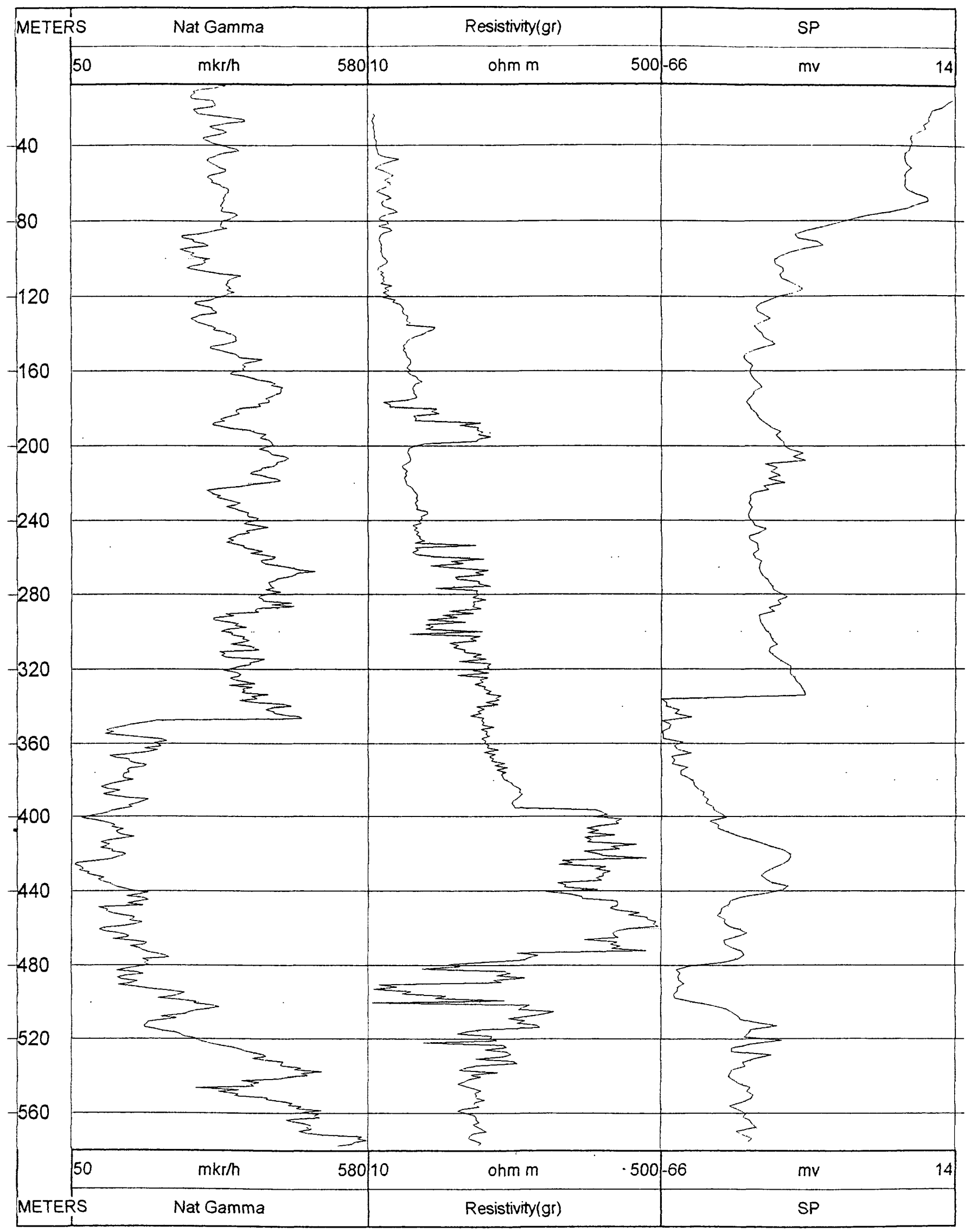

Hole 23 (for coal) 


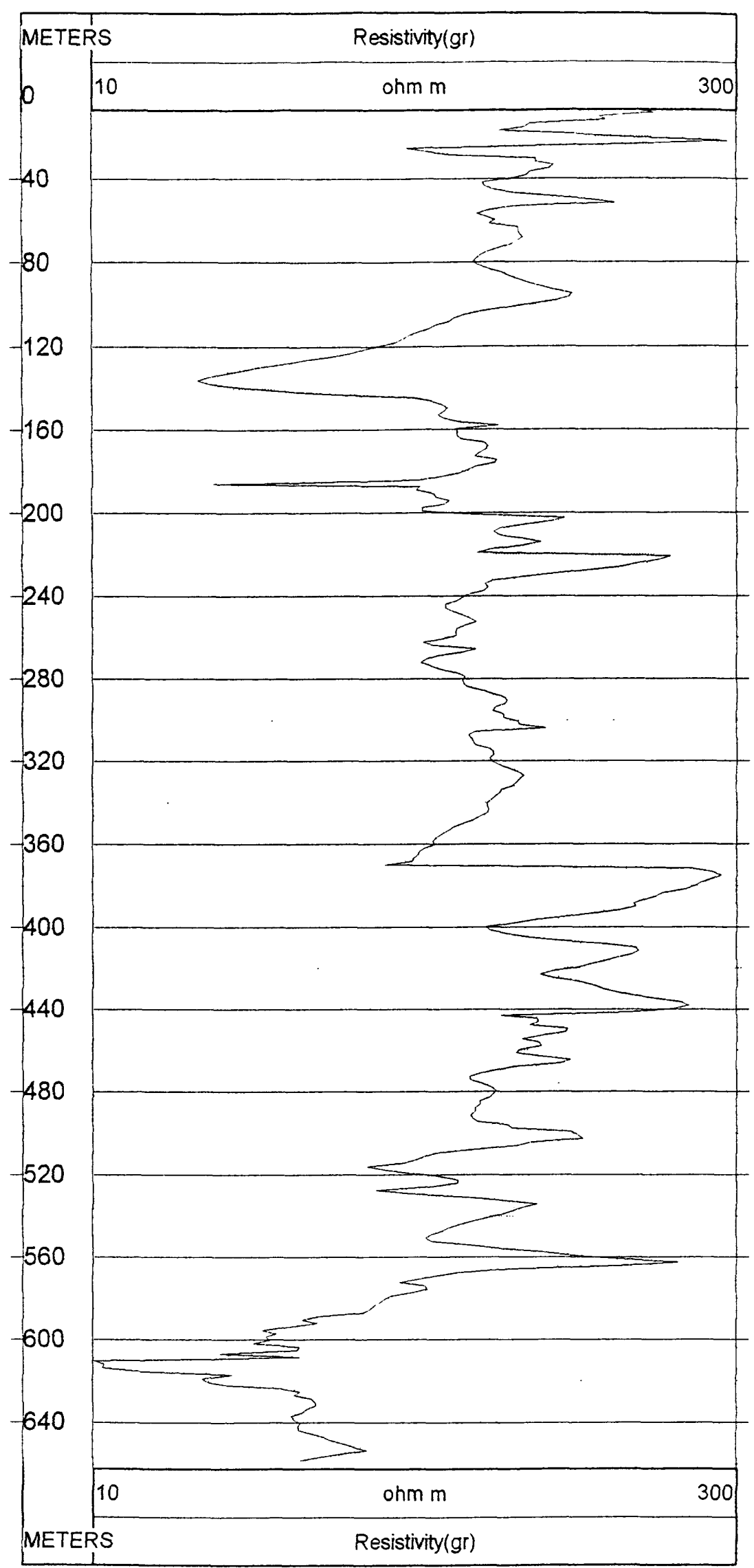

Hole 25 (for coal) 


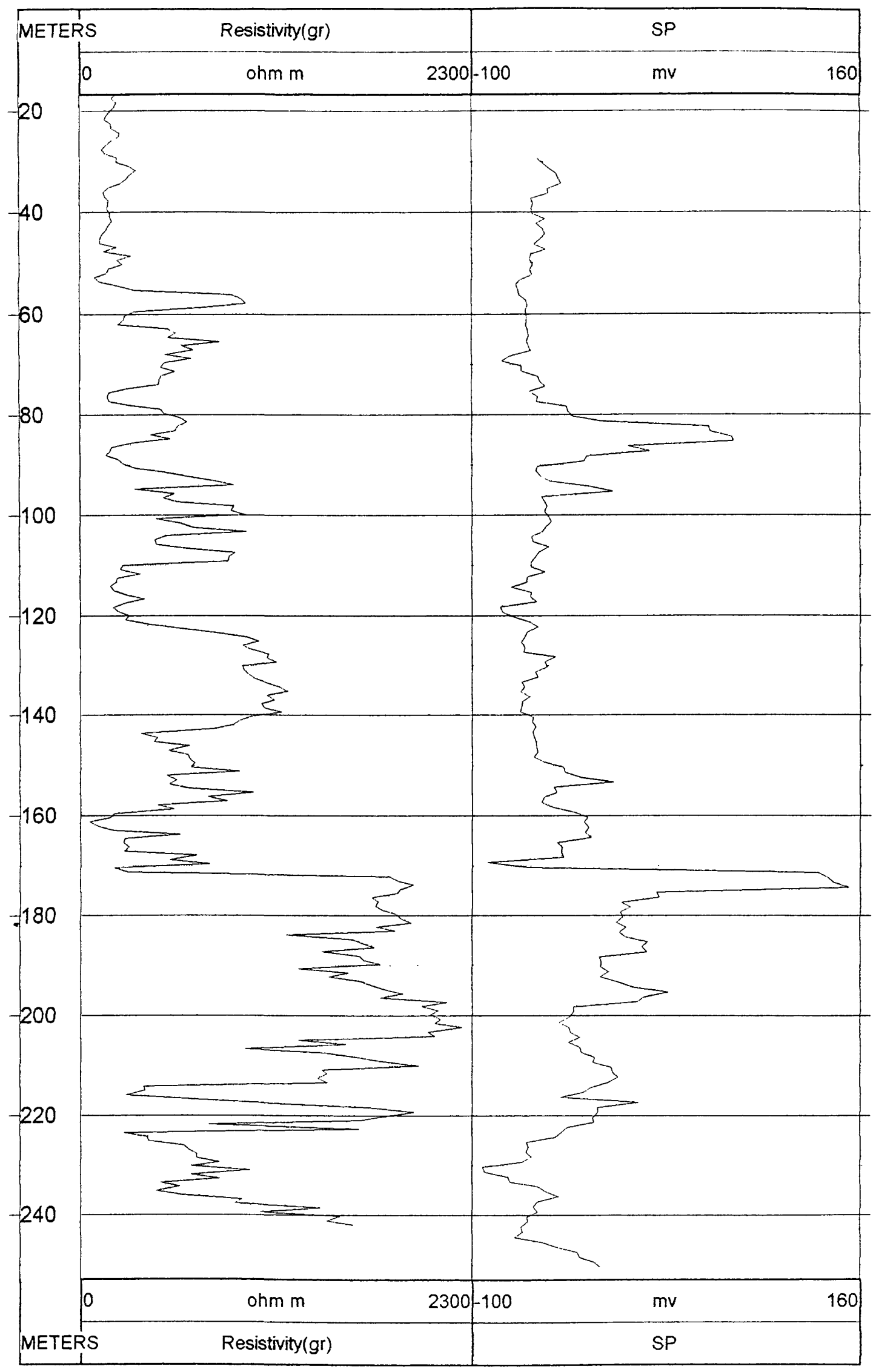

Hole 22 (for coal) 


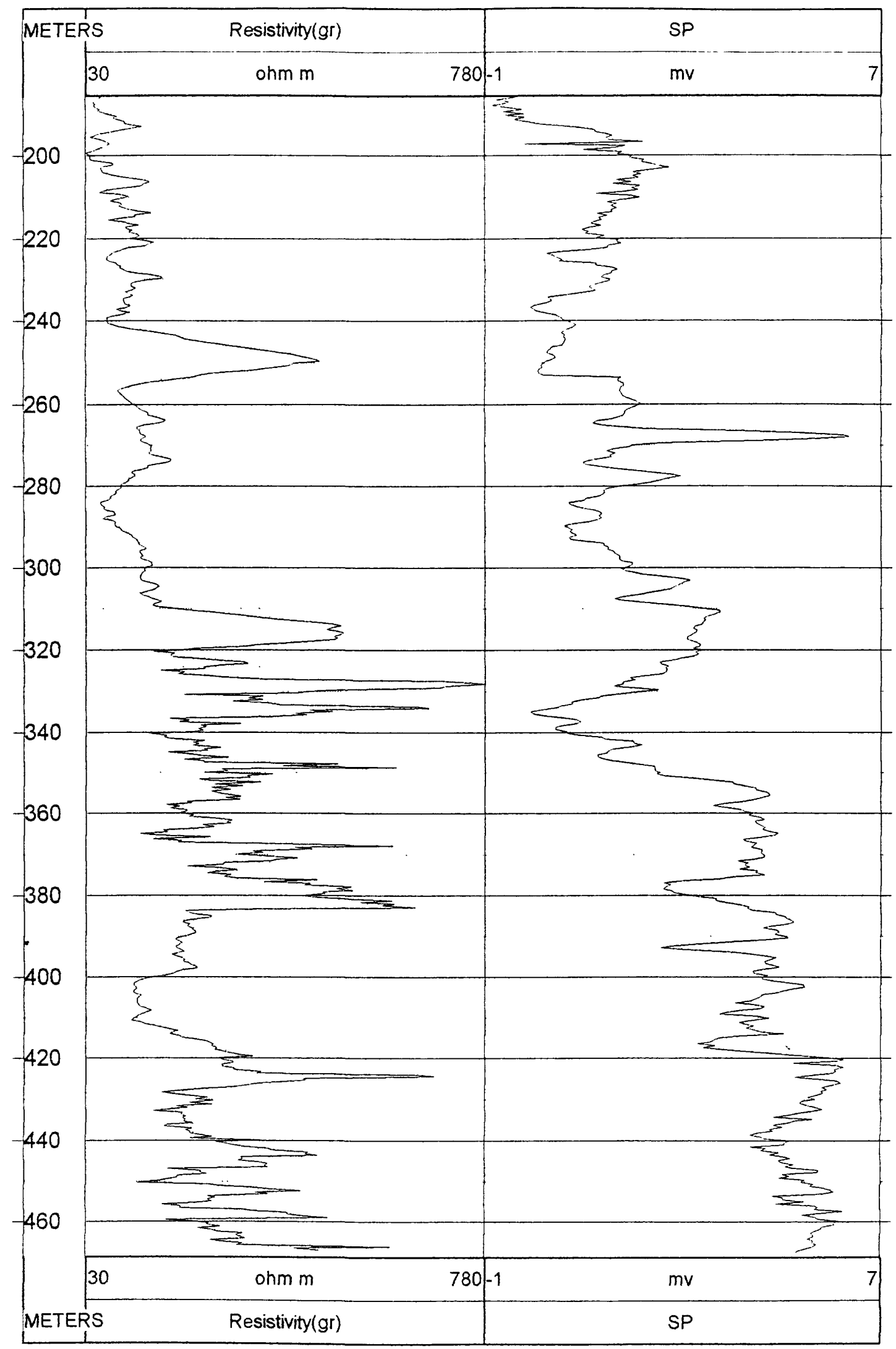

Hole 17 (for coal) 


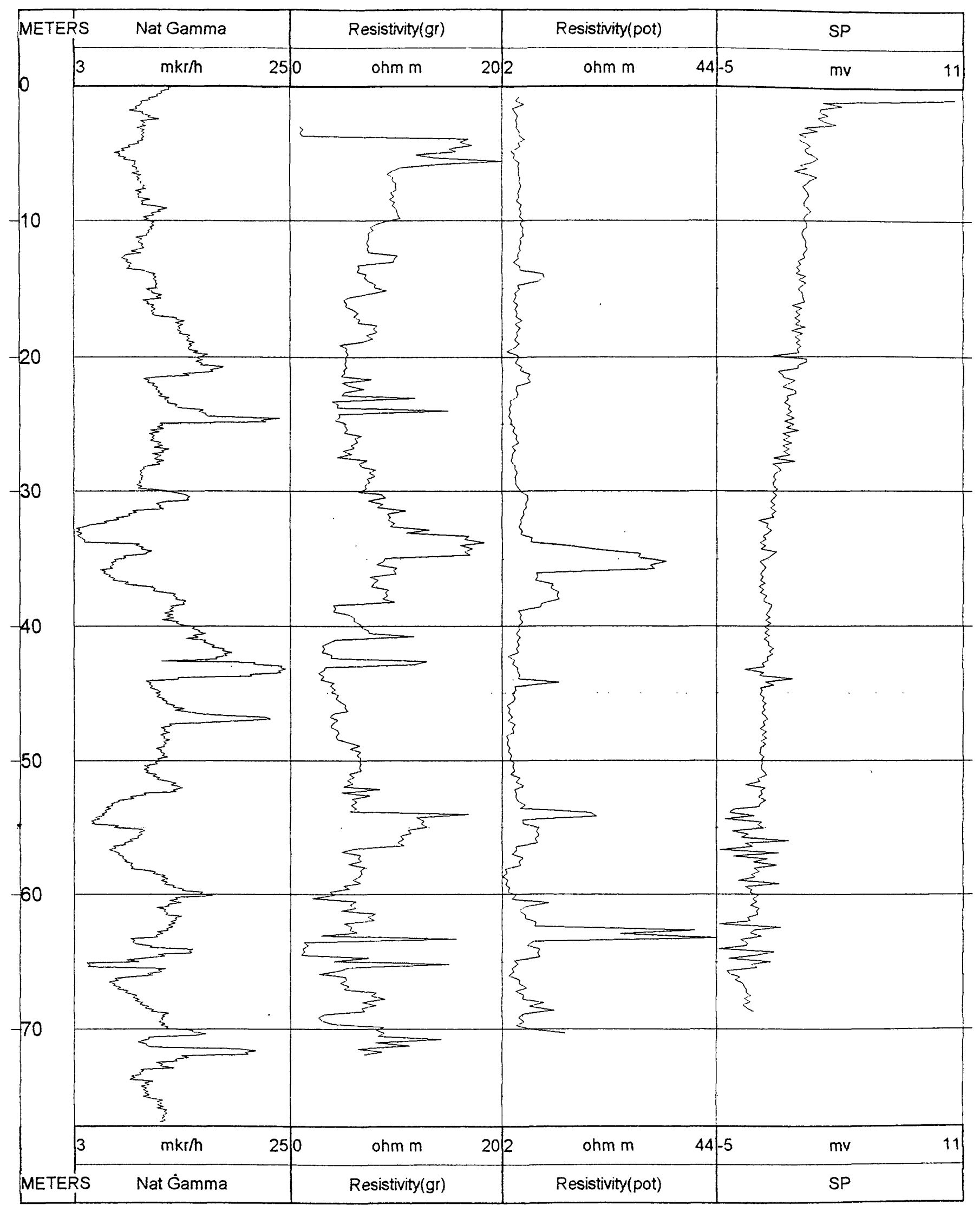

Hole 19 (for coal) 


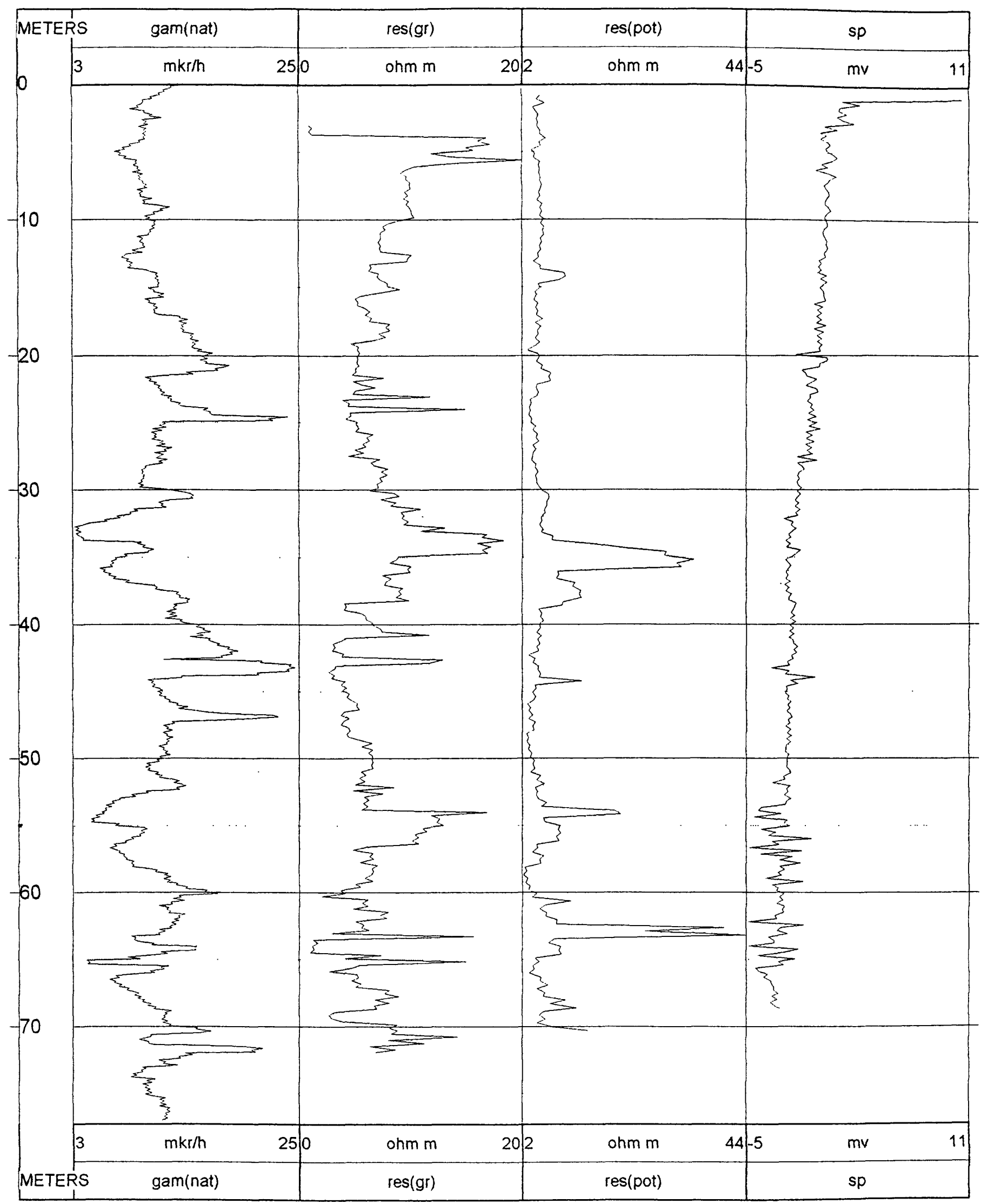

Hole 95 (for coal) 


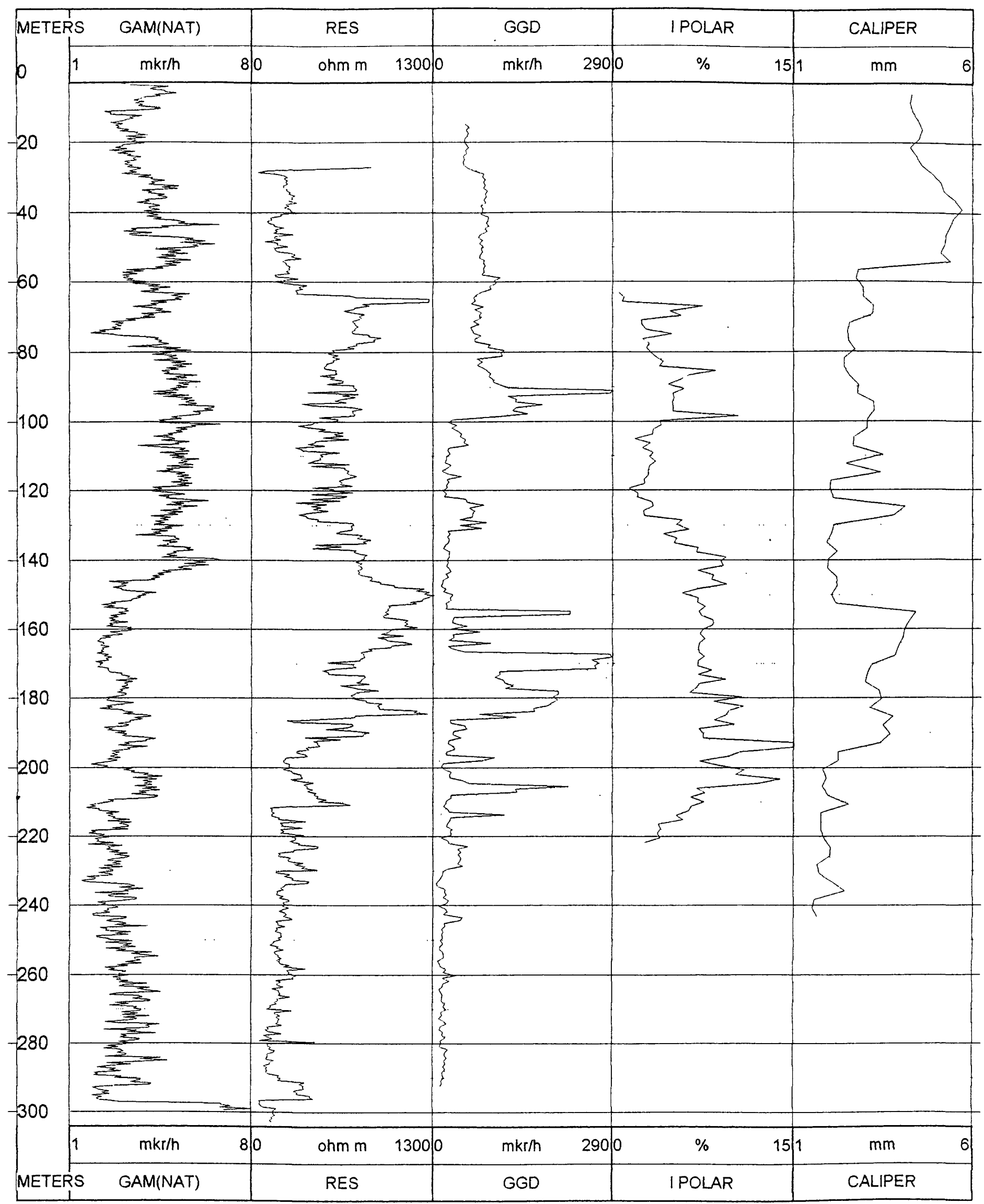

Hole 3 (for coal)

ljevan party, ljevan area 


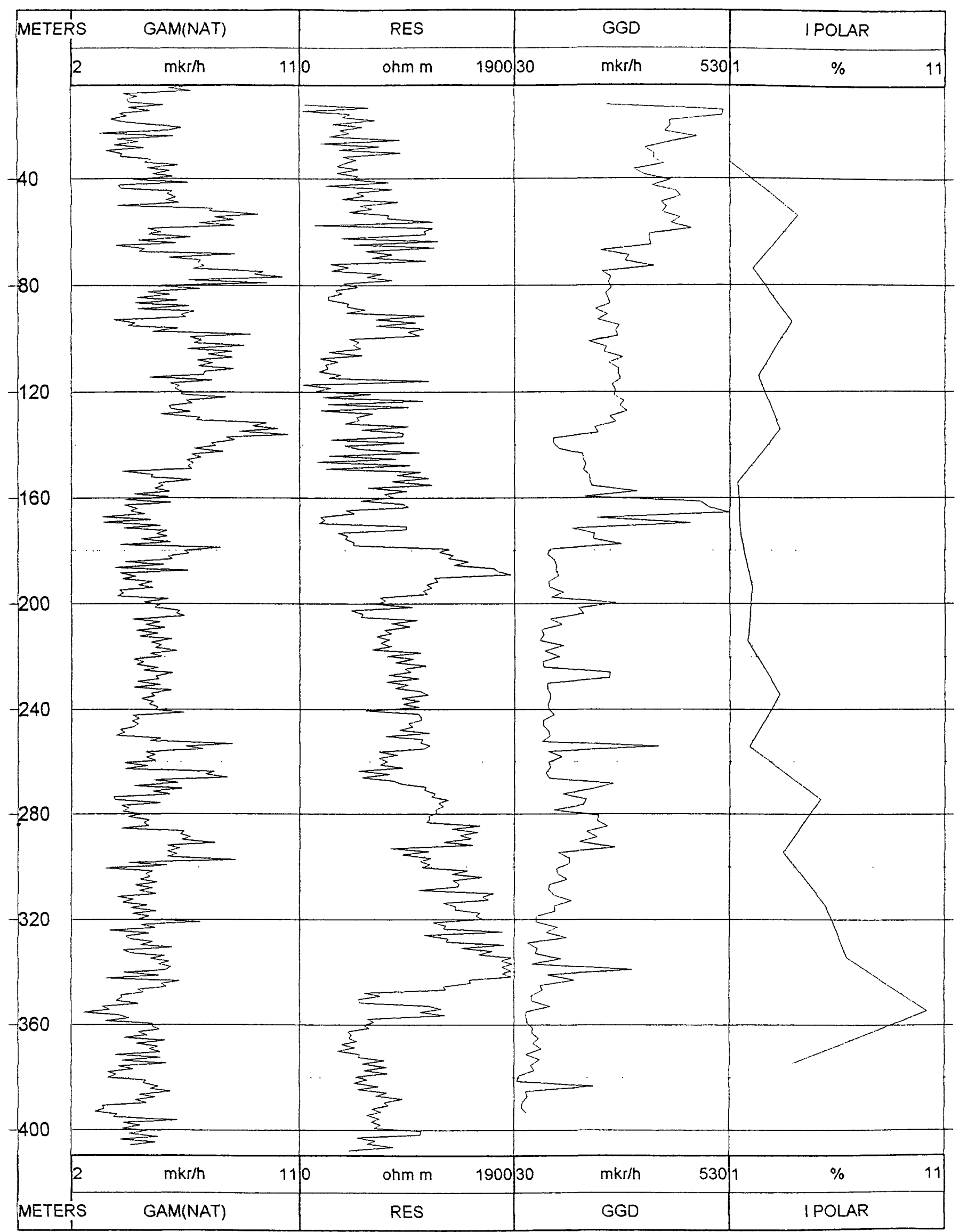

Hole 27 (for coal)

ljevan party, ljevan area 


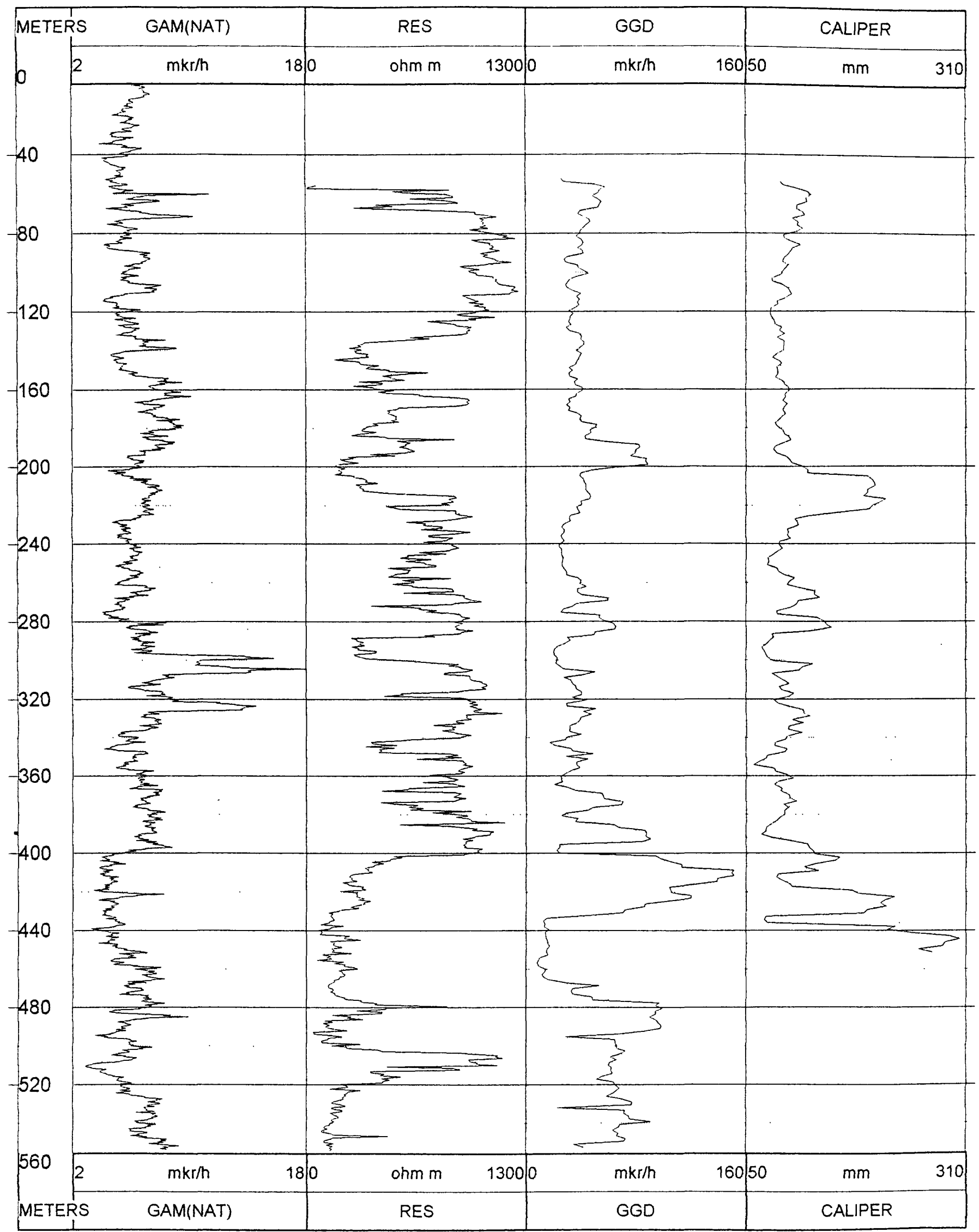

Hole 26C (for coal) 


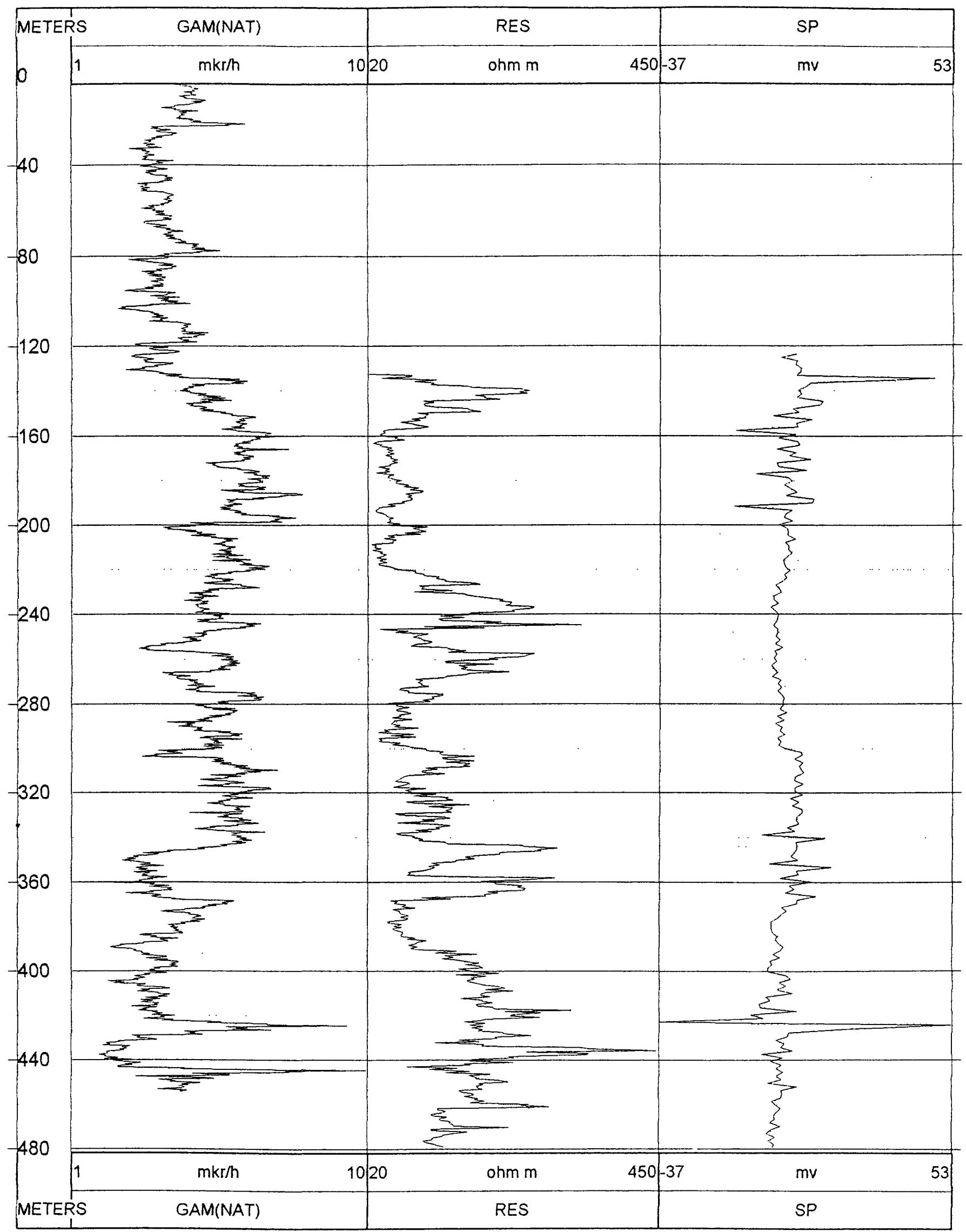

Hole 26A (for coal) 


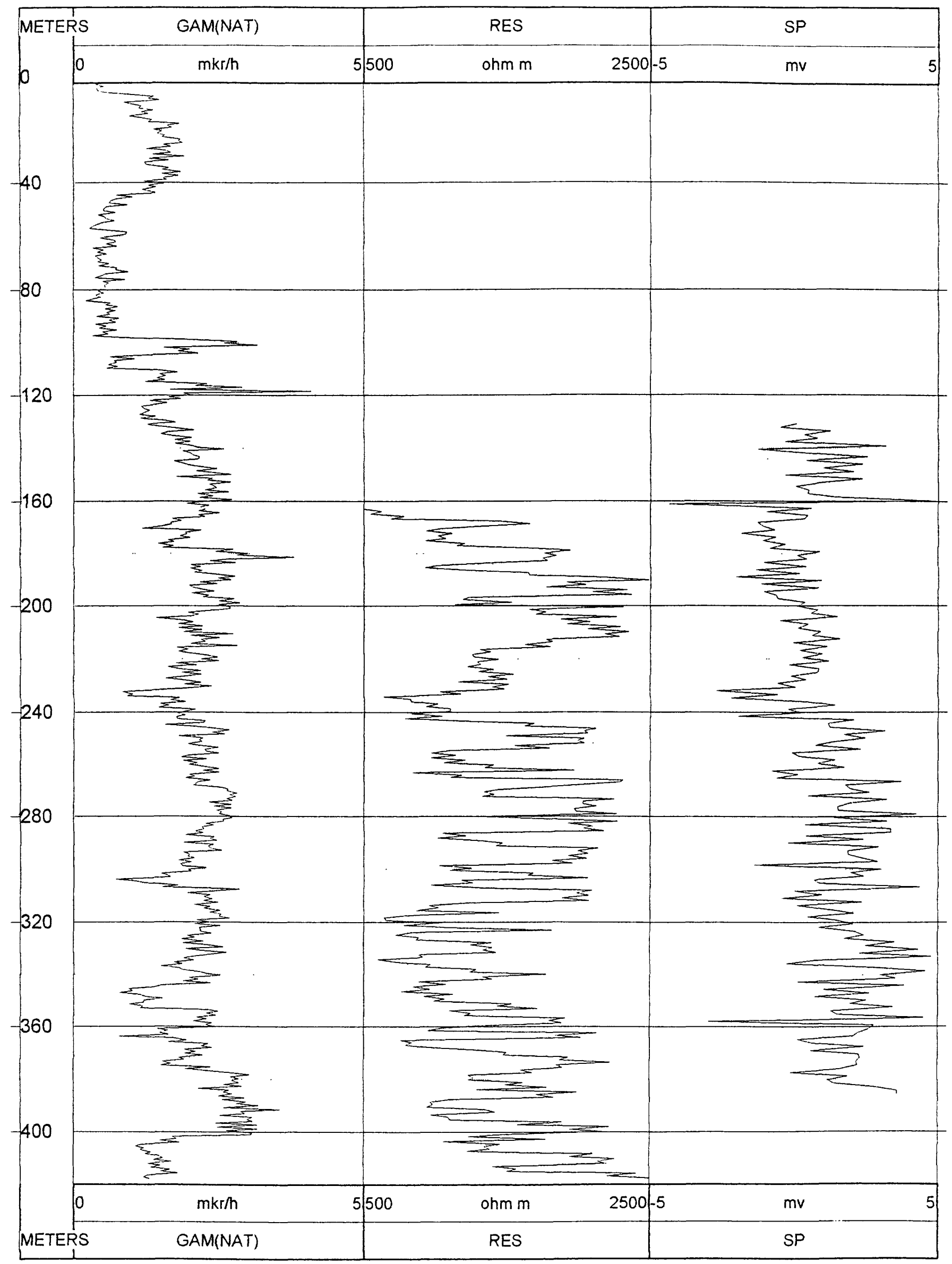

Hole 47 (for coal) 


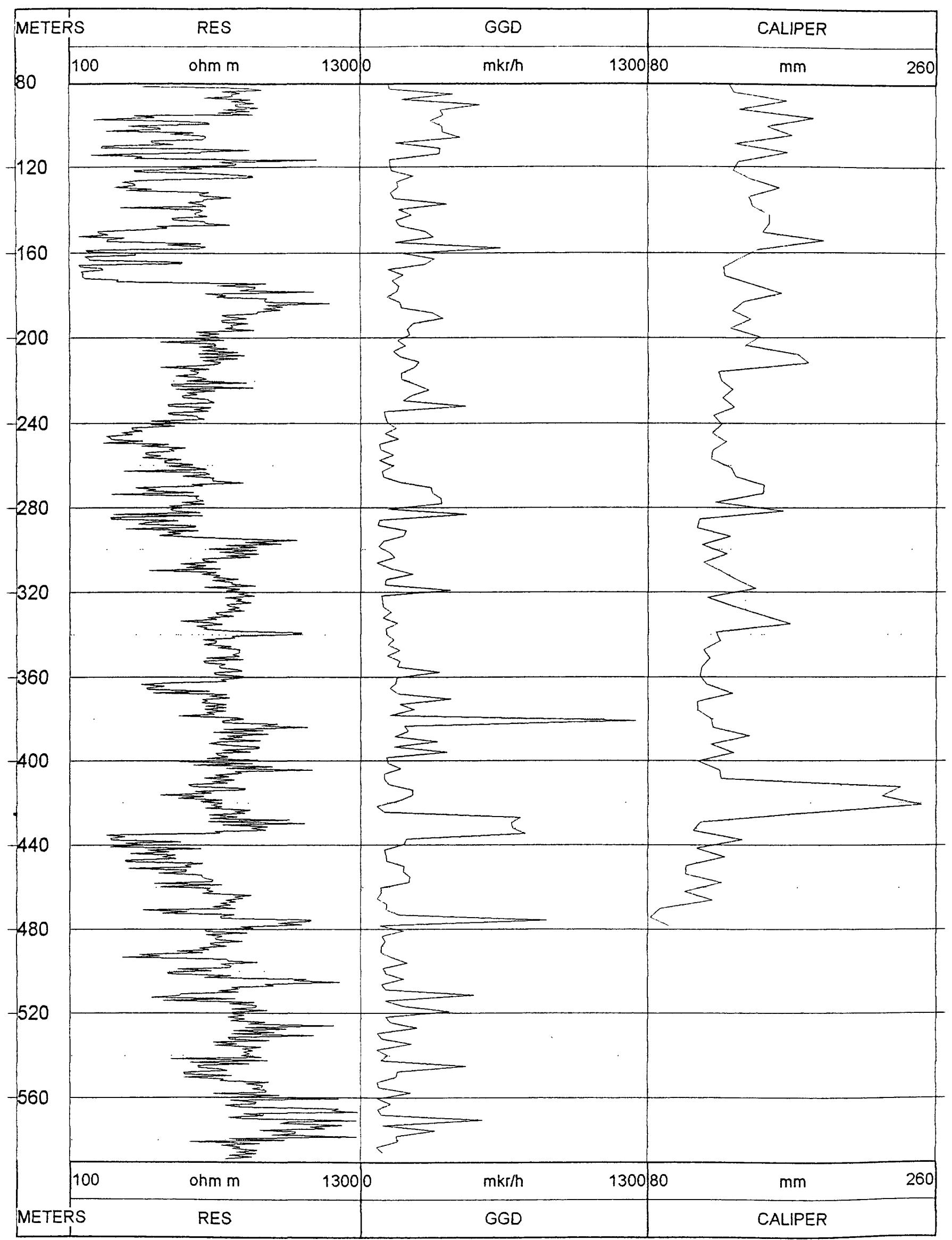

Hole 38 (for coal)

ljevan party, ljevan area 


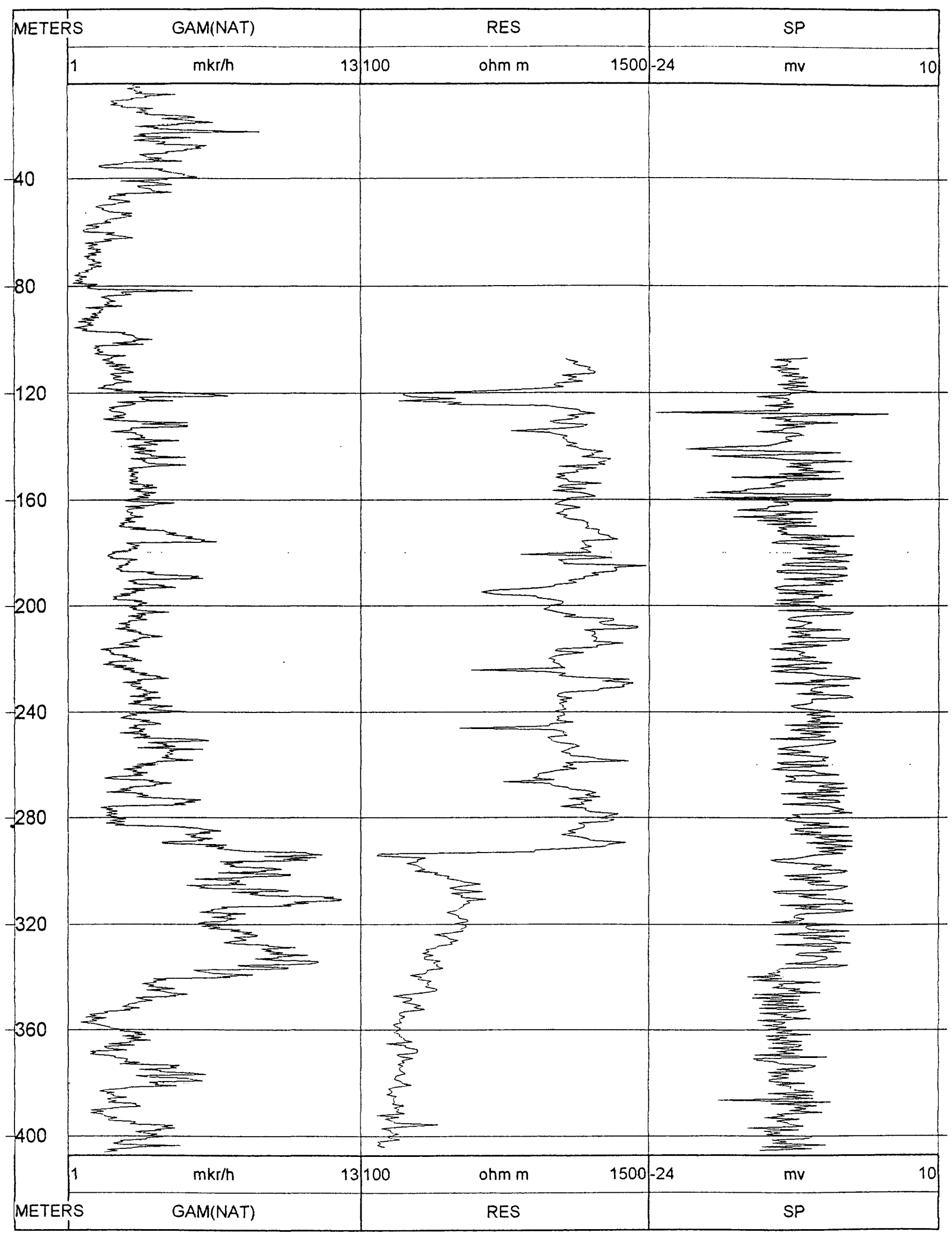

Hole 37 (for coal) 


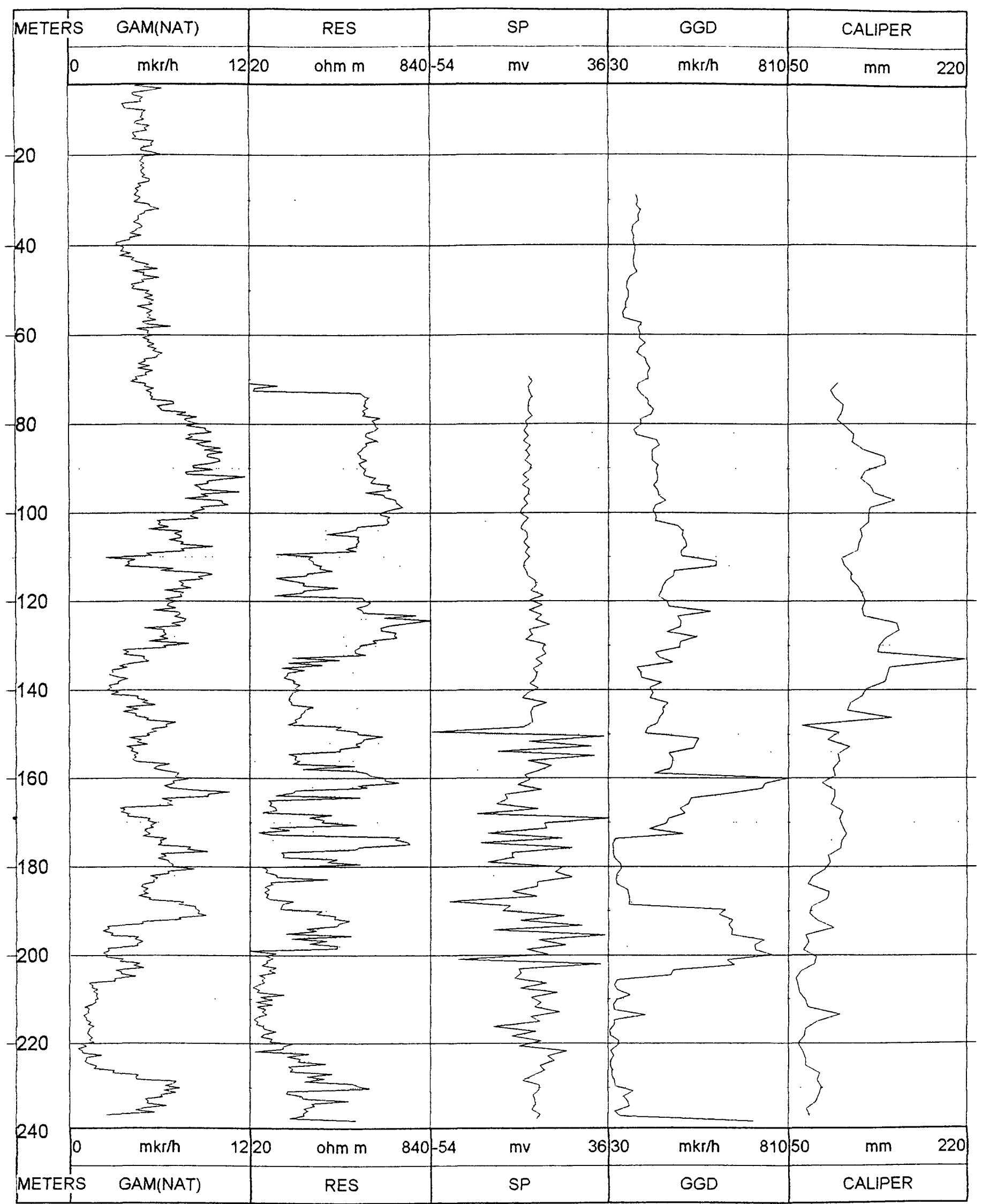

Hole 23 (for coal) 


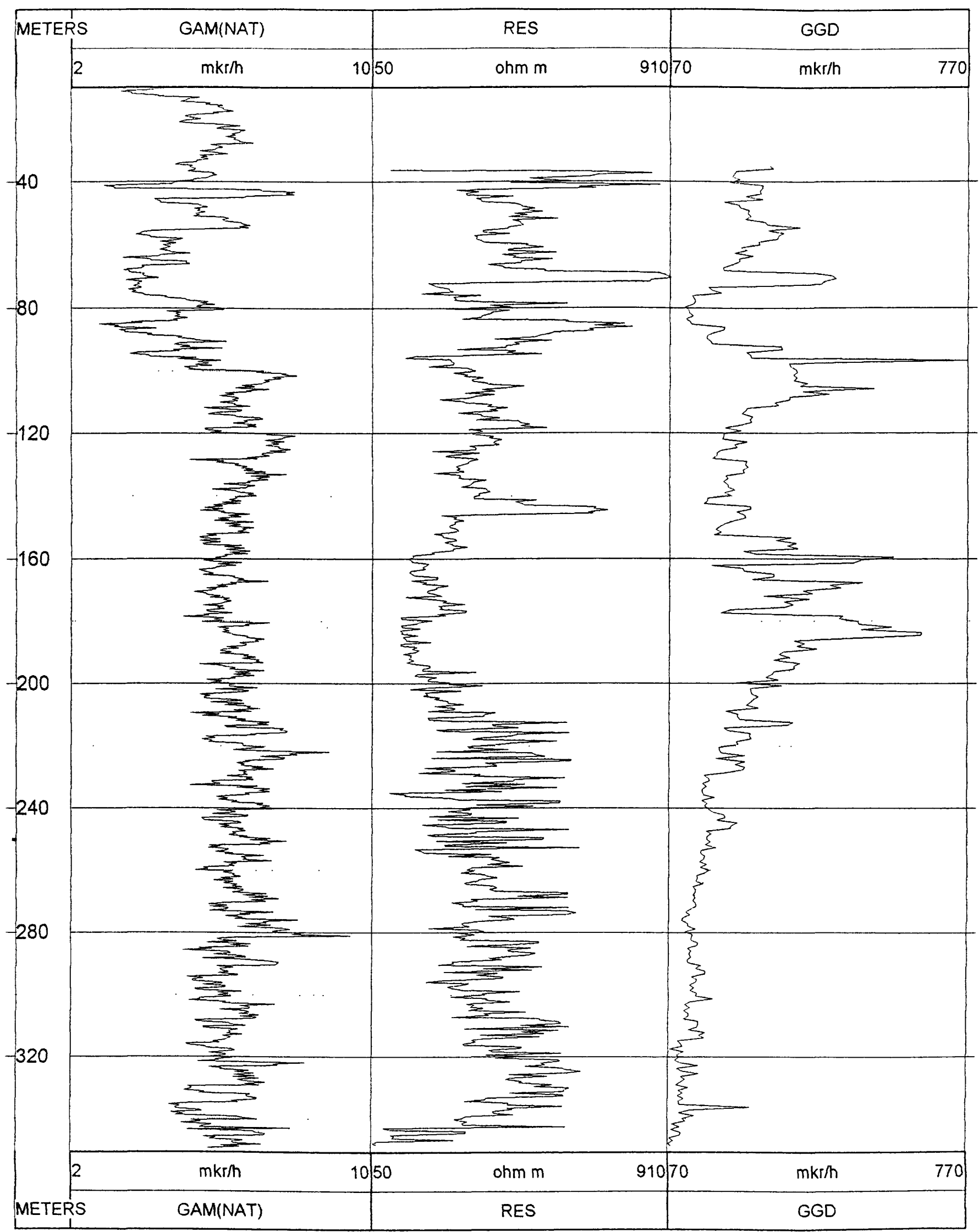

Hole 20 (for coal) 


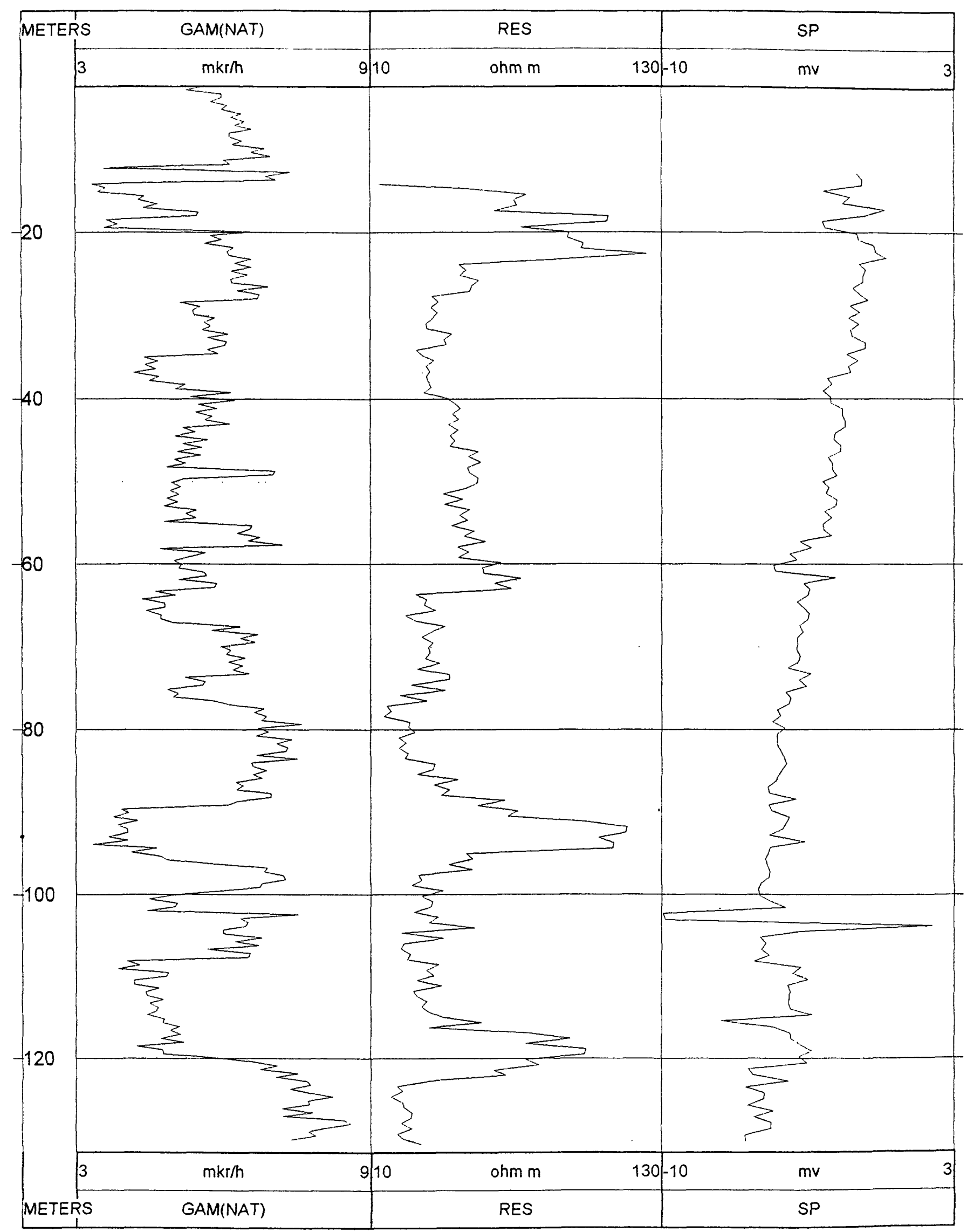

Hole 2/93 (for coal)

ljevan party, ljevan area 


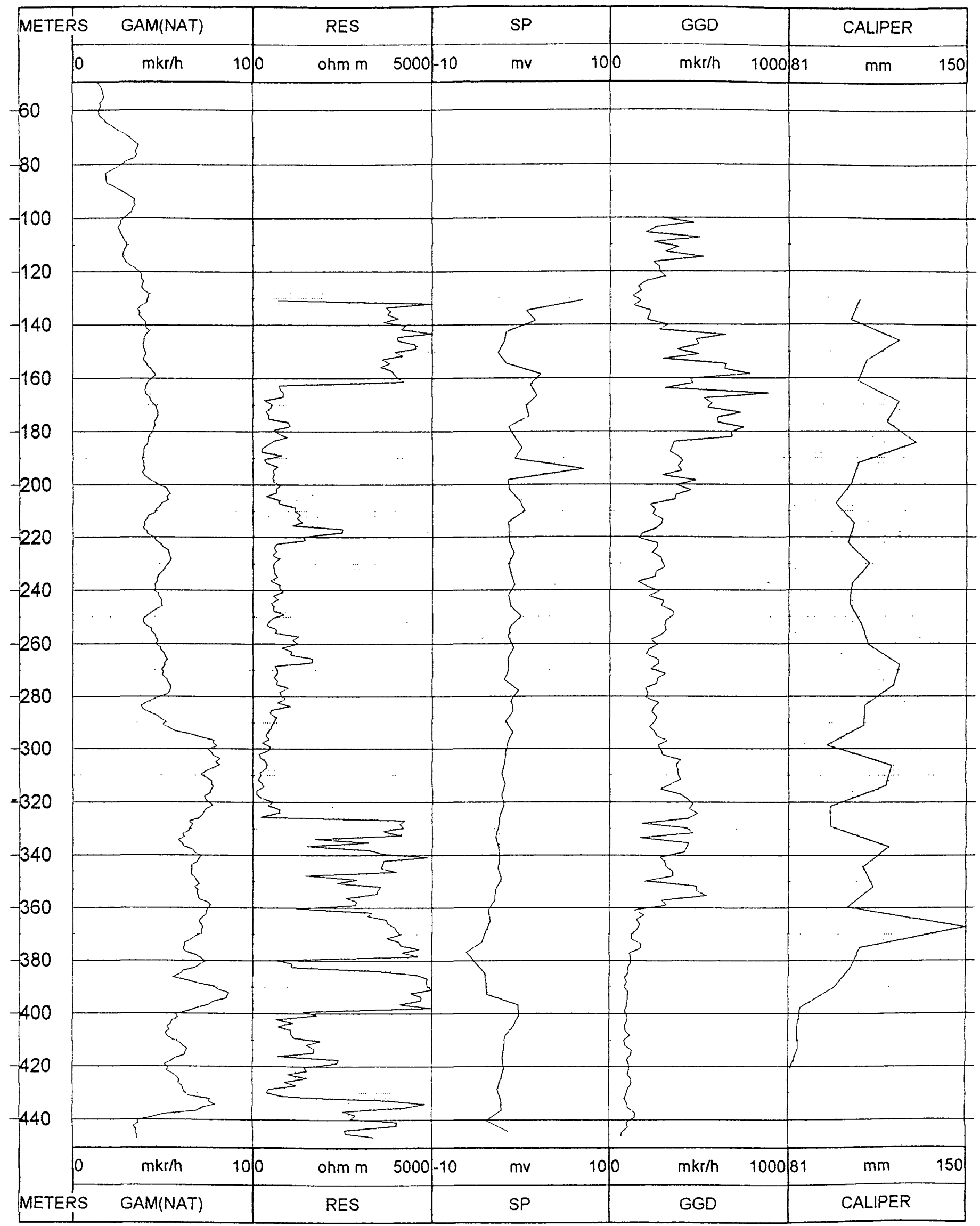

Hole 1A (for coal) 


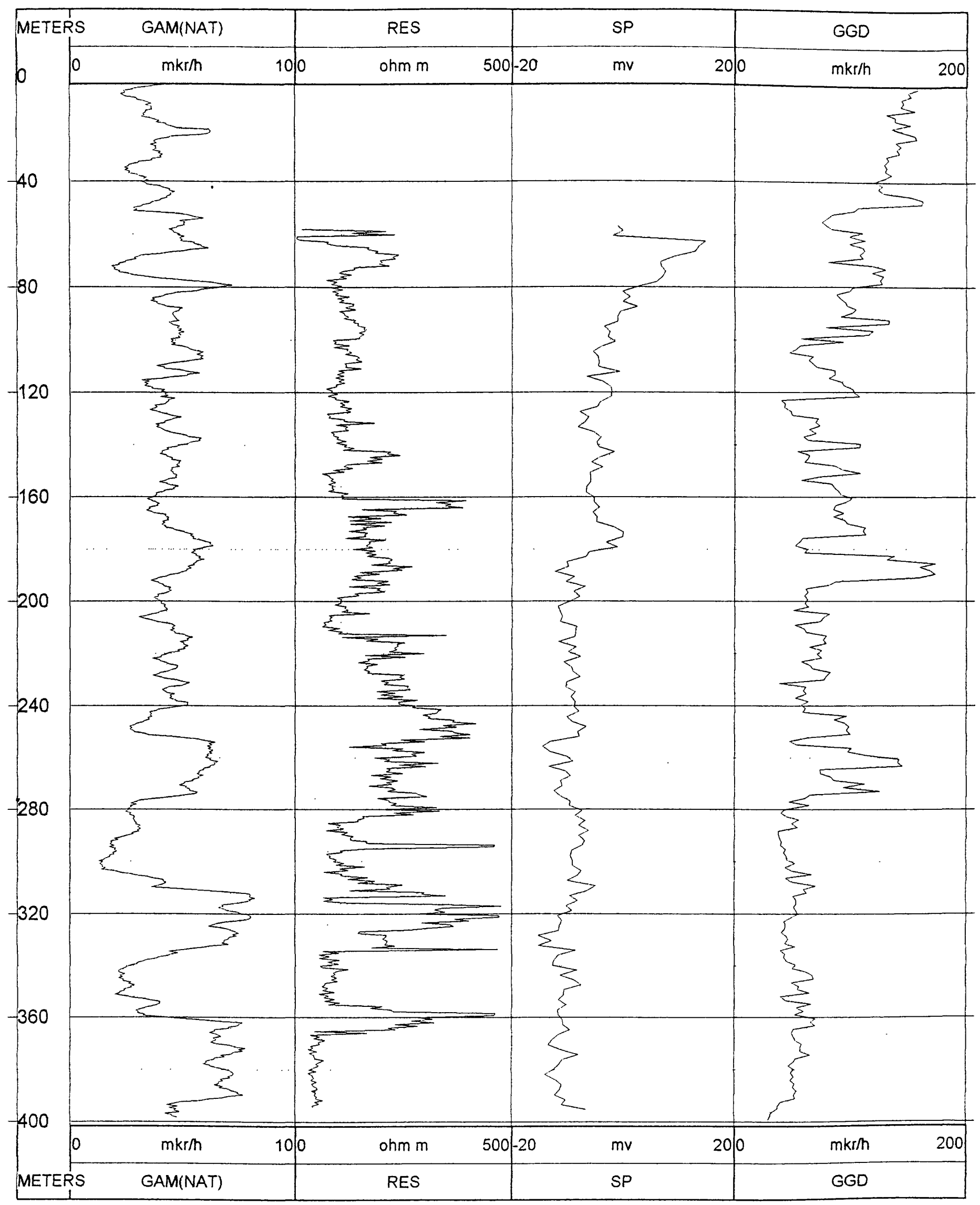

Hole 118K (for coal) 


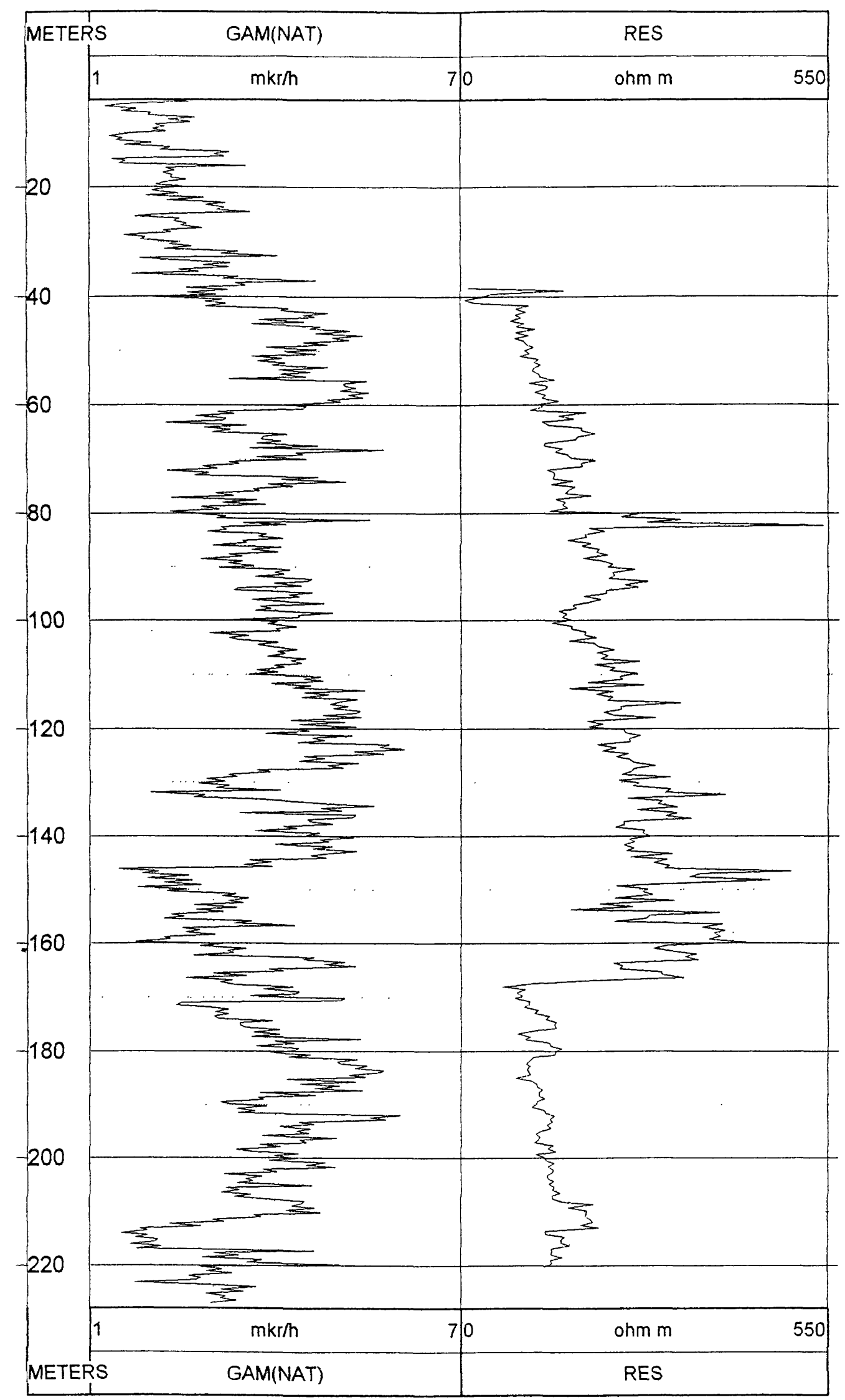

Hole $145 \mathrm{~K}$ (for coal)

ljevan party, ljevan area 


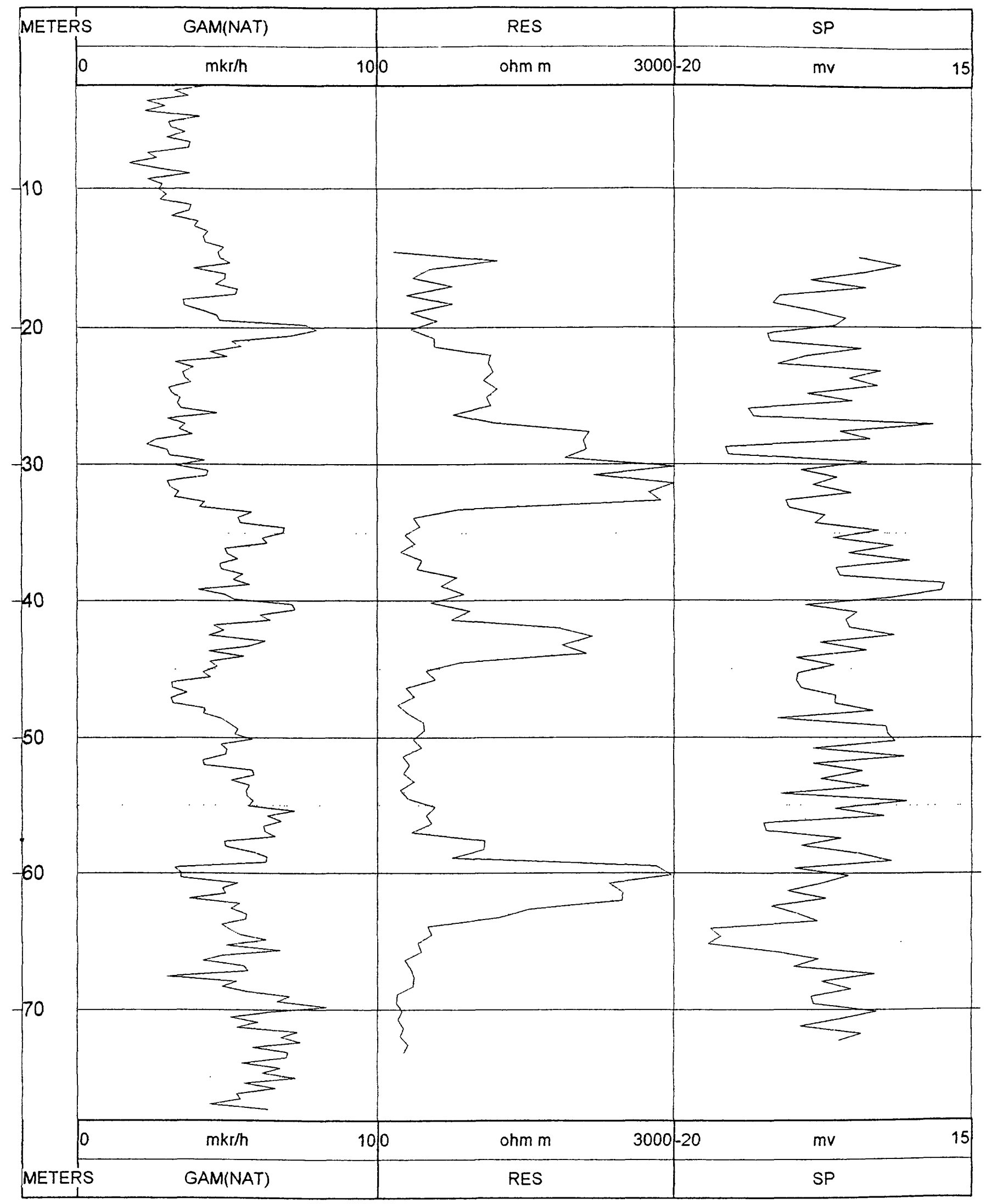

Hole 6/93 (for coal) 


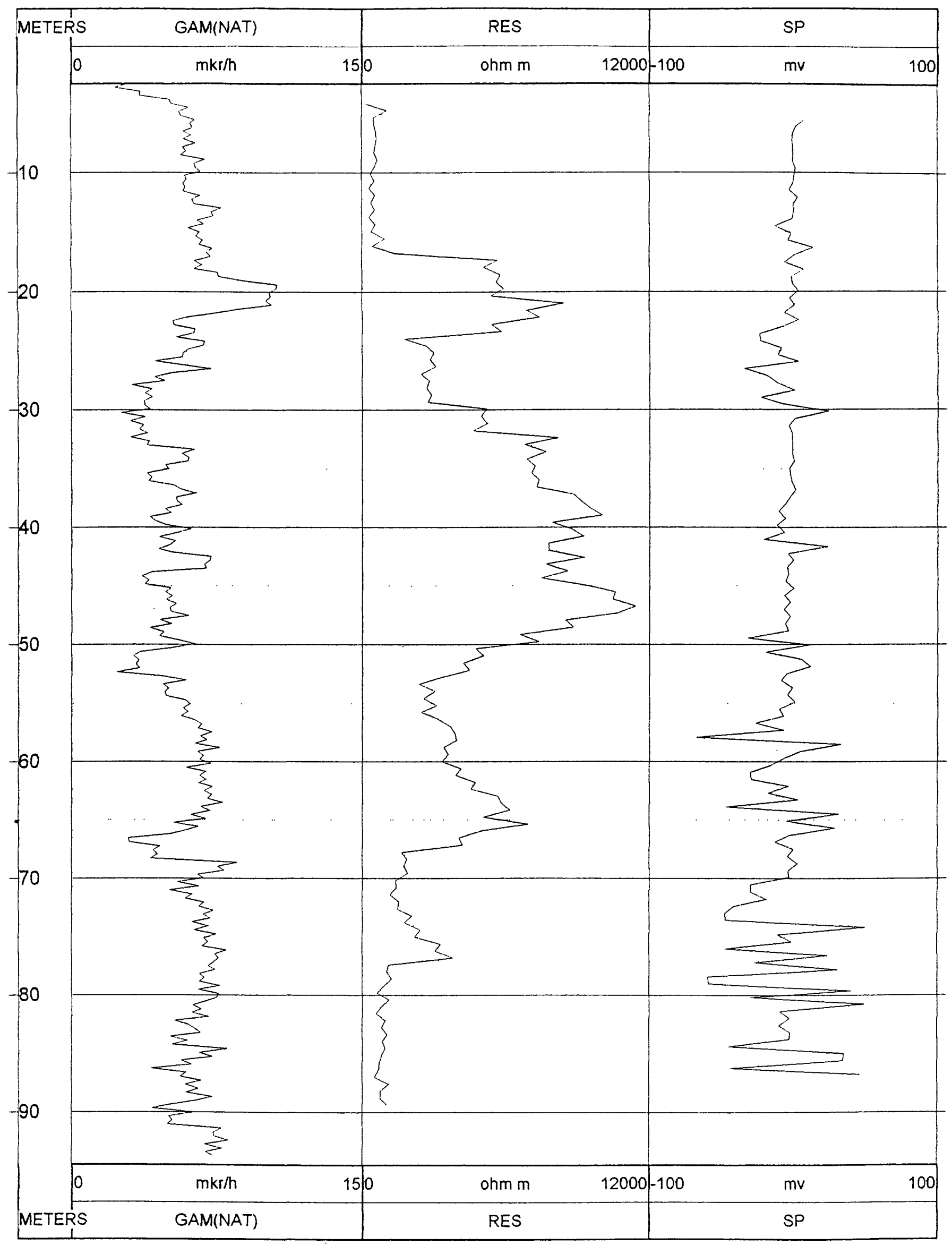

Hole 8/93 (for coal)

ljevan party, ljevan area 


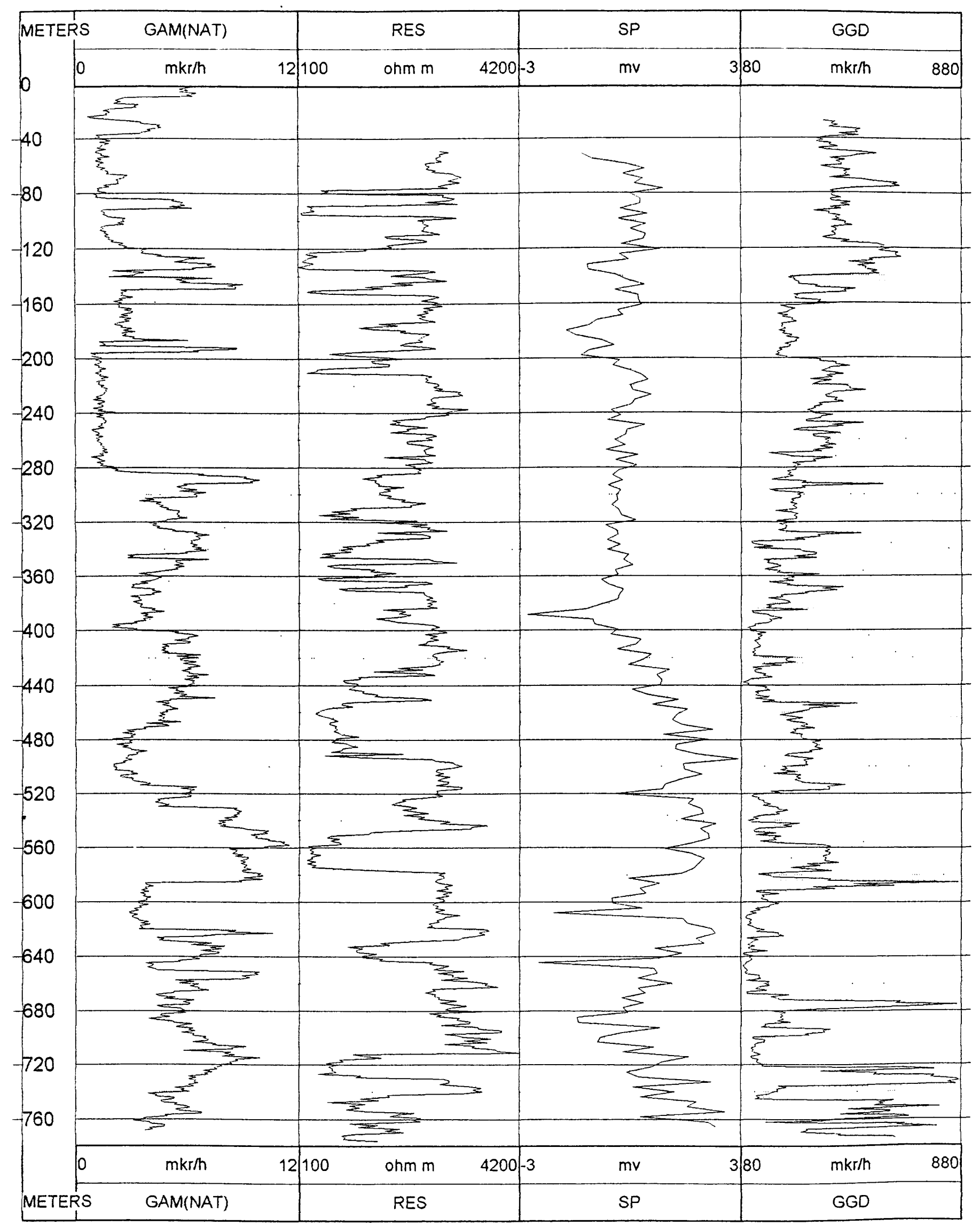

Hole 7 (for coal) 


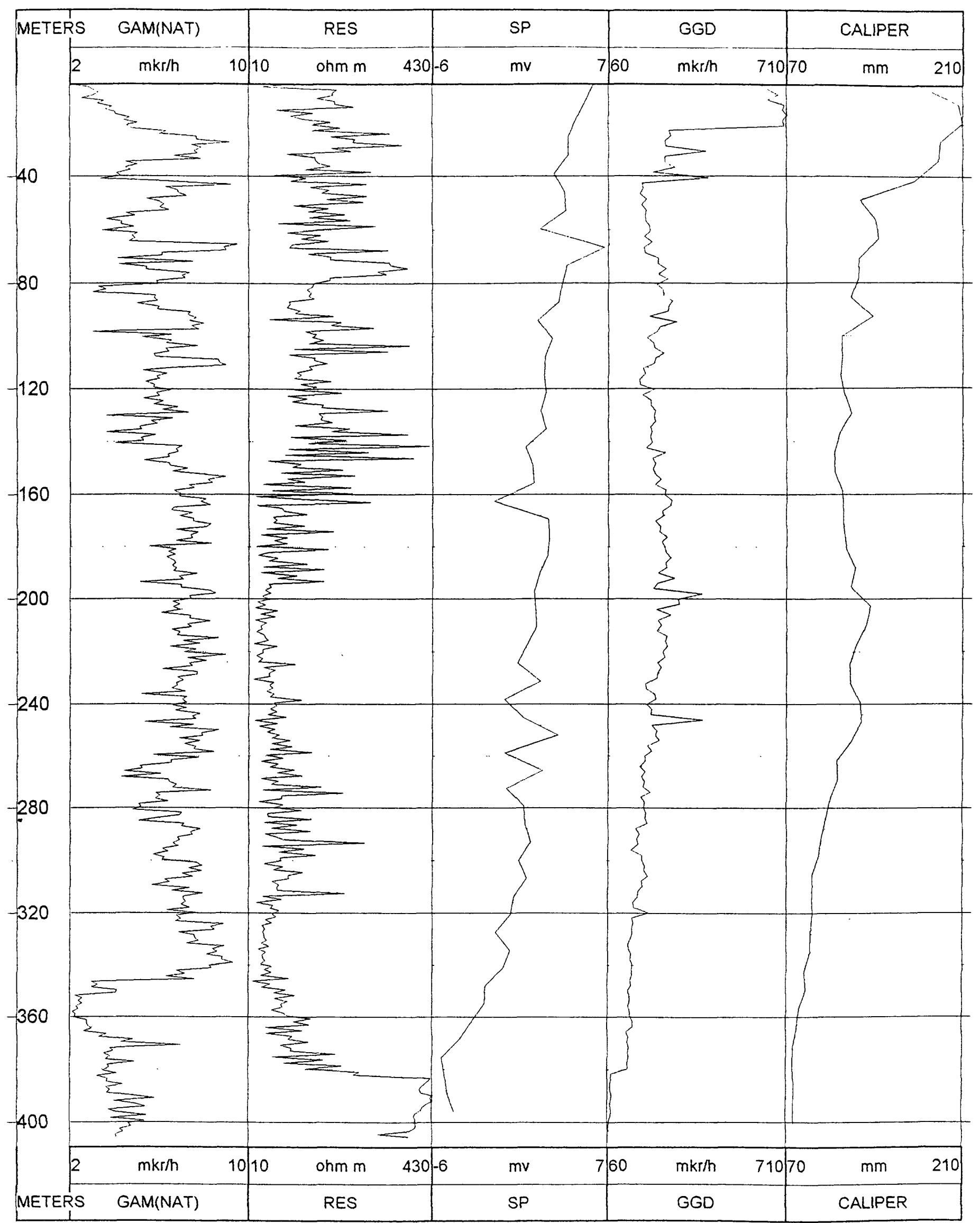

Hole 6 (for coal)

ljevan party, ljevan area 


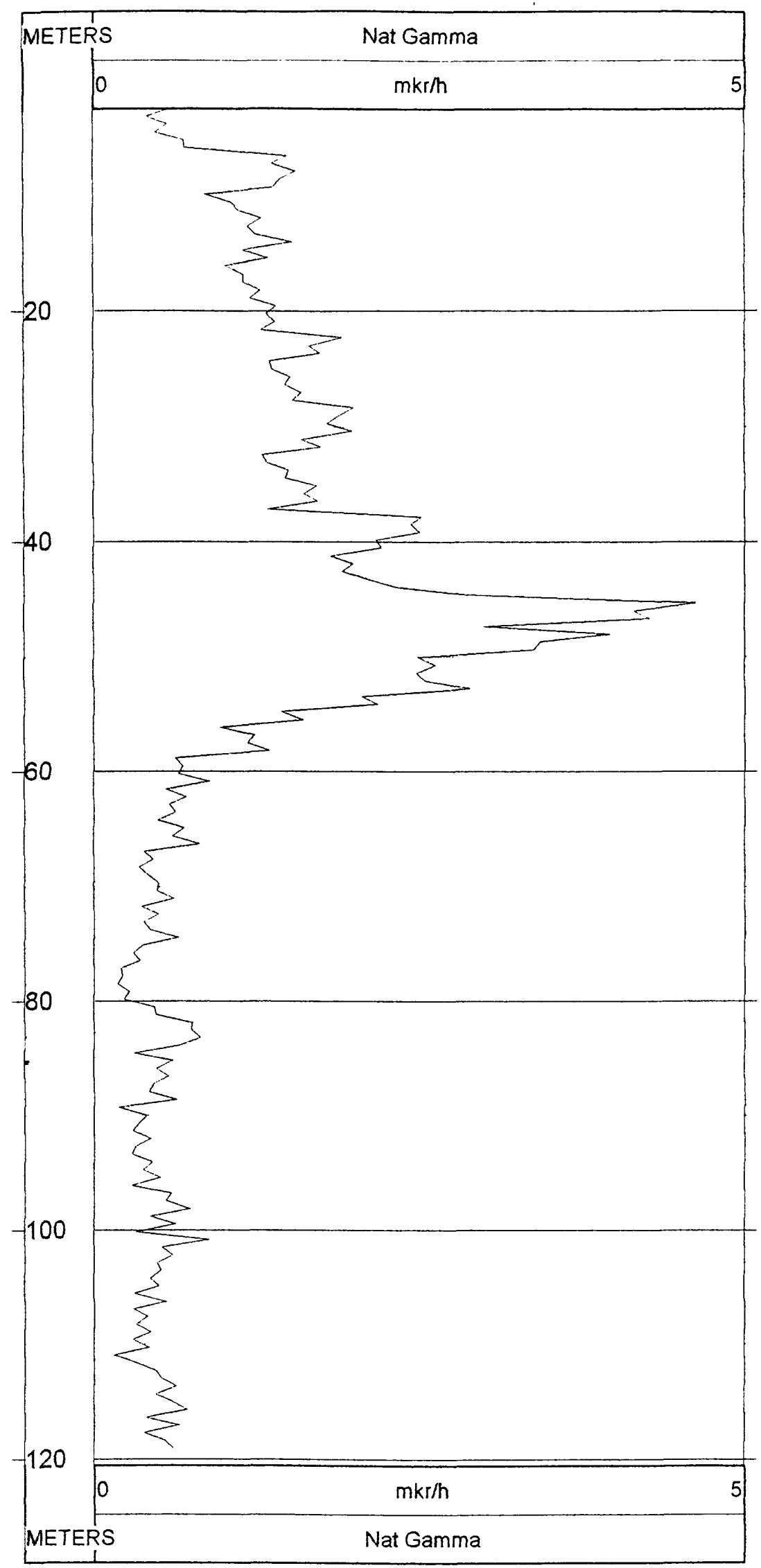

Hole 46 (for coal)

ljevan party, ljevan area 


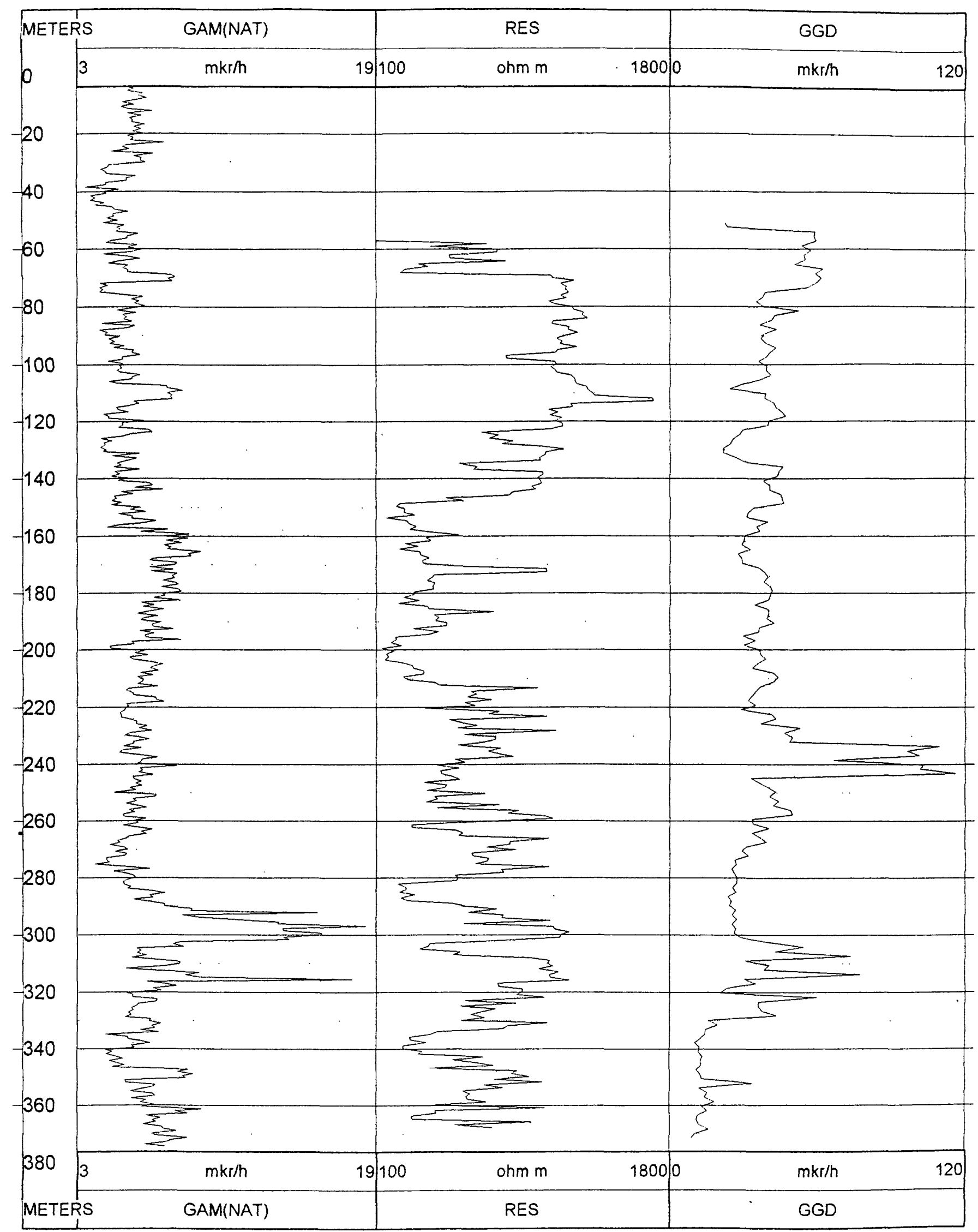

Hole 26 (for coal)

ljevan party, ljevan area 


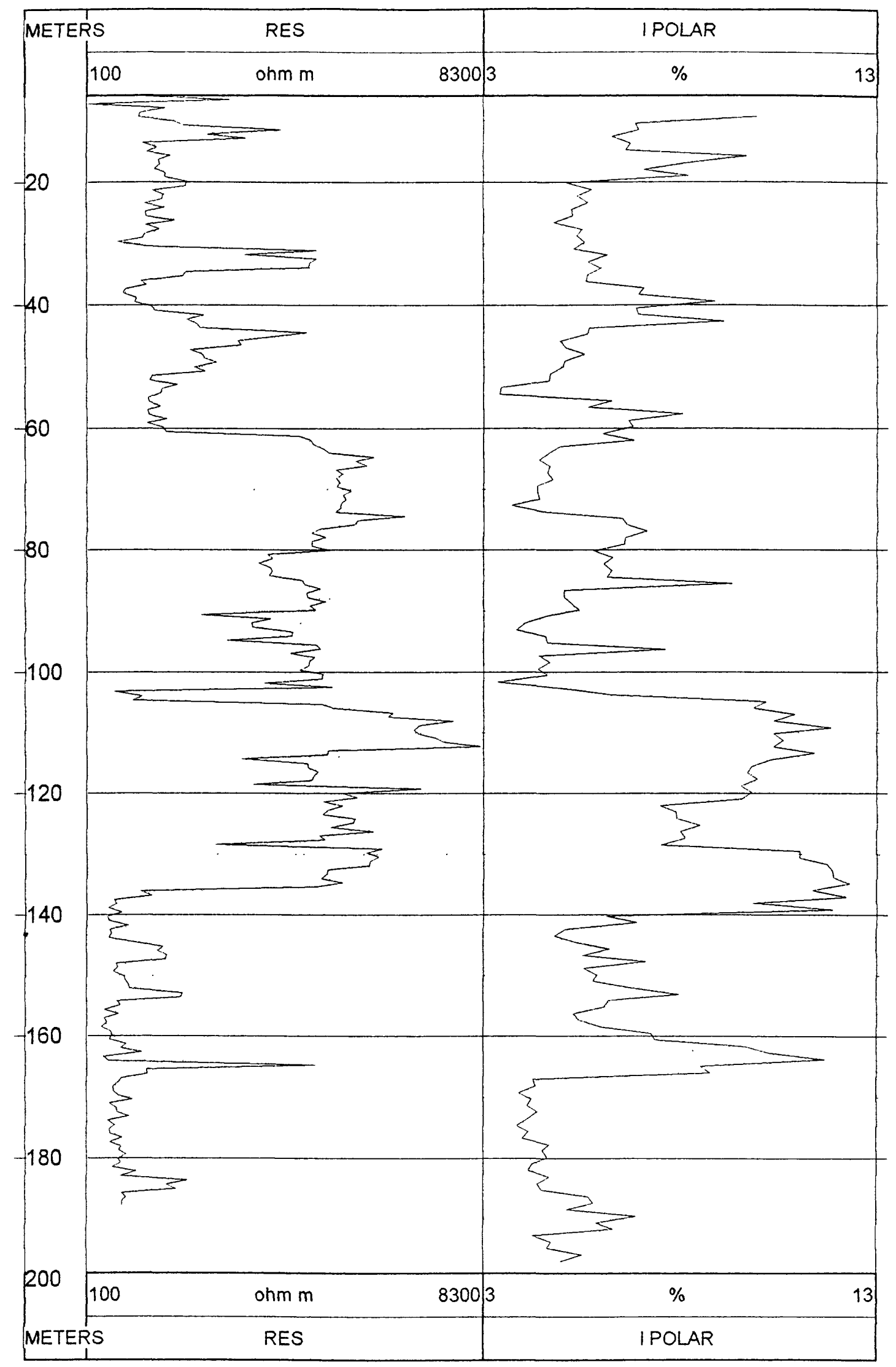

Hole 5 (for coal) 


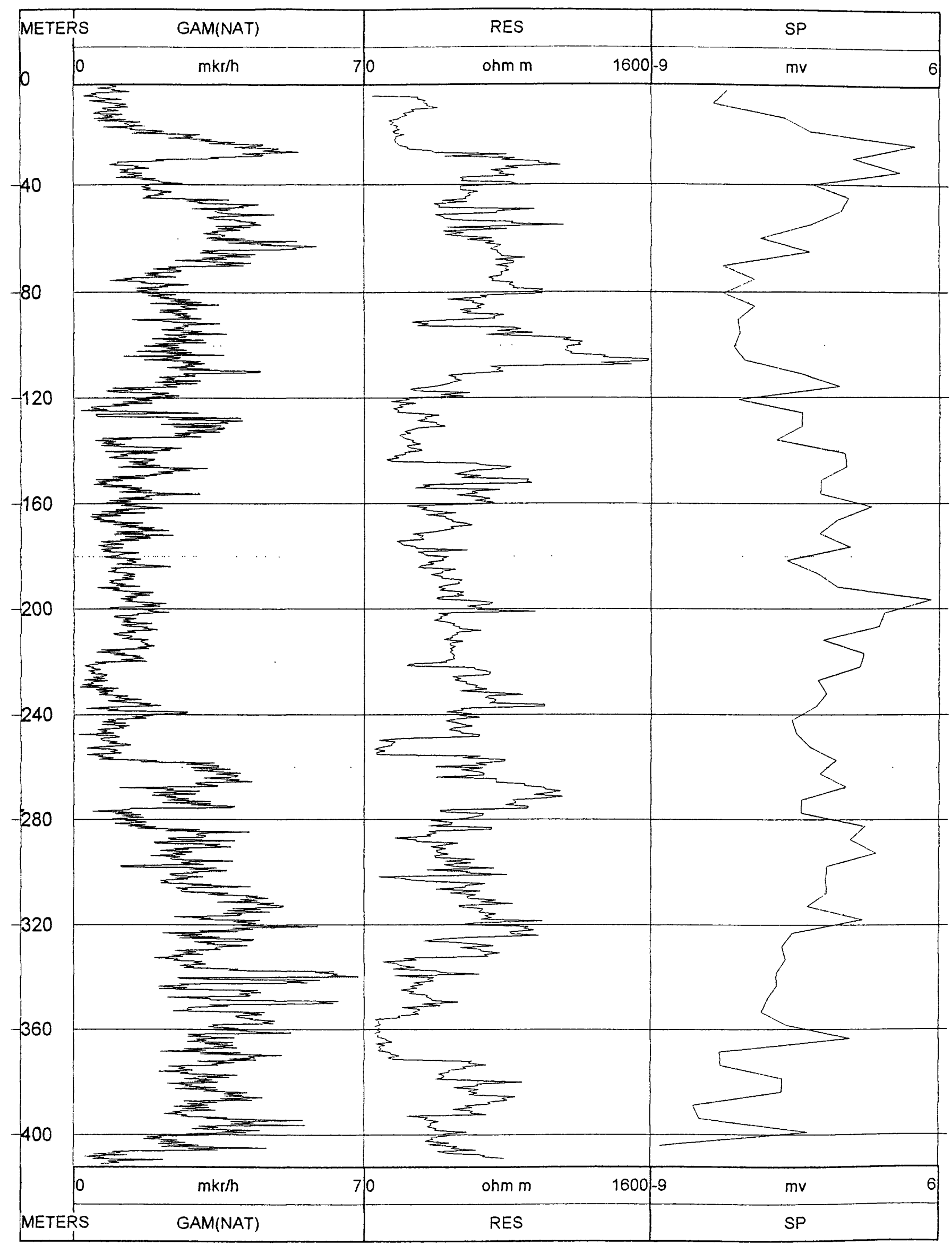

Hole 52 (for coal) 


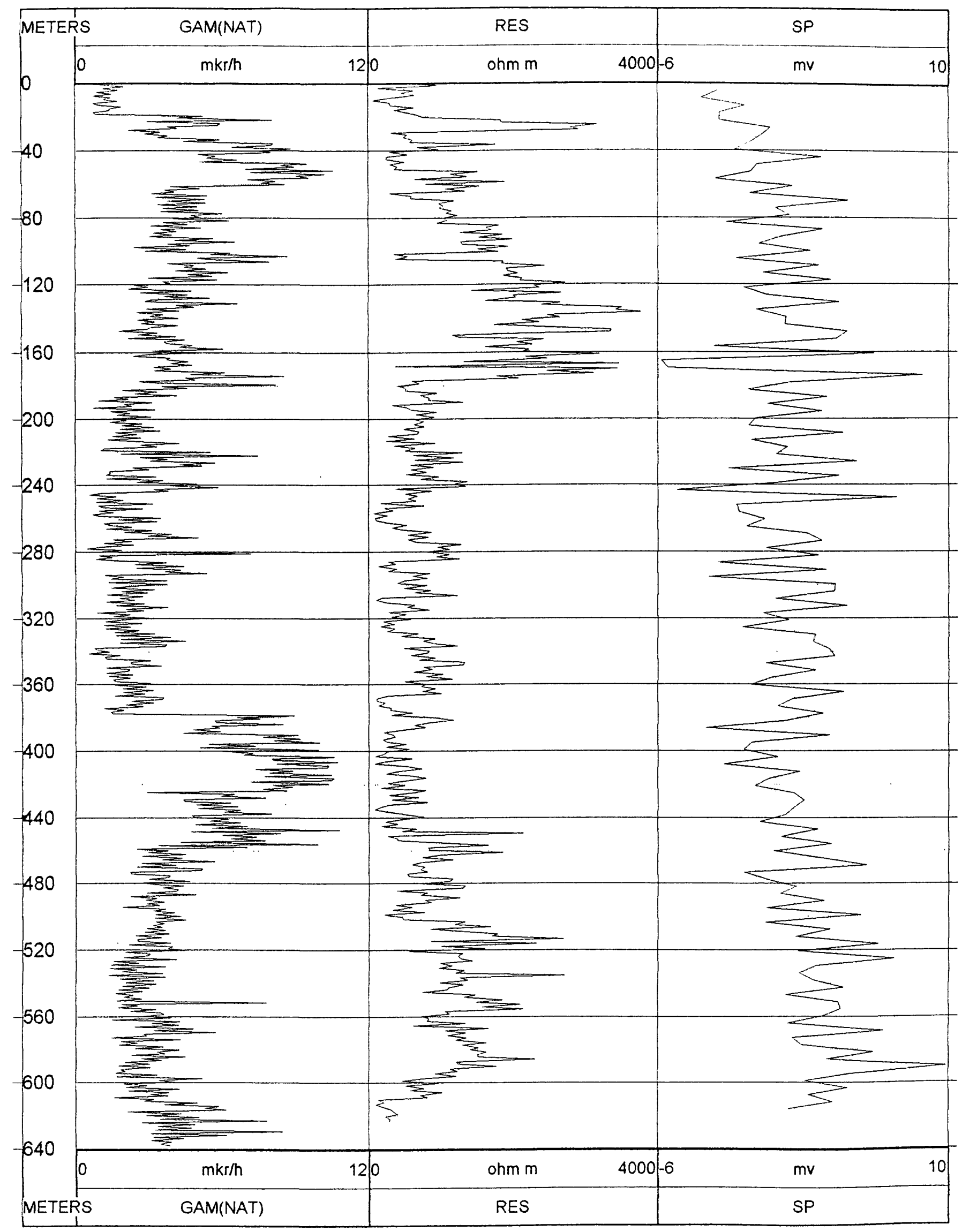

Hole 54 (for coal) 


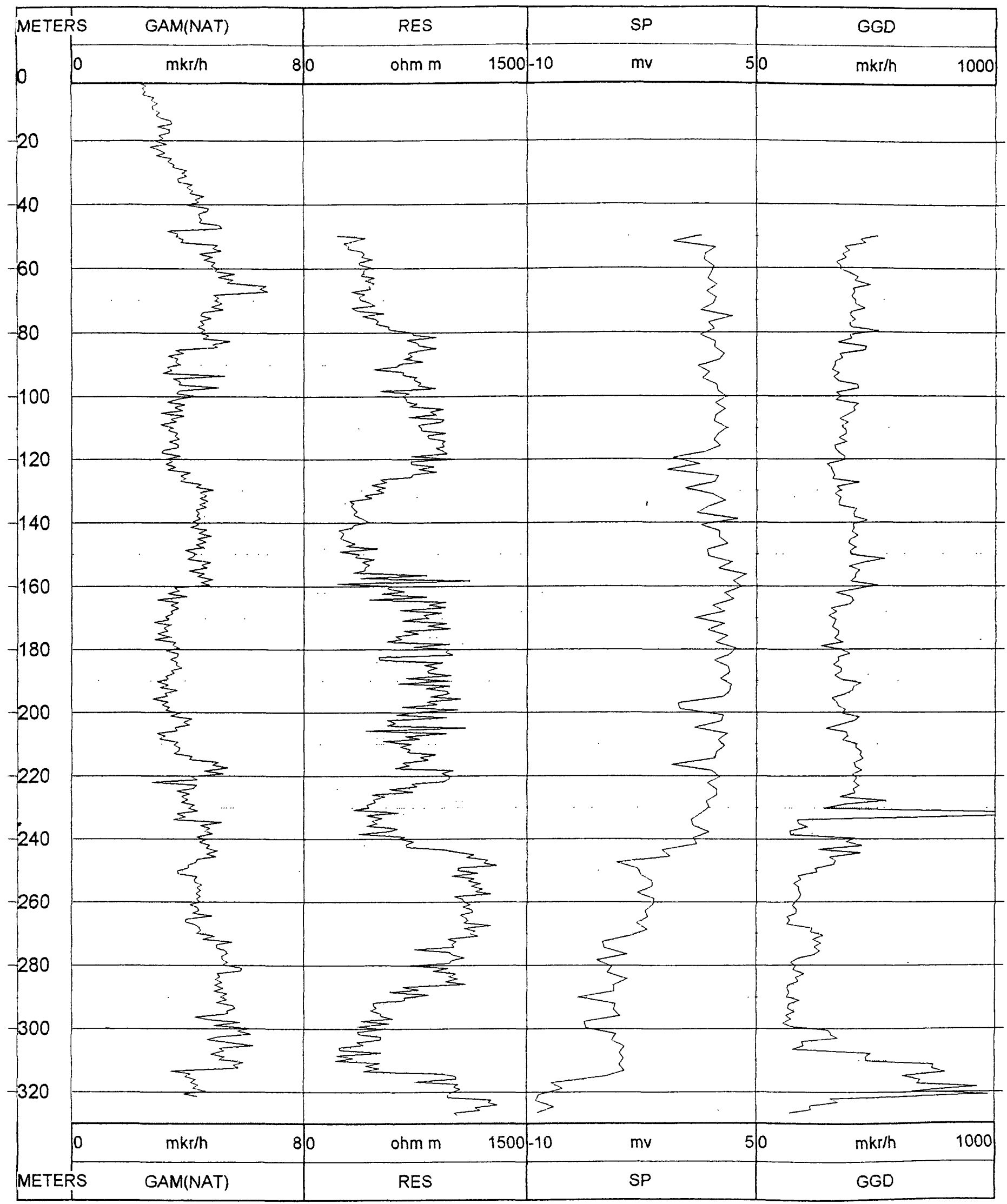

Hole 10 (for coal) 


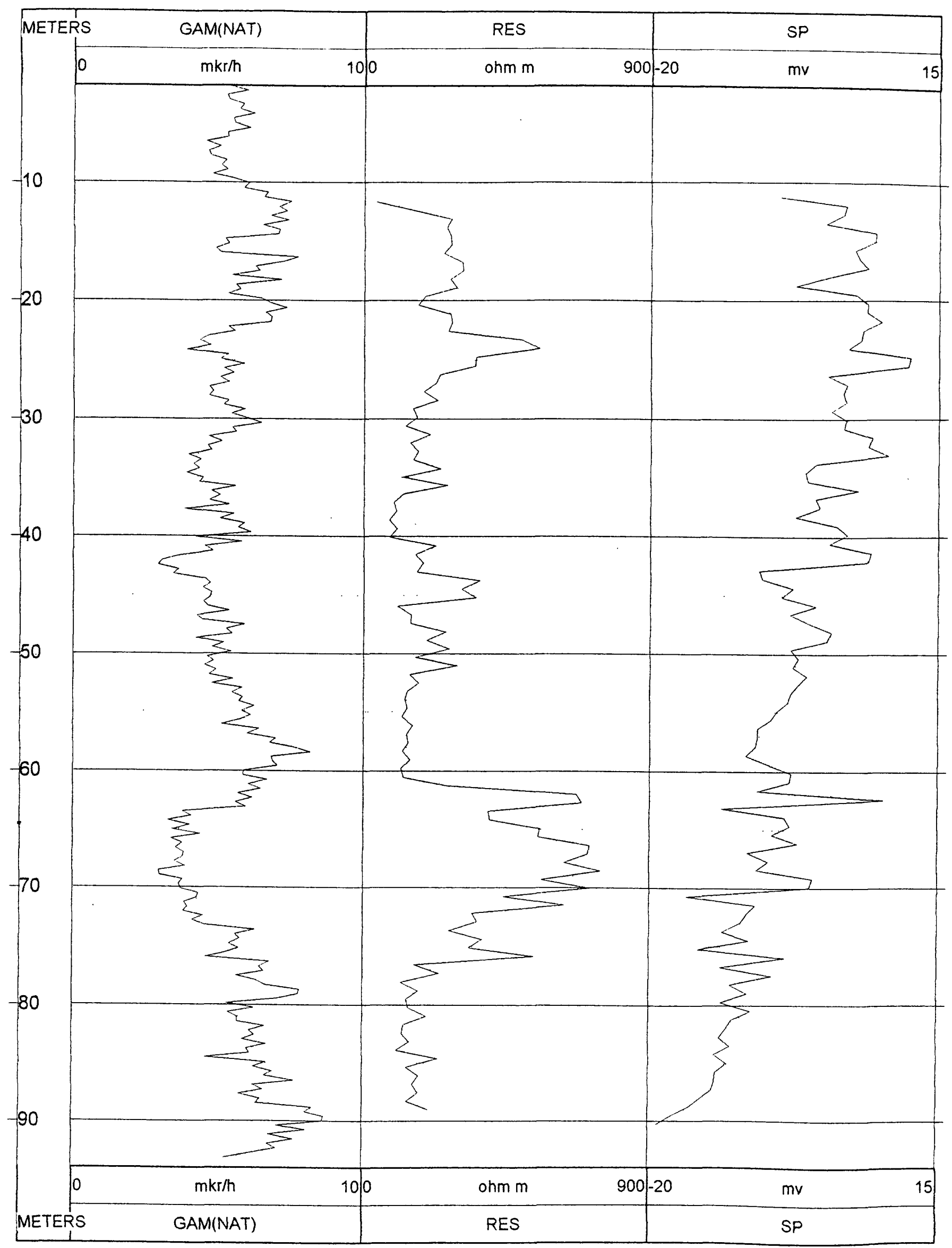

Hole 5/93 (for coal)

ljevan party, ljevan area 


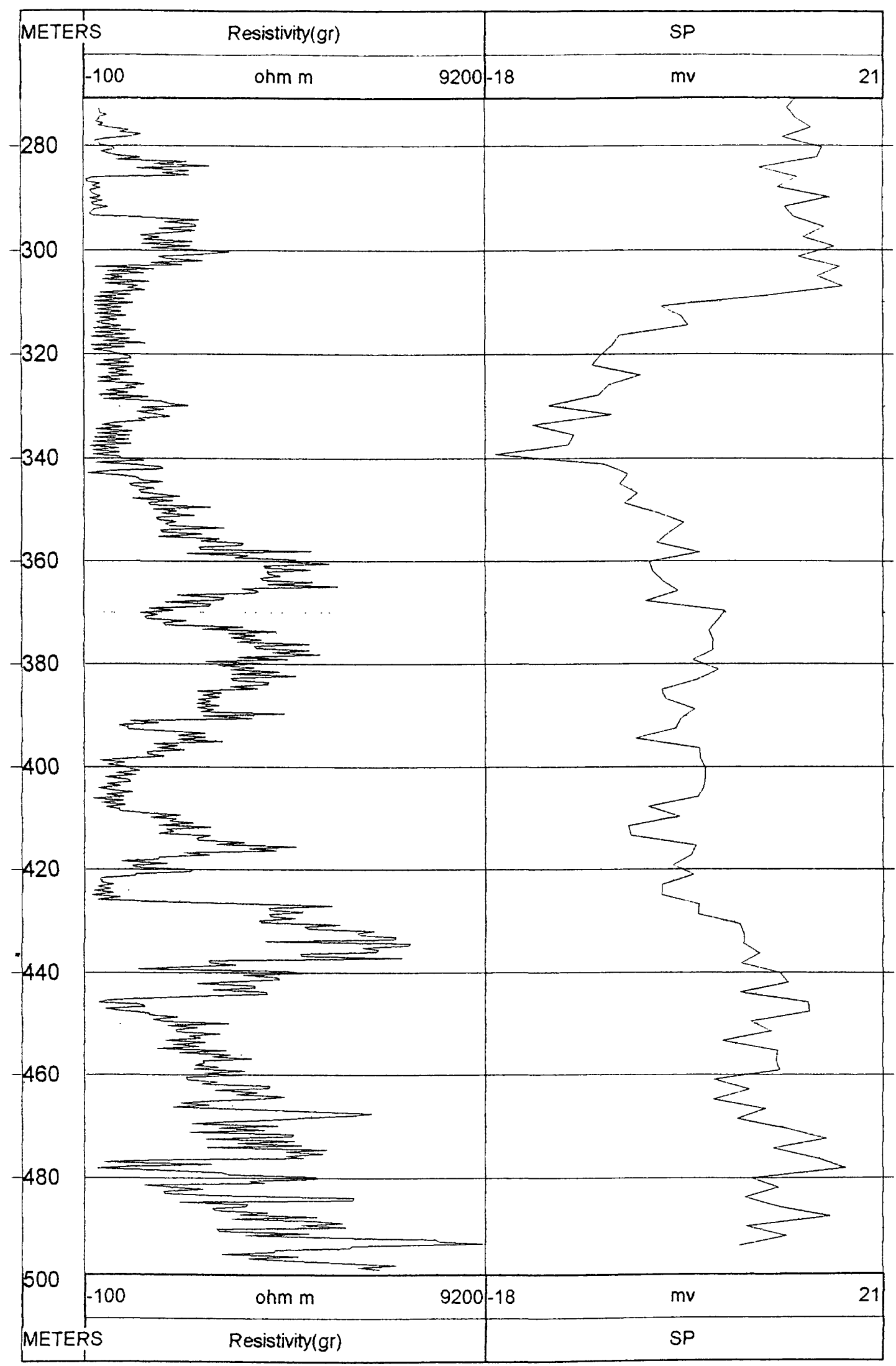

Hole 15 (for coal) 


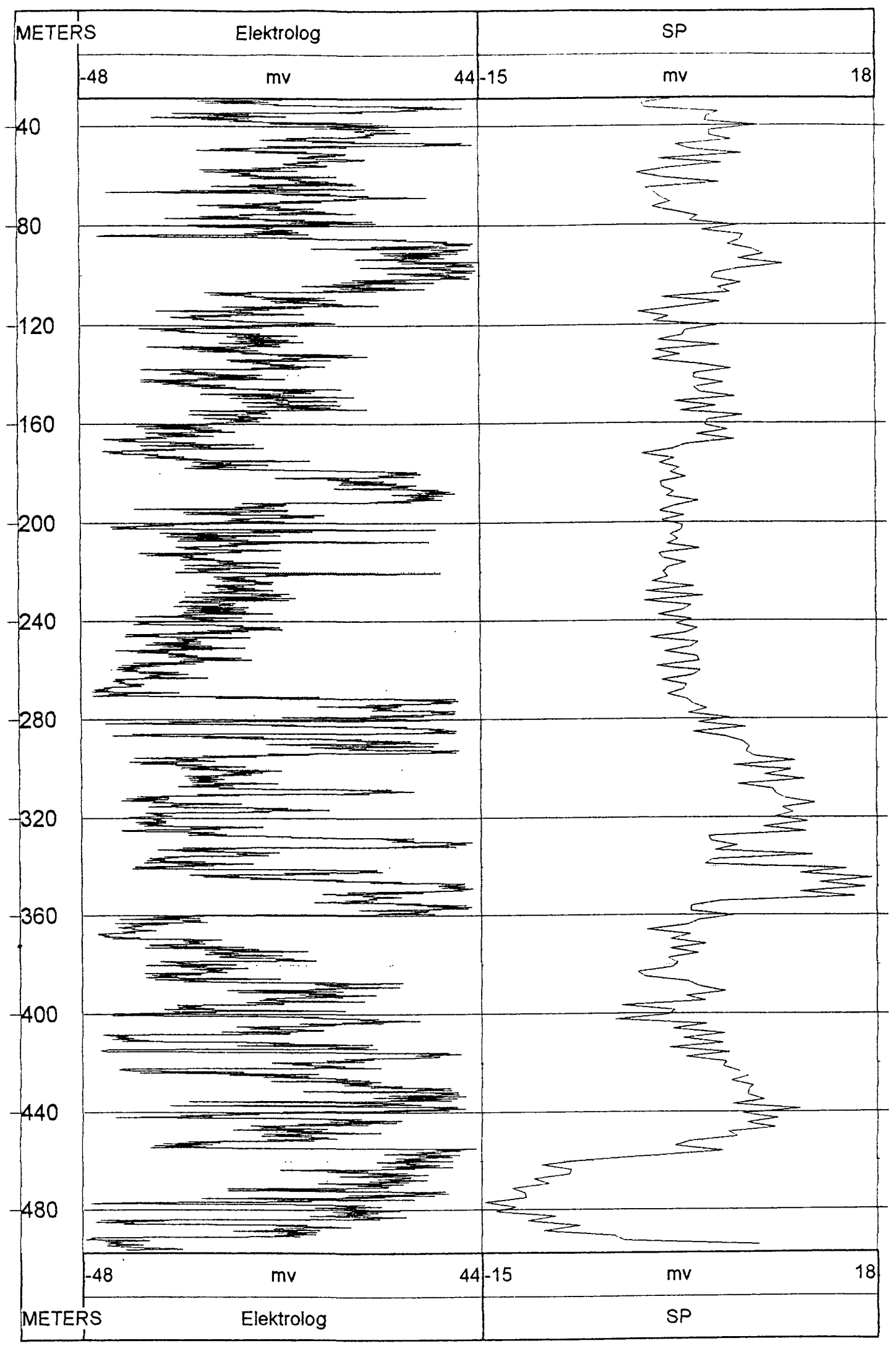

Hole 14 (for coal) 


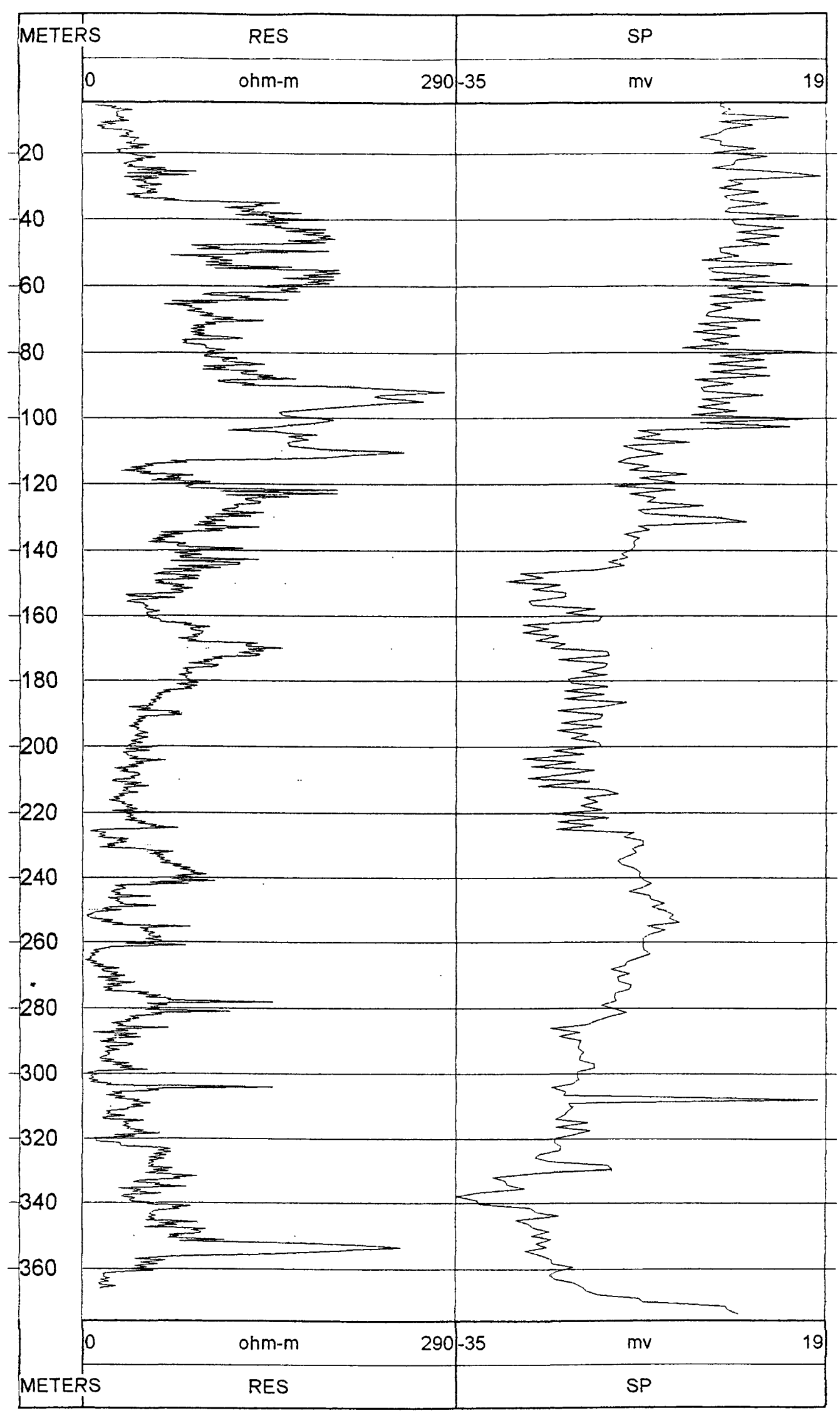

Hole 12 (for coal) 


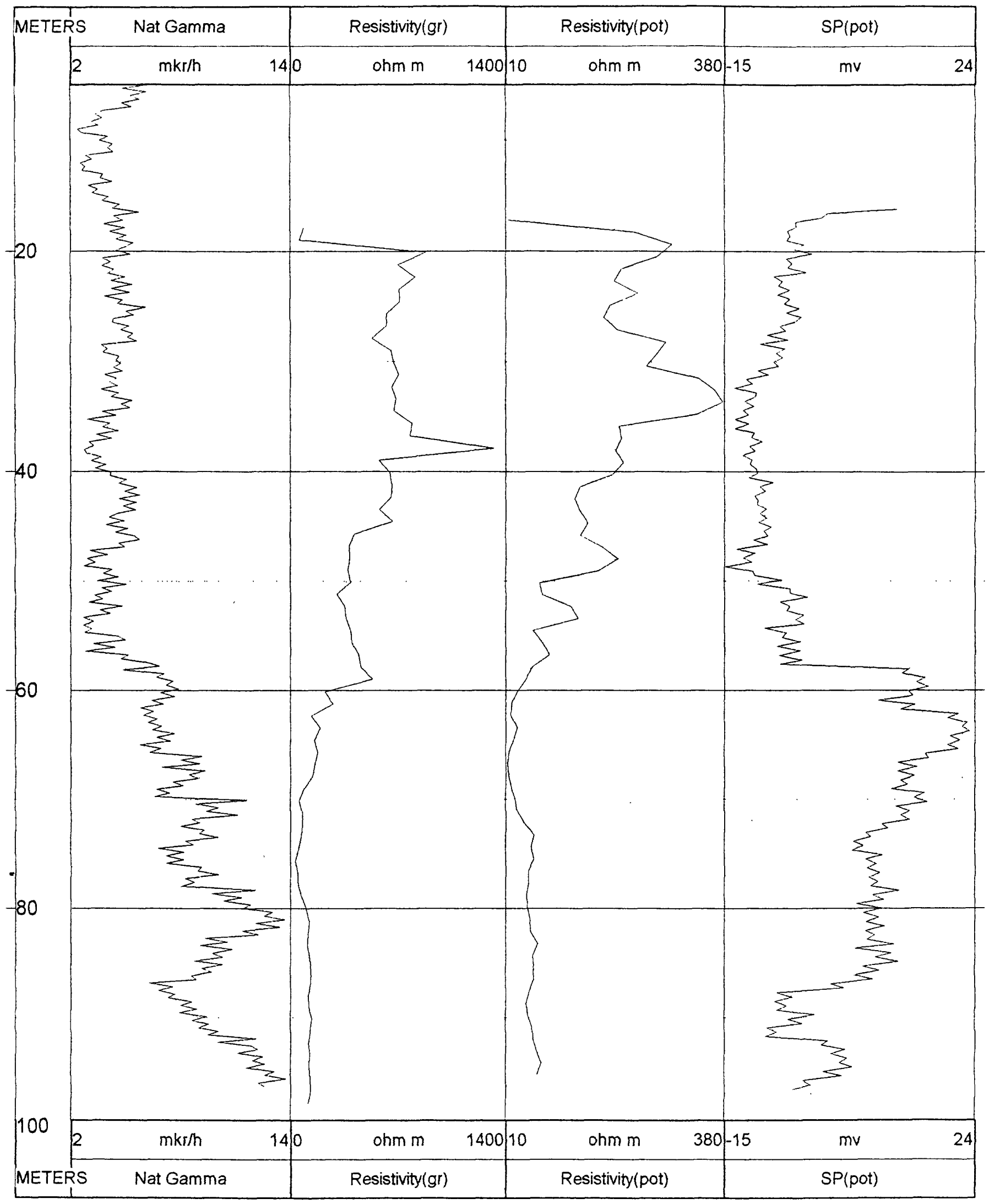

Hole $12 / 80$ (for structure) 